\title{
Water and Sustainable Development
}

H. Bogena, J.-Fr. Hake, H. Vereecken (Editors)

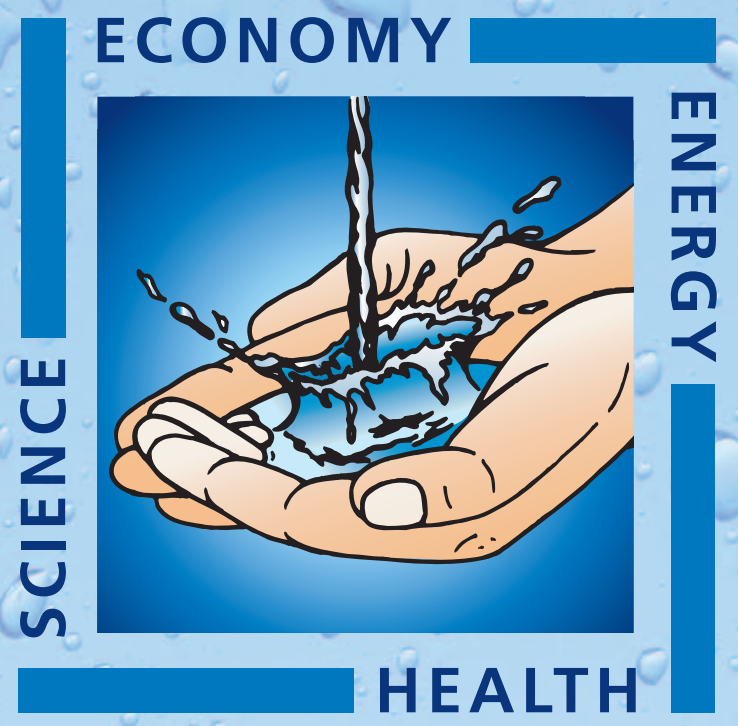

Umwelt

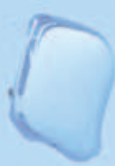


Schriften des Forschungszentrums Jülich

Reihe Umwelt/Environment

Band/Volume 48 

Forschungszentrum Jülich $\mathrm{GmbH}$

Programmgruppe Systemforschung und

Technologische Entwicklung

und

Institut Agrosphäre

Institut für Chemie und Dynamik der Geosphäre (ICG-IV)

\section{Water and Sustainable Development}

Heye Bogena, Jürgen-Friedrich Hake, Harry Vereecken (Editors)

Schriften des Forschungszentrums Jülich

Reihe Umwelt/Environment

Band/Volume 48 
Bibliographic Information published by Die Deutsche Bibliothek.

Die Deutsche Bibliothek lists this publication in the Deutsche

Nationalbibliografie; detailed bibliographic data are available in the

Internet at <http://dnb.ddb.de>.

Publisher and $\quad$ Forschungszentrum Jülich $\mathrm{GmbH}$

Distributor:

Zentralbibliothek

52425 Jülich

Phone +49 (0) $2461615368 \cdot$ Fax +49 (0) 2461616103

e-mail: zb-publikation@fz-juelich.de

Internet: http://www.fz-juelich.de/zb

Cover Design: $\quad$ Grafische Betriebe, Forschungszentrum Jülich GmbH

Printer: $\quad$ Grafische Betriebe, Forschungszentrum Jülich $\mathrm{GmbH}$

Copyright: $\quad$ Forschungszentrum Jülich 2004

The editors cannot accept any responsibility or liability for the accuracy of any statements or information given in the papers.

Schriften des Forschungszentrums Jülich

Reihe Umwelt/Environment Band/Volume 48

ISSN $1433-5530$

ISBN 3-89336-357-2

Neither this book nor any part of it may be reproduced or transmitted in any form or by any means, electronic or mechanical, including photocopying, microfilming, and recording, or by any information storage and retrieval system, without permission in writing from the publisher. 


\section{Introduction}

Life on earth is not possible without water. Only $3 \%$ of the total water available is freshwater. More than two thirds of it is locked up as ice in the polar regions or as glaciers and snow. The remaining third is made up of groundwater, surface waters (lakes, rivers) and water in the atmosphere.

Freshwater, also called the raw material of the 21st century, is part of a global cycle, since it emerges from the earth, flows through streams and rivers into the sea and returns as precipitation to the earth again. Humans intervene in this cycle. Roughly two thirds of the available ground and surface water is globally withdrawn from the natural cycle for irrigation projects in agriculture.

In many regions, a sufficient future water supply of the population is not ensured due to the overuse of freshwater resources. Above all the developing countries and emerging nations are affected. For example, the Aral Sea, which used to be the world's fourth largest freshwater lake, has meanwhile lost three quarters of its volume due to the irrigation of cotton plantations. According to the UNESCO's "World Water Development Report", at least two billion people in 48 countries will suffer from water scarcity by the middle of this century.

Water pollution represents a further problem, which not only affects the developing countries, but also the industrialised countries. According to UN estimates, $95 \%$ of all waste water worldwide is passed untreated into ground and surface waters, so that about half of the 500 largest rivers on earth are heavily polluted. Dramatic consequences for the health of the population in these regions have to be expected.

The resource-conserving use of water resources is one of the important tasks of the future. In the sense of sustainable development, the focus must not only be on covering short-term demand, but time lags of hydrogeological processes must also be taken into account which only lead to serious impacts on human society in the course of decades.

In view of the importance of freshwater and the problems of overusing it, a sustainable management of water as a natural resource must therefore be ensured. Therefore, the water demand of present generations should be covered without jeopardising the water supply for future generations. This basic principle of operationalising the sustainability principle is embodied in the European Union's Water Framework Directive in force since 2001. Its overriding aim is to ensure the good status of water resources in terms of quantity and quality in the EU member states across national borders. 
The volume "Water and Sustainable Development" intends to integrate some important issues dealing with the above mentioned topics. It brings together the knowledge of some well-known experts being engaged with the challenge of working towards a sustainable usage of freshwater. The volume is subdivided into five main parts:

1. Global water issues: In this section the authors identify problems on water demand and quality on a global scale and try to give answers addressing these issues.

2. Basic principles of water in biogeosystems: These authors look from a scientific view on the basis principles of the water cycle with emphasis on the water in biogeosystems.

3. Operationalisation of sustainable water management in the European Union: In this section the authors deal with technical, political and scientific aspects in order to assist the implementation of a sustainable water management in the European Union.

4. Operationalisation of sustainable water management in arid and semiarid regions: These authors take up environmental, social and economic aspects in the framework of a sustainable water management in areas where water scarcity is a severe problem.

5. Hydropower and sustainability: The last part is dedicated to water as a renewable energy source and discuss their opportunities and disadvantages.

The editors are grateful for the interesting and well written contributions of the authors and hope that this volume will give an impetus towards a deepened, multidisciplinary engagement with the complex challenge of a sustainable management of the scarcely resource freshwater.

Jülich, August 2004

Heye Bogena, Jürgen-Friedrich Hake and Harry Vereecken 


\section{TABLE OF CONTENTS}

\section{Global Water Issues}

Water in a Globalised World .....

(R. Gimbel)

Actual and potential Conflicts in Transboundary River Basins

(H.-J. Liebscher)

\section{Basic Principles of Water in Biogeosystems}

Water in Biogeosystems

(H. Vereecken, M. Herbst \& J. Vanderborght)

Interaction between Plant, Soil and Water

(J. Lindenmair)

Operationalisation of Sustainable Water Management in the European Union

The EU Water Framework Directive as a Framework for Sustainable Groundwater Management

(G. Dörhöfer)

Nitrate Contamination of Surface- and Groundwater in Germany -

Results of Monitoring

(R. Wolter)

Water Fluxes and Diffuse Nitrogen Pollution at the River Basin Scale......85

(F. Wendland, H. Bogena, H. Goemann, P. Kreins \& R. Kunkel)

Operationalisation of Sustainable Water Management in Arid and Semiarid Regions

Modelling for Sustainable Groundwater Management in Arid and Semiarid Environments

(W. Kinzelbach, P. Bauer, P. Brunner \& T. Siegfried)

Towards a Sustainable Use of Natural Resources in the Aral Sea Basin

(C. Martius, J. Lamers, M. Ibrakhimov \& P. Vlek)

Water and Irrigation in Australia.

(K. L. Bristow)

\section{Hydropower and Sustainability}

Hydropower and Sustainability

(K. U. Birnbaum \& J.-F. Hake)

The Three-Gorges-Project in China.

(G. Subklew) 

Global water issues 

$-7-$

WATER IN A GLOBALISED WORLD

\author{
R. Gimbel \\ IWW Rhenish Westphalian Institute for Water Research \\ University of Duisburg-Essen \\ Moritzstr. 26, 45476 Mülheim an der Ruhr, Germany \\ r.gimbel@iww-online.de
}

\begin{abstract}
Water, also called the raw material of the $21^{\text {st }}$ century, is the most important source of sustenance. Concerning freshwater, due to its manifold use, e.g. in agricultural irrigation, as drinking water, in sanitation, in industry and for power generation, there will be an increasing scarcity in the next decades on a global level. Therefore, the competing demands for freshwater for the growing world population must also be seen as a source of conflict. Furthermore, meeting the concept of sustainable development is coming under increasing threat due to the permanent over-exploitation of many resources. There is a strong need for water demand management in which social, economic and technical developments are integrated in a well balanced way. This is the challenge for water Research and Development Programmes (R+D), which have to be seen more and more as inter- and transdisciplinary activities.
\end{abstract}

\title{
1 General considerations
}

Life in its present from is only possible due to water; it serves as an almost universal means of transport and solvent. We have been using water for all manner of transportation since ever: E.g. we generally leave our waste products to be simply flushed away by water - a habit which can have fatal consequences, particularly in densely-populated areas if the water's natural self-cleaning abilities become overstretched. Sewage works can help with this problem, but they are still few especially in the less-developed regions of the world. Even in the industrialised countries it is only with great difficulty, if at all, that they are able to remove all hazardous substances from the water once they have got into it. Our globalised world also uses water as a means of transport for goods.

Water is the most important source of sustenance. We can survive weeks without food, but can go no more than a few days without water. Even today there are more than a thousand million people throughout the world who have no access to a hygienic source of drinking water. Water is also used increasingly in the production of foods for the ever-growing world population (Figure 1 and Figure 2).

Last but not least, men also derives valuable nutrition from oceans, lakes, reservoirs and rivers, such as fish and other seafood, which currently provide around one-fifth of men's protein requirement. Water is also used in industry, for instance as a cooling agent or processing medium, or to generate electricity. 


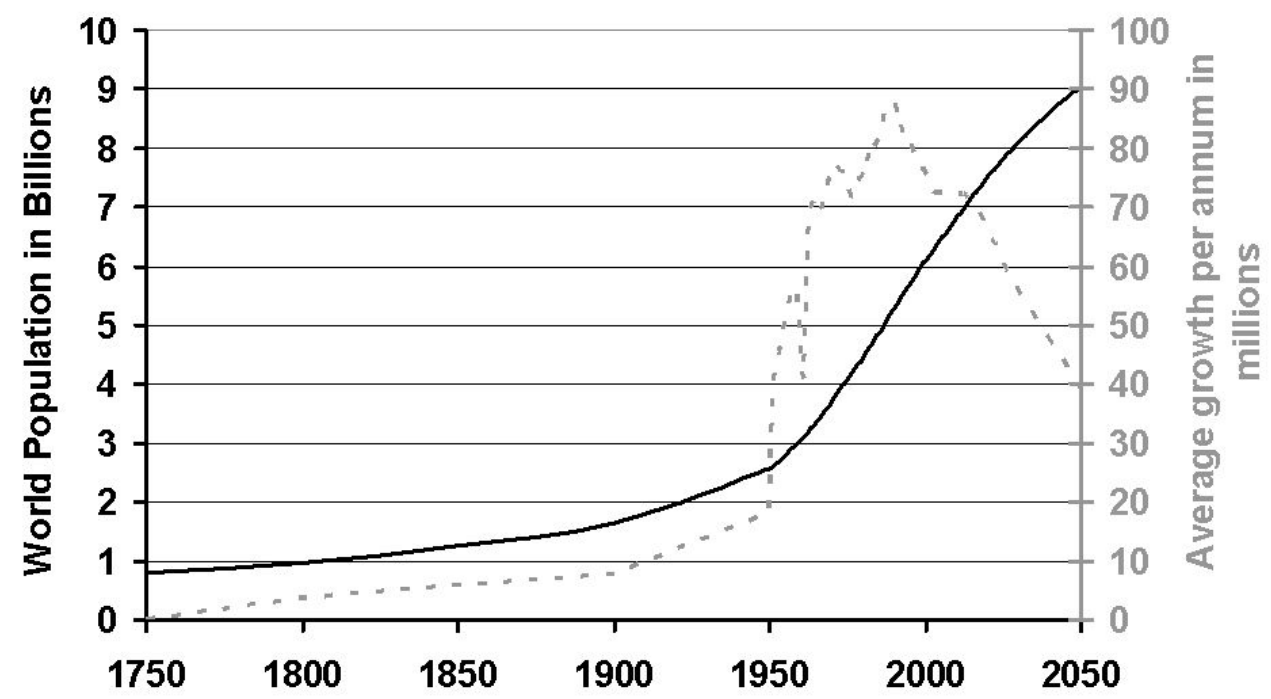

Figure 1: World population growth

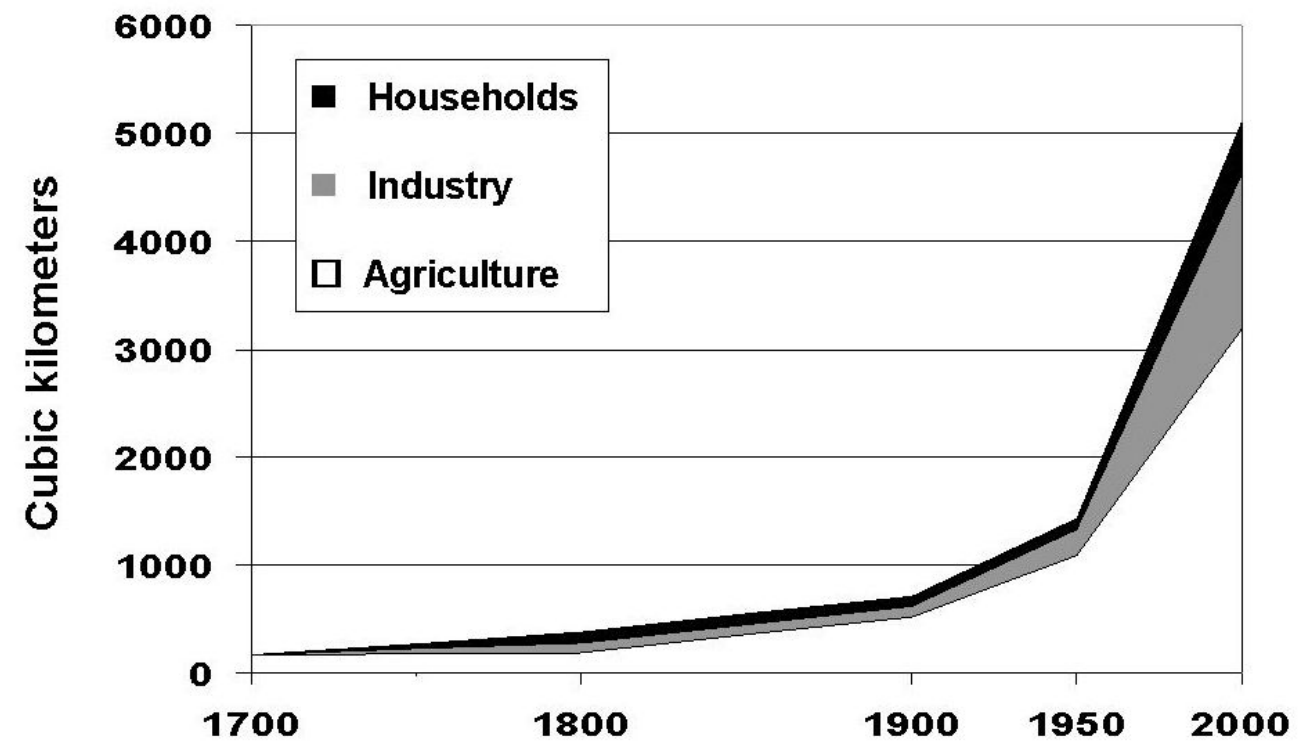

Source: National Geographic ,Deutschland‘ 3, 2002

Figure 2: Global freshwater consumption

Due to population growth and due to the increasing demand for resources one of the greatest tasks of this century must be to guarantee an adequate, completely 
harmless, socially acceptable and sustainable supply of drinking water and sewage treatment (Figure 3). This must include finding integrated solutions for systems that are adapted to particular natural and social conditions and which can also be used in cases of extreme pollution. Basically, a distinction has to be made between urban and rural structures of supply and waste management. Above all, the technology used for the purification of sewage, the abstraction and treatment of water and its sparing use, as well as for the distribution of drinking water and industrial water has to be cost effective but still sufficiently efficient. It is currently the case in many areas that more than half of the water is being lost in the course of distribution - a fact that cannot be justified either ecologically nor economically.

- $0.025 \%$ of the worldwide water is available as freshwater

- 1.4 billion people do not have access to clean drinking water

- 2.3 billion people lack basic sanitary care

- 7.0 million people per year die of diseases caused by water

- Daily per-head water consumption within households:

- 350 litres in North America

- 200 litres in Europe

- 10-20 litres in Sub-Sahara-Africa

- More than 260 rivers are being used by two or more countries without clear agreements.

W. König, fbr-wasserspiegel, 3/03

Source: Water in Crisis, World Water Council, Marseille 2002

Figure 3: Some data and facts concerning water use

To solve these problems we need effective and comprehensive Research and Development Programmes $(R+D)$ concerning the whole topics of water. Whereas in the past it was possible to address both fundamental issues and many applied questions largely through individual classical disciplines, it is now becoming increasingly clear that water $R+D$ can only answer the key questions relating to safeguarding the future by adopting inter- and transdisciplinary approaches.

In 2003 the Senate Commission for Water Research of the German Research Foundation (DFG) has published a memorandum with the title "Water Research - A Balancing Act Between Meeting the Demands of the Present and Safeguarding the Future" in which 7 key topics are treated: 
- Water in the Landscape

- Water in Urban Areas

- Water in Coastal Zones

- Aquatic Ecosystems

- Water and Natural Disasters

- Water and Health

- Water in a Globalised World

These topics highlight the complex interplay between active hydrological, hydraulic, biological and hydrochemical processes as well as economic and social conditions, which can only be analysed realistically using the interaction of the traditional disciplines of water research.

The large variety of functions and uses of water means that it is also a great potential source of conflict. There has always been a certain amount of friction between people living upstream and downstream of a river. But, as the world population grows, so too does the danger of over-exploitation of rivers, lakes and oceans, and ultimately the destruction of environments; these factors explain the vehemence in disputes over water. The supply of clean water is already going down in many parts of the world, and water - the indispensable food of life - is already being viewed as the raw material of the $21^{\text {st }}$ century. There is a genuine fear that even wars of the future could be wars over water. In recent years a considerable number of national and international committees have researched on the topic of water as a source of conflict and have identified steps that need to be taken urgently to use water in a responsible and sustainable way.

A basic guideline for future water $R+D$ is the leading concept of sustainable development, as defined in 1987 by the World Commission for Environment and Development: "Sustainable development is development which is able to meet the needs of the present without compromising the ability of future generations to meet their own needs." Sustainability of this kind is, however, coming under increasing threat due to the constant over-exploitation of many resources whose natural functions are being damaged in various ways. Neither the further development of technical expertise nor the strengthening of legislation to limit environmental pollution by contaminants can obscure this fact.

Even in Central Europe, where a moderate climate prevails, the criteria for a sustainable development may be violated. But this occurs even more drastically in arid and semi-arid regions and also in humid areas of tropical and subtropical regions. Today, we already observe problems like declining ground water tables, salt water intrusion, salinisation of soils, drying out of reservoirs, lakes and rivers, change of vegetation and - last but not least - desertification. 
An especially serious problem for today and tomorrow is the water supply and sewage handling from megacities especially in developing countries. It may be argued that the world wide water problems could be overcome just by using the actually available knowledge with the help of the corresponding economic and social conditions. However, this perspective only holds true up to a point. It is not generally a viable starting point that developing countries need only to adopt the solutions that have been implemented in the highly developed countries. This would fail to take into account the qualitative differences resulting from differences in climate, culture, scale ranges or economic situations. What is really needed in order to achieve any kind of acceptable solution in these circumstances are new, intelligent ideas and further developments in water research.

\section{Water demand management}

One of the most important tasks is to come up against freshwater scarceness in many regions of the world, the so called world water crisis. This can and has to take place by an optimisation of the water usage. The strong rise of the water consumption in the past century led to the fact that the freshwater in many areas of the world became already limited. How strong the water scarceness will intensify in the future depends on the water demand in households, industry, agriculture and power generation according to the demographic, socio-economic and technological developments (see World Water Vision and Rijsberman, 2000). At present the worldwide most important water user is thereby the irrigation agriculture, which is responsible for approximately 70 percent of all freshwater withdrawals.

In the meantime water must be considered as a limited resource, which has to be used in an optimal way. In the areas which actually have a sufficient quantity of water, often water pollution becomes the limiting factor. The task of the water management in former times were primarily the satisfaction of a given water requirement; today a water demand management is necessary for sustainable water supply and distribution. Such a water demand management has the aim to optimally use the water under social, ecological and economic aspects. The competing needs of different sectors or areas have to balanced against each other - for instance the urban water supply of an increasing population must be weighed out against the irrigation agriculture, or the opposite interests of people living upstream or downstream of a river; questions which can be connected with conflicts between population groups or states. In order to be successful, the traditional water management must be seriously expanded contently, institutionally and spatially. A sustainable water demand management must be able to avoid irreversible and quasi irreversible (that means long-term) damages for the water resources and connected natural resources and to keep their ability to achieve essential services.

In the sense of a democratic society, water demand management decisions for the fair allocation of water requires the participation of all water users as well as other interested groups. Firstly, the drainage area may be seen as the suitable spatial unit. 
In this area a sustainably oriented and integrated river-catchment management has to take place, which considers water availability, water use, flood protection, water supply, water quality as well as land use. However the control of the water use cannot be limited to the spatial unit of a water drainage area or a country, if it is acted nation wide or even global as a virtual water. Water demand management occurs in different forms. It represents one of the large options for the solution of the global water problems, but it has to be seen in connection with some other options which are mentioned here:

- Water saving irrigation methods

- Rain harvesting

- Transition to vegetarian nutrition

- Sectoral shifts in the economy

- Desalination of sea and brackish water

- Resettlement and population politics

Furthermore, the narrow and mutual connection between water and energy should not be ignored. On one hand it results from the possibilities to gain water power, on the other hand from the requirements to open new water resources or to enlarge their range of use with a higher need of energy - for example by desalination of sea water or modern irrigation procedures in agriculture.

The price is a fundamental element to control the use of water. There could be substantial effects. The decrease of the drinking water consumption in the eastern German states is a good example for this: after the German reunification and the introduction of cost covering water prices (for the production, treatment, transport and cleaning) the water consumption partly decreased around more than the half.

\section{Dams and Reservoirs}

As a clean regenerative energy source water power could make a considerable contribution to global environmental relief: According to current estimations approximately 2.4 million Megawatt could be produced by hydro-electric power plants. Scarcely a quarter of that exists in our days. Since hydro-electric power plants are connected with strong interferences to inshore waters and landscape, there had to be a critical ecological evaluation.

There is a large potential of application for multipurpose water power plants mainly in developing countries with a high need of additional energy, food production and water-economical compensation measures. These plants can also serve for irrigation at the same time. Therefore, new plants of this kind are established particularly in emerging nations and developing countries of arid regions. Extensive tasks result from the demand to build these plants as economically and at the same time as environmental friendly as possible. 
The world commission on dams has published in 2000 a report with the topic: "Dams and Development", which argues critically the role of large dams for the use of water resources and for power production. The most important conclusions are listed below:

- Large dams for irrigation usually did not achieve the expectations which were set into them. They did not bring back the investment costs, were economically far less reasonable than expected and led also to salting of soil as well as losses of farming land (approximately one fifth of the irrigated surface).

- Large dams build in order to generate electricity are economically more favorable and usually fulfill their financial aims. Nevertheless there are large differences between the dams.

- Large dams used to supply households and industry are rather uneconomic and do not permit a recovery of investment costs.

- Large dams build for flood control led important contributions for security, but at the same time they led to higher vulnerability of the population in case of extreme floods and to larger damage due to the increase of the population density in downstream regions.

- Multipurpose dams belong to the dams, which usually do not achieve the aims which they were constructed for.

- Dams usually cost more than estimated and need also longer than planned for their completion.

- In many cases the sustainability of dams comes into question by sedimentation of particulates which decrease continuously the storage volume.

- Dams led to losses of forests, of animals and of bio-diversity. All measures for rehabilitation were practically unsuccessful.

- Dams led to the resettlement of 40 up to 80 million peoples, who often ended up in poverty.

- The people living downstream, which were dependant on flood recession agriculture, were aggrieved. In some cases it is questionable if the growth of production by the dam is still positive when it is reduced by the loss in down stream areas.

According to these perceptions it is possible to define some demands: Indispensably for the decision to build a dam are more objective cost/benefit analysis, a consequent participation of all groups of interest from the beginning, a more democratic procedure with the completion of the project and above all using modern planning- and management-practices, which were developed on a scientific basis and which consider holistic aspects. 


\section{Drinking water supply and waste water treatment}

One of the greatest tasks of this century might consist of a sufficient, healthy, socially acceptable and sustainable supply of drinking water and the corresponding waste water treatment for the increasing world population.

Technologies protecting the environment and more specifically the natural water cycle have been developed as an reaction to the environmental pollution in developed countries; these have to be transferred to emerging nations and to less developed countries. This has to take place in a well adapted way. The technologies for waste water purification and drinking water processing should also work under extreme conditions. It has to be possible to integrate these technologies into comprehensive system solutions. Drinking water supply depends strongly on the quantity and quality of the raw water resources, which, in many regions of the world, may vary from one extreme to another. For example, depending upon season Monsoon rains or Typhoons can cause extreme turbidities in surface waters. In addition, these waters can have very high loads of anthropogenic compounds. Also, the self purification of surface waters, which determines the quality of the raw water, depends strongly on climatic conditions and differs often completely from conditions like in Central Europe.

Of course, our established and well proven technologies and systems for drinking water and waste water should be improved and further developed for urban as well as for rural areas. These technologies have to be adjusted to "foreign" and partially extreme conditions. This may lead to some progress on a global level in near- and medium-term view. But, the presently primarily applied transfer or simple adaptation of our technology- and system-know-how from developed countries to the developing countries will reach quite soon limitations, which are caused by the usually different conditions between the countries. E.g. a stronger coupling of energy- and watermanagement could be interesting and could enlarge the economically and ecologically beneficial developments. This is especially true with an increased usage of regenerative energies to win, process and distribute drinking water and to treat the waste water. Therefore, in a longer term, the development of completely new systems and technologies for a sustainable use of the natural water cycle also under extreme conditions have to be developed. In this context we may also discuss the possibility of a more consequent separation between drinking water (in a narrow sense) and service water (grey water) for households and industry. 
$-15-$

\section{References}

BMBF-Aktionskonzept "Nachhaltige und wettbewerbsfähige deutsche Wasserwirtschaft" (2000) (Fachberichte, Bundesministerium für Bildung und Forschung (BMBF), Referat 421, März 2000).

Dams and Development (2000) (The report of the world commission on dams, 2000). http://www.dams.org/report/execsumm.htm.

Deutsche Forschungsgemeinschaft (DFG) (2003) "Wasserforschung im Spannungsfeld zwischen Gegenwartsbewältigung und Zukunftssicherung".

IPCC (Intergovernmental Panel on Climate Change) (2001) Third Assessment Report. Technical Summary of the Working Group I Report. http://www.ipcc.ch.

Rijsberman, F. R., Hrsg. (2000) World Water Scenarios: Analysing Global Water Resources and Use. Earthscan, London.

UNEP (2000) Global Environment Outlook 2000.

http://www.grida.no/geo2000/index.htm.

World Water Vision (World water council). http://www.worldwatervision.org.

WBGU (Wissenschaftlicher Beirat der Bundesregierung globale Umweltveränderungen) (1997) Welt im Wandel - Wege zu einem nachhaltigen Umgang mit Süßwasser. http://www.wbgujg1997. 



\title{
ACTUAL AND POTENTIAL CONFLICTS IN TRANSBOUNDARY RIVER BASINS
}

\author{
H.-J. Liebscher \\ Vallendar, Germany \\ hans-juergen.liebscher@t-online.de
}

\begin{abstract}
With the increasing scarcity of water, the danger of conflict is rising in transboundary river basins across the world. Human activities which promote conflicts over water include water abstraction, water pollution, construction of dams, measures which intensify floods and the changes in riverbeds where sections of rivers form the border. A series of other factors must also be taken into account, which have influence on conflicts. Water availability, population growth, the balance of power, dependencies, ideological imbalance, as well as political structure are among the indicators. Water can also play a connective role, because of its essential and threatening character and because it can be a catalyst for international cooperation in conflict areas. A reduction of the potential of conflicts can be done through confidence building measures, such as the carrying out of common projects between the institutions of the countries within a transboundary river basin and by the common management of the water resources. Water scientists such as hydrologists can contribute to the avoidance of, and the solution of, conflicts in transboundary rivers through the exchange of hydrological data and forecasts, the collection of such hydrological, climatological, morphological and land use data which are of interest to all the countries within the river basin (compilation of a hydrological inventory), together with the development of more robust and transparent water management models and assessment methods.
\end{abstract}

\section{Introduction}

Over the last 100 years the world's population has tripled, the world wide demand for water has increased by seven times and the irrigated areas by six times. Agriculture is the world's greatest water consumer. Global water resources are decreasing due to increasing water pollution. A time when the world's usable water resources is less than the demand made on them is foreseen [4].

This development is leading to a growing shortage of water resources and thus to a worldwide water crisis that can be expected to be experienced virtually everywhere. As water is essential in all spheres of life, a water crisis will have an impact on the majority of activities. Health care, the economy, politics, culture, the standard of life and human rights are as affected as the environment. In the world as a whole there are 263 transboundary river basins shared by two or more sovereign states [5,11]. Approximately one-third of the 263 transboundary basins are shared by more than two countries, and 21 involve five or more nations. The Danube has 17 and the Congo 13 riparian countries. Six basins (Amazon, Lake Chad, Niger, Nile, Rhine, 
Zambezi) are shared by between nine and eleven nations. The remaining 13 basins (Aral Sea, Ganges-Brahmaputra, Indus, Jordan, Kura-Araks, La Plata, Lake Turkana, Mekong, Neman, Tarim, Tigris-Euphrate, Vistula, Volta) have between five and eight riparian countries. The 263 transboundary catchments account for almost half the earth's land area and half the world's population. The number of transboundary aquifers is probably even larger. The potential for conflict in transboundary river basins is very apparent. During the last 50 years 507 conflictive events on water were recognized, 37 of them involved violence and 21 of them military actions [5]. Therefore the need for extensive and cooperative solutions for the management of the water resources in such areas is extremely high.

The increasing diversity of water use, as well as the rapid growth in demand, coupled with the decreasing water resources, the international character of water and the great temporal and spatial variability of water resources across the globe have increased tensions over utilization of water. Added to these problems are the changes to water resources expected through global climate change. More and more countries are experiencing difficulties and more and more experiment in order to solve their problems, sometimes applying inappropriate methods for the management of water resources.

However, water can also play a connective role, because of its essential and threatening character and because it can be a catalyst for international cooperation in conflict areas. For example, the necessity for the common management of the water resources or the development of flood defences can connect the riparian countries. In this respect, water has a cooperation potential in parallel to its conflict potential. During the last 50 years 1228 cooperative initiatives have taken place in transboundary river basins [5].

\section{Causes and prerequisites for water conflicts}

Those activities which promote conflicts over water include: water abstraction, water pollution, construction of dams, measures which intensify floods and the changes in riverbeds where sections of rivers form the border. However, they do not usually operate alone. A series of other factors must also be taken into account, which may lead to conflicts. Water availability, population growth (birth rate, migration), the balance of power (military, economic and positional), dependencies (political, economical and cultural), ideological imbalance (ethnicity, religion, culture), as well as political structure (democracies, dictatorships) are among the indicators (Figure 1) $[1,2,11]$. Water conflicts can appear at different scales: nationally between different user groups as well as between political units and internationally between the countries with transboundary waters (rivers, lakes, groundwater). However, excessive abstraction, when water resources are limited, is the most frequent cause of water conflicts. 
$-19-$

Ways to avoid or reduce water conflicts include the acknowledgment of the principle of the sustainable development of water resources, the acknowledgment of the right and claims of weaker partners, as well as striving for the common management of water resources (e.g. through the Water Framework Directive of the European Union), through the founding of river basin commissions and the effective involvement in such commissions.

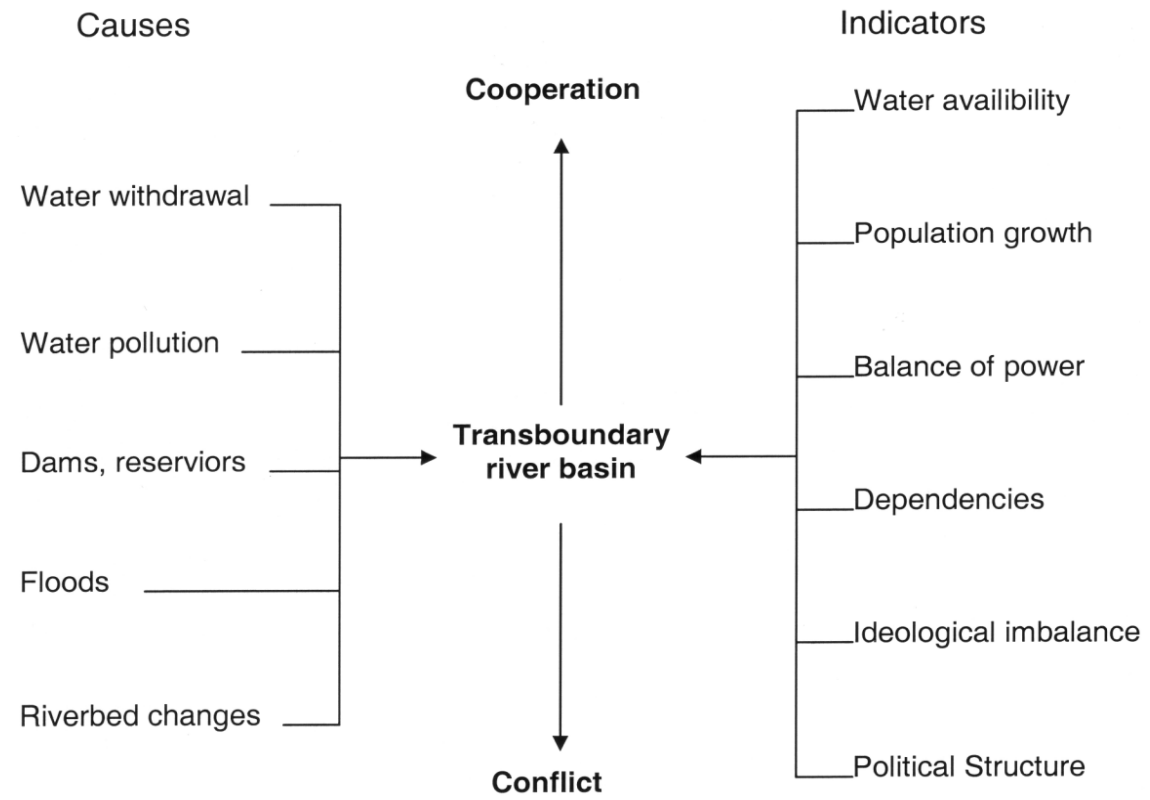

Figure 1: Effects of causes and indicators on the potential of conflicts after Clevering [1] (somewhat modified and enlarged).

\section{Methods for quantifying the potential of conflicts}

At present there are very few methods for the estimation of the potential of conflicts in transboundary river basins available. The estimation of the conflict potential in such areas is important, and timely introduction of preventive measures can avoid the escalation of conflicts. Wolf et al. [11) took an important step in this direction. On the basis of a transboundary freshwater dispute database [9], which contains digital maps of the world's 263 transboundary basins [7], a compilation of 400 water treaties [8], a collection of 1831 reported events on water related disputes during the last 50 years, a methodology for identifying the risk of conflicts was developed [11]. This methodology is based on a Geographical Information System (GIS) [12]. In order to evaluate the intensity of interactions, either cooperative or conflictive, a scoring system was developed, which assigned the basin at risk (BAR) intensity values from -7 (indicating the highest level of conflict, i.e. war) to +7 (indicating the highest level 
of cooperation, i.e. voluntary merging of countries) to each event (Figure 2). The method was applied to all 263 international basins worldwide. The study identified 21 transboundary river basins at risk. These are Aral-Sea, Ganges-Brahmaputra, Han, Incomati, Jordan, Kunene, Kura-Araks, Lake Chad, La Plata, Lempa, Limpopo, Mekong, Nile, Ob (Ertis), Okavango, Orange, Salween, Senegal, Tigris-Euphrates, Tumen and Zambezi.

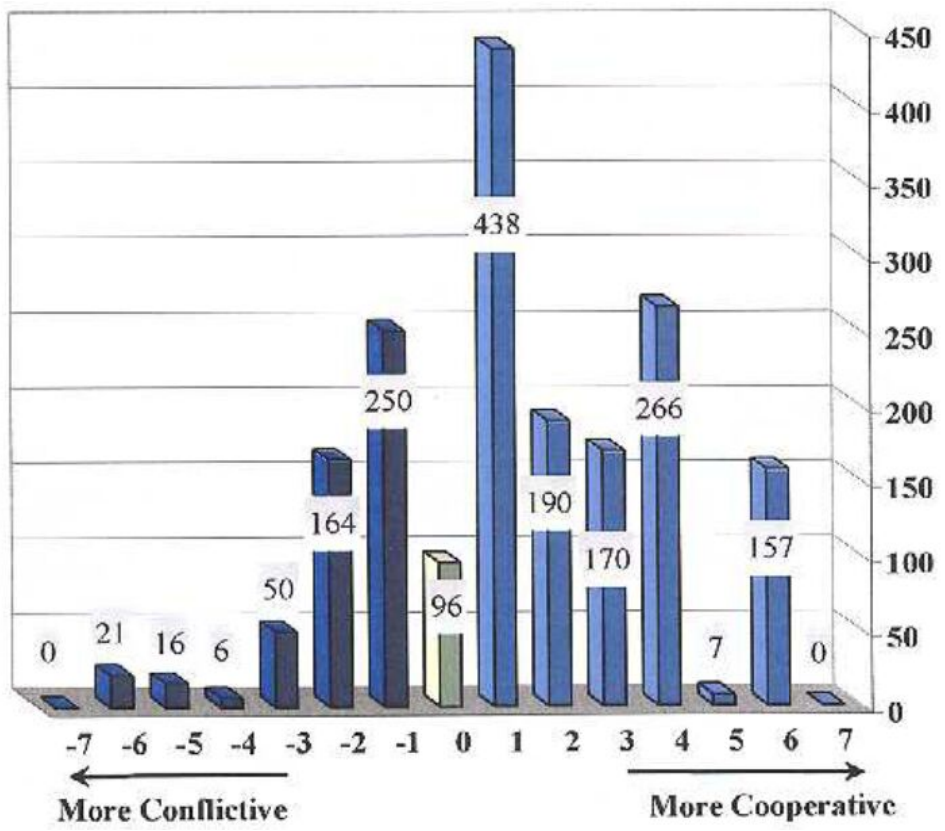

Figure 2: Number of events by basins at risk (BAR-scale) [11].

Clevering [1] undertook another interesting study on this matter. He introduced an evaluation method in which the degree of involvement of four the five individual causes (water withdrawal, water pollution, dams and reservoirs, floods) and of the six indicators of conflicts is estimated in a five class system. Class 1 means none, class 5 means high involvement. The potential for conflicts is determined by the addition of the individual evaluation numbers. The method does not take into account existing cooperation's. This procedure is subjective. It has not been tested as to its degree of objectivity. The method was applied by Clevering on only 10 transboundary river basins, six of them are the same as those which were found at risk by Wolf et al. [11].

In another study [3], the methodology developed by Clevering was applied to six additional basins, of which five are basins at risk (Figure 3). The Volta basin is not in the list by Wolf et al. [11]. 
$-21-$

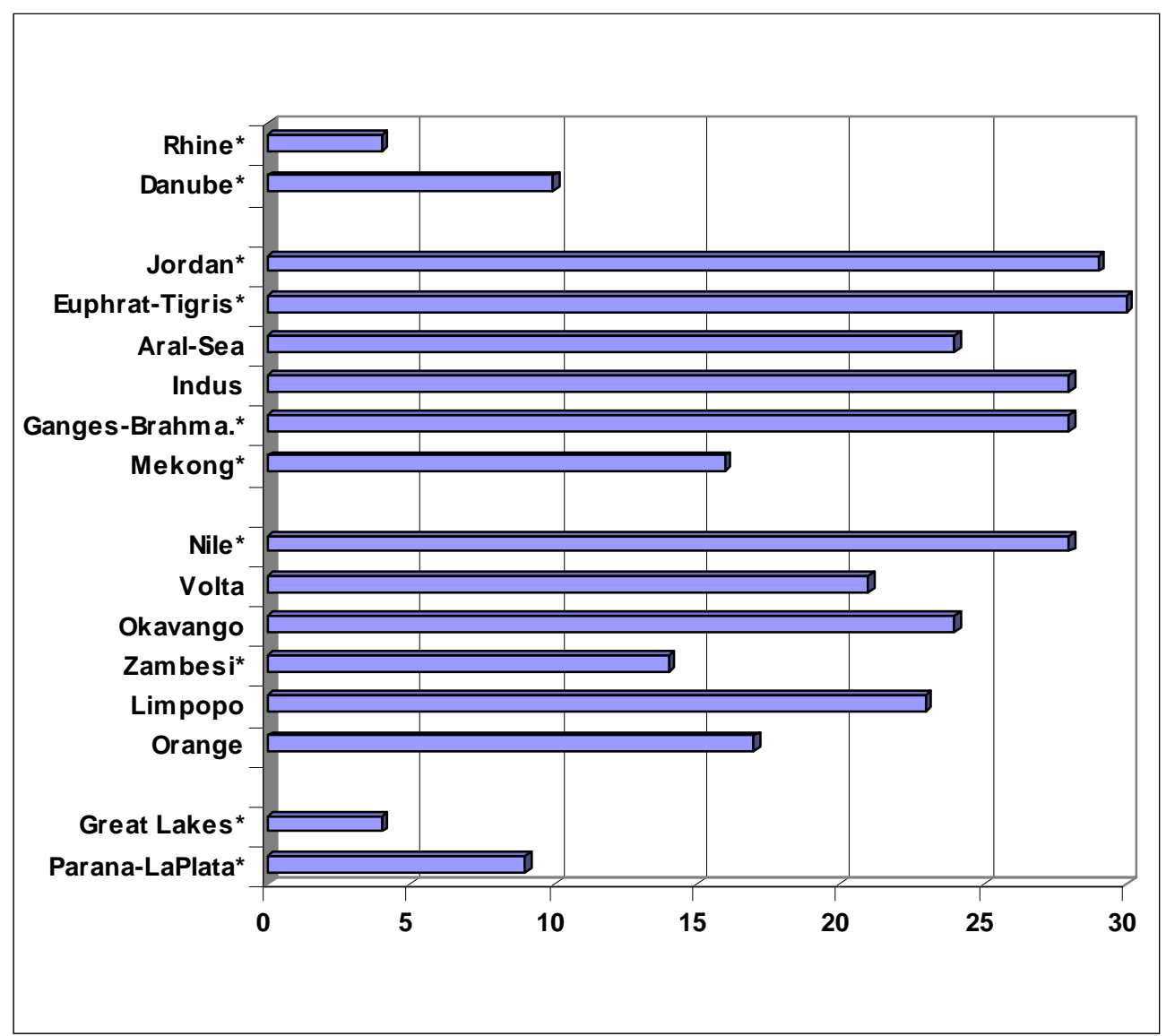

Figure 3: Estimation of the potential of conflicts after Clevering [1) (somewhat modified). The estimates of the river basins signed by * were taken from Clevering with small modifications.

\section{The contribution of water scientists towards the solution of conflicts}

Which contribution can water sciences such as hydrology make in order to reduce tensions in an international river basin? It certainly can do little to counter population growth, alter the balance of power, and change dependences, ideological imbalances and political structures. Scientists are, in general, politically independent. They are usually unprejudiced, objective and furthermore they are usually ready for cooperation across international borders. Indeed they are normally ready to keep or develop contacts with colleagues in neighbouring countries even when tension exists. An example of this was the 30-years of cooperation between the hydrologists in the Danube Basin during the Cold War. Conferences on flood forecasting were organized every 2 years in different countries. The national committees of UNESCOs 
International Hydrological Programme (IHP) and the Hydrological Working Group of the Danube Navigation Commission cooperated and developed a comprehensive monograph of the Danube basin.

The potential for conflict decreases in transboundary river basins if, in general, cooperation already exists. Such co-operation can operate in different ways. It can extend from relatively loose consultative meetings, bi- and multilateral agreements or contracts as far as membership in river basin commissions with a supranational character. The hydrologists of the countries concerned are required to make their own contributions to whatever pattern of cooperation exists, as these contributions are very important for all confidence building measures.

\section{Confidence building measures}

\subsection{Development and maintenance of contacts among hydrologists}

Cooperation in international river basins begins with the utilization of existing friendships or friendly contacts between the hydrologists of the riparian countries. Such contacts occur at conferences, symposia and workshops, from cooperation in scientific-technical commissions or committees established by international governmental organizations (IGOs) and non-governmental organizations (NGOs). Such contacts are familiar to many hydrologists. These events must also be used for the development of new contacts and friendly relationships.

Such relationships are a prerequisite for future cooperation. The next step is the organization of common institutional meetings. This move can be used as a basis for later official bi- or multilateral contacts. Such cooperation can end with the foundation of river basin commissions based on bi- or multilateral treaties. The support of regional cooperation is also important in this context through IGOs, especially through UNESCO. Within the framework of international programmes (e.g. the IHP), hydrologists can form their own means for river-basin cooperation. The examples of the Rhine and the Danube show that contractually secured cooperation can follow from such earlier cooperation.

The establishment of contacts between scientists in conflict areas can be supported by IGOs and NGOs. The bringing together of scientists from conflict areas has special importance. This can happen during international conferences, symposia or workshops on transboundary river basins and also on general topics, while regional conferences or meetings are also suitable for this purpose. Where possible IGOs should fund the participation of hydrologists and water professionals from conflict areas and they should be encouraged to present papers at such meetings. Discussions between these scientists should be organized at such events and perhaps IGOs could nominate a representative, who would be tasked to bring these participants together on such occasions. 
The implementation of certain projects can contribute to the solution of conflict situations. A good example of this is the project on "Potential conflicts vs cooperation potential (PC-CP)" promoted by UNESCO and Green Cross International [5]. In November 2002, an interesting conference, which found great interests, took place in Delft, The Netherlands on this topic. Hydrologists are urged to participate in such conferences.

The regional projects executed by IGOs are of great importance to cooperation between hydrologists in conflict areas. Examples are the project "Flow Regimes from International Experimental and Network Data (FRIEND)" which is a part of the IHP and WMO's "World Hydrological Cycle Observation System (WHYCOS)". The Hydrological Working Groups of the Regional Associations of the WMO have an important role in this context. These Groups should be encouraged to deal with potential water conflicts within their region and involve scientists from conflict areas. The organization of special training courses on cooperation in transboundary river basins is also helpful.

The existing river basin commissions might make contributions to the cooperation between hydrologists, especially in transboundary river basins, where such cooperation does not exist. Inviting scientists from conflict areas to make visits is a relatively simple measure.

Developed countries and supranational agencies can also help for confidence building in water conflict regions. They can organize special training courses and invite to those courses scientists and technicians from such regions. They may be able to finance and carry out bi- or multilateral projects in transboundary river basins. Examples of such projects are the training courses held in Delft, The Netherlands, Madrid, Spain or Budapest, Hungary and a special project to set up a water quality monitoring network in the Danube Basin financed by the European Union.

\subsection{Exchange of research results, monitoring, data and forecasts}

Hydrologists contribute to confidence building measures through the exchange of research results, monitoring hydrological variables and exchanging data which may be of interest to upstream and downstream countries. Special importance is attached to data for flood warning and to the prevention of disasters. Access to relevant monitoring data needs to be agreed between the different parties sharing a river basin. This may lead to other confidence building measures.

\subsection{Sharing in projects}

Most riparian countries within transboundary river basins have a primary interest in an inventory of the process-oriented hydrological conditions, their relevant components and their temporal and spatial distribution. Climate, morphology, groundwater resources, hydrogeology, soil characteristics, vegetation, land use, dams and reservoirs, abstraction of water, waste water discharges, water supply and monitoring systems are of particular interest. Of special importance is the 
assessment of water resources including their spatial and temporal distribution together with their dynamics. This information can be compiled by the joint development and publication of a monograph for the relevant river basin. Examples of this are the monographs on the rivers Rhine and Danube

With the representation of the spatial distribution of hydrological components in the area, inconsistencies at borders usually become visible within the river basin. These are caused by different measuring systems, measuring instruments, network densities and calculation procedures, but also through different cartographic material. One possibility for clearing up such inconsistencies on transboundary rivers are shared measuring actions. Currently the joint operation of environmental monitoring systems is important for the early recognition of ecological damage. Such activities are usually dealt with in the technical programmes of the international river commissions of European rivers and by European Union activities.

With the shared production of monographs, inconsistencies also become visible in the cartographic material. Therefore standardization of cartographic material is necessary. These needs bring together others groups of scientists within the transboundary river basin to undertake the agreed programme of action.

\subsection{Development and use of transparent methods for the management of the water resources}

In order to reduce tension, the common management of water resources in transboundary river basins is necessary. The demand is especially high for extensive and cooperative solutions to the management of the water resources in water-scarce areas. In these circumstances hydrologists are required to take part in the development of new methods in cooperation with socio-economists, ecologists and other groups. Transparent and objective water management models, that take the socio-economic conditions into account, are required. The development of simple and robust models is necessary for the planning and operation of water systems, as well as for the management of the water resources. In addition hydrologists can contribute to develop the scientific basis for decision making models for the allocation of water among countries.

Danger often unites the riparian countries in transboundary river basins, particularly when there are floods or pollution incidents. Here the need for counter measures brings together hydrologists to develop forecast models. Downstream countries should be warned early enough during the occurrence of floods so that these countries are able to undertake appropriate steps to protect the people living in the area at risk, and their possessions. If a country is not in the position to provide forecasts, online access to basin wide hydrological monitoring stations should be given, so that other countries are put in a position of being able to develop and to employ their own forecast systems. Access to upstream data is particularly important for downstream nations. The development of a common transboundary forecast system can be a good basis for enduring bi- or multilateral cooperation. 
The common investigation of flood-intensifying land use developments in the upstream countries and the development of concepts to the decrease of the flood risk can enhance the cooperation between the riparian countries.

Another situation at the opposite extreme, namely drought, can connect the riparian countries when faced with water shortages. Here, particular effort is needed to develop rules for the management of the scarce water resources in order to minimize the damage during droughts.

It is also important to make provision for warnings to downstream countries in the case of natural disasters (e.g. tornados, earthquakes) and their effects on water systems, as well as in the case of accidental pollution, dam breaks, and ruptures to sewers and problems at sewage treatment works.

There are further common interests in transboundary rivers which are used for inland navigation and hydraulic power production. Here, it is the task of the hydrologists to prepare the required planning data to produce forecasts and to be involved in management.

\subsection{Assistance in the development of water saving methods and techniques}

Scarcity of water is one of the main reasons for water conflicts. Consequently it is necessary in such areas to save water as often as possible. Because agriculture is the greatest water consumer, it is necessary to cultivate plants which consume less water and to introduce more water saving irrigation techniques such as drip irrigation. Losses in the water supply channels of irrigation systems must be reduced. Reuse of water should be considered. To avoid pollution of groundwater it is necessary to collect and treat waste water. Water losses in waste water systems should also avoided. Furthermore much should be done to avoid or to reduce salinization of soils and groundwater by irrigation.

There is a broad field for action amongst hydrologists. They can contribute to solutions in this field, especially in consulting and advising decision makers, engineers and farmers. Special training courses on this matter for hydrologists and water engineers from water scarce countries organized by IGOs and donor countries are very valuable.

\subsection{Development of procedures for a more mathematically based estimate of the potential of conflict}

As mentioned in section 3 there is a lack of methods to estimate the potential of conflicts for transboundary river basins. The two methods described gave different results for some river basins. The results of the two methods should be compared.

Additional criteria need to be investigated and whether there are further criteria to be considered beside those in these methods. For example, the potential for conflict on river sections defining a border where natural morphological changes can occur in the river section is a case which should be taken into account. In order to gain a 
more objective approach, it is important to develop mathematical relationships for the individual evaluation criteria. This is not easy, but it must be possible for some indicators, such as water availability. Besides the mean annual water availability, the spatial and temporal variations including the seasonal distribution of water have to be taken into account. Cooperation with scientists from other disciplines is very important here.

\section{Conclusion}

A worldwide increase in water scarcity is underway. This increases the danger of conflicts in transboundary river basins. Measures have to be undertaken to reduce the potential for these conflicts. Water sciences can play an important role in alleviating these dangers because of its special importance and responsibilities for these matters. Water scientists can contribute through confidence building activities, carrying out of common projects between institutions of countries within transboundary river basins and the common management of their water resources. Hydrology can also contribute to the solution of conflicts in transboundary rivers through the exchange of research results, hydrological data and forecasts, the transboundary collection of such hydrological, climatic, morphological and land use data which are of interest to all countries within the river basin. The development of more robust and transparent water management models and assessment methods also contribute to the reduction of the potential for conflict. Water scientists should become more sensitive to the growing worldwide problems that produce the potential for water conflicts.

\section{References}

[1] J. Clevering (2002): Indicators of international river basin conflicts. Thesis Report, Wageningen University, The Netherlands.

[2] P. Gleick (1993): Water and Conflict. International Security 18, pp. 79-112.

[3] H.-J. Liebscher (2004): Potenzielle und aktuelle Wasserkonflikte in grenzüberschreitenden Flussgebieten. Hydrologie und Wasserbewirtschaftung, 48, pp. 71-79.

[4] J. Rodda (2002): Water under pressure. Hydrol. Sci. J., 46, pp. 841-854.

[5] UNESCO \& Berghahn Books (2003): Water for People-Water for Life. The United Nations World Water Assessment Report. Berghahn Books, Oxford, New York.

[6] UNESCO \& Green Cross International (2003): From Potential Conflict to Cooperation Potential: Water for Peace. http//www.unesco.org/water/wwap/pccp.

[7] A. Wolf (1998): Conflict and cooperation along international waterways. Water Policy 1, pp. 251-265. 
$-27-$

[8] A. Wolf (1999a): Criteria for equitable allocations: the heart of international water conflict. Natural Resources Forum 23, pp. 3-30.

[9] A. Wolf (1999b): The Transboundary Freshwater Dispute Database Project. Water Int. 24, pp. 160-163.

[10] A. Wolf, J.A. Natharius, J.J. Danielson, B.S. Ward and J.K. Pender (1999): International river basins of the world. Water Resour. Devel. 15, pp. 387-427.

[11] A. Wolf, S.B. Yoffe and M. Giordano (2003): International waters: identifying basins at risk. Water Police 5, pp. 29-60.

[12] S. Yoffe and G. Fiske (2001): Use of GIS for analysis of indicators of conflict and cooperation over international freshwater resources. In: Yoffe, S. Basins at Risk: Conflict and Cooperation over International Freshwater Resources, Diss., Oregon State University, Chapter 3, pp. 42-62. 



\section{Basic Principles of Water in Biogeosystems}





\title{
WATER IN BIOGEOSYSTEMS
}

\author{
H. Vereecken, M. Herbst and J. Vanderborght \\ Agrosphere Institute \\ Research Centre Jülich \\ $D-52428$ Jülich, Germany \\ h.vereecken@fz-juelich.de
}

\begin{abstract}
We present various approaches to quantify the terms of the water balance in biogeosystems. Specific emphasis is given to the estimation of the actual evapotranspiration. Its accurate estimation at various spatial and temporal scales is still an issue of intensive research. Four different approaches are discussed comprising mass balance methods, energy based methods, direct methods and remote sensing methods. Latter approach can be used either in the mass or energy balance approach. The mass balance approach is presented for the specific case of a land surface with mixed use.
\end{abstract}

\section{Introduction}

Water is the bloodstream of the biosphere and it determines the sustainability of all living systems on earth [1]. Table 1 gives an overview of the global water distribution on our planet. Most of the water on earth is stored in oceans, seas and bays. Of the available freshwater, ice caps, glaciers and permanent snow store most of it followed by groundwater systems which occupy a volume of $1.3 \times 10^{9} \mathrm{~km}^{3}$ and are therefore an important reserve for drinking water supply.

Vegetation, atmosphere and soil only store a minor part of freshwater totalling $3.1 \mathrm{x}$ $10^{4} \mathrm{~km}^{3}$ or $0.09 \%$ of the total amount of freshwater. The soil-vegetation-atmosphere system plays however an important role in routing rainfall either to the subsurface or to the atmosphere. A general representation of the terms of the water balance, referring to the fluxes of water in and between the compartments of biogeosystems (soil, plant, atmosphere, rivers, ocean) is presented in Figure 1. This exchange is governed by the land surface and the vegetation. Precipitation is either converted to vapour through the process of evaporation from the soil surface and transpiration by plants, stored in groundwater systems (recharge) or directed to rivers, lakes and oceans (runoff). The sum of evaporation and transpiration is coined evapotranspiration and constitutes about $63 \%$ of the total precipitation reaching the land surface.

An interesting distinction between green and blue water is made by [2]. Green water is defined as that part of rain precipitation which is converted in vapour form whereas blue water refers to the liquid part (e.g. runoff and groundwater recharge) of rainfall. The major part of green water is produced by evapotranspiration. Green water is stored in the subsurface and consumed by transpiration. Green water flux is 
estimated to be equal to $63,000 \mathrm{~km}^{3} / \mathrm{a}$ [2] whereas blue water equals about $37,000 \mathrm{~m}^{3} / \mathrm{a}$. Of the latter approx. $1000 \mathrm{~km}^{3} / \mathrm{yr}$ are used for irrigation and $2.500 \mathrm{~km}^{3} / \mathrm{a}$ are extracted for consumptive use and withdrawals. However, the estimation of the magnitude and the spatial variability of the evaporation and transpiration fluxes still remains an issue of scientific research. This is due to the fact that actual evapotranspiration fluxes may differ considerably from the potential fluxes and that land surfaces are

Table 1: The global water distribution [3].

\begin{tabular}{cccc}
\hline & Volume $\left(1,000 \mathrm{~km}^{3}\right)$ & $\begin{array}{c}\text { Percent of total } \\
\text { water }\end{array}$ & $\begin{array}{c}\text { Percent of } \\
\text { freshwater }\end{array}$ \\
\hline $\begin{array}{c}\text { Oceans, seas \& } \\
\text { bays }\end{array}$ & $1,338,000$ & 96.5 & - \\
$\begin{array}{c}\text { Ice caps, glaciers \& } \\
\text { permanent snow }\end{array}$ & 24,064 & 1.74 & 68.7 \\
Fresh groundwater & 10,530 & 0.76 & 30.1 \\
Saline groundwater & 12,870 & 0.94 & - \\
Soil moisture & 16.5 & 0.001 & 0.05 \\
Ground ice \& & 300 & 0.022 & 0.86 \\
Permafrost & 91 & 0.007 & 0.26 \\
Lakes : fresh & 85.4 & 0.006 & - \\
Lakes : saline & 12,9 & 0.001 & 0.04 \\
Atmosphere & 11.47 & 0.0008 & 0.03 \\
Swamp water & 2.12 & 0.0002 & 0.006 \\
Rivers & 1.12 & 0.0001 & 0.0003 \\
Biological water & 1.385 .984 & 100 & 100 \\
\hline Total & & &
\end{tabular}

inherently heterogeneous. The magnitude of the actual fluxes strongly depends on the state of the soil, vegetation and atmosphere and their spatial and temporal variations, like e.g. soil moisture content, micro-meteorological conditions and nutritional status of the plant. In the following we will discuss different methods to estimate the actual transpiration and evaporation from land and vegetation surfaces.

\section{Methods to estimate evapotranspiration}

Basically three different groups of methods can be distinguished to estimate evapotranspiration:

1. Mass balance approaches

2. Energy transfer methods

3. Direct methods 
Because remote sensing methods can be applied to either the first or second approach, they are discussed in a separate section.

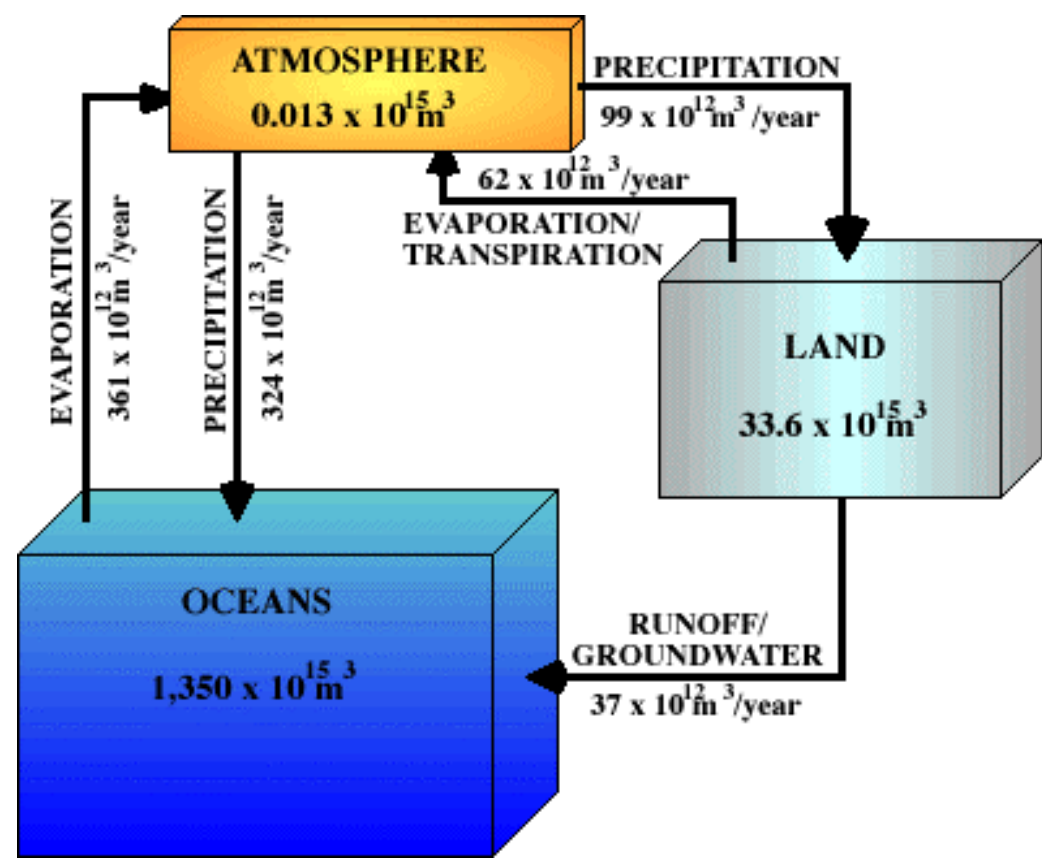

Figure 1: Storage and fluxes of water in the major compartments of biogeosystems [4].

\subsection{Mass balance approaches}

Mass balance approaches may be used to estimate evapotranspiration, if the change in storage of water and all the inputs and outputs are known for a well-defined control volume. Direct measurement of groundwater recharge and evaporative fluxes is however not possible under real field conditions. Therefore mathematical models are frequently used to estimate the terms of the water balance. To describe water movement of a cropped soil, Richards equation may be used

$$
\frac{\partial \theta}{\partial t}=\nabla \cdot \mathbf{K} \nabla(\psi+z)-S(x)
$$

where $\theta\left(L^{3} L^{-3}\right)$ is the volumetric water content, $\mathbf{K}\left(\mathrm{L} \mathrm{T}^{-1}\right)$ the hydraulic conductivity tensor, $\psi(\mathrm{L})$ the pressure head, $\mathrm{z}(\mathrm{L})$ the elevation head, and $S(x)\left(\mathrm{T}^{-1}\right)$ a sink term that accounts for water uptake, like e.g. water uptake by plant roots. In the unsaturated zone, $\psi$ is negative due to capillary forces and is also called the matric head. In the saturated zone, $\psi$ is positive and equal to the hydrostatic pressure head. 
Under unsaturated conditions, the water content $\theta$ and the hydraulic conductivity $\mathbf{K}$ are related to the matric head $\psi$. The functions $\theta(\psi)$ and $\mathbf{K}(\psi)$ are constitutive relationships that characterize the hydraulic soil properties. These functions are highly non-linear and an approximate solution of Eq. (1) can only be obtained using numerical methods. The TRACE code [5], which was developed at the Research Centre Jülich, is an example of a computer program that solves the 3-D Richards equation numerically.

The soil hydraulic properties are related to other soil properties like soil texture, bulk soil density, and organic carbon content. By pedo-transfer functions, parameters of the $\theta(\psi)$ and $\mathbf{K}(\psi)$ functions can be estimated from other soil properties [6][7]. For larger scale modeling, information is extracted from soil maps to obtain the spatial distribution of hydraulic soil properties.

The root water uptake sink term, $S(x)$, is a function of depth which is defined by the root density and the potential transpiration. When plants are not subjected to stress, the root uptake is at its potential maximum: $S(x)=S_{p}(x)$, and the integral of $S(x)$ with depth corresponds with the potential transpiration $T_{p}\left(\mathrm{~L} \mathrm{~T}^{-1}\right)$ by the plant cover :

$$
T_{p}=\int_{0}^{L r} S(x) d z
$$

where $L_{r}(L)$ is the rooting depth. The potential transpiration is a boundary condition that is estimated from meteorological and plant cover parameters (see below). When the soil is too wet or too dry, plants are under stress and roots cannot take up sufficient water. The reduction of root water uptake due to stress is modeled using a stress factor $\alpha(\psi)$ that reduces the sink term with respect to the potential sink term:

$$
S(x ; \psi)=\alpha(\psi) \cdot S_{p}(x)
$$

The stress factor $\alpha$ depends on the matric head and the plant ([8]). In order to solve flow equation, the boundary conditions must be defined. Here, we focus on the boundary conditions at the soil surface, which is relevant for remote sensing: the water that infiltrates in the soil $I\left(\mathrm{~L} \mathrm{~T}^{-1}\right)$, that evaporates from the soil surface, $E_{a}$ $\left(\mathrm{L} \mathrm{T}^{-1}\right)$, and that is taken up by the plant roots and transpired by the crop, $T_{a}\left(\mathrm{~L} \mathrm{~T}^{-1}\right)$.

Based on an energy balance at the soil surface, the reference evapotranspiration, $\mathrm{ET}_{0}$, can be calculated from meteorological parameters using the Penman/Monteith equation [9][10]. The Penman/Monteith equation for the reference evapotranspiration of grass on a hourly basis is given by: 


$$
E T_{0}=\frac{\Delta\left(R_{n}-G\right)}{\lambda\left[\Delta+\gamma\left(1+C_{d} u_{2}\right)\right]}+\frac{\gamma \frac{37}{T_{a}+273.16} u_{2}\left(e_{s}-e_{a}\right)}{\Delta+\gamma\left(1+C_{d} u_{2}\right)}
$$

where $\mathrm{ET}_{0}(\mathrm{~mm} / \mathrm{hr})$ corresponds to the evapotranspiration of a well watered grass surface, $\Delta$ the slope of saturation vapor pressure curve $\left(\mathrm{kPa}{ }^{\circ} \mathrm{C}^{-1}\right)$ at mean air temperature $(T), R_{n}$ the net radiation $\left(\mathrm{MJ} \mathrm{m}^{-2} \mathrm{~h}^{-1}\right), \mathrm{G}$ soil heat flux density $\left(\mathrm{MJ} \mathrm{m}^{-2} \mathrm{~h}^{-1}\right), \gamma$ the psychrometric constant $\left(\mathrm{kPa}^{\circ} \mathrm{C}^{-1}\right), \mathrm{T}_{\mathrm{a}}$ the mean hourly air temperature $\left({ }^{\circ} \mathrm{C}\right), \mathrm{u}_{2}$ the wind speed at two meters $\left(\mathrm{m} \mathrm{s}^{-1}\right), \mathrm{e}_{\mathrm{s}}$ the saturation vapor pressure $(\mathrm{kPa})$ at the mean hourly air temperature $(\mathrm{T})$ in ${ }^{\circ} \mathrm{C}, \mathrm{e}_{\mathrm{a}}$ the actual vapor pressure, $\lambda$ the latent heat of vaporization $\left(\mathrm{MJ} \mathrm{kg}^{-1}\right.$ ) and $\mathrm{C}_{\mathrm{d}}$ the bulk surface resistance and aerodynamic resistance coefficient. Another frequently employed equation is the modified Penman equation [11]. The potential evapotranspiration, $E T_{p}$ of a cropped or bare soil surface is calculated from $E T_{0}$ using a $K_{c}$ factor [11] (Figure 2), which depends on the plant, plant cover development stage, and climatic region:

$$
E T_{p}=K_{c} E T_{0}
$$

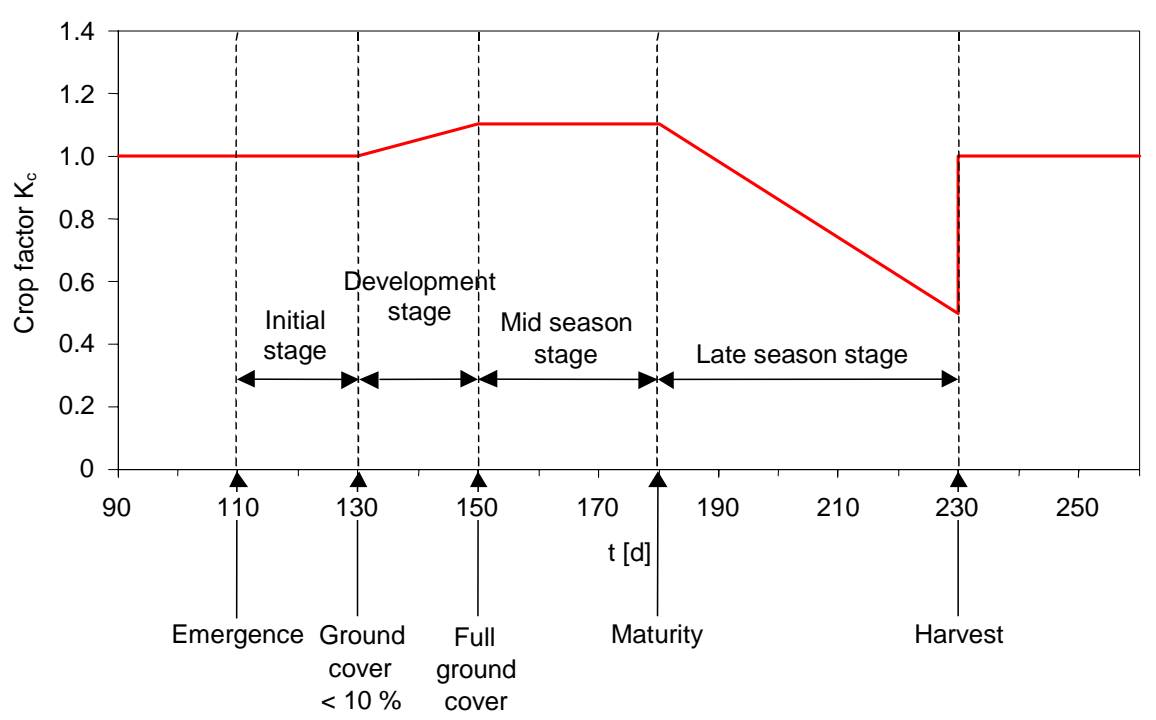

Figure 2: The crop coefficient is a function of development stage of the crop [11].

The potential evapotranspiration is split up in the potential evaporation from the soil surface, $E_{p}$, and transpiration from the crop using an empirical model that is controlled by the leaf area index (LAI): 


$$
E_{p}=E T_{p} \exp (-0.6 L A I)
$$

The potential transpiration is obtained from:

$$
T_{p}=E T_{p}-E_{p^{-}} I_{c e p}
$$

where $I_{\text {cep }}(L)$ is the evaporation of water intercepted by the plant. The evaporation and transpiration rates obtained until now are potential evaporation rates when both the soil and the plant can supply the atmospheric demand. Under water stress conditions, plant roots can not take up enough water and the transpiration is reduced according to Eq. (4). When plants suffer from water stress, hydraulic soil properties influence plant transpiration rates through the stress factor $\alpha(\psi)$ since the matric potential and how it changes with water loss from the soil profile are determined by soil hydraulic properties.

Due to evaporation from the soil surface, the upper soil layer dries out and the hydraulic conductivity of the surface layer drops. To guarantee upward water flow to an evaporating soil surface, the matric potential at the soil surface must drop. However, the potential at the soil surface cannot drop below a critical threshold value. When this threshold is reached, the potential at the surface remains constant so that the evaporation rate decreases with time. The reduction of the potential evaporation rate when the soil dries out is determined by the hydraulic soil properties and can be predicted using the Richards equation when hydraulic soil properties are known (Figure 3).

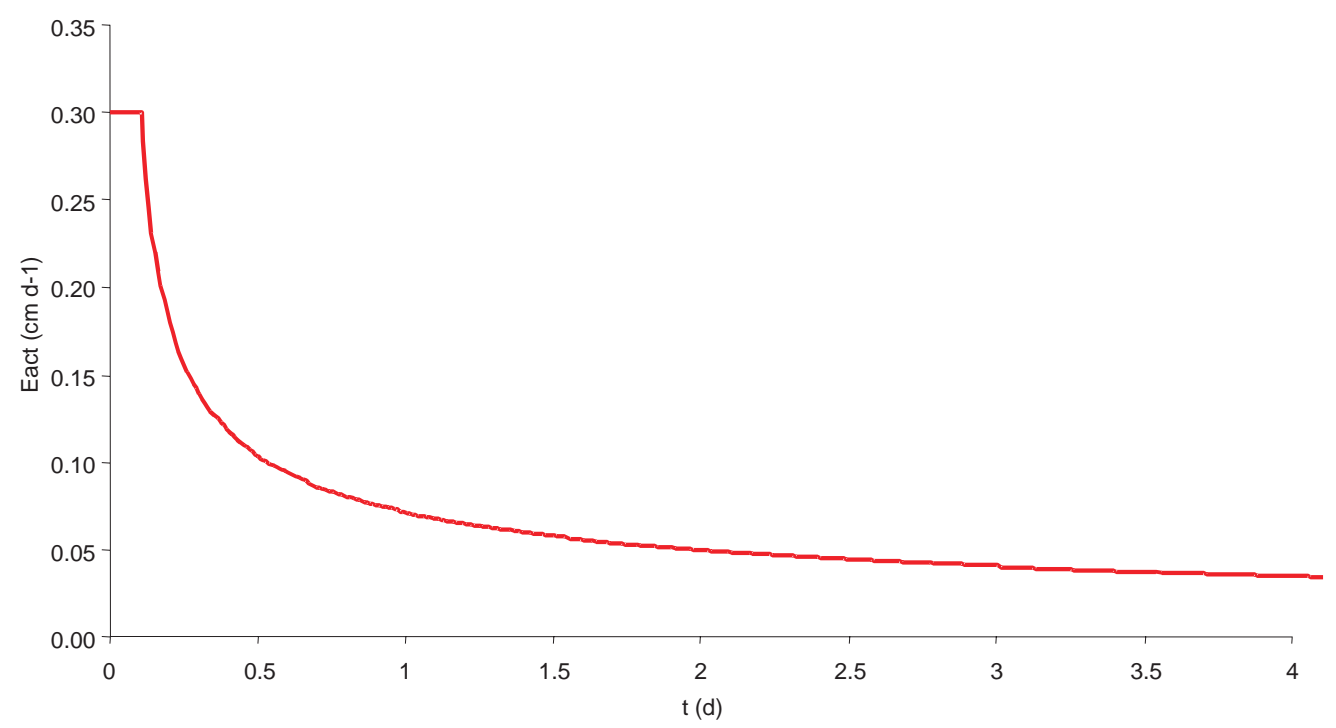

Figure 3: Development of the soil evaporation in function of time. 
$-37-$

Since surface boundary conditions and internal sinks in a water flow model are to a major extent controlled by plants, a water flow model should be coupled to a crop growth model. Therefore, the simple crop growth model SUCROS [12], was adapted to TRACE. Figure 4 shows the results of a one-dimensional simulation run concerning the pressure head distribution in the soil profile. The years 1984 and 1988 can be summarized as rather wet years, with high precipitation and only little evapotranspiration. Furthermore differences in root water extraction between plants are clearly visible.

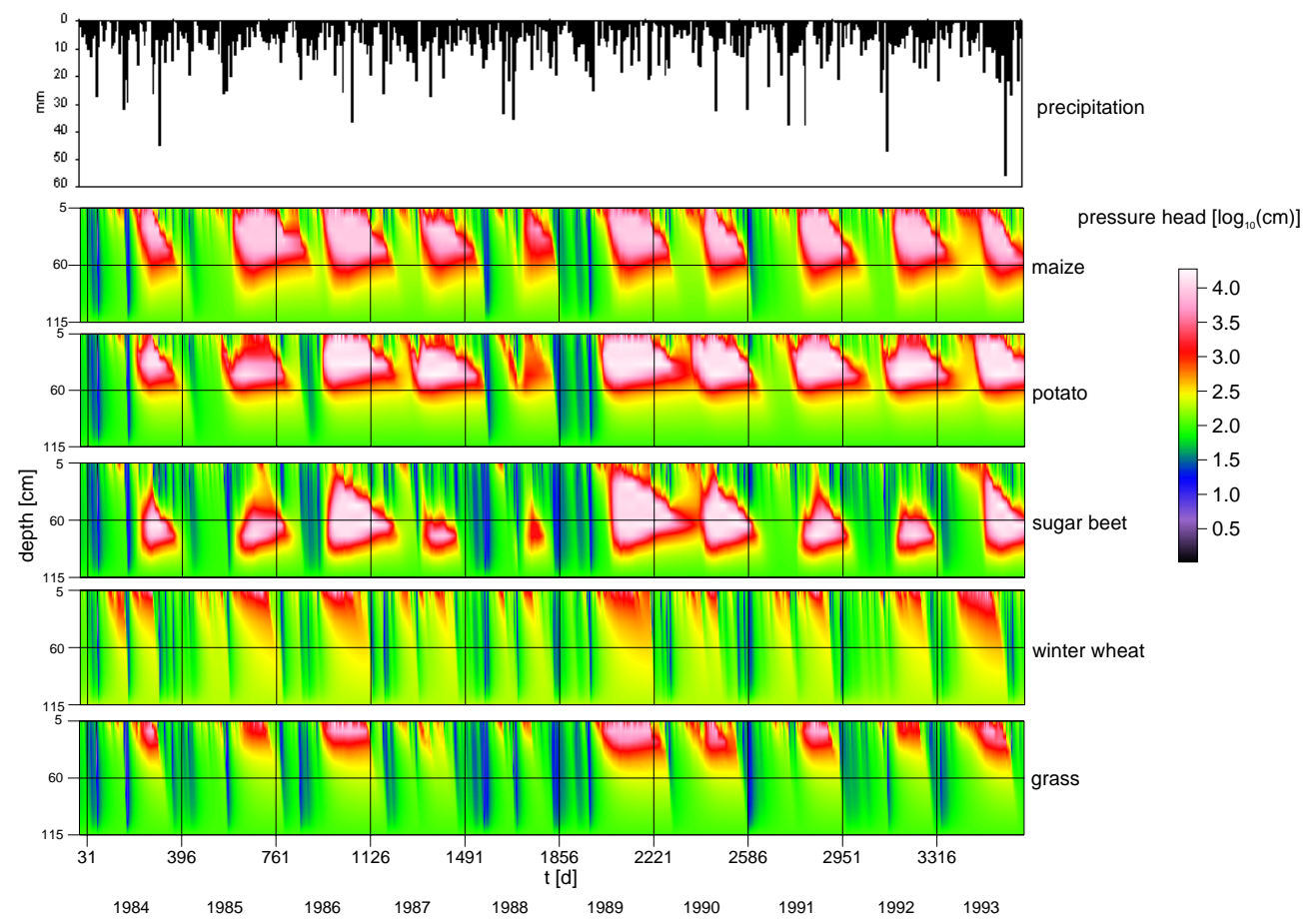

Figure 4: The effect of crop type on soil matric potential.

\subsection{Energy transfer methods}

The energy transfer methods are based on the definition of a control volume for energy conservation (Figure 5). The net radiation energy (Rn) entering the control volume must be balanced by fluxes of energy out of the volume $(H, \lambda L, G)$ and by the time rate of change in energy stored $(\mathrm{dQ} / \mathrm{dt}$ or $\mathrm{d} \Omega / \mathrm{dt}$ )

Evaporation involves an energy flux. So the rate of evaporation can be described using a surface energy balance equation: 
$-38-$

$$
\frac{d \Omega}{d t}=R_{n}-G-H-\lambda E
$$

where $R_{n}$ is the incoming net radiation $\left(W m^{-2}\right), G$ the ground heat flux $\left(W m^{-2}\right), H$ the sensible heat flux $\left(\mathrm{W} \mathrm{m}^{-2}\right), \lambda \mathrm{E}=\mathrm{E}_{\mathrm{L}}$ the latent heat flux $\left(\mathrm{Wm}^{-2}\right), \Omega$ the heat storage in vegetation (W), $\mathrm{t}$ the time (s), and $\lambda$ is the latent heat of vaporisation of water (= $\left.2.5 \times 10^{6} \mathrm{~J} \mathrm{~kg}^{-1}\right)$.

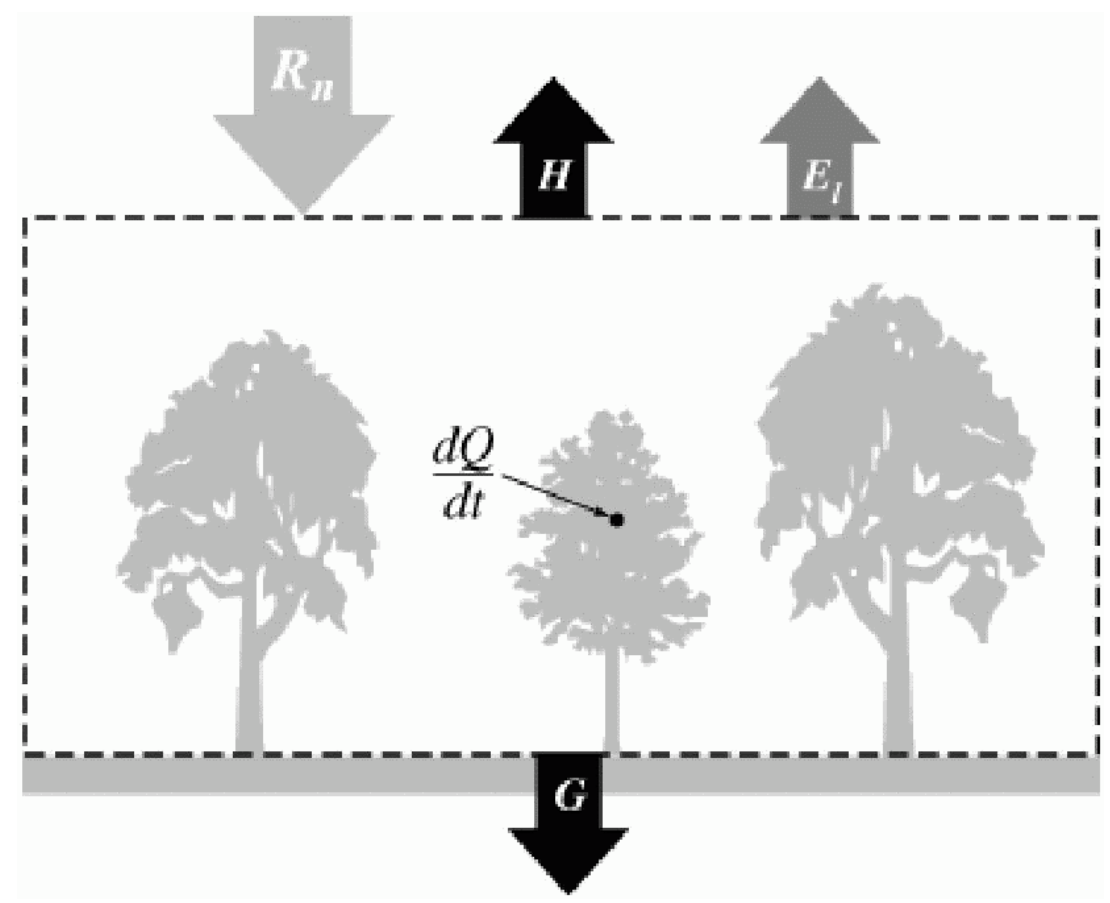

Figure 5: The energy balance of the soil-plant-atmosphere control volume.

Solving for the latent heat flux gives:

$$
E_{L}=R_{n^{-}} G-H-d \Omega / d t .
$$

The latent heat is related to actual evapotranspiration through the latent heat of vaporisation,

and therefore is

$$
E_{L}=\lambda \rho_{w} E T
$$

$$
E T=\left(R_{n^{-}} G-H-d \Omega / d t\right) /\left(\lambda_{v} \rho_{w}\right)
$$


where $\rho \mathrm{w}\left(\mathrm{M} \mathrm{L}^{-3}\right)$ is the density of water.

The Bowen ratio, a classical approach to estimate actual evapotranspiration, is defined as

$$
B=H / \lambda E
$$

and

$$
B \approx \frac{T_{s}-T_{a}}{e_{s}-e_{a}}
$$

where $\mathrm{T}_{\mathrm{s}}$ is surface temperature $\left({ }^{\circ} \mathrm{C}\right), \mathrm{T}_{\mathrm{a}}$ is air temperature $\left({ }^{\circ} \mathrm{C}\right)$ at some measurement height. $e_{s}$ is vapour pressure deficit at the surface and $e_{a}$ is vapour pressure deficit at the measurement height. Then for $\mathrm{d} \Omega / \mathrm{dt}$ small so that

$$
\lambda E+H=\lambda E(1+B)=R_{n}-G
$$

so that

$$
\lambda E=\frac{R_{n}-G}{1+B}
$$

The disadvantage of this method of estimating $E$ is that we need to know a surface temperature, and also air temperature and vapour pressure.

\subsection{Direct methods}

Classical direct methods make use of lysimeter systems to measure the terms of the water balance or pan evaporation methods. Basically weighable lysimeter systems are needed to provide direct estimation of the actual evapotranspiration flux.

The eddy-correlation method consists of determining the turbulent fluxes of latent and sensible heat from the covariance of vertical wind speed with vapour density and air temperature. Eddies are turbulent, highly rotational air flows that move across the surface of the earth transporting water vapour, heat, and gaseous substances between the surface and the atmosphere. This methods integrates over a spatial extent called the "fetch". The latent-heat flux is determined by the covariance of the fluctuations of wind speed $u_{z}^{\prime}$ and vapour density $\rho^{\prime}{ }_{v}$ defined as $\lambda E=<u_{z}^{\prime} \rho^{\prime}{ }_{v}>$ with $u_{z}=<u_{z}>+u_{z}^{\prime}$ and $\rho_{v}=<\rho_{v}>+\rho_{v}^{\prime}$. The sensible heat flux is determined by the covariance of instantaneous departures from the averages values of wind speed and air temperature [13]. In combination with the determination of the net radiation and 
$-40-$

subsurface-heat flux, the energy budget at a specific site can be estimated in principle.

The scintillometer technique integrates over the path length of the laser (up to several meter) and is based on the measurements of rapid fluctuations in air density using an infrared laser [14]. It therefore provides an estimate of actual evapotranspiration.

\subsection{Remote sensing approaches}

Remote sensing techniques show large potential in evaluating spatial variability of water fluxes at the soil-vegetation-atmosphere interfaces by providing input data and parameters required in mathematical models of the soil water balance. Overviews of the use of remotely sensed data for hydrological modeling are given by [15][16]. Reflectance spectra of sun light can be used to characterize land cover/land use [17], which is an important input parameter for hydrological models. Furthermore, the LAI can be derived from reflectance spectra using the NDVI index. The LAI can be predicted by a crop growth model and plays a crucial role by splitting up the evapotranspiration in crop transpiration and soil evaporation. Therefore, the remotely sensed LAI can be used to validate or even calibrate crop growth models or to define the upper boundary fluxes better, which improves the model performance of soilplant-atmosphere models [18].

Infrared surface brightness temperatures and short wave reflection spectra can also be assimilated in SVATs (Soil-Vegetation-Atmosphere-Transport models) to calculate sensible and latent heat fluxes [19][20][21][22][23][24][25]. Assimilation schemes were in most cases developed and tested based on measurements in agricultural field plots, cropped or bare. The SVATs that are commonly used in assimilation schemes are based on a capacity model to describe water and energy fluxes in the soil. These models currently have limited capability to describe the spatial dependence of water flow and root water uptake in soils.

The potential of remotely sensed parameters, soil moisture and actual evapotranspiration in combination with inverse modeling of unsaturated flow has first been discussed by [26]. Soil hydraulic properties were estimated from remotely sensed surface soil moisture content [27][28][29]. Given the control of hydraulic soil properties on the reduction of both potential evaporation and transpiration when the soil dries out, soil hydraulic properties may be derived from actual evapotranspiration estimates, which are derived from remotely sensed thermal infrared, using inverse modeling [30]. [31] suggested combining both thermal infrared and microwave remote sensing to confine the estimation of soil parameters.

A combination of multispectral remote sensing data, including spatial subsurface information has a great potential to improve the parameterization of subsurface water flow models. Remotely sensed parameters like IR surface brightness temperature, LAI derived from NDVI, short wave reflection or albedo, can be used as input in 
$-41-$

expanded Soil-Vegetation-Atmosphere-Transfer models (SVAT) to calculate latent and sensible heat fluxes [21][23][24][25]. Additional input parameters are the resistances for heat and vapor transfer in the atmospheric surface boundary layer and meteorological parameters like vertical wind speed profiles, air temperature and air humidity. Sensible heat transfer resistances are only determined by meteorological parameters whereas resistances for vapor transport are linked to the soil water content and increase with decreasing soil moisture content. The coupling between soil moisture status and actual evapotranspiration indicates the need for a SVAT to interpret remote sensed variables.

An additional advantage of a SVAT is that fluxes can be predicted at times when no remotely sensing data are available. Since remotely sensed data are instantaneous data of variables with a high temporal dynamic, a physically based model may be useful to predict the systems behaviour between observation times.

However, a disadvantage of SVATs is the larger number of parameters that is needed to run the model. Especially the spatial variability of meteorological parameters like air temperature, air humidity and wind speed profiles make a parameterization of SVAT cumbersome. This may be overcome using the SEBAL procedure proposed by [19]. In this procedure, area effective resistances for sensible heat transfer are derived from the relation between surface brightness temperature and albedo for regions where the latent heat flux can be neglected. Surface-air temperature differences are derived from surface temperatures. Latent heat fluxes are obtained by closing the surface energy balance.

In order to extrapolate the estimated evaporation rates in time, it is assumed that the evaporative fraction, i.e. the ratio of the energy used for evapotranspiration to the total net radiation, remains constant in time [20]. This assumption only holds true when the soil moisture content does not change a lot in time. When the soil dries out, actual evapotranspiration will drop below the potential one so that the fraction of the sensible heat flux will increase to compensate for the decrease in the latent heat flux. Since the change of actual evapotranspiration with time is controlled by hydraulic soil properties, a soil-plant-atmosphere model could be combined with remotely sensed instantaneous surface parameters to extrapolate evapotranspiration rates in time. 
$-42-$

\section{Spatial modeling of evapotranspiration using integrated datasets: a case study}

The TRACE/SUCROS model is applied to predict the terms of the water balance and groundwater quality in a $20 \mathrm{~km}^{2}$ area around the Research Centre Jülich (Figure 6).

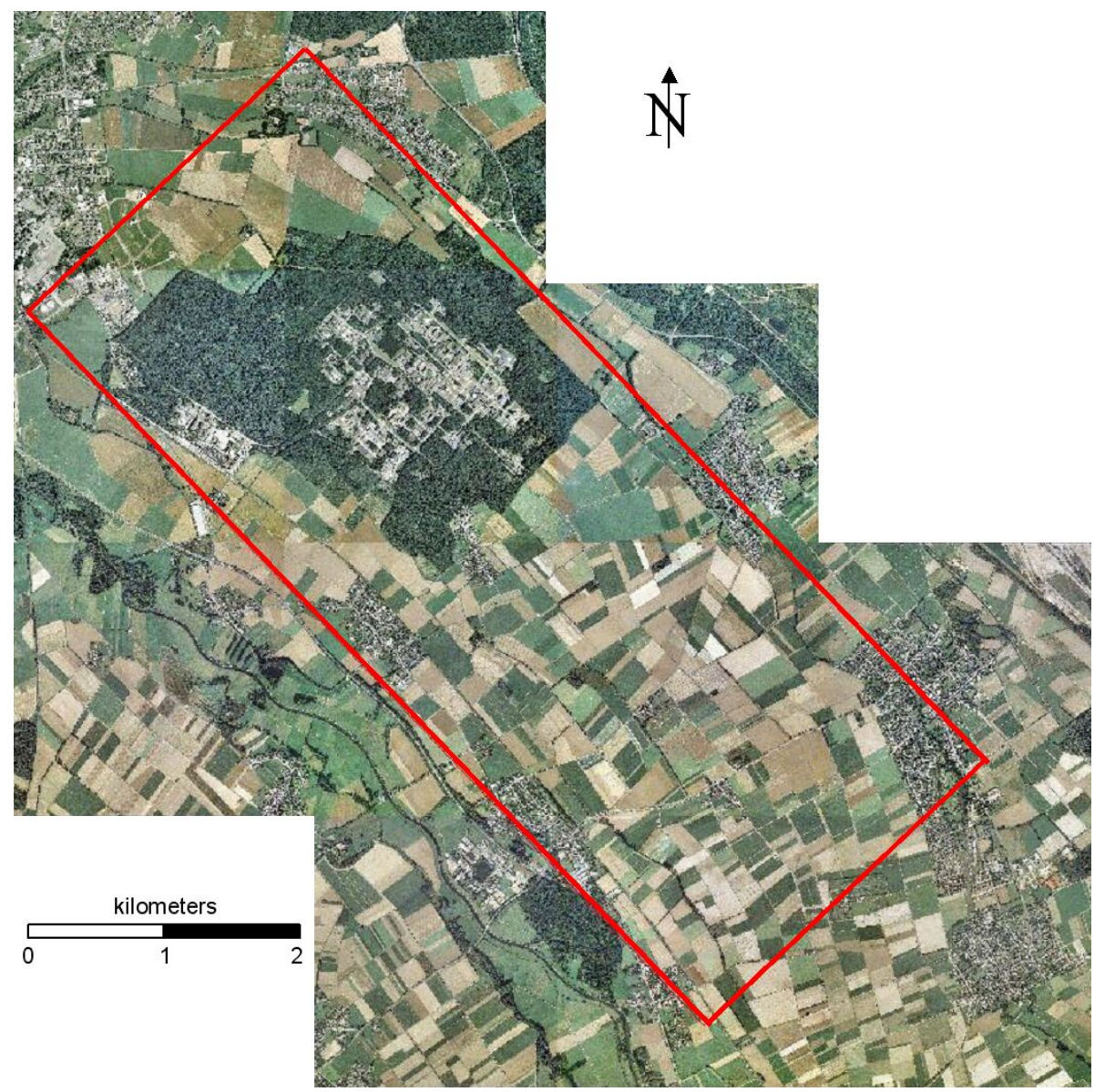

Figure 6: The model area Zwischenscholle.

In a first step, a 3-D hydrogeological model is built using the soil map and geological data (Figure 7). From the soil map, four characteristic soil profiles with typical soil layers were identified. Using a pedotransfer function, the hydraulic functions were determined for the different soil layers. Geological information was used to determine the base of the unconfined aquifer.

Since the modeled area was not hydrologically confined at the lateral boundaries, groundwater table depths at the boundaries were interpolated from piezometers and 
$-43-$

were used as Dirichlet boundary conditions. Landuse was derived from statistical information.

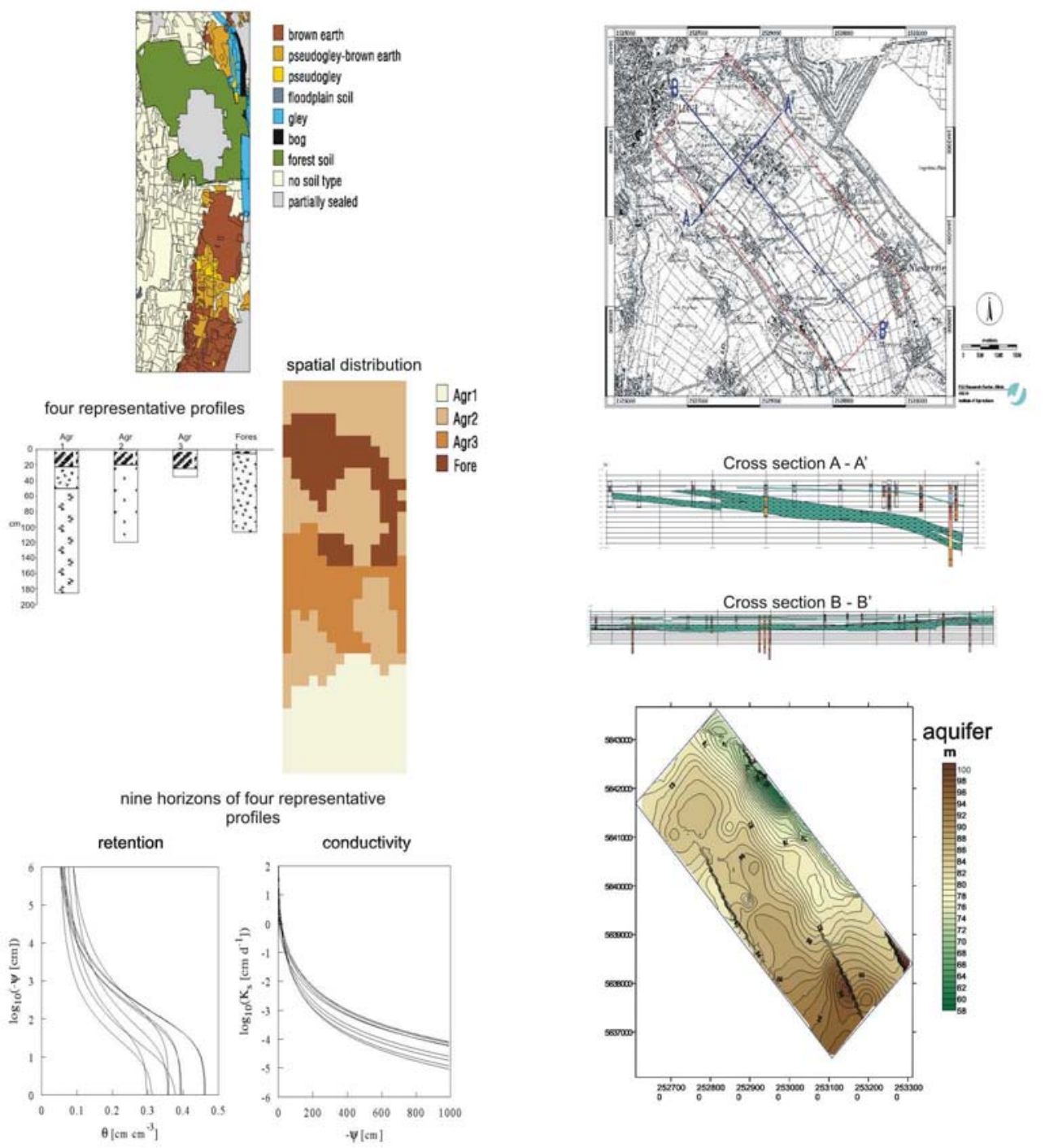

Figure 7: Soil and hydrogeological input data for the model TRACE.

Because the parcel size was smaller than the size of the used computation grid ( $200 \mathrm{~m}$ by $200 \mathrm{~m}$ ) and since no data was available on the landcover in the different parcels for the considered simulation period, the landuse of the non-forested and unsealed surfaces was attributed randomly to the grid cells and conforms to the landuse statistics (Figure 8). 
$-44-$
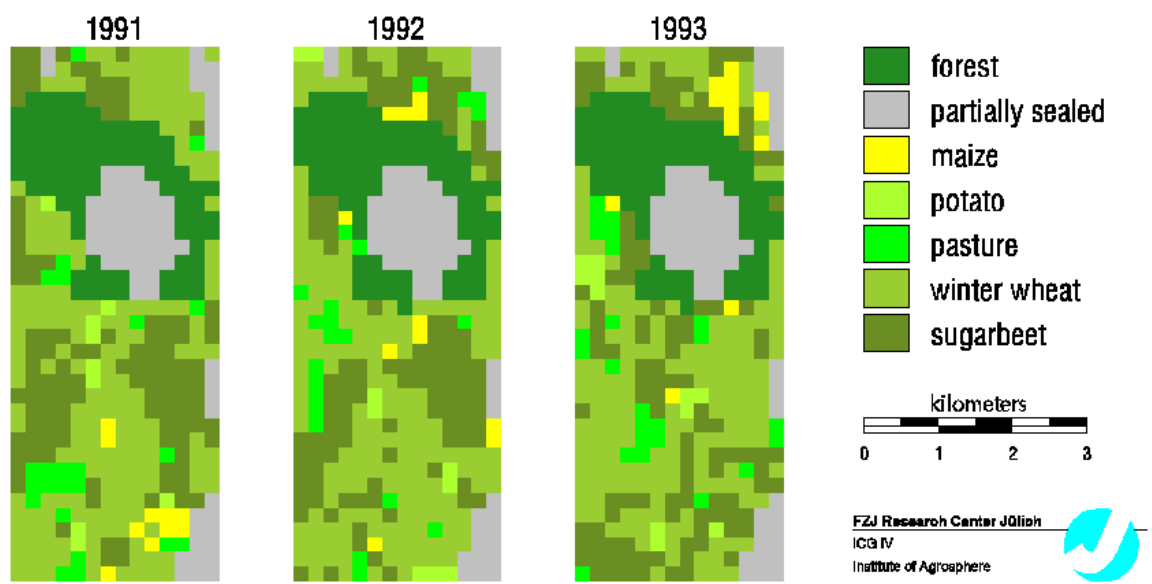

Figure 8: Distribution of the landuse at the Zwischenscholle area.

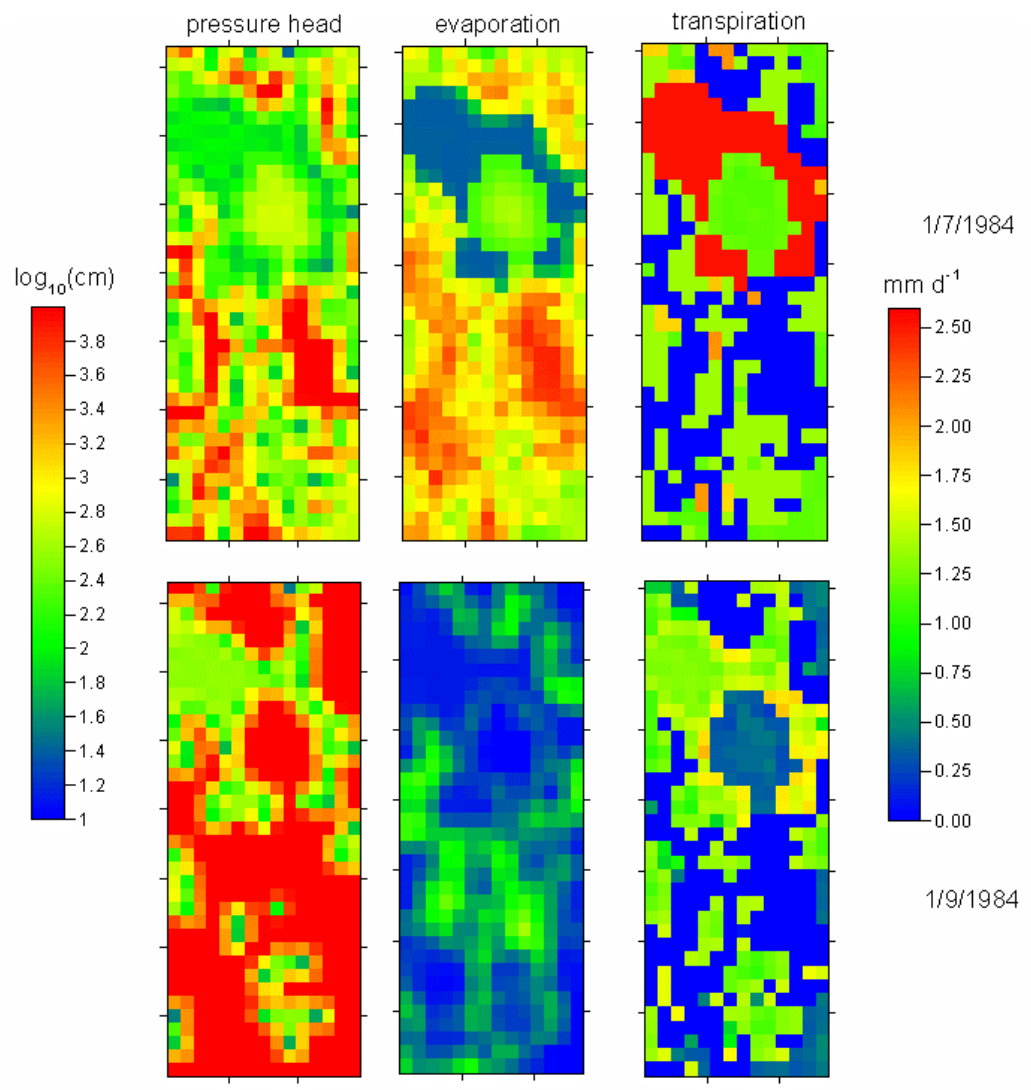

Figure 9: Calculated soil matric potential, actual evaporation and actual transpiration for two different days. 
$-45-$

The soil surface boundary conditions: precipitation and potential evapotranspiration are derived from meteorological data that were recorded in the meteorological station of the Research Centre Jülich. $\mathrm{ET}_{0}$ was calculated using the Penman/Monteith approach according to the revised FAO methodology [10]. The matric potential at the soil surface, the actual evaporation and transpiration predicted by the TRACE model are shown in Figure 9 for two exemplary days. Since the model considers threedimensional flow, spatially variable soil properties and land use, the spatial structure and heterogeneity of the flow processes at the soil atmosphere-surface are represented by the model. Furthermore, the model also represents the dynamics of water flow in the soil in response to the dynamics of the boundary conditions. However, the predicted fluxes and state variables are not validated against measurements.

The example of this case study illustrates the typical choices that have to be made in any concerted effort to integrate existing data and existing models to address practical question of public interest like predicting actual evapotranspiration.

\section{References}

[1] Riple, W, 2003. Water: the bloodstream of the biosphere. Phil. Trans. R. Soc. Lond. B 358: 1921-1934.

[2] Falkenmark M. and C. Folke, 2002. The ethics of socio-ecohydrological catchment management: towards hydrosolidarity, Hydrology and Earth System Sciences 6(1): 1-9.

[3] Gleick, PH., 1996: Water Resources. In Encyclopedia of Climate and Water, ed. By S.H. Schneider, Oxford University Press, New York, Vol. 2, pp. 817-823.

[4] Peixoto and Kettani, 1973. The Control of the Water Cycle. Scientific American 228: $46-61$

[5] Vereecken, H., Lindenmayr, G., Neuendorf, O., Döring, U. and Seidemann, R. 1994. TRACE A mathematical model for reactive transport in 3D variably saturated porous media. Internal Report KFA-ICG-4-501494, Jülich.

[6] Vereecken, H., Feyen, J , Maes, J., and Darius, P., 1989. Estimating the soil moisture retention characteristic from texture, bulk density and carbon content. Soil Sci. 48: 389-403.

[7] Vereecken, H., Maes, J. and Feyen, J., 1990 Estimating unsaturated hydraulic conductivity from easily measured soil properties, Soil Sci., 149,1-12.

[8] Feddes, R.A., Kowalik, P.J., and Zaradny, H., 1978. Simulation of field water use and crop yield. In: PUDOC, Simulation Monographs. Wageningen, 189p.

[9] Monteith, J. L., 1975. Vegetation and the atmosphere. Academic Press, 439 p. 
$-46-$

[10] Allen, R.G., Pereira, L. S., Raes, D., and Smith, L., 1998. Crop evapotranspiration Guidelines for computing crop water requirements - FAO Irrigation and drainage paper 56, Rome.

[11] Pruitt and Doorenbos, 1977) Proceeding of the International Round Table Conference on "Evapotranspiration", Budapest.

[12] Spitters, C.J.T., van Keulen, H., and van Kraalingen, H., 1988. A simple but universal crop growth simulation model, SUCROS87. In: R. Rabbinge, H. Van Laar and J. Ward - eds. Simulation and system management in crop protection. Simulation Monographs, Wageningen $1988 \mathrm{p}$.

[13] Berger D.L., Michael J. Johnson, M. L. Tumbusch, and J. Mackay, 2000. Estimates of Evapotranspiration from the Ruby Lake National Wildlife Refuge Area, Ruby Valley, Northeastern Nevada, May 1999-October 2000, WaterResources Investigations Report 01-4234.

[14] McAneney K.J., A.E. Green and M.S. Astill, 1995. Large aperture scintillometry: the homogeneous case. Agric. Forest Meteor. 76: 149-162.

[15] Droogers, P. and G. Kite, 2002. Remotely sensed data used for modelling at different hydrological scales. Hydrol. Process. 16: 1543-1556.

[16] Schmugge, T.J., Kustas, W.P., Ritchie, J.C., Jackson, T.J., and Rango, A., 2002. Remote sensing in hydrology. Adv. Water Resour. 25: 1367-1385.

[17] Hall, F.G., Townshend, J.R., and Engman, E.T., 1995. Status of remote sensing algorithms for estimation of land surface state parameters. Remote Sens. Environ. 51: 138-156.

[18] Andersen, J., Dybkjaer, G., Jensen, K.H., Refsgaard, J. C., and Rasmussen, K., 2002. Use of remotely sensed precipitation and leaf area index in a distributed hydrological model. J. Hydrol. 264: 34-50.

[19] Bastiaanssen, W.M.G., Menenti, M., Feddes, R.A., and Holtslag, A.A.M., 1998. A remote sensing surface energy balance algorithm for land (SEBAL) 1. Formulation. J. Hydrol. 212-213: 198-212.

[20] Bastiaanssen, W.G.M., Ahmad, M-U.-D, and Cheminm Y., 2002. Satellite surveillance of evaporative depletion across the Indus basin. Water Resour. Res. 38: 1273.

[21] Olioso, A., Chauki, H., Courault, D., and Wigneron, J.-P., 1999a. Estimation of evapotranspiration and photosynthesis by assimilation of remote sensing data into SVAT models. Remote Sens. Environ. 68: 341-356.

[22] Olioso, A., Chauki, H., Wigneron, J.-P., Bergaoui, K., Bertuzzi, P., Chanzy, A., P. Bessemoulin, and Calvet, J.-C., 1999b. Estimation of energy fluxes from thermal infrared, spectral reflectances, microwave data and SVAT modelling. Phys. Chem. Earth (B) 24: 829-836. 
$-47-$

[23] Mauser, W. and Schädlich, R., 1998. Modelling the spatial distribution of evapotranspiration on different scales using remote sensing data. J. Hydrol.: 250-267.

[24] Boulet, G., Chehbouni, A., Braud, I., Vauclin, M., Haverkamp, R. and Zammit, C., 2000. A simple water and energy balance model designed for regionalization and remote sensing data utilization. Agr. For. Meteo. 105: 117-132.

[25] Van der Keur, P., Hansen, S., Schelde, K., and Thomsen, A., 2001. Modification of DAISY SVAT model for potential use of remotely sensed data. Agr. For. Meteorol. 106: 215-231.

[26] Feddes, R.A., Menent, M., Kabat, P., and Bastiaanssen,W.G.M., 1993. Is largescale inverse modelling of unsaturated flow with areal average evaporation and surface soil moisture as estimated from remote sensing feasible? J. Hydrol. 143: 125-152.

[27] Burke, E.J., Gurney, R.J., Simmonds, L.P., and Jackson, T.J., 1997. Calibrating a soil water and energy budget model with remotely sensed data to obtain quantitative information about the soil. Water Resour. Res. 33: 1689-1697.

[28] Mattikalli, N.M., Engman, E.T., Jackson, T.J., and Ahuja, L.R., 1998. Microwave remote sensing of temporal variations of brightness temperature and nearsurface soil water content during a watershed-scale field experiment, and its application to the estimation of soil physical properties. Water Resour. Res. 34: 2289-2299.

[29] Chang, D.H. and Islam, S., 2000. Estimation of soil physical properties using remote sensing and artificial neural network. Remote Sens. Environ. 74 : $534-$ 544.

[30] Jhorar, R.K., Bastiaanssen, W.G.M., R.A. Feddes, and Van Dam, J.C., 2002. Inversely estimation soil hydraulic functions using evapotranspiration fluxes. J. Hydrol. 258: 198-213.

[31] Chanzy, A., Bruckler, L., Perrier, A., 1995. Soil evaporation monitoring: a possible synergism of microwave and infrared remote sensing. J. Hydrol. 165: 235-259. 

$-49-$

\title{
INTERACTION BETWEEN PLANT, SOIL AND WATER
}

\author{
J. Lindenmair \\ Institute Phytosphere \\ Research Centre Jülich \\ 52425 Jülich, Germany \\ j.lindenmair@fz-juelich.de
}

\begin{abstract}
A sufficient balance in the supply and loss of water is an important prerequisite for the growth and productivity of plants. For a higher plant, the water balance is given by the difference between water uptake from soil across the root and water losses by transpiration in the shoot. Much is known about the mechanisms used by plants to minimize water losses across stomata. For technical reasons, much less is known about the input side of the balance, i.e. about the regulation of water uptake from the soil. The interactions between plant roots, soil and water are characterized by a high spatial and temporal variability. Further developments in minimal invasive, non-destructive methods are central to studies of the plant-soil-interface due to its highly restricted visual and physical accessibility.
\end{abstract}

\section{Introduction}

The soil acts as a medium for plant root growth and a reservoir for water and minerals. Movement of water through soil determines whether a system will drain properly, whether a basement will flood, and how successful a farmer's harvest will be. The dependence on soil water availability becomes obvious e.g. when heavy spring rains delay planting or when crops are threatened by summer droughts. Less apparent, but equally important, are the effects of interactions between soil and water on the availability to crops of soil nutrients, fertilizers, and pesticides over the course of the growing season. Understanding how soil properties determine water movement, is critical in managing farm irrigation, fertilizer and pesticide applications, and protection of well-water quality.

Plant root systems as well as the soil environment are heterogeneous systems that are interrelated. The interaction zone between the roots of a plant and the soil is called the rhizosphere. Plants are able to react to spatial and temporal changes of their soil environment, i.e. they show special adaptation mechanisms and stress reactions. But on the other hand plants can also actively influence and change their environment.

The plant-soil-interactions show pronounced spatial and temporal dynamics on different scales and process levels. For example, water and nutrient uptake by roots 
$-50-$

are creating gradients in soil moisture and chemistry in the rhizosphere (Chapter 3.1). Root growth can influence soil structure and density (Chapter 3.2) and therefore create preferential pathways for water flow. The other way round, plants adapt to soil heterogeneity, for example, through high root activity or high root growth in soil regions with optimal water or highly concentrated nutrient supply. Roots can facilitate nutrient release by exudation of organic acids in nutrient poor zones or are able to redistribute water from wet to dry soil regions to improve water supply and associated properties (Chapter 3.3). Of special interest are possible plant adaptation mechanisms concerning changes of the environment due to global change.

\section{Role of Water in Plant Production}

Although water is the most abundant molecule on the earth's surface, the availability of water is the factor that mostly restricts terrestrial plant production on a global scale. Low water availability limits the productivity of many natural ecosystems, particular in dry climates. In addition, losses in crop yield due to water stress exceed losses due to all other biotic and environmental factors combined [7]. Even the effects of temperature are partly exerted through water relations because rates of evaporation and transpiration are correlated with temperature. Thus, if we want to explain natural patterns of productivity or to increase productivity of agriculture or forestry, then it is crucial to understand the controls over plant water relations and the consequences for plant growth of an inadequate water supply.

Water is important to the physiology of plants because of the critical role that water plays in all physiological and growth processes and because of the large quantities that are required. Water typically comprises 80 to $95 \%$ of the biomass of nonwoody tissues such as leaves and roots. At the cellular level, water is the major medium for transporting metabolites through the cell. At the whole-plant level, water is the medium that transports the raw materials (carbohydrates and nutrients) as well as the phytohormones that are required for growth and development from one plant organ to another.

A second general reason for the importance of water relations to the physiological ecology of plants is that plants require vast quantities of water. Whereas plants incorporate more than $90 \%$ of absorbed nitrogen, phosphorus, and potassium, and about 10 to $70 \%$ of photosynthetically fixed carbon into new tissues, less than $1 \%$ of the water absorbed by plants is retained in biomass. The remainder is lost by transpiration, which is the evaporation of water from plants. The inefficient use of water by terrestrial plants is an unavoidable consequence of photosynthesis [8]. 


\section{Plant-Soil-Water Relations}

Water added to the soil by rainfall or irrigation percolates downward to groundwater unless it runs off to surface waters, evaporates, is taken up by plants, or remains within the soil profile (Figure 1). Successful crop production depends on careful management of soils, water, and chemicals (fertilizers and pesticides) so that plant needs are met as they occur in the growing season [5]. Meeting these needs efficiently may also help to protect the quality of underlying groundwater by reducing the amount of chemicals being carried downward by recharge waters.

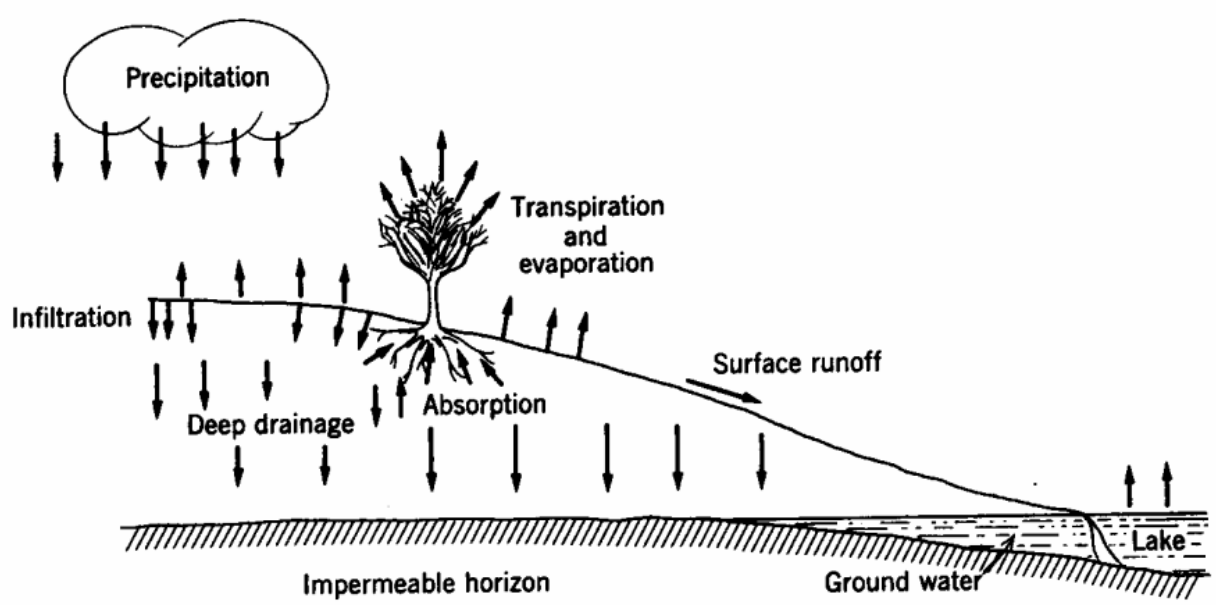

Figure 1: Hydrologic cycle [7].

\subsection{Water Potential - Soil-Plant-Air Continuum}

Water transport from the soil, through the plant, to the atmosphere, takes place in a soil-plant-air continuum that is interconnected by a continuous film of liquid water. Water moves through the plant along a gradient, either from high to low water potential (if transport occurs across a semipermeable membrane), from high to low hydrostatic pressure (if no such membrane is involved), or from a high to a low partial water vapour pressure (Figure 2,3). The low partial pressure of water vapour in the air, compared with that inside the leaves, is the major driving force for water loss from leaves. This, in turn, drives water transport along the gradient in hydrostatic pressure between the xylem in roots and leaves, and down a gradient in water potential between the soil and the cells in the roots (Figure 4). As soils dry out, there are parallel decreases in soil water potential and plant water potential, both 
$-52-$

immediately before dawn (when water stress is minimal) and at midday (when water stress is maximal) [8]. Since water under tension is in a metastable state, the cohesion-tension theory of the ascent of sap in plants has been questioned recently. At present, the stability of states of tension lacks a sufficient explanation [11, 15].

The steepest gradient in the soil-plant-atmosphere continuum occurs at the leaf surface (Figure 3), which indicates that the stomata are the major control point for plant water relations. There are substantial resistances, however, to water movement in soil, roots, and stems. So short-term stomatal controls are constrained by supply from the soil and resistances to transfer through the plant. In moist soil, water absorption is controlled largely by the rate of transpiration, but in drying soil it is gradually reduced by the decreasing difference in water potential between roots and soil and the increasing resistance to water movement through drying soil [6].

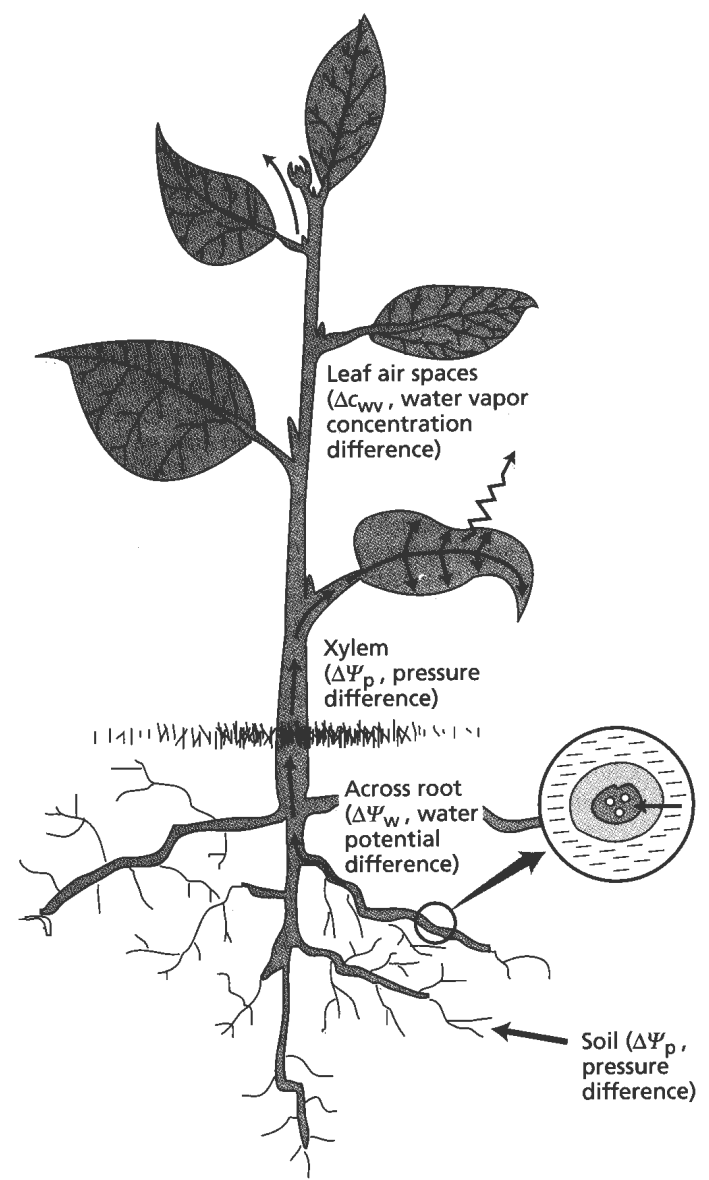

Figure 2: Main driving forces for water transport from soil, through the plant, to the atmosphere: gradients in water vapour pressure $\left(\Delta c_{W v}\right)$, hydrostatic pressure $\left(\Delta \Psi_{p}\right)$, and in water potential $\left(\Delta \Psi_{W}\right)[13]$. 


\section{Water potential}

\section{Resistances}

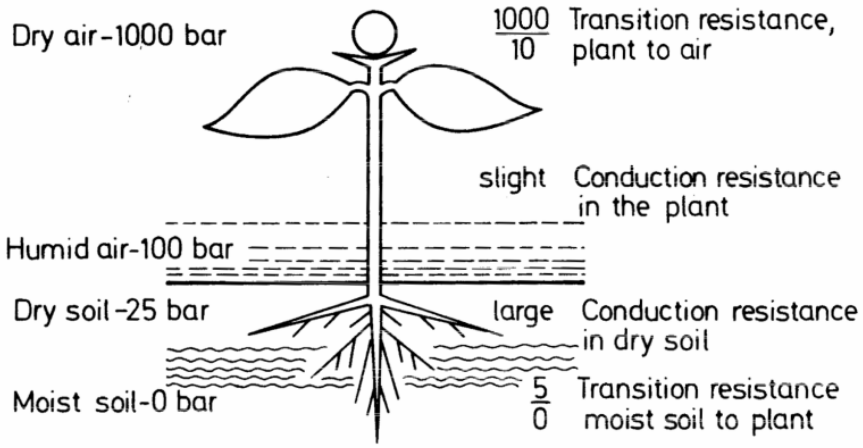

Figure 3: Gradients in water potential and transport resistances between soil, plant, and atmosphere [9].

When growing in moist soil, cell membranes are the major resistance to water flow through roots. Water can travel along different pathways from the outside to the inside of the root. The composite transport model integrates apoplastic and cellular components (symplastic and transcellular) of water flow across the root cylinder and explains why the hydraulic conductivity of roots changes dependent on environmental conditions [10].

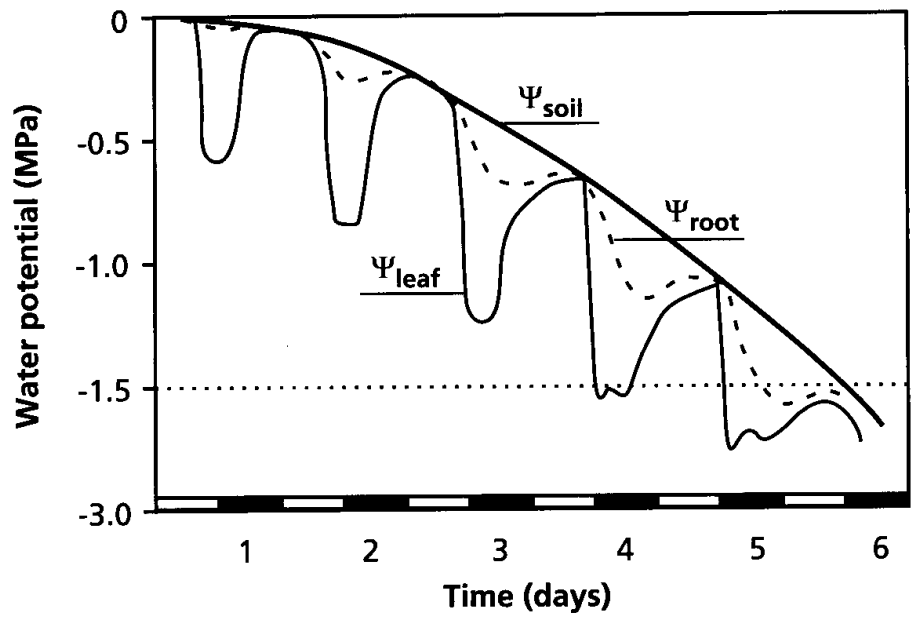

Figure 4: Typical diurnal changes in leaf water potential, root water potential, and soil water potential of a transpiring plant rooted in soil allowed to dry from a water potential near zero to a water potential at which wilting occurs. The dark bars indicate the night period [8]. 
New experimental findings result in models of the water transport across roots which incorporate molecular mechanisms, i.e. the gating of water channels (aquaporins) by different external and internal factors (such as water potential, drought, salinity, nutrient status, mechanical triggers, stress hormones, heavy metals, anoxia, and oxidative stress) [10].

\subsection{Water Availability in Soil}

The availability of soil water to plants depends primarily on the quantity of water stored in the soil and its relationship to soil water potential. Clay and organic soils, which have small soil particles, have more small soil pores. These small capillaries generate very negative pressures, i.e. large suction tensions. Pores larger than 10 $\mu \mathrm{m}$ hold the water only rather loosely, so that water drains out following a rain. Pores smaller than $0.2 \mu \mathrm{m}$ hold water so tightly to surrounding soil particles that most plants cannot extract water from these pores at sufficiently high rates. Thus especially the intermediate-sized pores ( 0.2 to $10 \mu \mathrm{m}$ diameter) store water that can be tapped by plants [8]. Cultivated soils usually have a greater bulk density and less macropore or noncapillary pore space than forest soils [6].

Figure 5 shows the water availability in soils for different textures ranging from sand to clay. Field capacity is defined as the water content after the soil becomes saturated, followed by complete gravitational drainage. The water potential of nonsaline soils at field capacity is close to zero $(-0.01$ to $-0.03 \mathrm{MPa})$. There is a higher soil water content at field capacity in fine-textured soils with a high clay or organic matter content. The lowest water potential at which a plant can access water from soil is the permanent wilting point. Although species differ in the extent to which they can draw down soil water, a permanent wilting point of $-1.5 \mathrm{MPa}$ is common for many herbaceous species. The available water is the difference in the amount of soil water between field capacity and permanent wilting point [7]. The amount of available water is higher in clay than in sandy soils (Figure 5). As long as the upper soil is fairly moist, plants tend to absorb most of their water from shallower soil regions, which is where roots are concentrated. As the soil dries out, relatively more water is absorbed from deeper layers. Water even from deepest soil layers, where no roots penetrate, may become available through capillary rise [8].

Roots have the ability to sense moisture gradients and grow toward moist patches, because they are hydrotropic. Positive hydrotropism occurs due to inhibition of root cell elongation at the humid side of the root. The elongation at the dry side is either unaffected or slightly stimulated, resulting in a curvature of the root and growth toward a wetter soil region [14]. 


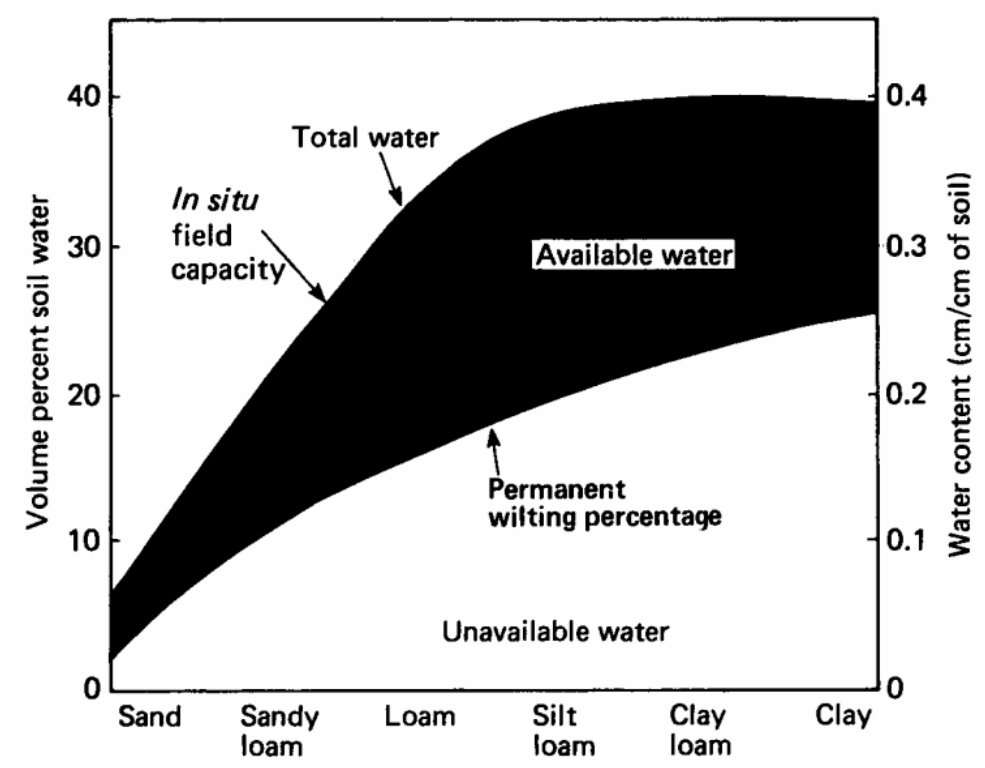

Figure 5: Relative amounts of available and unavailable water in soils with different texture [7].

\subsubsection{Soil Compaction}

Compaction e.g. by heavy machinery changes the physical properties of soils by increasing their bulk density and mechanical resistance. Soil compaction decreases total pore space, especially the number and size of macropores (those greater than $50 \mu \mathrm{m}$ ), and increases the proportion of micropore space. Decrease in macropore space limits draining and diffusion of $\mathrm{O}_{2}$ into and diffusion of $\mathrm{CO}_{2}$ out of the soil. When soil is compacted and bulk density increased, the amount of water available for uptake by plants is reduced and a greater proportion of the water moves through the capillary or micropore space. Associated with reduction in total pore space is a decrease in saturated hydraulic conductivity. Furthermore, soil compaction often results in development of a soil crust that reduces infiltration of water, thus increasing surface runoff of water and erosion [7].

Compaction of soil reduces growth of woody plants in complex ways. Contributing to growth reductions are changes in soil aeration, infiltration and retention of water, and soil strength [6]. Reduction of root extension into compacted soil makes less water available as that around the root is depleted. Capillary movement of water from moist to dry regions in soil at or below field capacity is very slow, hence continuous root extension is necessary for absorption of enough water to meet transpiration requirements and maintenance of a favourable internal water balance. Reduced water uptake in compacted soils also has been attributed to effects of high $\mathrm{CO}_{2}$ content in reducing permeability of roots. 
Upon soil compaction, roots are unable to explore a large fraction of the soil volume. The roots then tend to be clumped into sparse pores and water uptake is restricted. Compacted soils, however, are not uniformly hard and usually contain structural cracks and biopores (e.g. continuous large pores formed by soil fauna and roots). Roots grow best in soil with an intermediate density, which is soft enough to allow good root growth but sufficiently compact to give good root-soil contact [12].

\subsection{Adaptations to Drought}

Plants have adapted to a lack of water in the environment either by avoiding drought or by tolerating it. Desert annuals and drought-deciduous species avoid drought by remaining dormant until water arrives. Other plants in dry environments avoid drought by producing roots with access to deep ground-water. The alternative strategy is to tolerate drought. Tolerance mechanisms are found in evergreen shrubs and in plants that can dry out in the absence of water and resurrect upon exposure to water. Many plants in dry habitats exhibit intermediate strategies. For example, succulents, especially those with the CAM pathway, minimize effects of drought by opening the stomates at night and concentrating their activity in wet seasons, but they also have many characteristics typical of drought-tolerant species [8]. There is likely to be more research on the effects of water deficits on physiological processes at the molecular level. For example, water deficits seem to increase some enzymatically mediated processes but do decrease others [7].

\subsubsection{Hydraulic Lift}

A special mechanism of plant roots is their ability to transfer water between soil layers of different water potential and thereby significantly affect the distribution and availability of water in the soil profile. This phenomenon, termed "hydraulic lift" or "hydraulic redistribution" is the passive movement of water from roots into dryer soil layers with lower water potential, while other parts of the root system in moister soil layers, usually at depth, are absorbing water (Figure 6). This process can be significant in maintaining root viability, facilitating root growth in dry soils and modifying resource availability [2].

There are now data for nearly 30 species which show that root systems can facilitate transfer of water from deep layers to surface soil layers. Hydraulic redistribution may improve plant water and nutrient status, as well as provide benefits to neighbouring plants and even soil biota. While the number of reports of hydraulic lift has increased, its ecological importance is yet to be fully determined. Most evidence for hydraulic lift has come from measurements of soil water potential or content near plant roots and often has been accompanied by the use of stable isotopes to trace water sources [3]. 
Some studies measured sap flow within root systems to determine the pattern and direction of water transfer by roots [1].
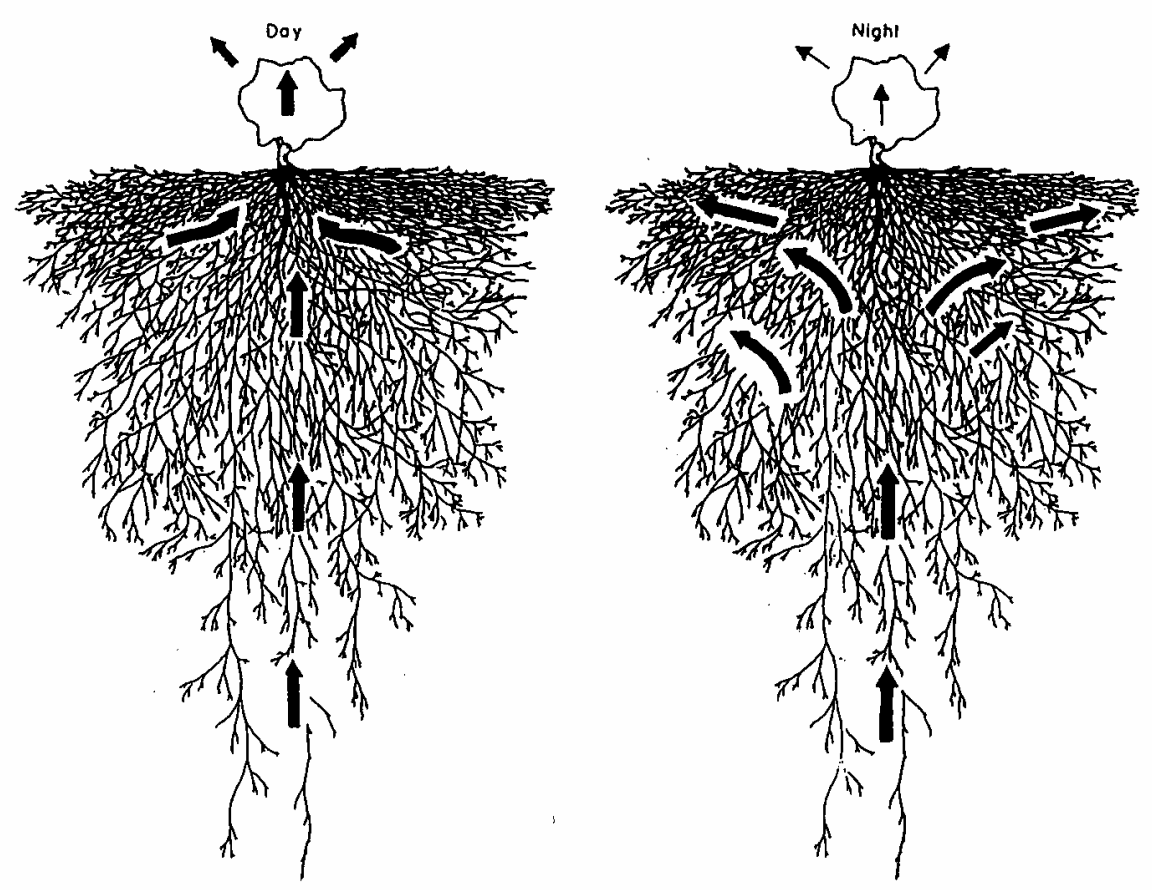

Figure 6: Pattern of water flow through the root system during day and night periods according to the hydraulic lift hypothesis. During the day, water is absorbed from all depths in which soil moisture is available and passes into the transpiration stream. At night when transpiration is reduced and plant water potential rises, the primary pathway of water movement is from moist soil through the root system to drier soil layers. Nighttimes water movement is passively down a water potential gradient. If soil at depth is moister, water moves from deeper to more shallow, drier layers [2].

\section{Outlook}

At last, the aim of research in the field of water relations at this interface is to better understand the dynamic interactions between plant and soil under natural and anthropogenic stress, in order to optimize plant performance concerning nutrient and water efficiency for a sustainable plant production. Special emphasis lies on possible plant adaptations to changes in the environmental conditions due to global change. Because of the difficult access to the root system, minimal and non-invasive methods are crucial to studies of the rhizosphere. New analytical methods (e.g. magnetic resonance imaging, electrical resistance tomography, microwave radiometry, radioactive tracer methods or tracer techniques with stable isotopes) [4] can contribute to the visualization and a so far not possible localization and quantification of water and nutrient transport in heterogeneous root-soil systems. 
$-58-$

\section{References}

[1] S.O. Burgess, M.A. Adams, Neil C. Turner, and Ch.K. Ong (1998): The redistribution of soil water by tree root systems. Oecologia 115, pp. 306-311.

[2] M.M. Caldwell, T.E. Dawson, and J.H. Richards (1998): Hydraulic lift: consequences of water efflux from the roots of plants. Oecologia 113, pp. 151161.

[3] T.E. Dawson (1996): Determining Water use by trees and forests from isotopic, energy balance and transpiration analyses - the roles of tree size and hydraulic lift. Tree Physiol. 16, pp. 263-272.

[4] J.E. Fernández, B.E. Clothier, and M. van Noordwijk (2000): Water uptake. In: A.L. Smit, A.G. Bengough, C. Engels, M. van Noordwijk, S. Pellerin, and S.C. van de Geijn (eds.), Root methods. A handbook. Springer, Berlin, pp. 461-507.

[5] S.R. Gliessman (2000): Agroecology: Ecological processes in sustainable agriculture. Lewis Publish., London .

[6] Th.T. Kozlowski, P.J. Kramer, and S.G. Pallardy (1991): The physiological ecology of woody plants. Academic Press, San Diego .

[7] P.J. Kramer and J.S. Boyer (1995): Water relations of plants and soils. Academic Press, San Diego .

[8] H. Lambers, F.S. Chapin, and Th. Pons (1998): Plant physiological ecology. Springer, New York .

[9] W. Larcher (2001): Ökophysiologie der Pflanzen: Leben, Leistung und Stressbewältigung der Pflanzen in ihrer Umwelt. Ulmer, Stuttgart .

[10] E. Steudle (2000): Water Uptake by Plant Roots: An integration of views. Plant Soil 226, pp. 45-56.

[11] E. Steudle (2002): Transport of water in plants. Environ. Control in Biol. 40, pp. 29-37.

[12] R.J. Stirzaker, J.B. Passioura, and Y. Wilms (1996): Soil structure and plant growth: Impact of bulk density and biopores. Plant Soil 185, pp. 151-162.

[13] L. Taiz and E. Zeiger (2000): Physiologie der Pflanzen. Spektrum, Akad. Verl., Heidelberg .

[14] H. Takahashi (1994): Hydrotropism and its interaction with gravitropism in roots. Plant Soil. 165, pp. 301-308.

[15] U. Zimmermann, H.J. Wagner, H. Schneider, M. Rokitta, A. Haase, and F.W. Bentrup (2000): Water ascent in plants: The ongoing debate. Trends Plant Sci. 5, pp. 145-146. 


\section{Operationalisation of Sustainable Water Management in the European Union}



$-61-$

\title{
THE EU WATER FRAMEWORK DIRECTIVE AS A FRAMEWORK FOR SUSTAINABLE GROUNDWATER MANAGEMENT
}

\author{
G. Dörhöfer \\ Geological Survey Lower Saxony \\ POB 510153, D-30631 Hannover \\ gunter.doerhoefer@nlfb.de
}

\begin{abstract}
The EU WFD leads to a restructuring of all aspects of water management within the EU countries. The WFD requires the pursuit of good water quality for all types of water bodies within a tight time frame and compulsory reporting intervals within river basin boundaries. For Lower Saxony the activities are being described to fulfil the requirements of the first phase of characterizing the status of groundwater bodies. The delineation of 129 such entities follows hydraulic plus hydrogeological patterns. The characterization is made for both the chemical and the quantitative status. Pressures on the chemical status of the groundwater system derive from the influence of diffuse sources mainly from agriculture; point sources play a minor role. In addition, a few groundwater bodies are being stressed by high abstraction rates.
\end{abstract}

\section{Introduction}

When the EU legislation regarding a "Directive... establishing a framework for Community action in the fields of water management" [1] was launched on Dec. $22^{\text {nd }}$, 2000 , the following turn of the millennium also marked the beginning of a turnover of water management structures all over Europe. This process of reorganisation of water management within the boundaries of large river basins instead of political boundaries is still under way. Most countries and provinces in the EU have either fully or nearly completed the implementation process for the required changes in their respective national water regulations and laws.

The first phase of initial and further characterisations of groundwater and surface water bodies required by the Water Framework Directive (WFD), needs to be completed until the end of 2004. Currently, a large effort is being undertaken by all partners in the EU to meet this deadline.

This paper deals with the experiences and the results which were made and achieved during the implementation process for the groundwater bodies in the state of Lower Saxony (Lower Saxony) in northern Germany. 


\section{Aims of the WFD}

The aims of the WFD have been described in short in the CIS document on Monitoring; the following passages are partly taken directly from pages 10-12 of that document [2].

The Directive establishes a framework for the protection of all waters (including inland surface waters, transitional waters, coastal waters and groundwater) which:

- prevents further deterioration of, protect and enhance the status of water resources;

- promotes sustainable water use based on long-term protection of water resources;

- aims at enhancing protection and improvement of the aquatic environment through specific measures for the progressive reduction of discharges, emissions and losses of priority substances and the cessation or phasing-out of discharges, emissions and losses of the priority hazardous substances;

- ensures the progressive reduction of pollution of groundwater and prevents its further pollution; and

- contributes to mitigating the effects of floods and droughts.

Overall, the Directive aims at achieving good water status for all waters by the year 2015. This task is being pursued by the following activities:

- identify the individual river basins lying within their national territory and assign them to individual River Basin Districts (RBDs) and identify competent authorities by 2003 (Article 3, Article 24);

- characterise river basin districts in terms of pressures, impacts and economics of water uses, including a register of protected areas lying within the river basin district, by 2004 (Article 5, Article 6, Annex II, Annex III);

- carry out, jointly and together with the European Commission, the intercalibration of the ecological status classification systems by 2006 (Article 2 (22), Annex V);

- make operational the monitoring networks by 2006 (Article 8);

- based on sound monitoring and the analysis of the characteristics of the river basin, to identify by 2009 a programme of measures for achieving the environmental objectives of the Water Framework Directive cost-effectively (Article 11, Annex III);

- $\quad$ produce and publish River Basin Management Plans (RBMPs) for each RBD including the designation of heavily modified water bodies, by 2009 (Article 13, Article 4.3); 
$-63-$

- implement water pricing policies that enhance the sustainability of water resources by 2010 (Article 9);

- make the measures of the programme operational by 2012 (Article 11); and,

- implement the programmes of measures and achieve the environmental objectives by 2015 (Article 4).

To achieve the results a deep rooted change of the water management processes is required, including new regulations on information, consultation and participation of the public and stakeholders. Article 14 of the Directive specifies that Member States shall encourage the active involvement of all interested parties in the implementation of the Directive and development of river basin management plans. Also, Member States will inform and consult the public, including users, in particular for:

- the timetable and work programme for the production of river basin management plans and the role of consultation at the latest by 2006;

- the overview of the significant water management issues in the river basin at the latest by 2007; and the draft river basin management plan, at the latest by 2008 .

The central concept underlying the Water Framework Directive is the concept of integration that is seen as key to the management of water protection within the river basin district:

- Integration of environmental objectives, combining quality, ecological and quantity objectives for protecting highly valuable aquatic ecosystems and ensuring a general good status of other waters;

- Integration of all water resources, combining fresh surface water and groundwater bodies, wetlands, coastal water resources at the river basin scale;

- Integration of all water uses, functions and values into a common policy framework, i.e. investigating water for the environment, water for health and human consumption, water for economic sectors, transport, leisure, water as a social good;

- Integration of disciplines, analyses and expertise, combining hydrology, hydraulics, ecology, chemistry, soil sciences, technology engineering and economics to assess current pressures and impacts on water resources and identify measures for achieving the environmental objectives of the Directive in the most cost-effective manner;

- Integration of water legislation into a common and coherent framework. The requirements of some old water legislation (e.g. the Fishwater Directive) 
$-64-$

have been reformulated in the Water Framework Directive to meet modern ecological thinking. Integration of all significant management and ecological aspects relevant to sustainable river basin planning including those which are beyond the scope of the Water Framework Directive such as flood protection and prevention;

- Integration of a wide range of measures, including pricing and economic and financial instruments, in a common management approach for achieving the environmental objectives of the Directive. Programmes of measures are defined in River Basin Management Plans developed for each river basin district;

- Integration of stakeholders and the civil society in decision making, by promoting transparency and information to the public, and by offering an unique opportunity for involving stakeholders in the development of river basin management plans;

- Integration of different decision-making levels that influence water resources and water status, be local, regional or national, for an effective management of all waters;

- Integration of water management from different Member States, for river basins shared by several countries, existing and/or future Member States of the European Union.

\section{Identification of groundwater bodies}

When the term groundwater body was first introduced into the WFD legislation it was not clear how these entities should be used in practice. This situation led to some confusion during the initial phase of identifying the required groundwater bodies. The clarification came one year too late when a Horizontal Guidance Document was released on the identification of water bodies [3]. There is now a large difference in the way individual states and countries have identified groundwater bodies on their territories. Unfortunately, this leads to a situation where groundwater bodies within one river basin in which several partners are involved are not made up in the same manner. In Germany the activities of the individual states have been coordinated by a Working Group Water of the States (LAWA) with only partial success. There is some difference in the way groundwater bodies have been defined.

The Horizontal Guidance Document allows some flexibility with regard to size and delineation of groundwater bodies. However, it is important that the resulting entities will be manageable units. The suggested process of identification based on either geological or hydraulic boundaries is given in Figure 1, originally from [3].

In Lower Saxony the groundwater bodies were defined on both principles. In the thick Quaternary soft rock aquifers the dividing principle was hydraulic boundaries, both negative (watersheds) and positive (river axis) ones. Within the more 
$-65-$

complicated structures of the hard rocks terrain the boundaries of aquifers or groups of such were taken instead.

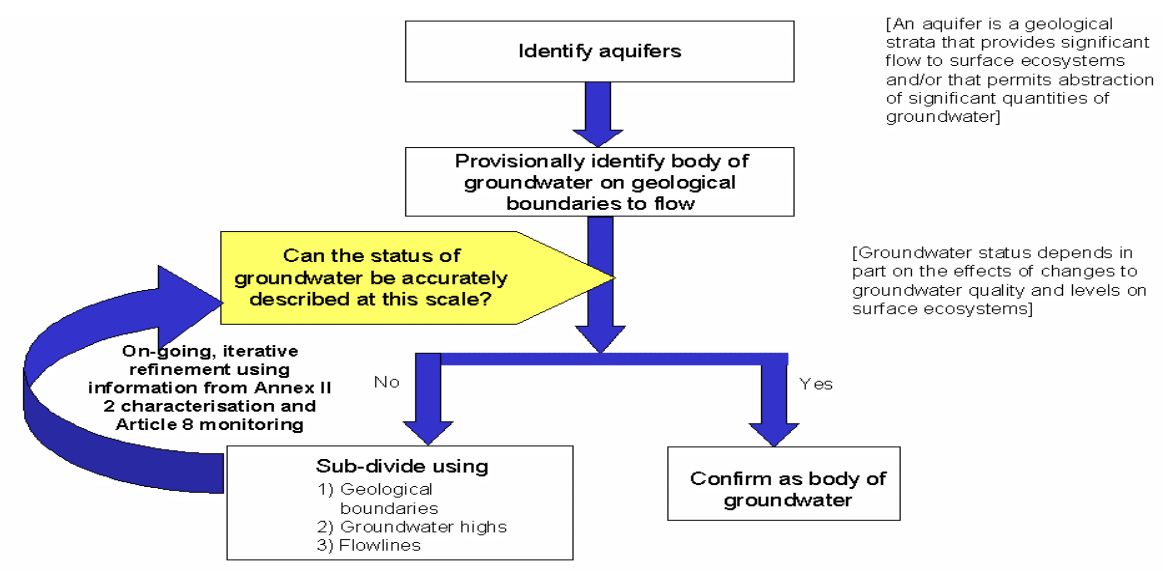

Figure 1: Summary of the suggested hierarchical approach to the identification of bodies of groundwater, from [3].

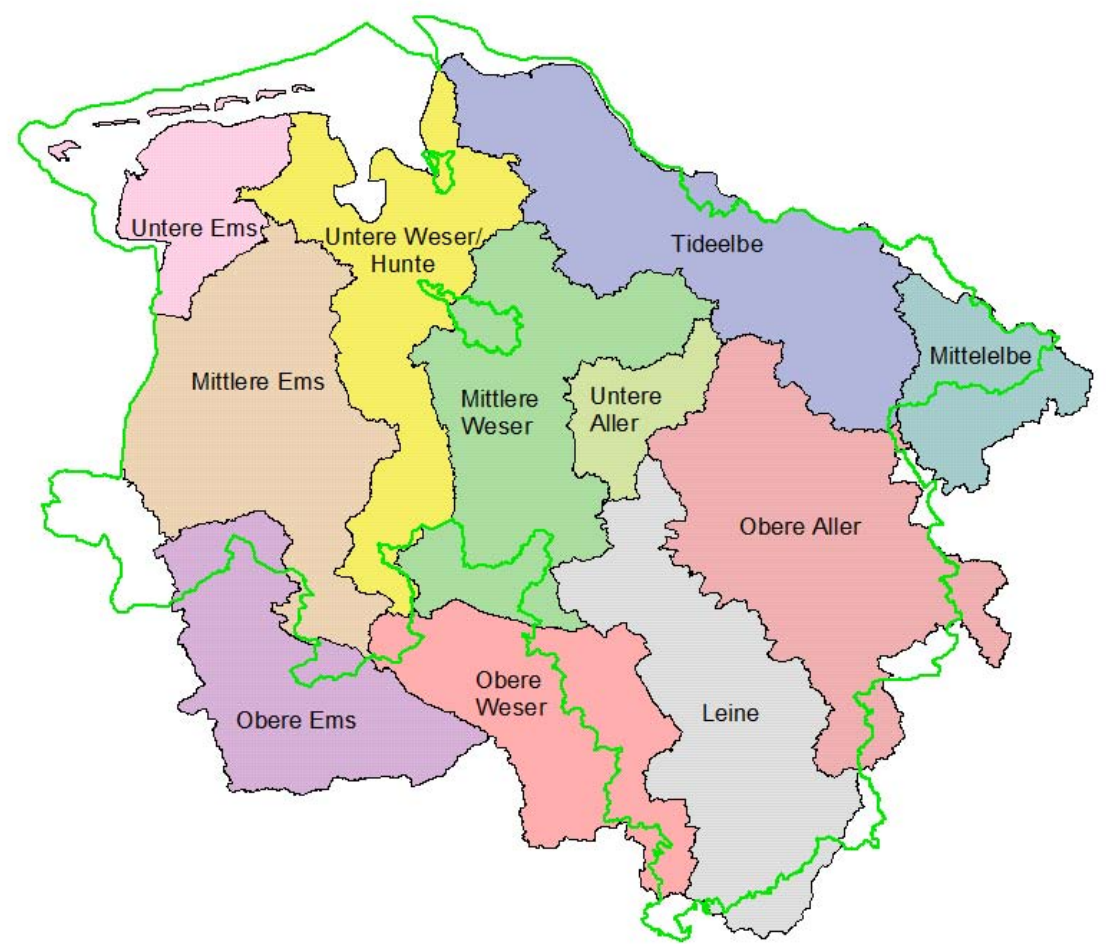

Figure 2: 11 consideration units defined for both surface and groundwater body groups in Lower Saxony, from [4]. 
$-66-$

In order to assure a coherent evaluation of both surface and groundwater bodies 11 consideration units were defined which have the same external boundaries for both types of bodies; within these boundaries delineation principles are different.

The consideration units were used to describe most of the general descriptive features of the groundwater situation. The individual groundwater bodies were addressed for the evaluation of the chemical and quantitative status.

Very helpful for the description of the hydrogeological features of the groundwater bodies was a set of maps prepared by a working group of the State Geological Surveys especially for the purpose of the WFD for the entire country. This includes completed map themes of the Hydrogeological Survey Map 1:200,000 on Groundwater Realms and Hydrogeology of the Upper Aquifer.

\section{Characterization of groundwater bodies}

The characterization of groundwater bodies with regard to their chemical and quantitative status needs to be completed and reported until the end of 2004. This is done in two steps which can be combined: the initial and the further characterization.

Reporting in Germany is done in three reports:

C-Reports are made for the individual states for their respective territories and those adjacent areas where the particular state is responsible [4]

B-Reports are drawn together from the results of the C-Reports for the defined river basin units and are prepared by the river basin managers

A-Reports are the final country reports to Brussels.

In Lower Saxony the C-Reports for groundwater are presently being completed [4]. They are based on the principles discussed in the following context.

\subsection{Characterization of chemical status}

The first step includes the determination of pressures which exert their influence on the groundwater resources. This collection of data on the presence of point and diffuse sources and the evaluation of the risk associated with them is a major task.

From the land use situation with prevalent agriculture and some larger industrial/ urban spots it became clear from the beginning, that the influence of diffuse sources would be the most prominent. Investigations therefore concentrated on describing this risk as accurate as possible. Figure 3 characterizes the process of determining the influence of diffuse sources upon groundwater during the further characterisation of groundwater bodies at risk in Lower Saxony.

The process for the determination of site and pollutant specific transport potential for the characterization of groundwater bodies with regard to point sources is presented in Figure 4. 
$-67-$

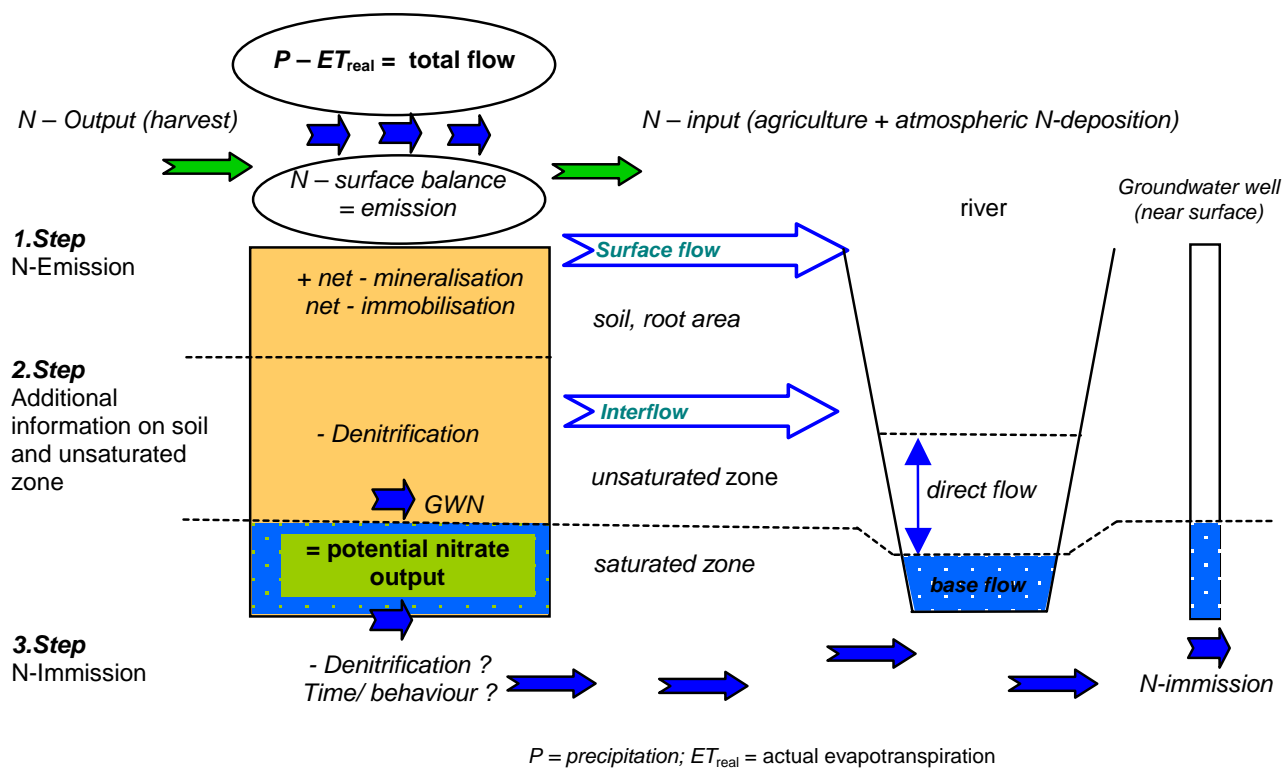

Figure 3: Process of characterizing the influence of diffuse sources upon groundwater during the further characterisation of groundwater bodies at risk in Lower Saxony, from [4].

Site specific pollution risk of groundwater

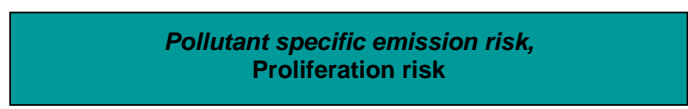

Selection of pollutants

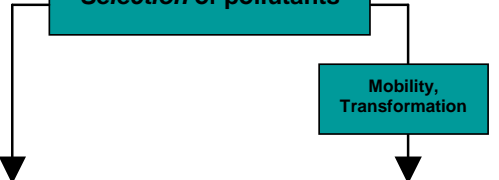

Pollutant specific

proliferation risk

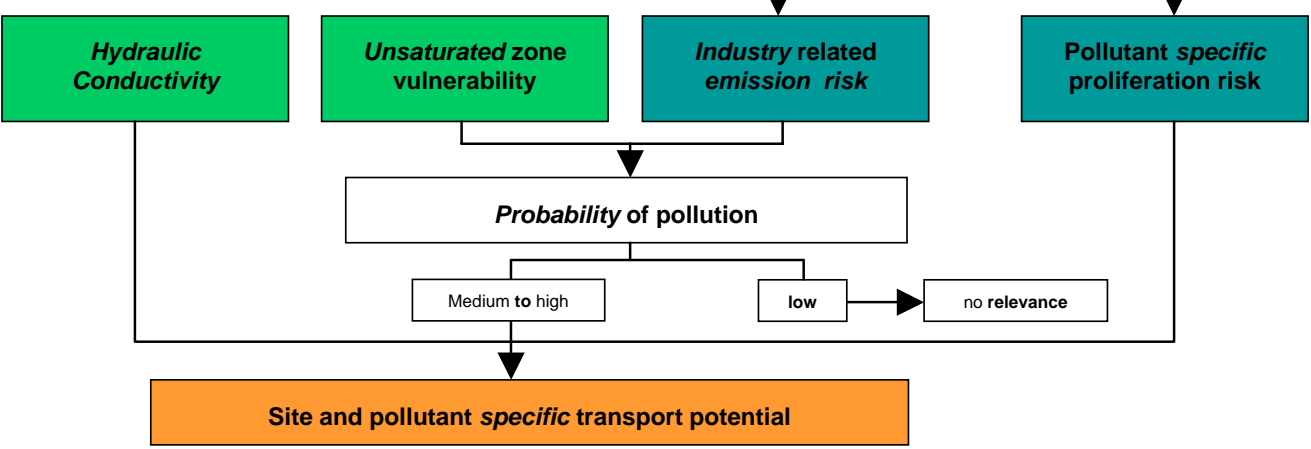

Figure 4: Process for the determination of site and pollutant specific transport potential for the characterization of groundwater bodies with regard to point sources, from [4]. 
$-68-$

The GIS-based process results in the definition and summing of virtual influential zones around each major point source.

The characterization of the quantitative status was accomplished by comparing the mean annual recharge rates of the groundwater bodies with the allowed respectively real abstraction rates. In addition, groundwater level trend calculations were performed for selective observation wells (Figure 5).

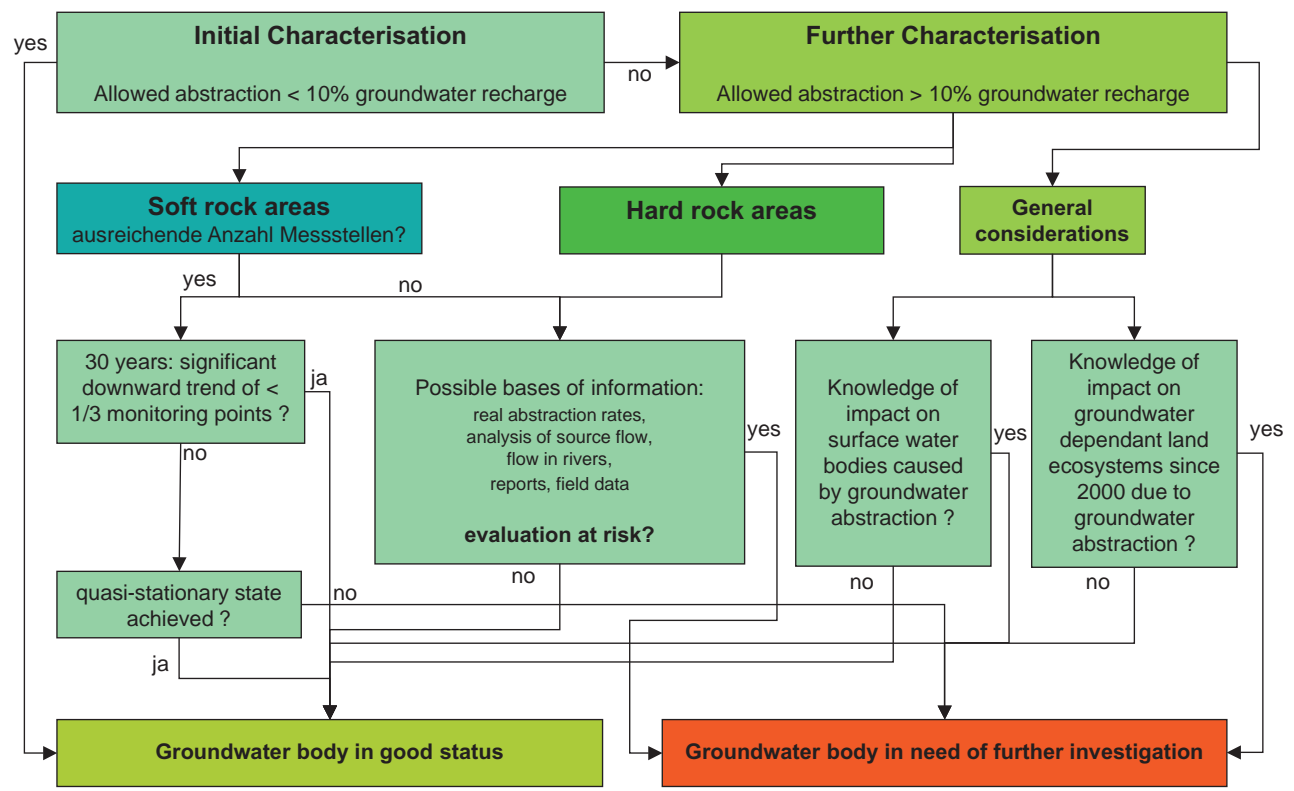

Figure 5: Process of characterizing the possible impact on the quantitative status of groundwater bodies in Lower Saxony, from [4].

As a result of the characterization steps the status of each groundwater body was assessed. The results were as follows. Of the sum of 129 groundwater bodies more than 60 are characterized as being in need for further investigations because of risk from diffuse sources, 7 because of risk from point sources and 8 because of quantitative risks. 
$-69-$

\section{References}

[1] European Parliament and Council (2000): Directive 2000/60/EC of the European Parliament and of the Council of October 2000 establishing a framework for Community action in the fields of water management, Official Journal of the European Communities L327, pp.1-72

[2] Guidance on Monitoring for the Water Framework Directive, Water Framework Directive Common Implementation Strategy, Working Group 2.7 Monitoring, Final Version 23 January 2003, pp. 1-170

[3] Identification of water bodies - Horizontal guidance document on the application of the term "water body" in the context of the WFD (Final version 15.1.2003)

[4] C-Bericht 2005 Lower Saxony Grundwasser, Stand 02.03.2004; Methodenbeschreibung; unpublished report NLfB 

$-71-$

\title{
NITRATE CONTAMINATION OF SURFACE- AND GROUNDWATER IN GERMANY - RESULTS OF MONITORING
}

\author{
R. Wolter \\ Federal Environmental Agency \\ Bismarckplatz 1 \\ D-14193 Berlin, Germany \\ ruediger.wolter@uba.de
}

\begin{abstract}
In Germany and many other European countries high nitrogen inputs to surfaceand groundwater have led to a significant deterioration of water quality. In order to protect waters against contamination by nitrogen the EU Commission has enacted the Nitrates Directive. Under this Directive, action programmes have to be carried out to prevent or reduce nitrogen inputs to surface -and groundwater. The effectiveness of these programmes is monitored by several surface-, ground- and coastal water networks. In accordance with the Nitrates Directive the results of the actions programmes and the development of nitrate concentrations in ground- and surface waters are reported to the Commission every four years.
\end{abstract}

\section{Introduction}

In Europe mineral $\mathrm{N}$ fertiliser consumption has increased significantly since 1950. Consumption in the $15 \mathrm{EU}$ Member States increased from about 1.5 million tons per year in 1950 to about 11 million tonnes in 1987 (Figure 1).

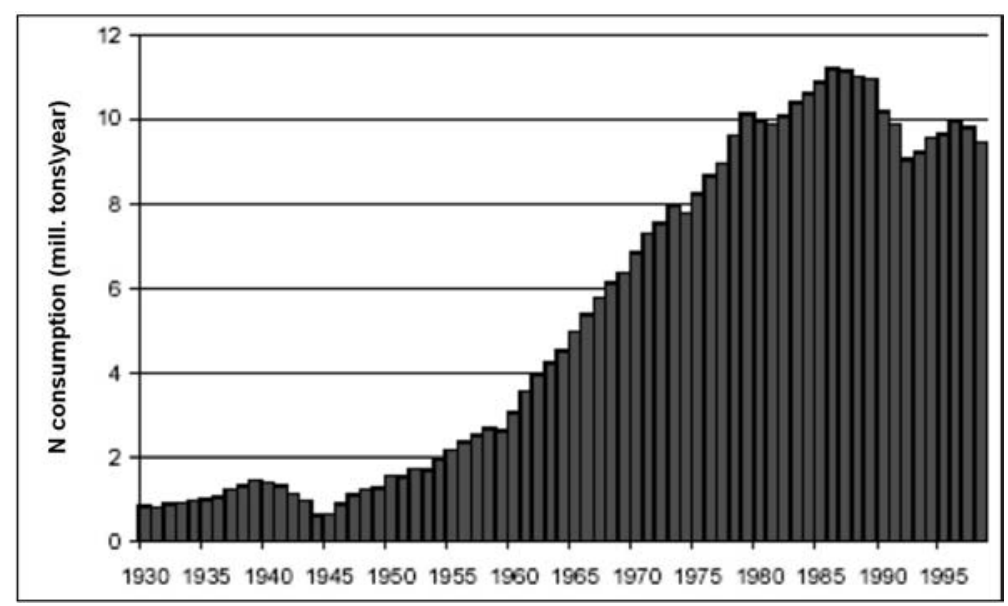

Figure 1: Mineral N fertiliser consumption - EU15 Member States, from 1930 to 1999. Source: EFMA (millions of tons of nitrogen per year). 
This also led to an increasing nitrogen surplus in many European countries and to increasing nitrate concentrations in ground- and surface waters. More than half of all nitrogen inputs and over $40 \%$ of all phosphate inputs to Germany's water resources originate from agricultural land. The nutrient content in German water bodies has multiplied over the last 30 to 40 years. For decades now, a continuous rise has been observed in the nitrate content of groundwater and drinking water, especially in regions where agriculture is intensive. The quality of drinking water in such areas is severely at risk.

The risk of water pollution by nitrogen in an area is characterised by the nitrogen (or ammonium) surplus. In Germany under arable land and areas with intensive animal husbandry the nitrate surplus increased from about $28 \mathrm{~kg} \mathrm{~N} / \mathrm{ha}$ (arable land) in 1950 to about $140 \mathrm{~kg} \mathrm{~N} / \mathrm{ha}$ in 1989 . It has fallen by $27 \%$ since reaching its peak in 1987 (Figure 2). Nevertheless the calculated resulting nitrate concentrations in water are significantly higher than $50 \mathrm{mg} / \mathrm{l}$, the limit value for nitrate in the Drinking Water Directive.

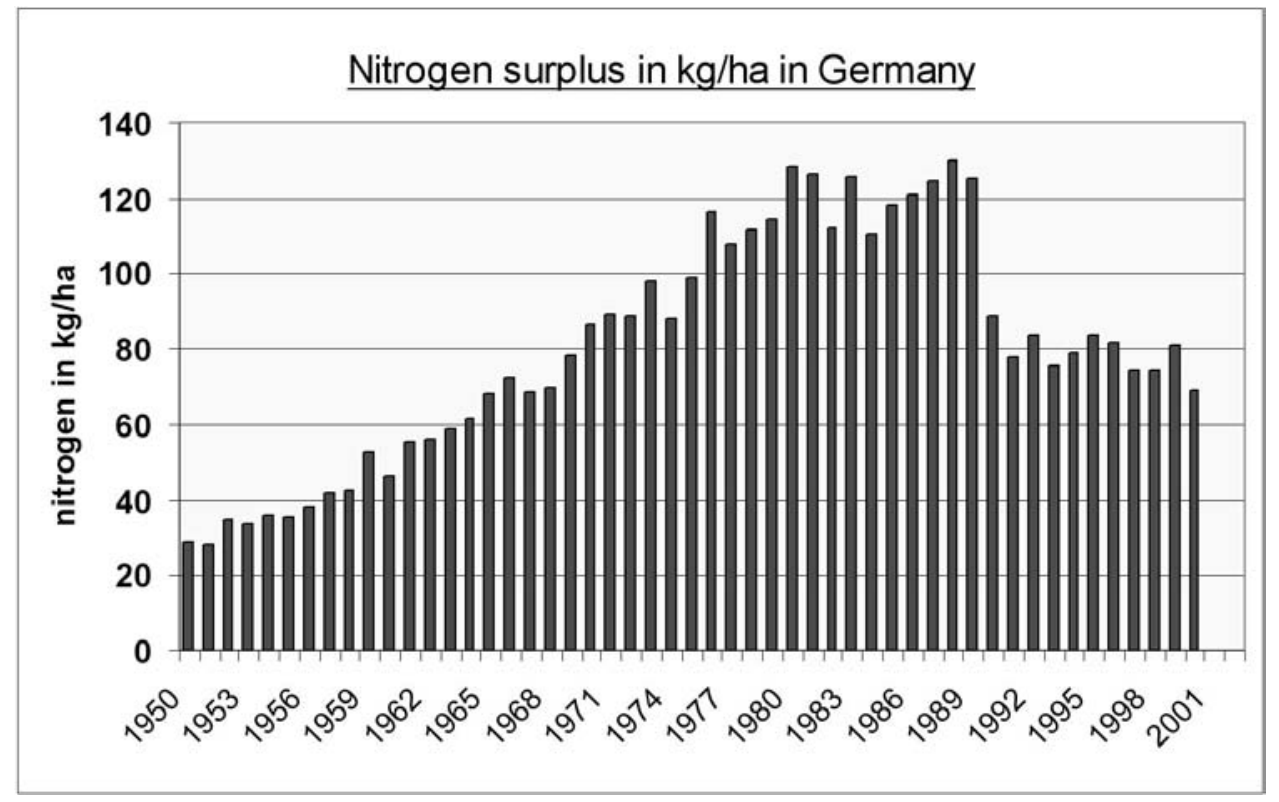

Figure 2: Development of the nutrient surplus of farmland (farm gate balance) according to [1]

\section{Overview of monitoring networks}

\subsection{Monitoring network for surface water}

For more than 20 years inorganic nitrogen compounds (ammonia, nitrite and nitrate) have been analysed at many surface water sampling sites in Germany. The map in Figure 3 shows the location of 152 representative sites at major watercourses in Germany (LAWA network). 


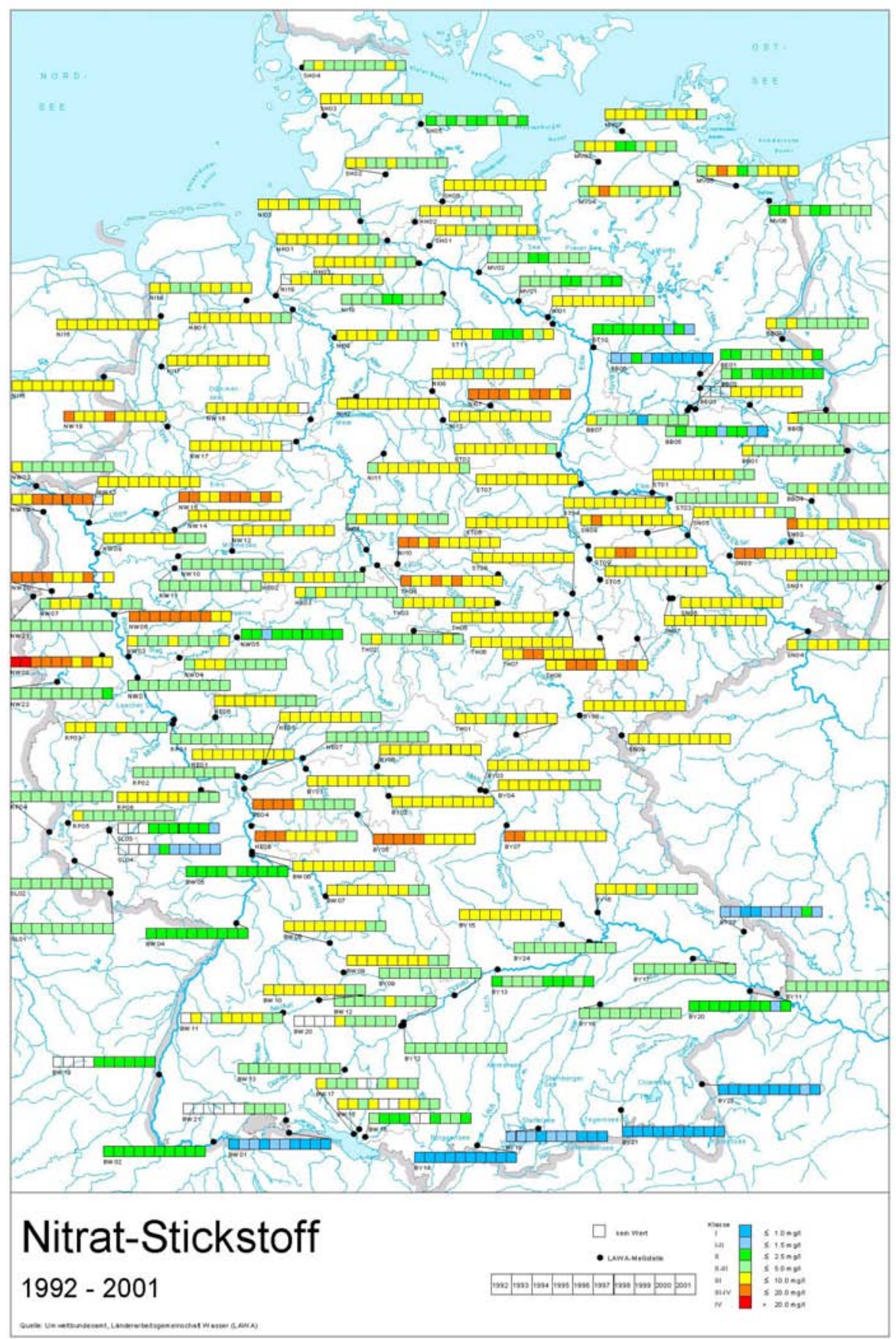

Figure 3: Development of total nitrogen concentrations in surface waters (90-percentile) from 1992 (left box) to 2001 (right box) 
This "water quality map of nitrate" gives an overview of the development of the nitrate concentration in surface water from 1992 to 2001. In Germany nitrate concentrations are classified according to a system consisting of seven quality classes (Table 1):

Table 1: The German nitrate classification system

\begin{tabular}{|c|c|c|}
\hline Class & $m g / I N$ & $m g / I \mathrm{NO}_{3}$ \\
\hline$I$ & $<=1$ & $<=4.4$ \\
\hline$I-I I$ & $<=1.5$ & $>4.4-6.6$ \\
\hline$I I$ & $<=2.5$ & $>6.6-11.1$ \\
\hline$I I-I I I$ & $<=5$ & $>11.1-22.1$ \\
\hline$I I I$ & $<=10$ & $>22.1-44.3$ \\
\hline$I I I-I V$ & $<=20$ & $>44.3-88.5$ \\
\hline$I V$ & $>20$ & $>88.5$ \\
\hline
\end{tabular}

Class II with an upper limit of $2.5 \mathrm{mg} \mathrm{N} / \mathrm{l}$ is the target value. For classification the 90percentile values of all analyses within a year are used.

For the second German nitrate report it was necessary to estimate the development of nitrate concentrations between the 1992-1995 and 1996-1999 action programmes. A total of 15 surface water sampling sites at major German rivers were selected for this purpose. For these sites a sufficient number of data as well as suitable time series were available (see Chapter 3 "Trend in nitrate concentrations in water").

\subsection{Monitoring network for coastal waters}

For reporting on the development of nitrate concentrations in coastal waters, a total of ten sampling sites were selected, i.e. five at the North Sea and five at the Baltic Sea. The North Sea sites are representative of the estuaries of the rivers Elbe, Eider and Jade as well as the Wadden Sea. The marine environment is covered by these sites. The Baltic Sea sites represent the inner as well as the outer coastal waters. The geographical location of these sites is shown in Figure 4. 
$-75-$

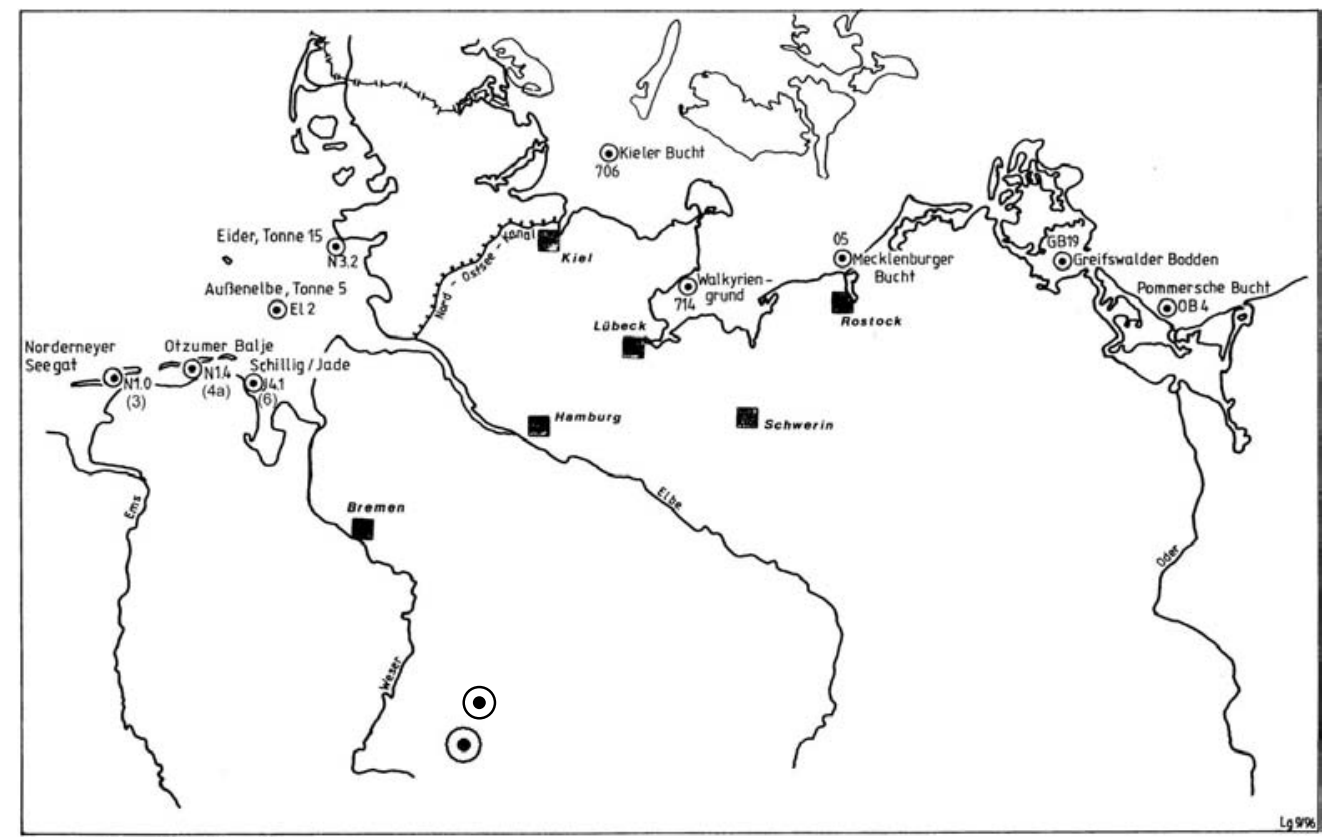

Figure 4: Sampling sites in German coastal waters for monitoring of nitrate concentrations

\subsection{Monitoring networks for groundwater}

Germany has two nationwide groundwater monitoring networks. In 1990 the "EEA network" was established. It is a representative groundwater monitoring network, comprises about 800 sampling sites and was installed to fulfil existing obligations for reporting to the European Environment Agency (EEA). Of major interest are the impacts of diffuse (non point source) anthropogenic inputs of contaminants, for example, nitrates, pesticides, acidifying components and other pollutants, on groundwater quality [2].

o sites must be polluted by nitrate,

o contamination has to be caused by agriculture,

o site must be located in the upper aquifer

The "EU nitrate network" is a "worst-case network" and describes the status of groundwater in polluted areas. It is not representative of the distribution of nitrogen in German groundwater (Figure 5).

\subsubsection{EEA Network}

Sampling sites were selected from existing monitoring networks operated by the Federal States. They reflect the known distribution of contaminated and uncontaminated groundwater bodies within each state. Sampling sites representing 
contaminated bodies of groundwater are located in regions in which groundwater contamination is more frequent.

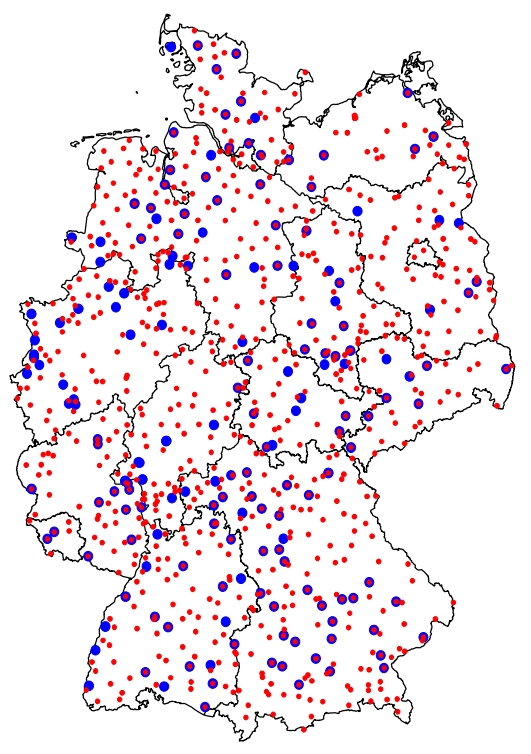

Results have to be reported to the European Environment Agency (EEA)

- representative network

- $\quad$ about 800 sites

- distributed across the Federal States

- $\quad$ upper main aquifer

Results are used for reporting under the EU Nitrates Directive

- $\quad$ worst case scenario

- $\quad$ about 180 sites

- influenced by agricultural use

- $\quad$ upper main aquifer

- EU Nitrate Network

Figure 5: Sampling sites of the EEA network (red) and the EU Nitrate Network (blue)

Table 2: Number of sampling sites in each of the Federal States

\begin{tabular}{|c|c|c|c|c|c|}
\hline Federal state & $\begin{array}{l}\text { Sampling } \\
\text { sites }\end{array}$ & Area in $\mathrm{km}^{2}$ & Federal state & $\begin{array}{l}\text { Sampling } \\
\text { sites }\end{array}$ & Area in $\mathrm{km}^{2}$ \\
\hline Bremen & 2 & 400 & Saxony-Anhalt & 51 & 20400 \\
\hline Hamburg & 5 & 800 & Hesse & 49 & 21100 \\
\hline Berlin & 5 & 900 & $\begin{array}{c}\text { Mecklenburg-Western } \\
\text { Pomerania }\end{array}$ & 38 & 23800 \\
\hline Saarland & 6 & 2600 & Brandenburg & 60 & 29100 \\
\hline Schleswig-Holstein & 36 & 15700 & North Rhine-Westphalia & 77 & 34100 \\
\hline Thuringia & 30 & 16300 & Baden-Württemberg & 79 & 35800 \\
\hline Saxony & 39 & 18300 & Lower Saxony & 106 & 47400 \\
\hline \multirow[t]{2}{*}{ Rhineland-Palatinate } & 50 & 19800 & Bavaria & 158 & 70600 \\
\hline & & & Total: & 791 & 357100 \\
\hline
\end{tabular}

The "EEA network" consists of about 800 sampling sites distributed more or less evenly across the 16 Federal States. The number of sampling sites in each state 
depends on its size. City states, that is Berlin, Hamburg and Bremen, are overrepresented in terms of number of sampling sites in relation to their area.

This apparent overweighting was found necessary in order to better characterise groundwater quality in these states and the variations therein. At present there is an average of one sampling site per 450 square kilometres. In close co-operation with the Federal States, the Federal Environmental Agency defined the set of data necessary to characterise sampling sites and their catchment areas. Important parameters are location and type of sampling site, petrographic composition of the aquifer, and predominant land use in the catchment area. In addition to temperature, conductivity and acidity, parameters used to characterise groundwater quality include all major anions and cations, selected heavy metals, metalloids, some organic components and selected pesticides (Table 3).

Table 3: Parameters to characterise the sampling site, catchment area and groundwater status

\begin{tabular}{|l|}
\hline Sampling site: \\
\hline $\begin{array}{l}\text { Code number and location of sampling } \\
\text { site }\end{array}$ \\
\hline Altitude of site and filter position \\
\hline Type of sampling site (well, spring, etc.) \\
\hline Land use \\
\hline $\begin{array}{l}\text { Hydrogeology (stratigraphy, } \\
\text { petrography) }\end{array}$ \\
\hline $\begin{array}{l}\text { Type of aquifer (unconsolidated rock, } \\
\text { fractured rock, karst) }\end{array}$ \\
\hline River basin \\
\hline
\end{tabular}

\begin{tabular}{|l|}
\hline Important parameters analyzed: \\
\hline Groundwater specific data \\
\hline Temperature; $\mathrm{pH} ;$ electrical conductivity \\
$\mathrm{O}_{2} ; \mathrm{NH}_{4} ; \mathrm{NO}_{2} ; \mathrm{NO}_{3} ; \mathrm{o}-\mathrm{PO}_{4} ; \mathrm{Cl} ; \mathrm{SO}_{4} ; \mathrm{B} ;$ \\
$\mathrm{DOC}$ \\
$\mathrm{K} ; \mathrm{Na} ; \mathrm{Ca} ; \mathrm{Mg}$ \\
\hline $\mathrm{Heavy}$ metals/metals/metalloids $\mathrm{Al} ; \mathrm{As} ; \mathrm{Pb} ;$ \\
$\mathrm{Cd} ; \mathrm{Cr} ; \mathrm{Fe} ; \mathrm{Cu} ; \mathrm{Mn} ; \mathrm{Ni} ; \mathrm{Zn}$ \\
\hline Aliphatic halogenated hydrocarbons \\
\hline Pesticides \\
\hline
\end{tabular}

In general sampling at the sites of the "EEA network" should be conducted at least twice a year. The data have to be reported to the Federal Environmental Agency once a year using a specific data transfer format. The Federal States have agreed to deliver data from earlier years for these 800 sampling sites, starting in 1990. In June 2000 a database was installed at the Federal Environmental Agency to store, verify and summarise the information delivered. Some ten thousand sets of data have arrived to date, and need to be verified. After checking for compliance with certain formal criteria, data validity is verified by drawing up the ion balance and by comparing the reported concentrations with known concentration ranges of similar types of groundwater and of the sites where they were measured. The network is designed to give a representative picture of groundwater quality in Germany (Figure 6). In 2002 about $49.6 \%$ of the sites had nitrate concentrations of less than $10 \mathrm{mg} / \mathrm{l} .36 \%$ of all sampling sites have nitrate levels between 10 and $50 \mathrm{mg} / \mathrm{l}$. This 
$-78-$

concentration range in general indicates a deterioration of groundwater quality. At $14.4 \%$ of all sites groundwater does not fulfil the requirements of the Water Framework Directive and/or the forthcoming Groundwater Directive. The groundwater status at these sites is "poor" and measures to achieve a good status have to be implemented by 2015 .

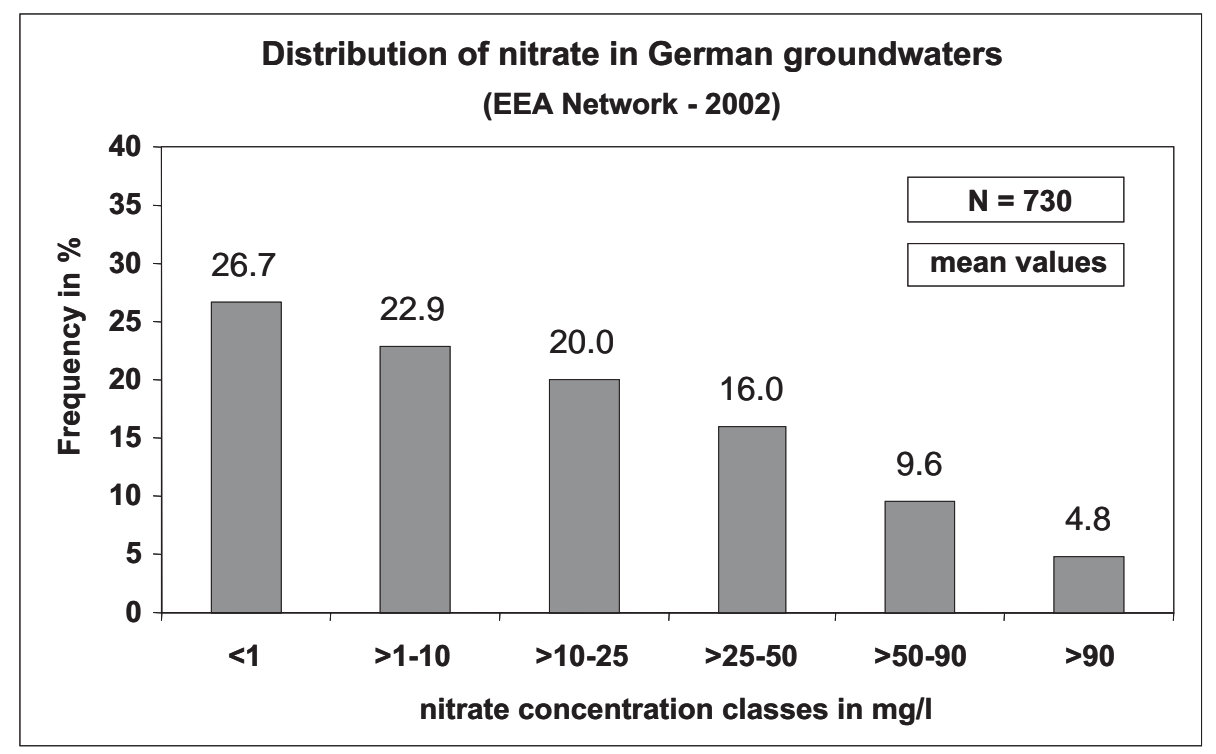

Figure 6: Frequency distribution of nitrate in German groundwater based on the results of measurements in 2002 at 730 sites of the German EEA Network

\subsubsection{EU Nitrate Network}

The German "EU Nitrate Network" was specifically designed for reporting under the Nitrates Directive [3]. The Nitrates Directive requires regular reporting about the preventive measures taken by the Member States. It provides that, at the end of each four-year programme (1995-99, 2000-2003), and for each water monitoring report of measures associated with this programme, a report describing the situation and its development be submitted to the Commission. Germany has not designated vulnerable zones since the measures to limit nitrate contamination are applied throughout its territory. The nitrate network was set up in order to depict the existing nitrate contamination of German groundwater resources and to evaluate the effectiveness of the measures taken. It focuses on regions with significant groundwater contamination by nitrates. The network consists of 181 monitoring sites predominantly situated in the upper groundwater layer. Sampling sites selected had to be significantly influenced by nitrate from agricultural sources (see Figure 5).

This means that unlike the groundwater monitoring network, the nitrate network is not representative of the nitrate status of Germany's groundwater bodies. As a result, 
$-79-$

the frequency distribution of the nitrate concentrations measured in the nitrate network (Figure 7) differs significantly from the "representative" nitrate distribution shown in Figure 6.

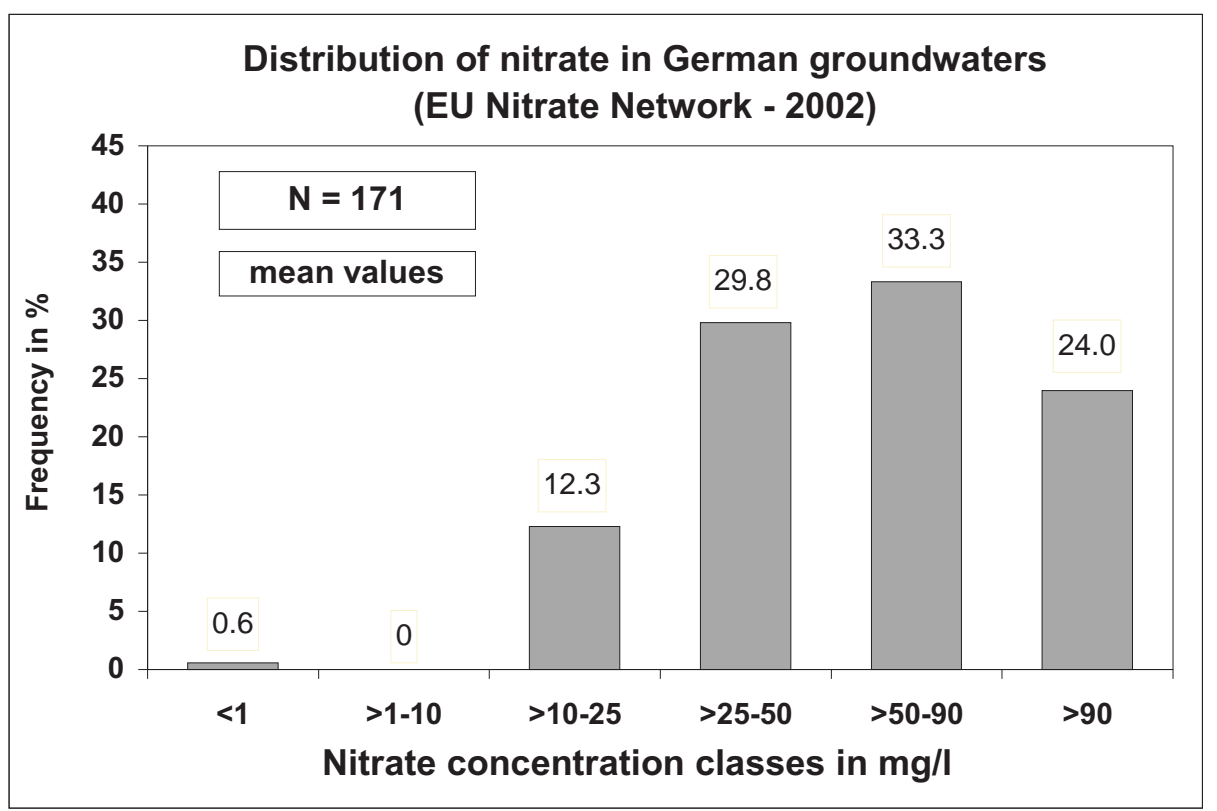

Figure 7: Frequency distribution of nitrate concentrations measured at stations of the German EU Nitrate Network in 2002

\section{Trend in nitrate concentration in water}

The Nitrates Directive and the Water Framework Directive (WFD) require Member States to implement action programmes to reduce the input of harmful substances such as nitrates. All bodies of surface water or groundwater must achieve good status by 2015. For groundwater, good status means nitrate concentrations of less than $50 \mathrm{mg} / \mathrm{l}$. Additionally in all bodies of groundwater in which the nitrate concentration is found to be increasing this trend has to be reversed. Reduction of nitrate concentration is an indicator of the effectiveness of action programmes. Therefore the reporting guidelines for the Nitrates Directive EC (1999) [4] provide that the trend in nitrate contamination must be evaluated.

\subsection{Nitrate trends in German surface waters}

Based on the data of the 152 sites of the German LAWA network a reduction of nitrate-nitrogen concentrations in German surface waters has been visible since 1993 (Figure 8). 
$-80-$

The target of $2.5 \mathrm{mg} \mathrm{N} / \mathrm{l}$ (90-percentile) was reached at only $13 \%$ of the sites, but an improvement can be seen: The number of sites with elevated nitrate concentrations (classes III to IV) is decreasing. However, this development is due mainly to the installation of additional nitrification systems in municipal waste water treatment plants rather than the measures resulting from the Nitrate Directive.

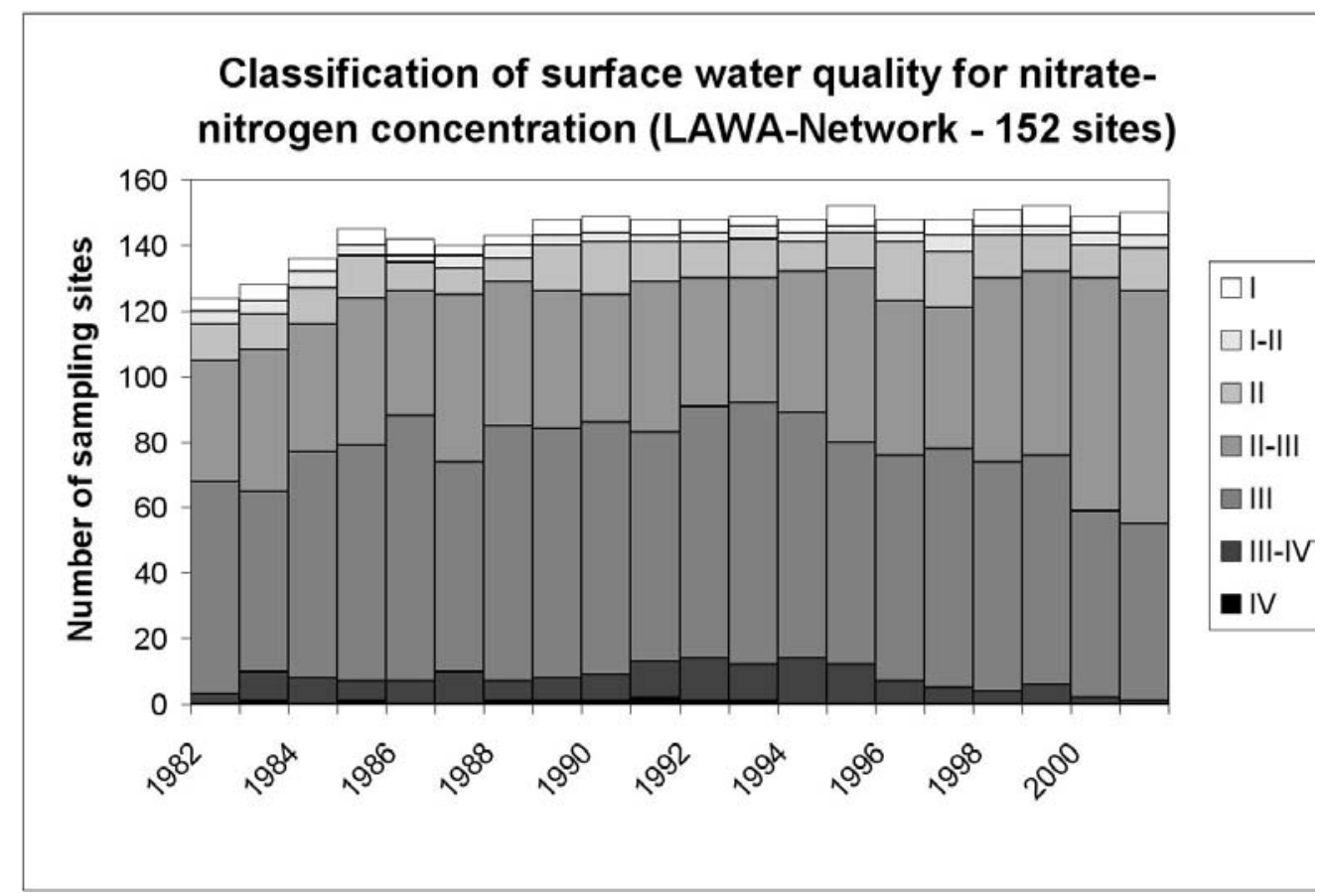

Figure 8: Development of nitrate-nitrogen concentrations in German surface waters from 1982 to 2001

Another type of effect monitoring is the evaluation of specific nitrate trends according to the requirements of the reporting guidelines of the Commission [4]. This was carried out at 15 sites representing important watercourses in Germany. They are thought to be representative for Germany as a whole. As depicted in the map (Figure 9) about half of the sites show a slight reduction of nitrate concentrations whereas the nitrate concentrations at the other sites remained constant. In addition in 2001 at all sites (Figure 3) the nitrate concentration was below the target value of $50 \mathrm{mg} / \mathrm{l}$.

\subsection{Nitrate trends in German groundwaters}

The development of nitrate distribution from 1995 to 2002 has been evaluated based on the data of the EEA Network (Figure 10). Only data from common points were used in this analysis. Compared to surface water (Figure 8) nitrate concentrations in groundwater show no significant change. The nitrate distribution in German groundwaters remained more or less stable between 1995 and 2002. 


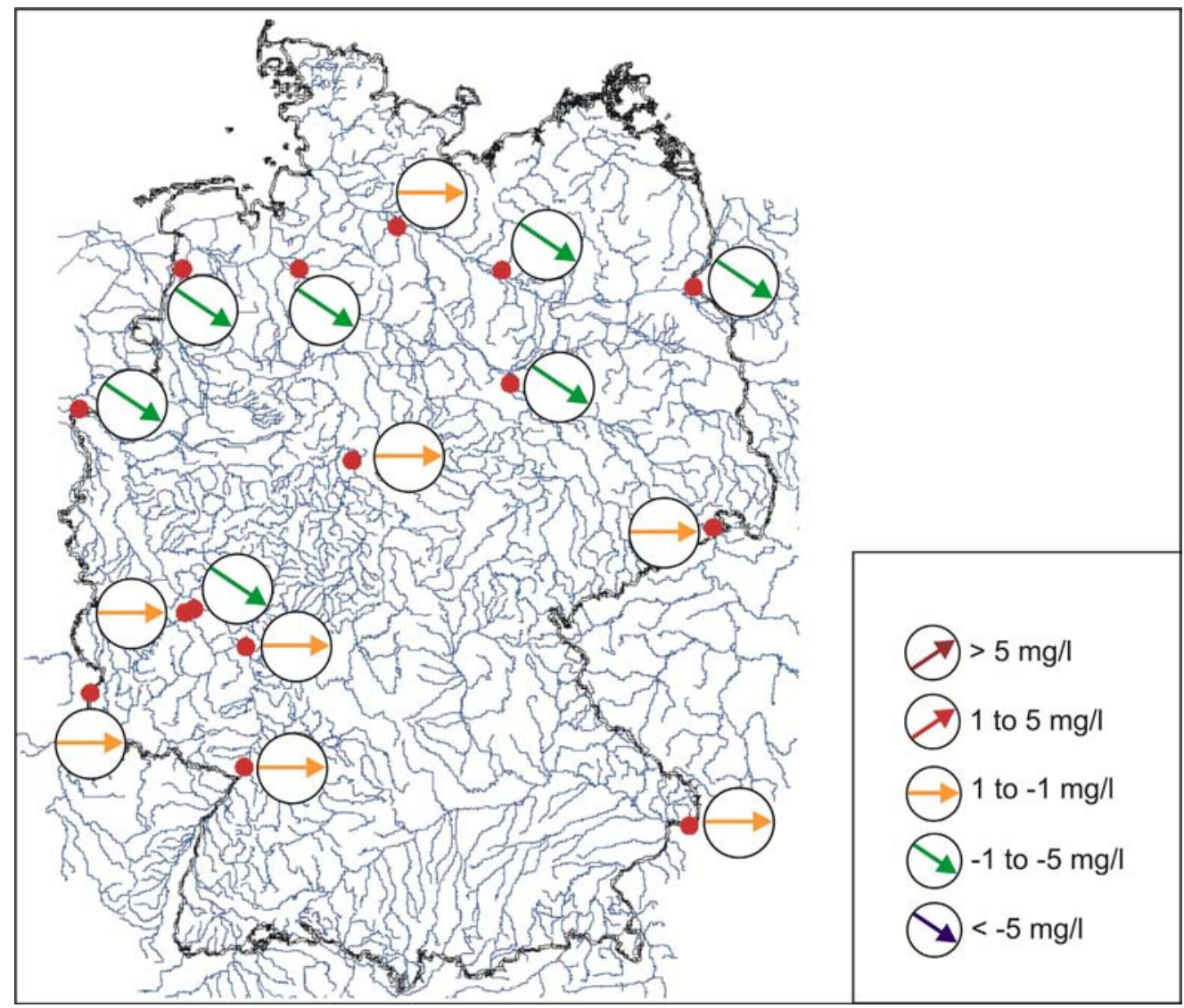

Figure 9: Sampling sites and change in the mean nitrate concentration in winter between 1996-1999 and 1992-1995

This seems curious, because during that period a lot of measures to reduce nitrogen inputs and the nitrogen surplus under arable land were implemented. These measures were carried out predominantly in agricultural areas. In order to evaluate the effectiveness of these measures especially sampling sites in heavily polluted groundwater under arable land were analysed.

This type of sites is represented in the German EU Nitrate Network. Compared to the EEA Network the percentage of EU Nitrate Network sites with nitrate concentrations of more than $90 \mathrm{mg} / \mathrm{l}$ decreased from 1995 to 2002. At the same time the percentage of sites with nitrate concentrations of less than $25 \mathrm{mg} / \mathrm{l}$ increased clearly, from $7.1 \%$ in 1995 to $12.3 \%$ in 2002. 
$-82-$

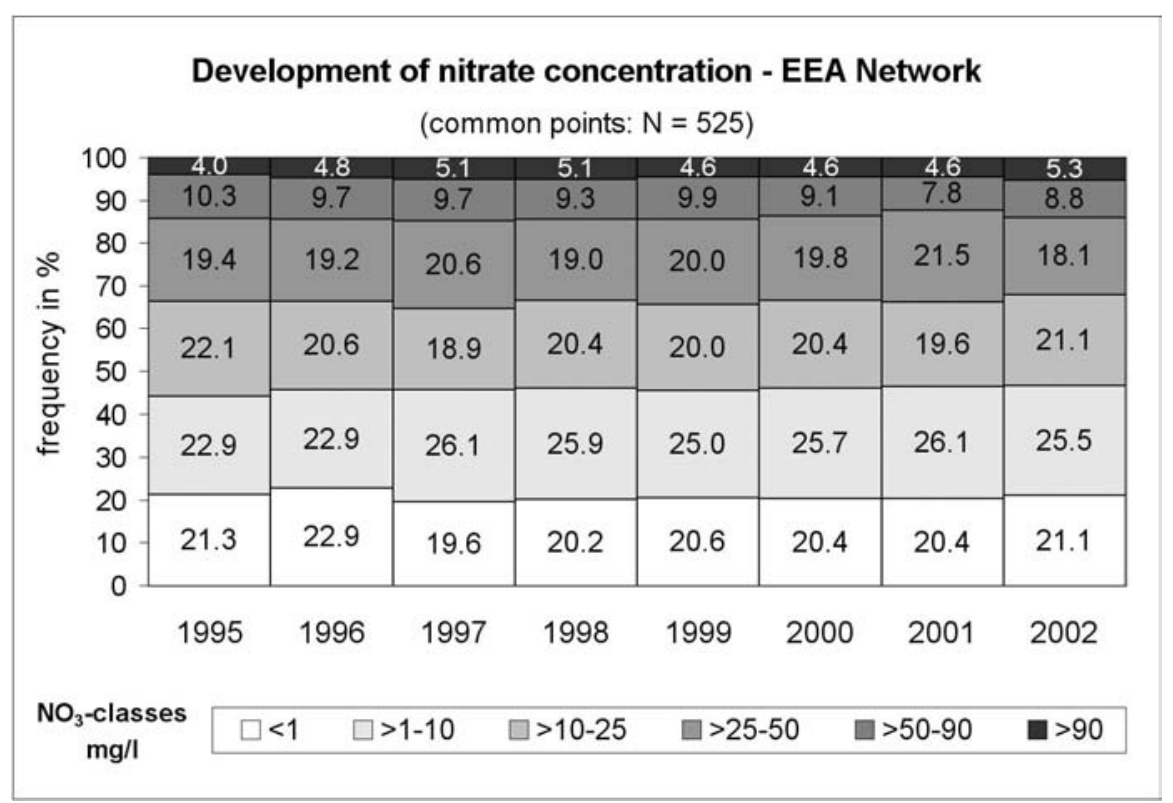

Figure 10: Trend in nitrate concentrations in German groundwater from 1995 to 2002 based on data of the EEA Network

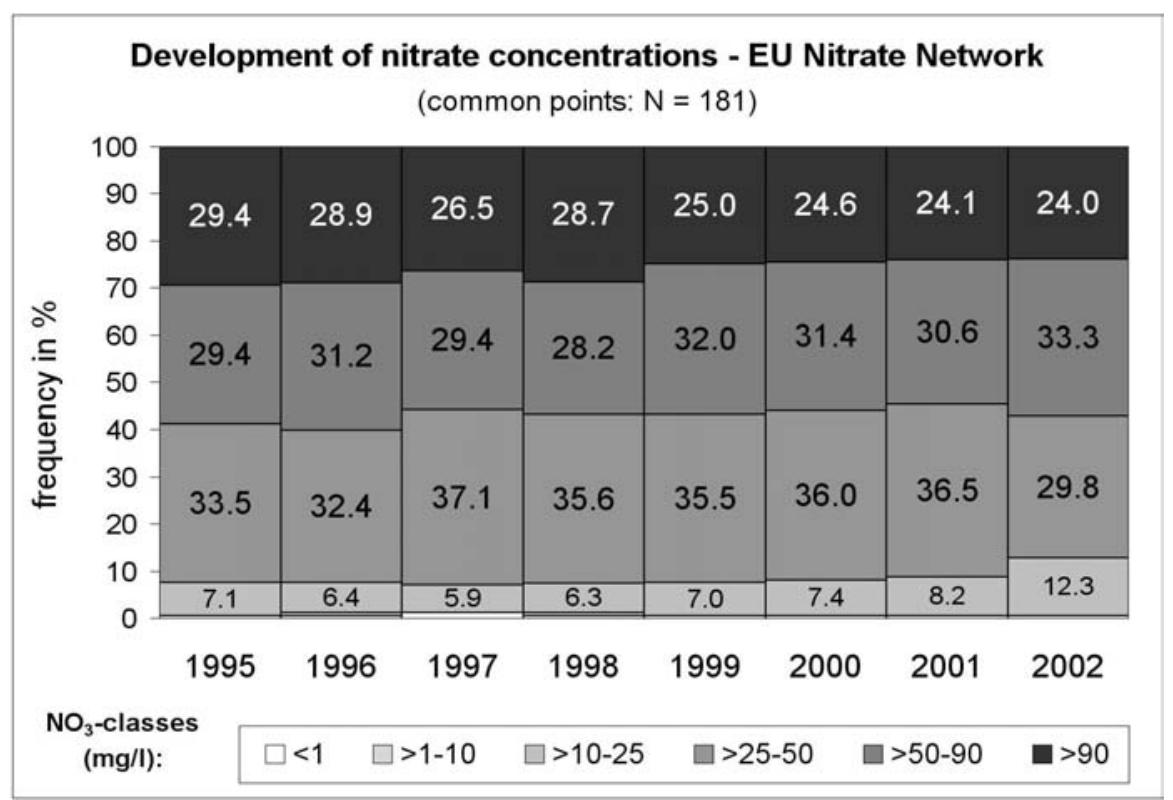

Figure 11: Change in nitrate concentration in groundwater in Germany between the first (92/94) and second (2000/2002) 
$-83-$

To describe the trend as required by the Water Framework Directive, mean and median nitrate values were calculated for each year from 1995 to 2002. These mean values are plotted in Figure 12. No mathematical trend calculation is necessary to see the downward trend. The calculated linear regression gives a decrease of about 0.6 to $0.8 \mathrm{mg} / \mathrm{l}$ nitrate per year in groundwater significantly polluted.

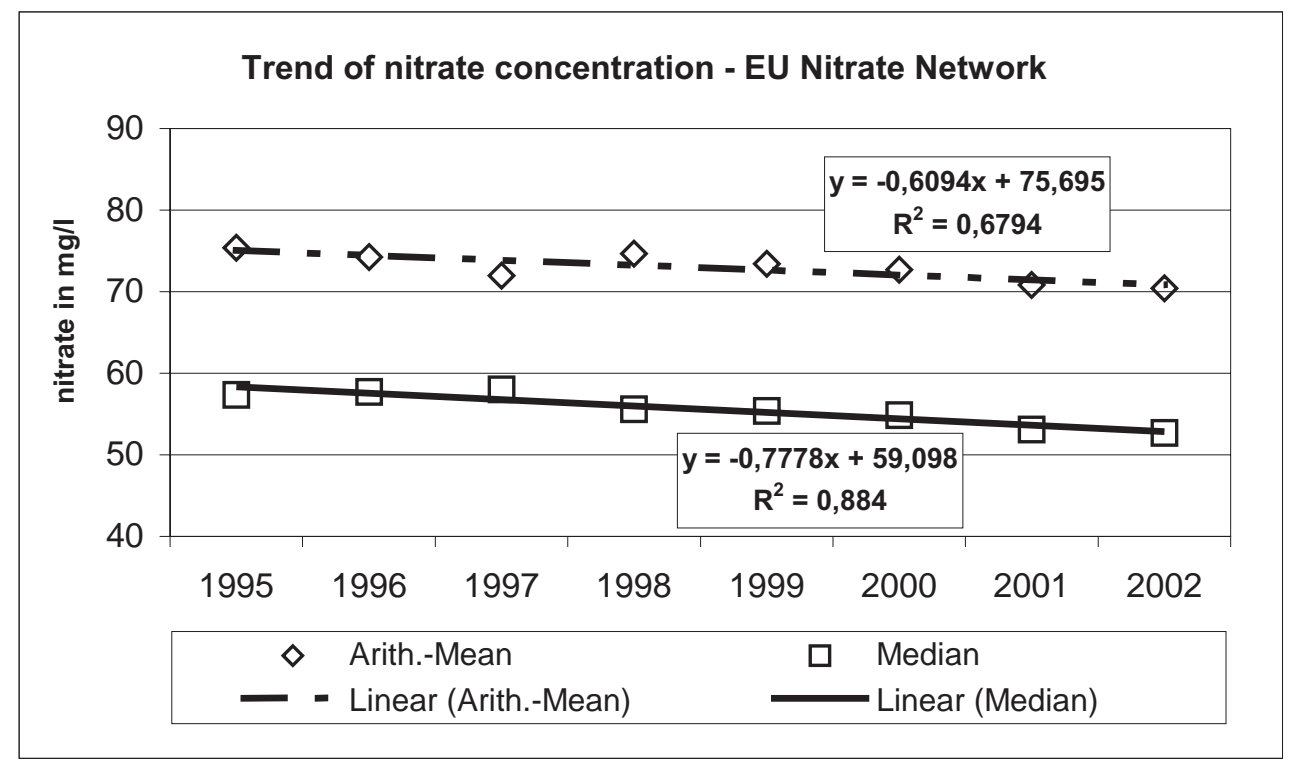

Figure 12: Trend in nitrate concentrations in German groundwater from 1995 to 2002 based on data of the German EU nitrate network

Overall the action programmes are judged to be effective. Effect monitoring at federal level does not comprise detailed investigations at the site or its catchment. The action programmes might also be effective at many sites at which nitrate concentrations are still currently increasing, because in some areas it takes years or even decades until the water reaches the top of the aquifer. In these cases effect monitoring should comprise a farmgate balance, estimation of groundwater recharge, flow velocity, attenuation capacity, etc.

\section{Conclusions}

German surface waters and groundwater are still significantly contaminated by nitrogen. Previous action programmes for surface waters have led to a significant decrease of nitrate levels in surface water. Looking at groundwater a distinct decrease of nitrate concentrations is recognisable only for heavily polluted groundwater but overall nitrate concentrations in Germany's groundwater bodies could not be reduced significantly over the last seven years. To fulfill the 
$-84-$

requirements of the Water Framework Directive further reduction of nitrogen surplus in agriculture and a reduction of nitrogen input to surface water is necessary.

\section{References}

[1] H.T. Behrendt et al. (2003): Quantifizierung der Nährstoffeinträge in die Oberflächengewässer Deutschlands auf der Grundlage eines harmonisierten Vorgehens. Ergebnisse eines Forschungsvorhabens des Umweltbundesamtes, UBA-Texte 82/03, Berlin (in print)

[2] R. Wolter, S. Rosenbaum and S. Hannappel (2000): The German groundwater monitoring network. in: Timmerman, J.G., Cofino, W.P. et al. (Eds.), Proceedings Monitoring Tailor-Made III, Nunspeet, The Netherlands. p. 277282.

[3] EC (1991): Council Directive 91/676/EEC of 12 December 1991 concerning the protection of waters against pollution caused by nitrates from agricultural sources. Official Journal of the European Communities, L375, 31/12/1991, 1-8.

[4] EC (1999): Draft guidelines for the monitoring required under the Nitrates Directive (91/676/EEC). Version 2, with annexes 1 through 6. European Commission, Directorate-General XI (Environment, Nuclear Safety and Civil Protection), Directorate D (Environment, Quality and Natural Resources). 


\title{
WATER FLUXES AND DIFFUSE NITROGEN POLLUTION AT THE RIVER BASIN SCALE
}

\author{
F. Wendland ${ }^{1}$, H. Bogena ${ }^{1}$, H. Goemann ${ }^{2}$, P. Kreins ${ }^{2}$ \& R. Kunkel ${ }^{1}$ \\ ${ }^{1}$ Research Centre Jülich, \\ Systems Analysis and Technology Evaluation, D-52425 Jülich, \\ ${ }^{2}$ Research Association for Agricultural Policy and Rural Sociology D-53175 Bonn \\ f.wendland@fz-juelich.de
}

\begin{abstract}
The REGFLUD-project, commissioned by Germany's Federal Research Ministry (BMBF), addresses the problem of reducing diffuse pollution from agricultural production. The objective of the project is the development and application of multi-criteria scientific methods, which are able to predict diffuse pollution in river basins subject to economic feasibility and social acceptability. The selected river basins (Ems and Rhine basins) cover a variety of landscape units with different hydrological, hydrogeological and socio-economic characteristics.
\end{abstract}

This paper focuses on the analysis of the effects of certain policy measures to reduce diffuse pollution by nitrogen. For this purpose a model system consisting of an agricultural sector model, a water balance model and a residence time/denitrification model was developed and applied. First results indicate a wide range of annual nitrogen surpluses for the rural areas between less than $10 \mathrm{~kg} \mathrm{~N} / \mathrm{ha}$ up $200 \mathrm{~kg} \mathrm{~N} / \mathrm{ha}$ or more depending on the type and intensity of farming. Compared to the level of nitrogen surpluses the level of nitrogen inputs into the surface waters is relatively moderate because of degradation processes during transport in soil and groundwater. Policy impact analysis for a nitrogen tax and a limitation of the livestock density stress the importance of regionally tailored measures.

\section{Introduction}

In Germany, considerable progress has been achieved towards the improvement of water quality. However, diffuse water pollution, a source largely attributed to agricultural production, continues to be of concern. As described by [1], a wide range of problems concerning nutrient pollution of water bodies are prevalent in the river catchment areas Rhine and Ems. It is to be expected that political measures towards a solution of these problems will have different effects on the reduction of nitrogen in the different water bodies. Thus, the efficiency of measures has to be evaluated, taking into account both socio-economic conditions as well as natural site conditions. On one hand the different historically evolved and partly established socio-economic conditions in the study area, such as agricultural farm structures or the structure of water protection, as well as water supply and sewage disposal are an important prerequisite for the development of effective nitrogen reduction measures. On the 
$-86-$

other hand the natural conditions, which determine pathways and transport of diffuse nitrogen surplus into surface waters have to be considered. By the coupling of an agricultural sector model RAUMIS and the hydrological/hydrogeological models GROWA and WEKU the definition of relevant indicators for the detection or classification of "hot-spot" regions is improved.

\section{Methodological Approach}

Coupling of agricultural economic and hydrological models is a scientific challenge. Regarding the differences and complexity of such a model integration the most suitable and efficient way to couple these models is the development of a model interface for data exchange. This interface has to guarantee a uniform definition (e.g. scope of representation, spatial and temporal dimension) of variables being exchanged within the model network. Figure 1 shows the integration of the agricultural economic model RAUMIS with the hydrological models GROWA and WEKU.

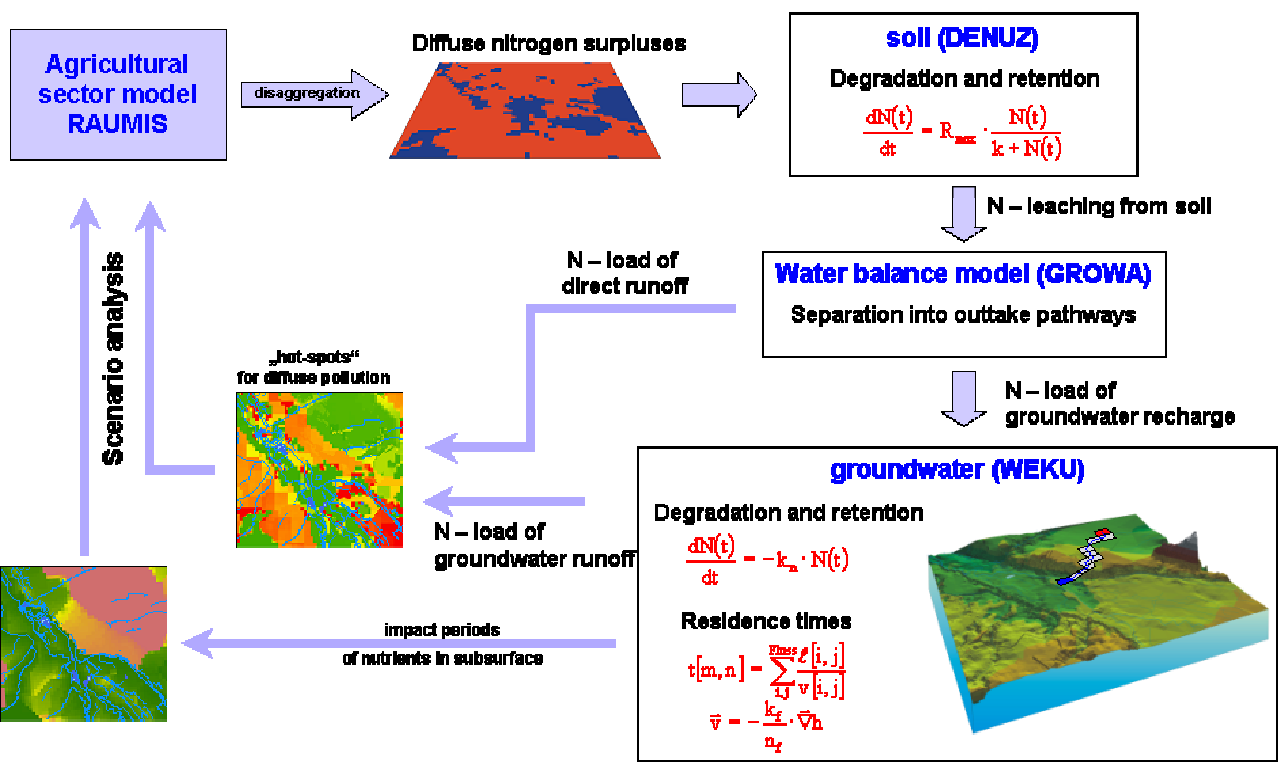

Figure 1: The integrated agro-economic / hydro(geo)logic model system.

A central interface between RAUMIS and GROWA/WEKU are regional nutrient surpluses and land use patterns. Developing the model link according to requirements specified above, it has to be considered that the two models display different regional resolutions - raster cells in the hydrological models opposed to administrative units in RAUMIS. Additionally, the models use different data sources e.g. in terms of agricultural area. While GROWA/WEKU are based on data from the 
land register (cadastral maps), RAUMIS employs agricultural survey data. Hence, the models display significant differences not only with respect to spatial resolution but to acreages as well as. For this reason, regional nitrogen balances per ha AA calculated by RAUMIS cannot be directly used as input variables in GROWA/WEKU. As a first step, nitrogen surpluses quantified by RAUMIS for individual regions are disaggregated on raster cells as required by GROWA/WEKU.

The agricultural sector model RAUMIS [2] was used in order to quantify nitrogen surpluses from agriculture. Agricultural statistics with data, e.g. on crop yields, livestock farming and land use, were used to balance the nitrogen supplies and extractions for the agricultural area. The long-term nitrogen balance averaged over several vegetation periods is calculated considering the organic nitrogen fertilization, the mineral nitrogen fertilization, the symbiotic $\mathrm{N}$-fixation, the atmospheric $\mathrm{N}$-inputs and the $\mathrm{N}$-extractions with the crop substance. As a rule, the difference between nitrogen supplies, primarily by mineral fertilizers and farm manure, and nitrogen extractions, primarily by field crops, leads to a positive balance [1].

The displacement of $\mathrm{N}$-surpluses into surface waters is coupled to the runoff components. Against the background of a long-term treatment for the hydrological period 1961-1990, runoff was distinguished into direct runoff and groundwater runoff. Whereas direct runoff reaches the surface waters within short time periods (within about a week), groundwater runoff needs much more time (years) to percolate into surface waters. The runoff components were quantified area-differentiated as a function of climate, soil, geology, topography and land use conditions using the GROWA98 model [3]. The ratio between groundwater recharge and total runoff was taken as a measure for the extent diffuse nitrogen surpluses, which are displaced from soil to groundwater.

During transport through the soil and the groundwater nitrogen surpluses may be denitrified to molecular nitrogen. Denitrification losses in the soil occur mainly in the effective root zone. These were modelled by a Michaelis-Menten kinetics as a function of nitrogen surpluses, average field capacity, runoff level and denitrification conditions [4]. Reactive nitrate transport in groundwater was modelled using the stochastic WEKU model ([5] and [6]) on the basis of a first order reaction depending on the nitrogen inputs into the aquifer, denitrification conditions in groundwater and groundwater residence times.

For the determination of groundwater residence times the groundwater velocity field was calculated according to Darcy's law. These velocities were combined with the results of an analysis of the lateral flow dynamics along the flow paths from all intake locations to the outflow into the groundwater-effective recipients. This is done by paying attention to information on the water network as well as groundwater discharge or transfer areas.

Rather simple indicators, such as the presence of Fe (II), Mn (II) and the absence of dissolved oxygen and nitrate, can be used to decide whether denitrification in 
$-88-$

groundwater is possible or not [6]. On the basis of a statistical analysis of groundwater samples the groundwater bearing formations occurring in the investigated area were classified as belonging to the predominantly reduced aquifers, in which denitrification may occur. In this case, a halving of the nitrogen leached to the groundwater after a residence time between 1.2 and 4 years was considered. In the other areas displaying oxidized groundwater conditions significant nitrate reduction can be neglected.

\section{Case study river basins}

Two German river basins, namely the Ems and a sub-catchment of the Rhine, have been selected as study areas in order to cover a wide range of different landscape units with different hydrological, hydrogeological and socio-economic characteristics. Key features describing the status quo situation (1999) in the study areas are summarized in Table 1. Due to data availability indicators are based on a sample of administrative bodies "Landkreise" whose areas predominantly span the river basin. Selected regions that correspond to RAUMIS regions cover an area of $32,700 \mathrm{~km}^{2}$ and over-extend the catchment areas that actually stretch across some $25,000 \mathrm{~km}^{2}$.

Table 1: Key features of the study area in the status quo situation 1999

\begin{tabular}{ccc}
\hline & Ems & Rhine \\
\hline Catchment area $\left(1,000 \mathrm{~km}^{2}\right)$ & 12.9 & 12.1 \\
Population density (Inhabitants/km²) & 190 & 600 \\
Agricultural Area (1,000 ha) & 989 & 497 \\
Share of arable land (\% of AA) & 70 & 49 \\
Livestock density (LU/ha AA) & 2.3 & 0.8 \\
Nitrogen Surplus (kg/ha AA) & 138 & 73 \\
Agricultural GVA (Mio. EUR) & 1,473 & 644 \\
Agricultural labour force (1,000) & 39.2 & 17.9 \\
\hline
\end{tabular}

GVA: gross value added

The river Ems basin $\left(12,900 \mathrm{~km}^{2}\right)$ is located in the North-German Plain. Agriculture plays an important role in comparison to the German average for two reasons: Agricultural area (AA) accounts for about $62 \%$ of total area and production is dominated by intensive animal husbandry which is more competitive on the prevailing less fertile sandy soils than cash cropping. Farmers typically grow fodder crops, such as silage maize and corn-cob-mix on arable land. These generate higher yields than permanent grassland and enable a higher livestock production. This production structure explains the visible correlation between shares of arable land and livestock densities (LD) that are displayed in for the regions within the Ems catchment. 
$-89-$

The situation is quite different in the Rhine sub-catchment i.e. Sieg, Wupper, Erft, Ruhr $\left(12,100 \mathrm{~km}^{2}\right)$. A striking socio-economic difference is the population density being three times higher than in the Ems basin. Settlements, traffic, and industries, in addition to forests, play an important role such that agricultural area amounts to $30 \%$ of total area.

Eastern parts of the Rhine sub-catchment are located in consolidated Palaeozoic rock areas with high total area runoff levels, dominated by fast (direct) runoff components. These conditions hamper tilling of soil so that permanent grassland dominates land use. Farmers specialise in cattle and milk production on a fairly extensive level. All these regions can be classified as areas with a high risk of surface water pollution e.g. of storage dams. On the other hand, it can be expected, that nutrient reduction measures will improve surface water quality in these areas rapidly. Western parts of the Rhine sub-catchment are located in the unconsolidated quaternary rock area of the lower Rhine bay with considerable ground water recharge levels. Because of the very fertile loess soil, intensive cash cropping is the main agriculture production activity. These regions feature a share of arable land of more than $90 \%$ of $A A$ and low livestock densities.

\section{Results and Discussion}

\subsection{Nitrogen surpluses and pathways of nitrate displacement}

The nitrogen surpluses represent the amount of nitrogen that potentially leaches into groundwater and surface waters. From the RAUMIS model the nitrogen surpluses from agriculture were calculated on district level. The surpluses were calculated for a projection of the development under the current Common Agricultural Policies (Agenda 2000) of the European Union for the year 2010. This is used as reference scenario instead of the actual situation, because it allows a direct comparison to the effects of the investigated nitrogen reduction measures leaving all other policies constant. Comparison to the actual situation would lead to a convolution between the effects of these already implied policies and the effects of the investigated reduction measures.

On average, the calculated nitrogen surpluses for the agricultural acreages based on this reference scenarios amounts to about $130 \mathrm{~kg} \mathrm{~N} / \mathrm{ha}$ a in the Ems basin, whereas the average for the investigates sub basins of the Rhine basin is much less (74 kg $\mathrm{N} / \mathrm{ha}$ a), due to the generally less intensive agriculture. In Map 1 the nitrogen surpluses from agriculture are plotted, normalized to the portion of agricultural areas within each district to take into account the different portion of agricultural areas. Especially in regions with area-independent animal processing (intensive animal production) large annual nitrogen surpluses up to more than $75 \mathrm{~kg} \mathrm{~N} /$ ha result from the animal excretions. This kind of land use management occurs mainly in the northwestern part of the Ems basin. In addition, the western sub basins of the Rhine basin, dominated by fertile loamy soils and favourable climatic conditions display 
$-90-$

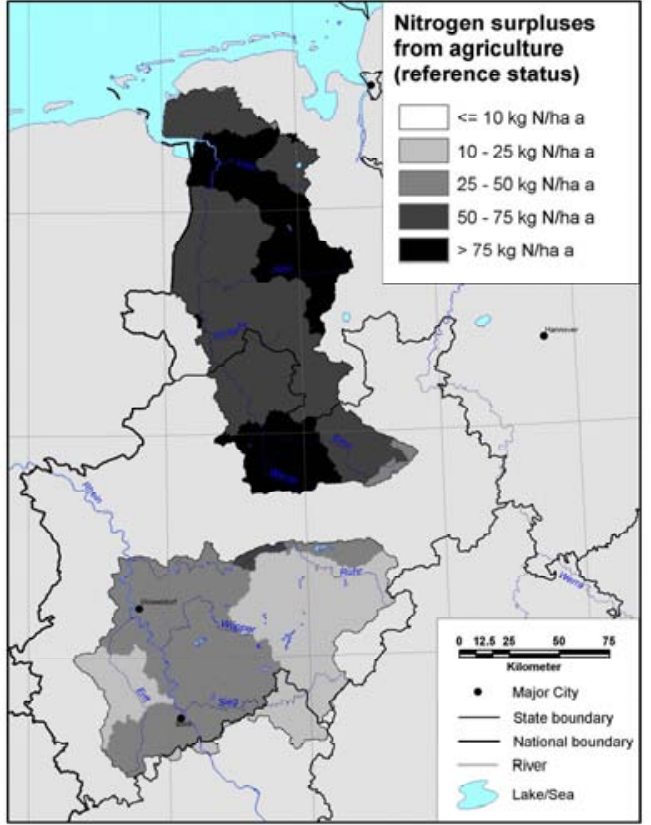

Map 1: Annual nitrogen surpluses from agriculture.

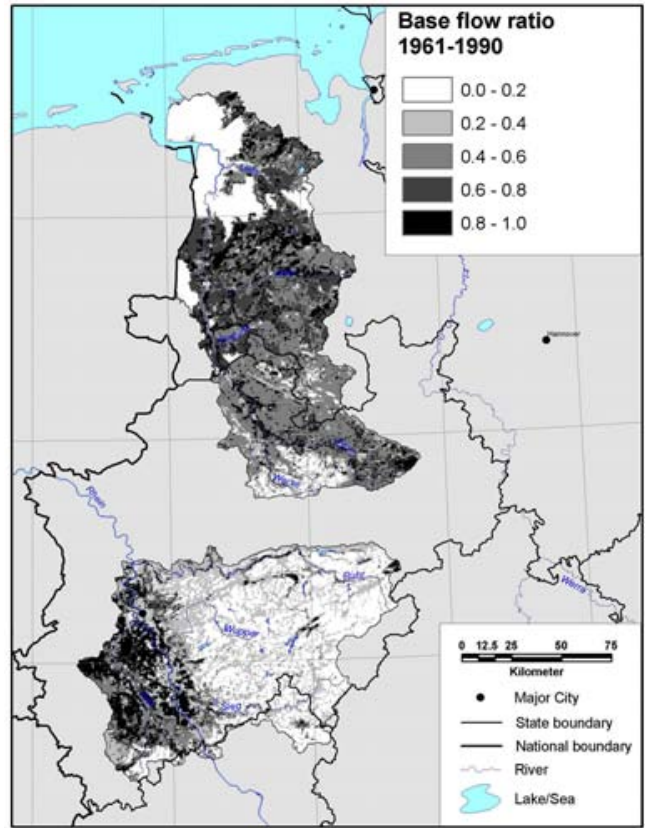

Map 2: Calculated ratio between groundwater runoff and total runoff.

significant nitrogen surpluses because of intensive growing of commercial and specialty crops. Low nitrogen surpluses are calculated for regions with mostly forage crops production, which is typical for the eastern parts of the Rhine basin.

These nitrogen surpluses from agriculture, calculated as averages on a district level, are disaggregated with respect to the current land use. In addition, atmospheric inputs as well as denitrification in the soils, which may reduce the total inputs by up to $50 \%$, have been considered. The remaining nitrogen leaching from the root zone is transported to the surface waters either by direct runoff or leaches into groundwater according to the calculated base flow ratio shown in Map 2. It becomes evident, that in some areas, e.g. the marshy regions in the north-western part of the river Ems basin or in the mountainous regions in the eastern part of the Rhine basin, groundwater runoff is not more than 20 to $40 \%$ of the total runoff. In these regions direct runoff is the dominant pathway of nitrogen input into surface waters. In other areas, e.g. the central part of the Ems basin, the base flow ratios above 0.8 indicate that groundwater runoff is the main pathway for nitrate entries into surface waters.

The results of coupling nitrogen surpluses for the reference status with water balance are shown in Map 3 and Map 4. In Map 3 the nitrate inputs into surface waters from direct runoff are shown. It has been assumed that after denitrification in the root zone no further denitrification occurs. N-inputs to surface waters from direct runoff are important especially in the marshy areas of the Ems basin and the mountainous 
$-91-$

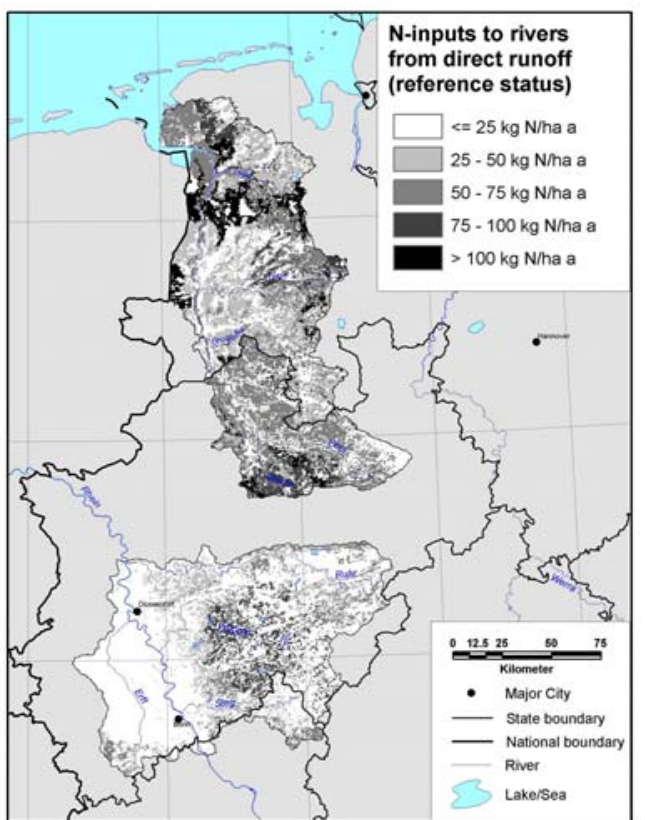

Map 3: Nitrogen inputs into surface waters from direct runoff for the reference status.

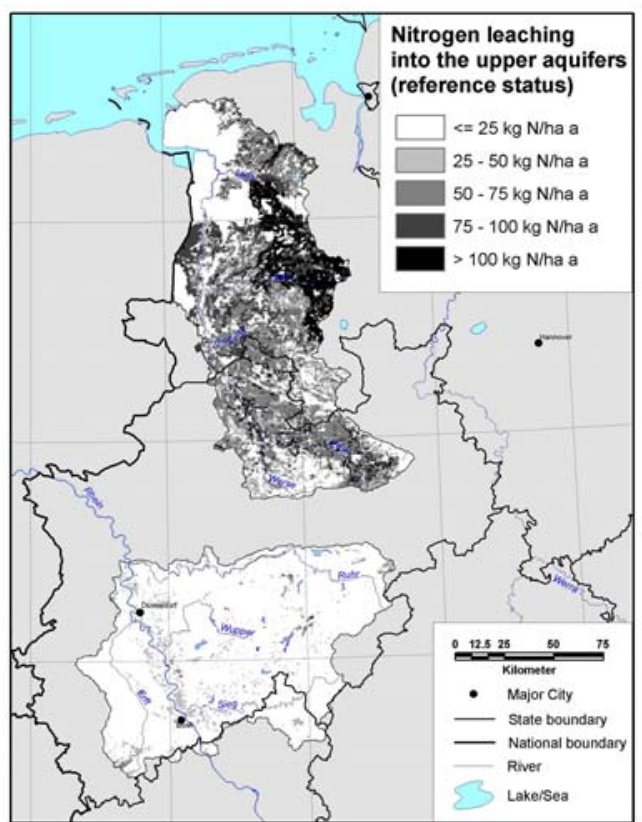

Map 4: Nitrogen leaching into the upper aquifer for the reference status.

regions in the Rhine basin, where direct runoff is the most important transport pathway for nitrogen. Map 4 shows the nitrogen inputs into the aquifer via groundwater recharge. High nitrogen leaching to the groundwater is calculated for regions with a high groundwater runoff portion and high nitrogen surpluses, which is important in particular for the central part of the Ems basin.

\subsection{Groundwater-borne Nitrogen inputs into the surface waters}

During transport through the aquifer, nitrate may be denitrified to molecular nitrogen by micro organisms. Transport and denitrification in the aquifer is calculated using the WEKU model taking into account groundwater residence times and natural nitrate degradation in the aquifers. Calculated groundwater residence times range between less than 1 year and more than 150 years. Long residence times result both from small groundwater velocities as well as from long flow paths up to the recipient, pointing at the long time periods, after which nitrate inputs into the aquifer can contribute to the pollution of surface waters in some regions. Short residence times generally result for areas in the vicinity of rivers and/or regions with high groundwater velocities.

The quantification of the parameters of denitrification kinetics in groundwater was done separately for the groundwater bearing formations occurring in the river basins. In total, about 1050 groundwater samples were evaluated and classified with respect to nitrate-degrading capacity. From this analysis the groundwater bearing formations 
$-92-$

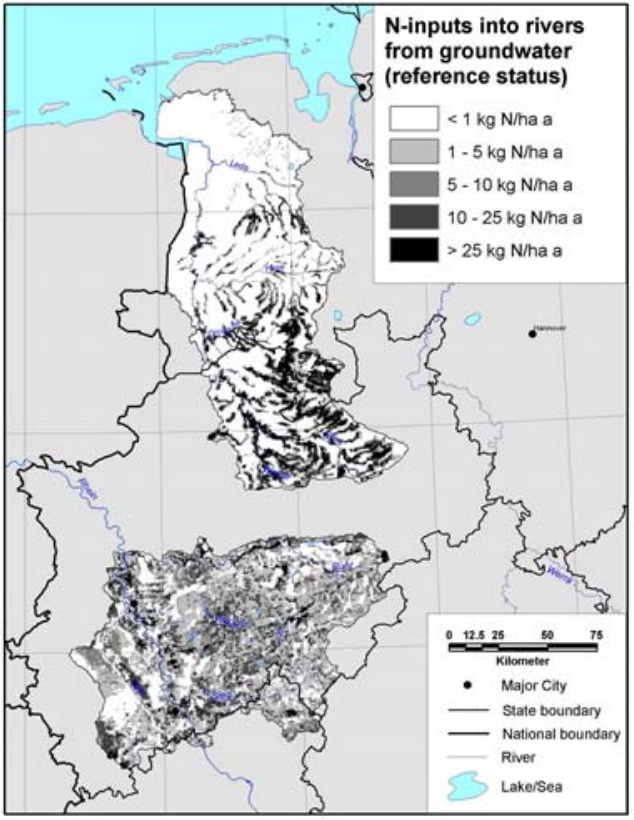

Map 5: $\mathrm{N}$-inputs to surface waters from groundwater for the reference status. glaciofluviatile sands and moraine deposits, both occurring in the river Ems basin, were classified as nitrate degrading. Most aquifers in the investigated sub basins of the river Rhine, predominantly consolidated rocks (e.g. shists and limestones), showed instead usually non-nitrate degrading conditions.

The remaining nitrogen outputs to surface waters from groundwater were calculated by combining the N-leaching into the aquifers and the reactive $\mathrm{N}$ transport in the aquifers. The result is shown for the reference status in Map 5 for the initial cells for which the inputs into the soil have been calculated. It can be seen that nitrogen intakes in the vicinity of surface waters and high nitrogen leaching levels contribute considerably to the groundwater-borne nitrate inputs to the surface waters.

Even with good conditions for a complete degradation of nitrate in the aquifer, the brief residence times are not sufficient for an adequate degradation of high nitrate inputs. There is, furthermore, a hazard potential in many regions where high nitrate inputs are associated with relatively short residence times of the groundwater, as well as restricted and/or insignificant degradation conditions in the aquifer. These regions include almost the whole Rhine catchment area. The loose rock aquifers in the northern part of the Ems basin show an opposite behaviour. There, even high nitrogen inputs into the groundwater systems result only in very slight nitrate inputs to surface waters after transport through the aquifers. The, as a rule, long groundwater residence times and good denitrification conditions cause high denitrification of up to $99 \%$ of the inputs into the aquifer systems. As a consequence, groundwater is almost nitrate-free when it enters the rivers after transport through the aquifer systems.

The validity of the model results was checked according to the procedure described in [7]. The modelled groundwater-borne nitrogen inputs into surface waters have been compared to the observed nitrogen concentrations in rivers at low flow conditions and at temperatures below $5^{\circ} \mathrm{C}$ to avoid effects of nutrient retention in rivers. Comparison with observed data showed a satisfactory agreement [8]. 


\subsection{Evaluation of $N$ reduction measures}

Two measures aiming at a reduction of agricultural nitrogen use have been conducted and compared to the simulation of the intakes into surface waters according to the input pathways on the basis of the nitrogen surpluses for the references status. The first scenario (Scenario 1 ) reflects to nitrogen reduction by rising a tax on the price of mineral fertilizer of $200 \%$. The implementation of a nitrogen tax has been repeatedly discussed since the mid-eighties. The second scenario (scenario 2 ) reflects on the limitation of the livestock density (LD) to not more than 1.0 livestock units (LU) per ha.

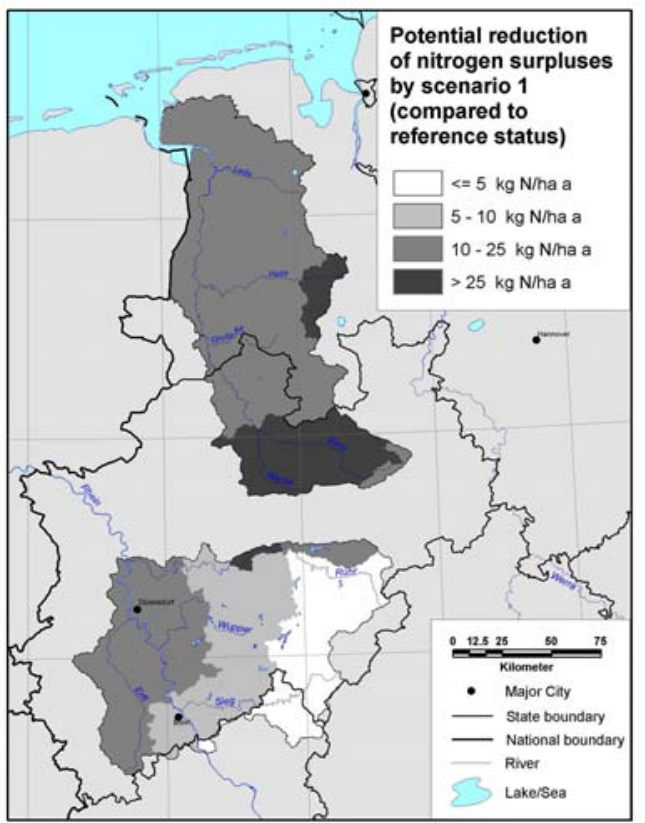

Map 6: Potential reduction of $N$ surpluses from agriculture by rising a fertilizer tax of $200 \%$ compared to the reference status.

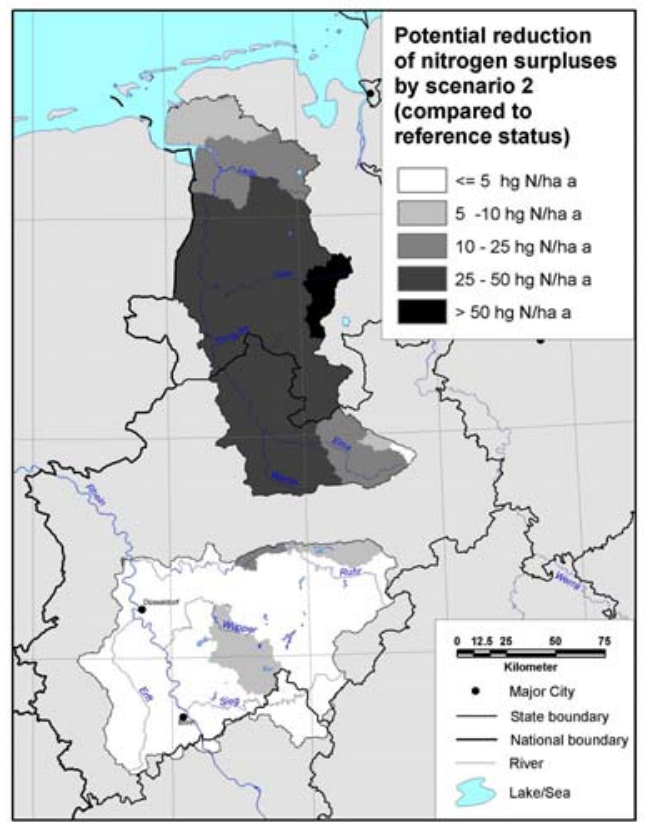

Map 7: Potential reduction of $N$ surpluses from agriculture by limitation of livestock density com-pared to the reference status

The effects of these scenarios on the potential reduction of $\mathrm{N}$-surpluses from agriculture compared to the reference status (Map 1) is shown in Map 6 and Map 7. It can be seen easily that the measures affect the nitrogen surpluses in the two selected study areas differently. The nitrogen tax (scenario 1) noticeably reduces nitrogen use in all arable farm regions such as the western part of the Rhine sub basin and the southern part of the Ems basin by at least $10 \mathrm{~kg} \mathrm{~N} / \mathrm{ha}$ a. It has a minor effect on the $\mathrm{N}$-surpluses in the central parts of the Ems basin, which are characterized by intensive animal production and the associated animal food production areas. Thus, a nitrogen tax does not mitigate the hot-spot problems since 
$-94-$

the manure supply in regions with intensive livestock production is not affected. From Map 7 it becomes clear that especially in these regions a limitation of livestock density would be much more effective, since it would lead to a potential reduction of the $\mathrm{N}$-surpluses to at least $25 \mathrm{~kg} \mathrm{~N} / \mathrm{ha}$ a. On the other hand, scenario 2 has almost no effect in regions with extensive animal production like in the major parts of the Rhine subbasins.

In Map 8 and Map 9 the effects of the implementation of a nitrogen tax on the price of mineral fertilizer (scenario 1 ) on the potential reduction of the $\mathrm{N}$-inputs into surface waters are shown compared to the reference status. It can be seen that a significant reduction of the $\mathrm{N}$-inputs to surface waters can be achieved only for the inputs from direct runoff components (see Map 8). In the Ems basin, even large $\mathrm{N}$-inputs into groundwater are denitrified to a large extent. This has the effect that potential reductions of groundwater-borne $\mathrm{N}$-inputs to surface waters are obtained only for areas in the vicinity of surface waters with incomplete nitrate reduction (see Map 9).

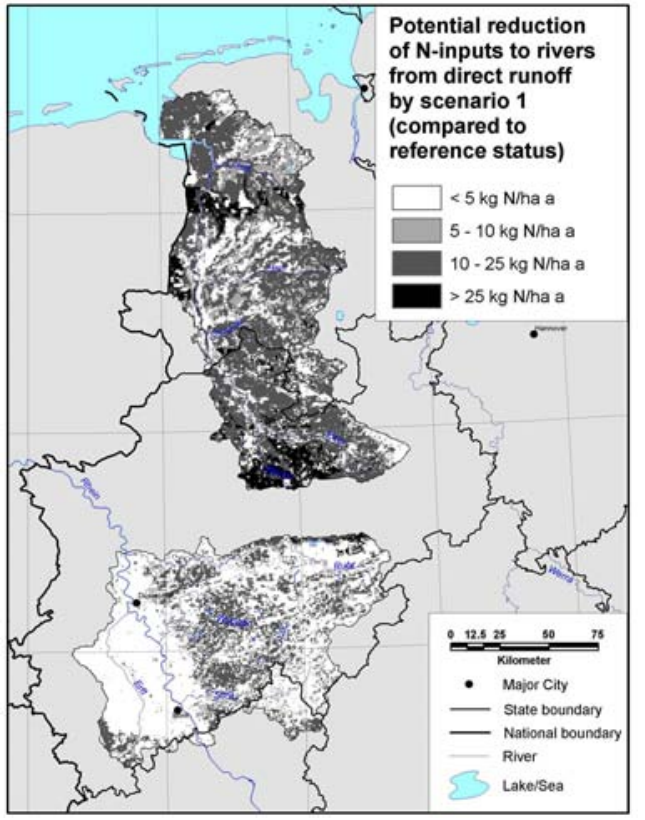

Map 8: Potential reduction of $\mathrm{N}$-inputs to rivers from direct runoff by scenario 1 compared to the reference status.

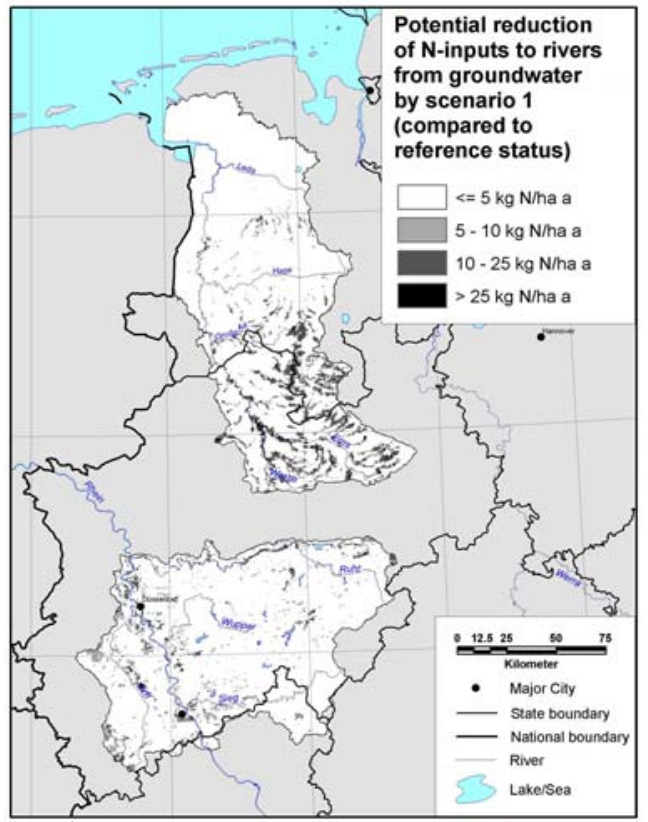

Map 9: Potential reduction of $\mathrm{N}$-inputs to rivers from groundwater runoff by scenario 1 compared to the reference status. 
$-95-$

Map 10 and Map 11 show the effects of the limitation of the livestock density (LD) to not more than 1.0 livestock units (LU) per ha (scenario 2) on the potential reduction of the $\mathrm{N}$-inputs into surface waters. On the first sight, the results seem to be quite similar, since significant $\mathrm{N}$-reductions are obtained almost exclusively for inputs from direct runoff components. These reductions, however, are much larger than in the first scenario and can amount up to $100 \mathrm{~kg} \mathrm{~N} / \mathrm{ha}$ a. Secondly, because scenario 2 affects areas with intensive animal production, significant $\mathrm{N}$-reduction can be achieved only in the Ems basin. In the Rhine sub basins almost no reduction of the $\mathrm{N}$-inputs to river can be obtained, in contrast to scenario 1 .

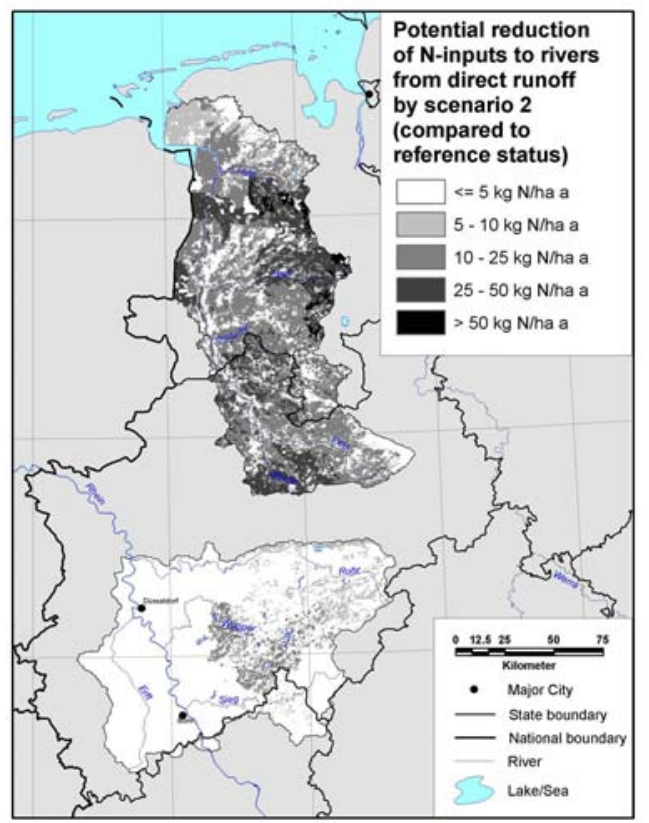

Map 10: Potential reduction of $\mathrm{N}$-inputs to rivers from direct runoff by scenario 2 compared to the reference status.

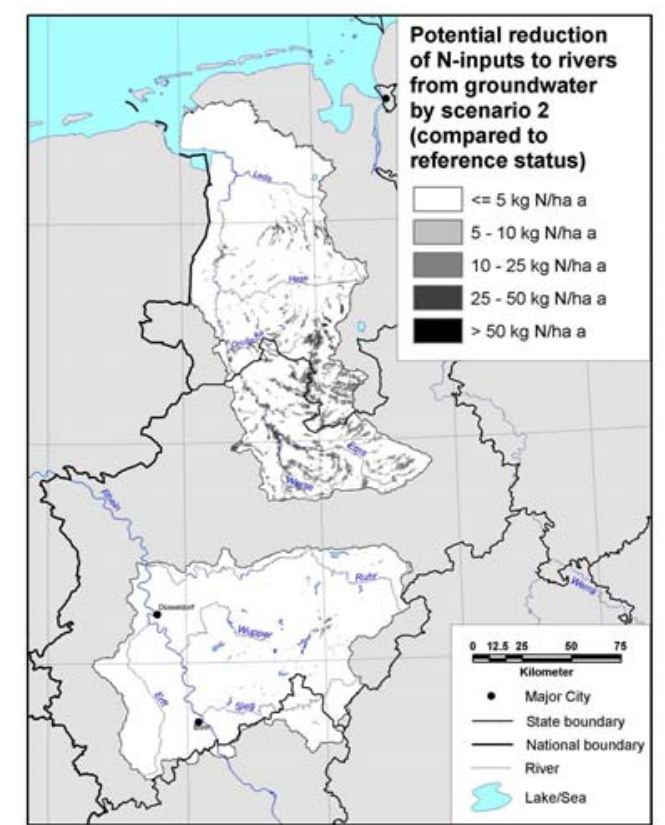

Map 11: Potential reduction of $\mathrm{N}$-inputs to rivers from groundwater runoff by scenario 2 compared to the reference status.

\section{Conclusions and Outlook}

In Germany, the water pollution caused by diffuse nitrogen from agriculture are regionally different. Using the nitrogen surpluses as an indicator to detect or classify "hot-spot" regions, the Ems catchment seems to be quite endangered by N-inputs from agriculture. However, a direct inference from the risk indicator "nitrogen surplus" being calculated with the agricultural sector model RAUMIS to actual depositions of 
$-96-$

nitrogen into water bodies is limited since natural site conditions (e.g. nitrogen degradation capacities, residence times, etc.) vary considerably among regions.

These natural conditions are accounted for in the hydrological and hydrogeological models GROWA and WEKU, which were used to quantify the nitrogen inputs into the surface waters from the different transport pathways. From the results of this study we conclude that in the groundwater systems of the river Ems basin about $90 \%$ of the diffuse nitrogen input into the ground water is degraded in groundwater due to long ground water residence time and favourable denitrification conditions. There, groundwater borne nitrate input into the surface waters turned out to be relatively low even if the region were addressed as a "hot-spot" in terms of total nitrogen surplus from agriculture.

The agricultural policy impact analysis pointed out that nitrogen reduction measures affect the regional nitrogen use differently. In particular, the investigated effects of a tax on mineral nitrogen or a limitation of the regional livestock density highlight that the mitigation of the diffuse water pollution problems require regionally tailored measures. However, it could also be shown that in areas where natural degradations capacities are missing only very drastic measures lead to a significant improvement of the nitrogen load of surface waters.

The coupling of the agro-economic model RAUMIS with the hydro(geo)logic models GROWA and WEKU has shown, that the very complex interactions between the driving-Force indicator "diffuse nitrogen surpluses" and the state indicators "nitrogen loads in surface waters and groundwater" can be analysed in a consistent and regionally differentiated way. The synergetic effects shows the potential of interdisciplinary model networks for the implementation of political measures aiming at the sustainable management of nitrogen fluxes in river basins.

\section{References}

[1] Goemann, H., Kreins, P., Møller, Ch. \& Wendland, F. (2003): Management of Regional German River Catchments (REGFLUD) - General conditions and policy options on diffuse pollution by agriculture of the river Rhine and Ems. In: Proceedings of the Conference on Diffuse Pollution and Basin Management, Dublin 2003.

[2] Henrichsmeyer, W. et al. (1996): Development of the German Agricultural Sector Model RAUMIS96. Final Report of the Cooperation-Project. Research Report for the BMELF (94 HS 021), unpublished, Bonn/Braunschweig.

[3] Kunkel, R. and F. Wendland (2002):, The GROWA98 model for water balance analysis in large river basins - the river Elbe case study. Journal of Hydrology 259, 152-162. 
$-97-$

[4] Köhne Ch. \& Wendland, F. (1992): Modellgestützte Berechnung des mikrobiellen Nitratabbaus im Boden, Internal Report, KFA-STE-IB 1/92, Research Centre Jülich.

[5] Kunkel, R. \& Wendland, F. (1997). WEKU-a GIS supported stochastic model of groundwater residence times in upper aquifers for the supraregional groundwater management. Envir. Geol., 30(1/2), 1-9.

[6] Wendland, F. and R. Kunkel (1999), Das Nitratabbauvermögen im Grundwasser des Elbeeinzugsgebietes. Schriften des FZ Jülich, Reihe Umwelt/Environment 13, Jülich.

[7] Behrendt, H., Huber, P., Kornmilch, M., Opitz, D., Schmoll, O., Scholz, G. \& Uebe, R. (2000): Nutrient balances of German river basins. UBA-Texte, 23/2000, $261 \mathrm{p}$.

[8] Wendland, F., Bach, M., Behrendt, H. \& Kunkel R. (2002): Integrated modelling of groundwater-borne nitrate intakes into the river Elbe basin (German part). Proceedings of the 9th International Specialized Conference on River Basin Management, Edinburgh, Scotland. 



\section{Operationalisation of Sustainable Water Management in Arid and Semiarid Regions}



$-101-$

\title{
MODELLING FOR SUSTAINABLE GROUNDWATER MANAGEMENT IN ARID AND SEMIARID ENVIRONMENTS ${ }^{1}$
}

\author{
W. Kinzelbach, P. Bauer, P. Brunner and T. Siegfried \\ Institute for Hydromechanics and Water Resources Management, \\ Swiss Federal Institute of Technology \\ Zurich, Switzerland \\ kinzelbach@ihw.baug.ethz.ch
}

\begin{abstract}
Non-sustainable use of groundwater resources is a wide spread practice worldwide showing up in aquifer depletion, reduction of low flows of rivers, seawater intrusion, salination of irrigated lands and the drying up of wetlands. Urgent measures are required to bring development back on a sustainable path. As time constants of change are usually large, predictive methods are needed to evaluate management scenarios. This makes modelling an indispensable tool. As most of the globally relevant non-sustainable practices have to do with groundwater directly or indirectly, groundwater modelling plays a prominent role. A number of new methods are available which can contribute to more meaningful modelling even in regions with weak infrastructure. They include remote sensing, environmental tracers, geophysics and uncertainty analysis. To be of real use, groundwater modelling has to interface to surface water modelling, ecological modelling and economic modelling.
\end{abstract}

\section{Introduction}

Freshwater is a scarce resource on a worldwide basis. This becomes apparent when looking at the basic items of the global freshwater balance, e.g. [1]. Of the 110,000 $\mathrm{km}^{3} / \mathrm{a}$ of precipitation on the landmass of the earth, 50,000 are returned to the atmosphere via evapotranspiration by the planet's natural plant cover. Another 21,000 are used by man-made ecosystems $\left(18,000 \mathrm{~km}^{3} / \mathrm{a}\right.$ by rain fed agriculture including pastures and $3,000 \mathrm{~km}^{3} / \mathrm{a}$ by irrigated agriculture). This shows that agriculture is already a fierce competitor of nature for the available freshwater. Of the accessible runoff of $13,000 \mathrm{~km}^{3} / \mathrm{a}$ about 4,000 are appropriated by mankind. $70 \%$ of those go into irrigated agriculture. This means that a global water crisis would above all be a global crisis in food production. Compared to the $13,000 \mathrm{~km}^{3} / \mathrm{a}$ available, the abstracted 4,000 appear small. One should, however, not forget that these figures are averaged in time and space and therefore hide the real problem, e.g. droughts and floods. One can still use the ratio a of withdrawals and available renewable resources as an indicator if one takes into account the variability of the available

\footnotetext{
${ }^{1}$ Invited Talk given at the FEM-MODFLOW conference, Karlsbad, September 13-16, 2004
} 
resource in space and time. Due to this variability of the quantities involved, it is the experience that a value of $a>0.4$ already reflects severe scarcity [2]. On a global scale we find $a=0.31$. This indicates that scarcity on a global level is a reality today, with the arid world already experiencing very severe scarcity problems.

\section{Sustainability}

Sustainable water management is a practice, which avoids irreversible or quasiirreversible damage to the resource water and other natural resources linked to it, such as soil and ecosystems. Such a practice conserves the ability of the resource water to provide its services including ecological services. Water scarcity and poverty are usually the causes of non-sustainable behaviour as they lead to overexploitation and depletion of stocks.

What are the relevant issues for global sustainability in the water sector? To identify big and possibly existential problems for whole regions we have to look for ubiquitous negative global trends. In that sense there are a number of nonsustainable practices, which are of global importance. Above all, these are

- the overpumping of aquifers

- the reduction of low flows of rivers,

- the destruction of wetlands,

- the salination of soils, and

- the pollution of aquifers with persistent pollutants.

Globally about $800 \mathrm{~km} 3 / \mathrm{a}$ of freshwater are abstracted from aquifers. About one quarter of this abstraction is non-sustainable in the sense that it is not replaced by recharge, i.e. it is provided by reducing the available stock. On the Arabian Peninsula, in North Africa, China and the arid Western United States for example, abstractions for large-scale irrigation have withdrawn large quantities of fossil water, which under present climatic conditions are not replenished any more.

Due to consumptive use in irrigation in the upper reaches of large river basins the low flows in the lower reaches have been considerably diminished. Even large rivers such as the Yellow river in China have become ephemeral rivers. In recent years the Yellow river has not been flowing for more than 100 days in a year over a stretch of more than $200 \mathrm{~km}$ length. The precarious shift in availability from the downstream to the upstream is harbouring many severe future conflicts.

A related issue is the fate of wetlands. The global area of wetlands has diminished by $50 \%$ since the year 1900 . This has a severe impact on species diversity. It is a consequence of the expansion of man-made ecosystems at the cost of natural ecosystems both with respect to land and water resources. 
Of the 260 million ha of irrigated farmland in the world about 80 million are affected by soil salination. Salination is a common phenomenon in hot climates. It occurs if in a soil more salt is deposited by evapotranspiration than is removed by drainage. In irrigated agriculture, the most common mechanism of salination is triggered by the groundwater table rise due to seepage of irrigation water. Once a groundwater table is closer than about $2 \mathrm{~m}$ to ground level, capillary rise leads to direct evaporation of groundwater and to fast salination of the topsoil.

Finally, there is the deterioration of groundwater quality by persistent pollutants. One might expect that among those chlorinated hydrocarbons are the most important. This is only true for industrialized countries, while globally the most prominent pollutant is salt, especially in arid regions and coastal areas, where seawater intrusion occurs.

In principle, all these violations of sustainability are reversible. But the required timescales are on the order of several generations. For all practical purposes these damages are therefore irreversible.

The following three examples illustrate the three globally important sustainability problems related to groundwater. The common features of these examples are that

- there is water scarcity (all three areas are in arid or semi-arid climate zones),

- a model is developed to analyze and understand the system,

- the model is used for the testing of management strategies and/or for optimization, and finally

- the connection is made to the social and economic issues.

\section{Overpumping of the North-West Sahara Aquifer System}

The North Western Sahara is underlain by an aquifer system, which is twice the size of France and consists of two major aquifers, the deeper "Continental Intercalaire" (CI) and the shallower "Complexe Terminal" (CT) (Figure 1). Their water resources serve three countries: Algeria, Tunisia and Libya. The system nowadays hardly receives any recharge. At most $30 \mathrm{~m}^{3} / \mathrm{s}$ are estimated as recharge along the Atlas where the aquifers strike out. Compared to the size of the system, this recharge flux is - if at all - only of local importance. The system discharges mainly via the sink of the Chotts or salt lakes, which are the topographic lows of the endorheic basin and the end points of groundwater flow. Here approximately $10 \mathrm{~m}^{3} / \mathrm{s}$ evaporate. A very small portion of no more than $5 \mathrm{~m}^{3} / \mathrm{s}$ is thought to discharge to the sea in Libya. 
$-104-$

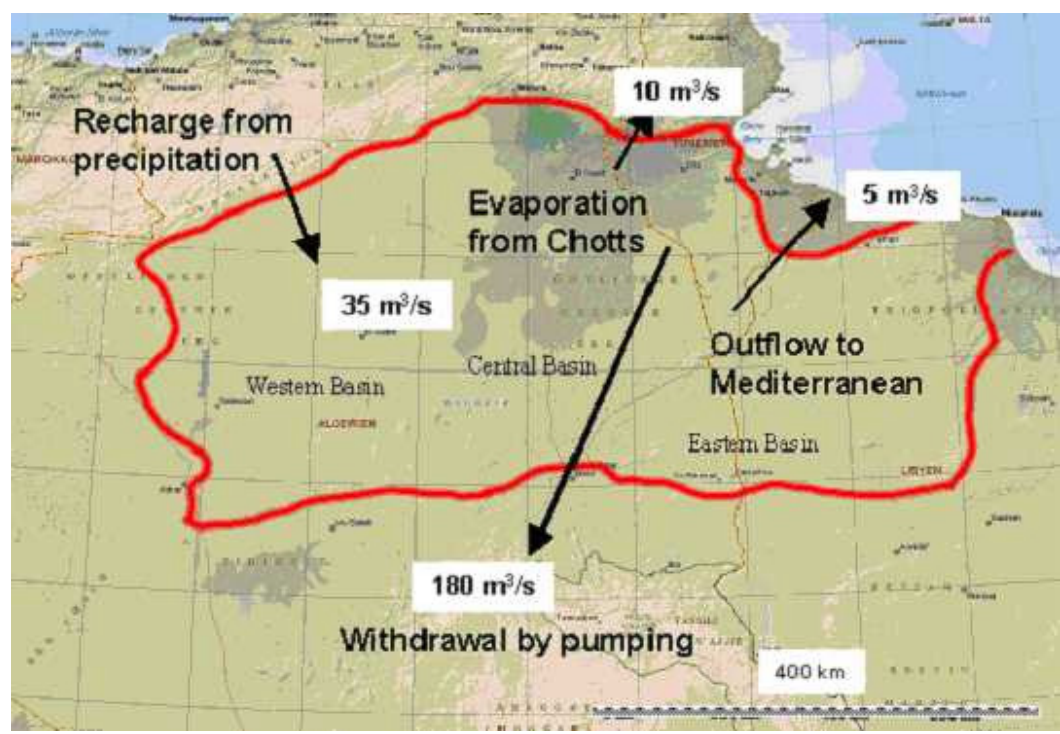

Figure 1: Location of the North-Western Sahara Aquifer System and its water balance [3].

Until 1950 abstractions were small. Since then the population has tripled and with it the amount of water pumped for irrigation. An estimated rate of $180 \mathrm{~m}^{3} / \mathrm{s}$ is abstracted today. As a consequence the large springs in the vicinity of the Chotts have run dry (Figure 2). Artesianism has vanished over large areas and the water, which before flowed at no energy cost, now has to be pumped.

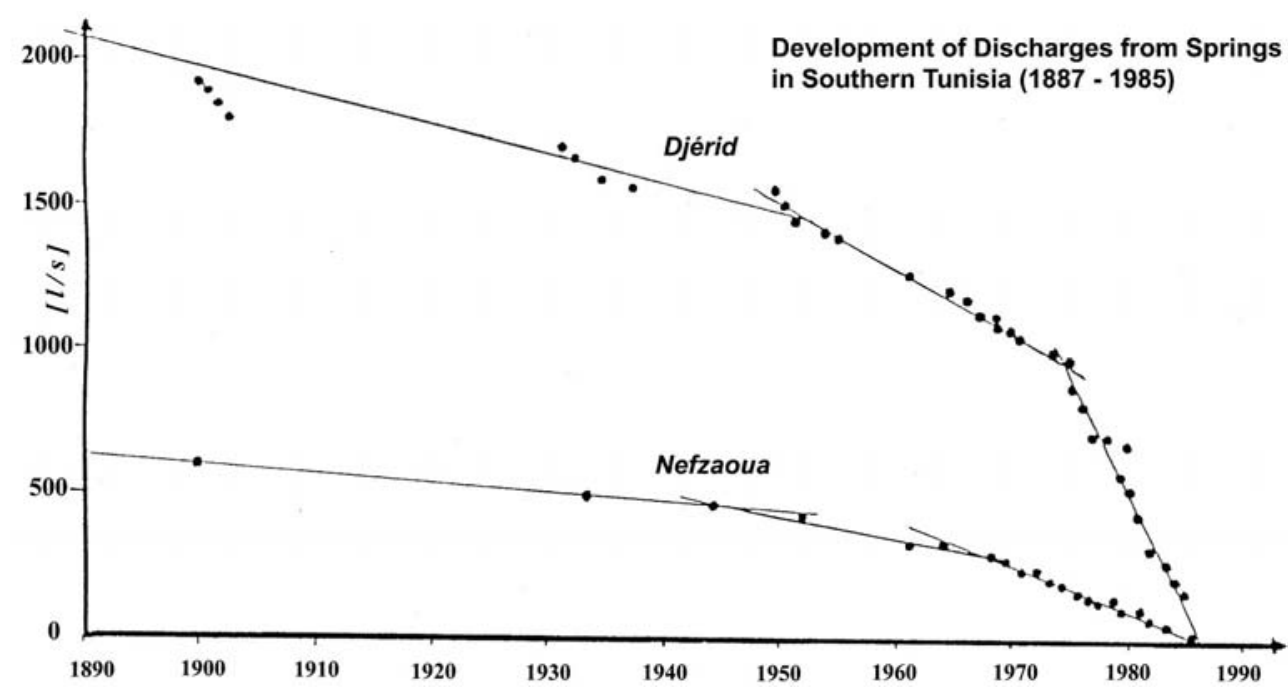

Figure 2: Development of discharges from two springs in Southern Tunisia (1887-1985) [4]. 
$-105-$

The present situation is characterized by an abstraction, which is 6 times as large as the recharge rate. This brings up the question whether a non-renewable resource should be used at all. Looking at the size of the system and its storage coefficient, an enormous amount of about $100,000 \mathrm{~km}^{3}$ of water is stored. About one tenth of that amount can be accessed with an economically feasible drawdown of less than $250 \mathrm{~m}$. With a projected future withdrawal rate of $500 \mathrm{~m}^{3} / \mathrm{s}$ the total resource can still last for about 600 years. But this water comes at a price.

First, energy is necessary for its pumping and distribution and investments in pipes and boreholes have to be made. Second, pumping can lead to deterioration of water quality. Sources of pollution are various. Near the Chotts for example, large drawdowns will reverse the groundwater flow, which under natural conditions is always directed from the oases to the Chotts. A reversed gradient mobilizes brine, which finally leads to degradation of the water quality pumped and contributes to the die-off of oases. A similar phenomenon is observed along the coast, where overpumping leads to seawater intrusion. Salt water can also be mobilized from underlying saline aquifers such as the Turonian. With a reduced pressure overburden this confined aquifer can infiltrate at a larger rate into the $\mathrm{CT}$ from below.

A numerical model of the system has been built which demonstrates that with the required total pumping rate by 2050 large areas of the presently strongly pumped regions will face a piezometric decline with economically infeasible drawdowns of more than $250 \mathrm{~m}$ below ground level (compare red areas in Figure 4 to Figure 3).

At the same time the constraints for water quality locally can no longer be fulfilled. The groundwater model was then coupled with genetic optimization algorithms to find allocation patterns that conform to demand, drawdown and quality constraints in time while minimizing overall provision costs [5]. The wells in an optimal scheme spread out over the area to equalize drawdown while increasing distribution cost. They further spread to the $\mathrm{Cl}$ from the CT.

Finally it is noticed that well fields tend to work in tandems with one field recovering while another is pumped and vice versa. With optimization the cost increase cannot be avoided but strongly diminished. The model demonstrates that it is possible to minimize pumping cost to reasonable levels and provide water for the next 50 years. This time however must be used to develop alternatives based on water saving irrigation, replacement of agricultural activities by other economic activities and even resettling of people. All optimization runs were carried out ignoring national borders in order to utilize benefits from cooperative management. As the results demonstrate, cooperation between the three countries involved brings considerable advantage in the exploitation of the resource. In the long run the conservation of the oasis culture requires heavy subsidies as the substitution between the production factors water and capital progresses. 
$-106-$

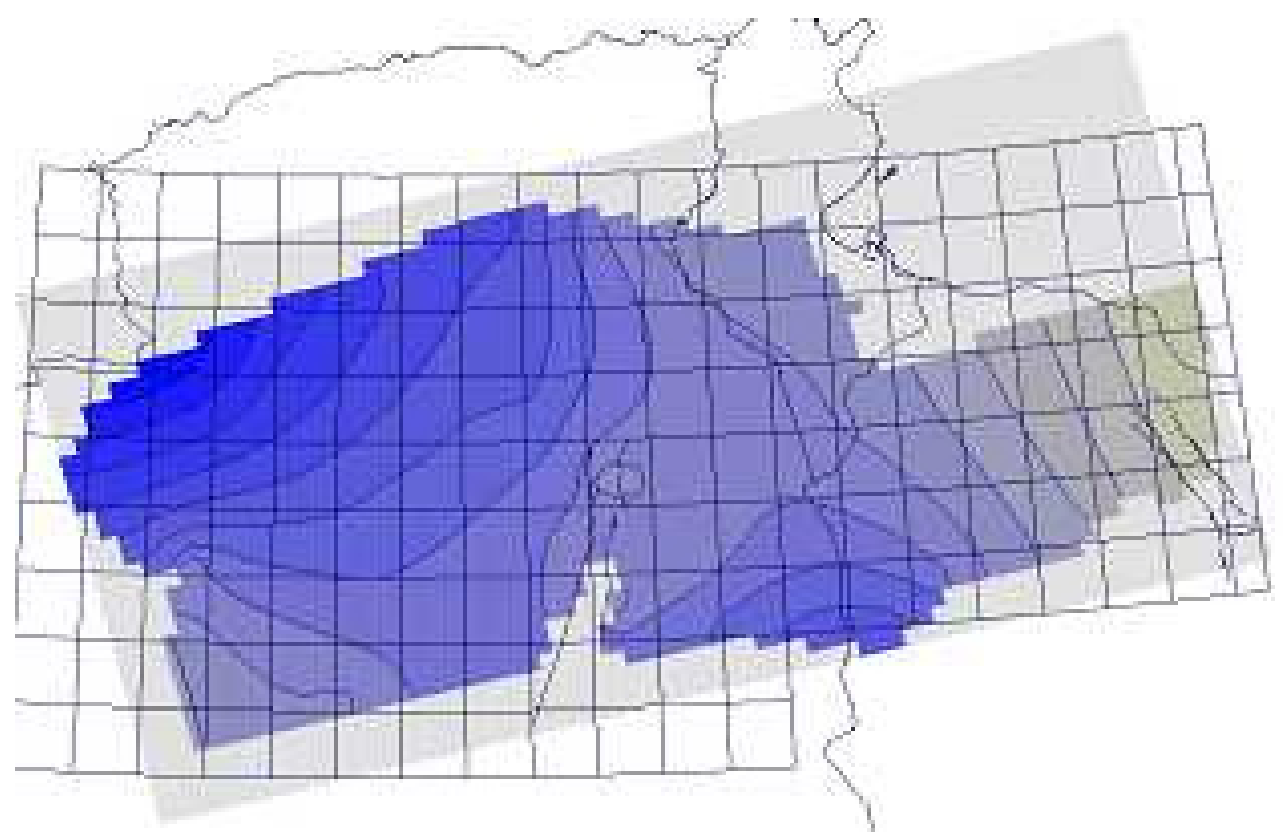

Figure 3: Modelled head distribution in Cl, 1950 (head contours from 530 mamsl (blue) to 70 mamsl (yellow) in steps of $35 \mathrm{~m}$ ).

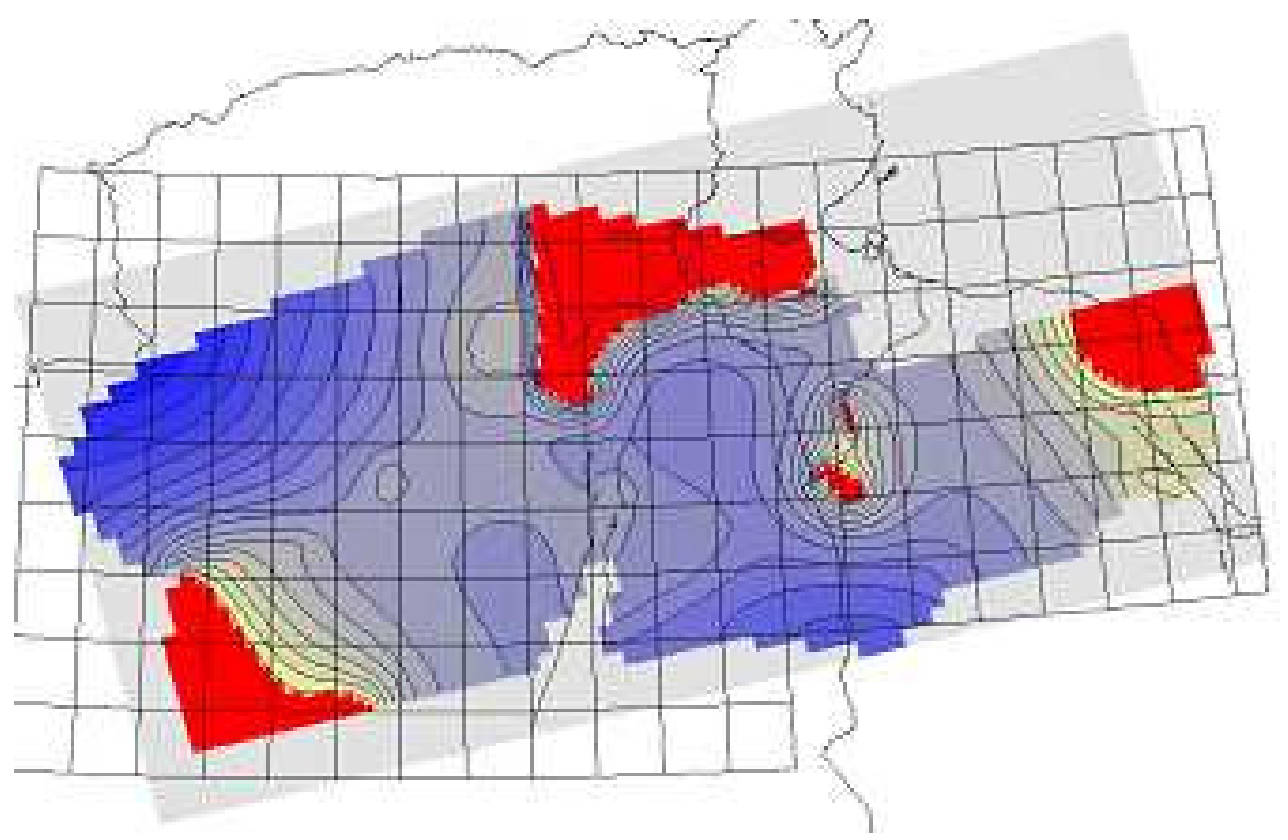

Figure 4: Predicted head distribution in Cl, 2050 for planned pumping (head contours from 530 mamsl (blue) to -250 mamsl (red) in steps of $55 \mathrm{~m}$ ). 


\section{Management of the Okavango Delta, Botswana}

The Okavango river flows from the Benguela plateau of Southern Angola in southeastern direction through the northern tip of Namibia and then into Botswana, where it forms an inland delta in which it is consumed completely by evapotranspiration (Figure 5). The delta is one of the largest wildlife areas in Africa and is an attraction for numerous tourists. The yearly floods of the river turn a large area of the delta into a seasonal swamp [5-12].

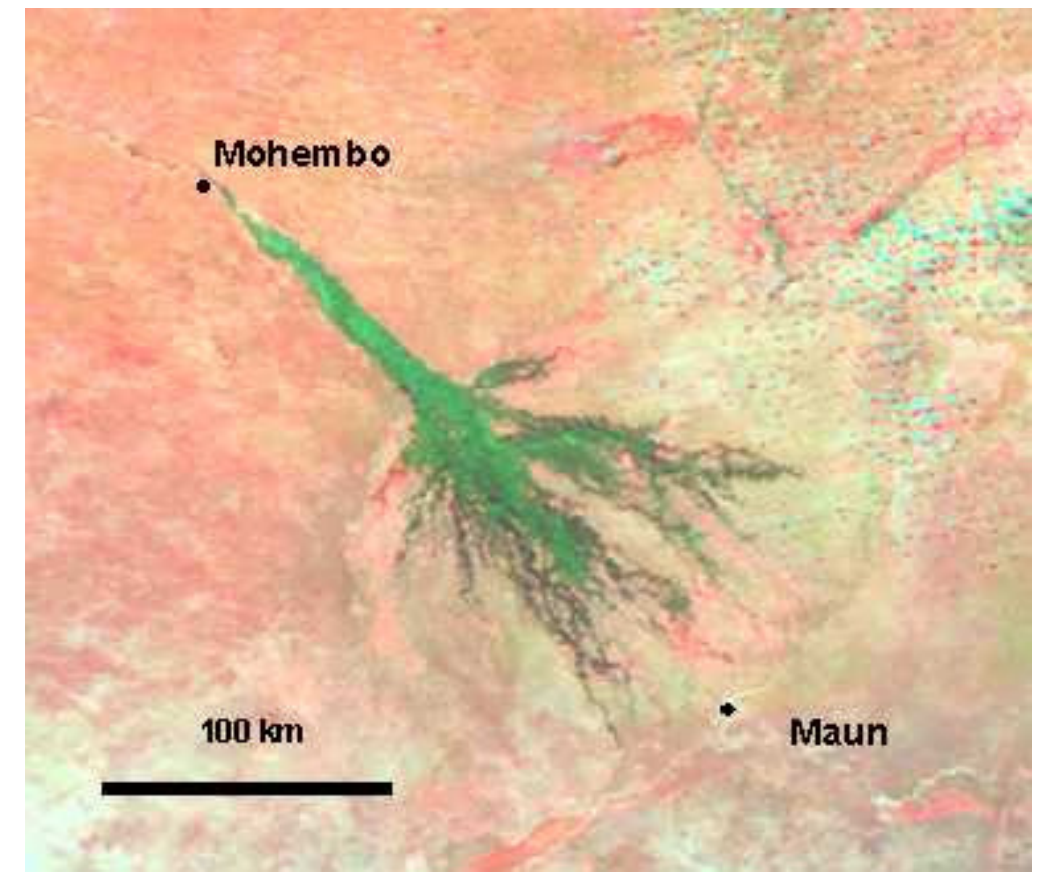

Figure 5: Satellite image of the Okavango Delta (Green: Flooded area in July 1999).

As the flood takes 3 months to propagate from the inflow at Mohembo to the distal side at Maun, it is out of phase with the local rainy season and thus increases the water availability over the year. The upstream countries are discussing plans to abstract water from the river and build dams for electricity production or agricultural purposes. In Botswana itself, various sectors of the economy have also proposed to make use of the Okavango water, be it for agriculture or for mining purposes. All measures proposed threaten the existence of the delta as the unique ecosystem it is. Both abstraction of water in the upstream and acceleration of the through-flow e.g. by dredging of channels will cause a decrease in the size of the seasonal swamp. In order to assess the impact of hydraulic measures on the size and distribution of the flooded area a numerical model was constructed [13-14], which contains both the 
$-108-$

surface water and the groundwater in two separate layers, the boundary between the two being the topography. The surface water flow is calculated with the DarcyWeissbach flow law, while in the groundwater layer and in strongly overgrown swamp the Darcy law is applied. The average water table over a cell determines whether the cell is flooded and thus transporting surface water. The exchange with groundwater is essential as the groundwater supporting the trees on the islands is supplied via infiltration of surface water. In an innovative approach satellite data on the time-varying size of the delta were used to calibrate the model.

Further data used in this approach are a high-resolution digital terrain model obtained from the flooding patterns and the related vegetation patterns, the inflow at Mohembo, the precipitation from METEOSAT data, the evapotranspiration from multi-spectral satellite data, and last not least local measurements which are routinely performed by the Botswana Department of Water Affairs. The model is able to reproduce satisfactorily the seasonal dynamics of the flooded areas both in total extent and in distribution over a period of 20 years for which data are available (Figure 6). The sink of all water is essentially the evapotranspiration by the plant cover. This process also governs the distribution of salts in the delta. Pronounced salt crusts indicate areas, which are natural disposal sites of salts. Their continued functioning is of considerable importance to the conservation of the delta. This process will be incorporated in a future version of the model.

One example of measures with potentially serious impacts on the delta is the abstraction of water upstream of the inflow (Figure 7). The natural variation of the delta's flooded area (black line) is governed by the yearly flood and longer term drought cycles. It is seen that the effect of an abstraction is amplified i.e. the relative reduction in area is considerably larger than the relative reduction in inflow. The reduction of flooded area by abstractions stays still smaller than the natural variation of flooded area. But the frequency of events with extremely small areal extents (say below $3000 \mathrm{~km}^{2}$ ) is strongly increased. Dams have an effect on both inflow reduction and temporal inflow distribution.

Model calculations showed that the change in input distribution not necessarily is detrimental to the size of the flooded area. A more stretched out flood will bring water further downstream. Morphological changes such as dredging of channels and removal of blockages by papyrus have also a pronounced effect, not so much on the total flooded area as on the distribution of flooded areas within the delta. The local abstraction for household consumption, be it directly or from the aquifer, is so small that it will at no stage be of relevance for the delta. The tentative ranking of different interventions according to their severity is as follows:

- abstractions larger than $20 \mathrm{~m}^{3} / \mathrm{s}$ in the upstream,

- building of large dams in the upstream,

- morphological changes (dredging, cutting of vegetation),

- local drinking water supply. 

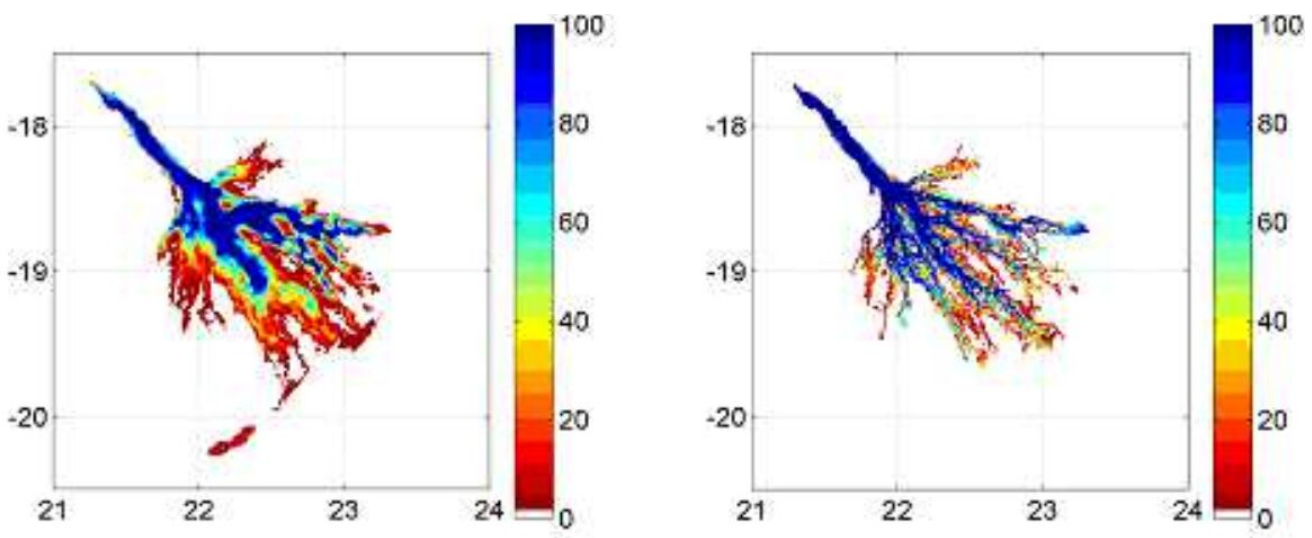

Figure 6: Observed and modelled flooding frequency (\%).

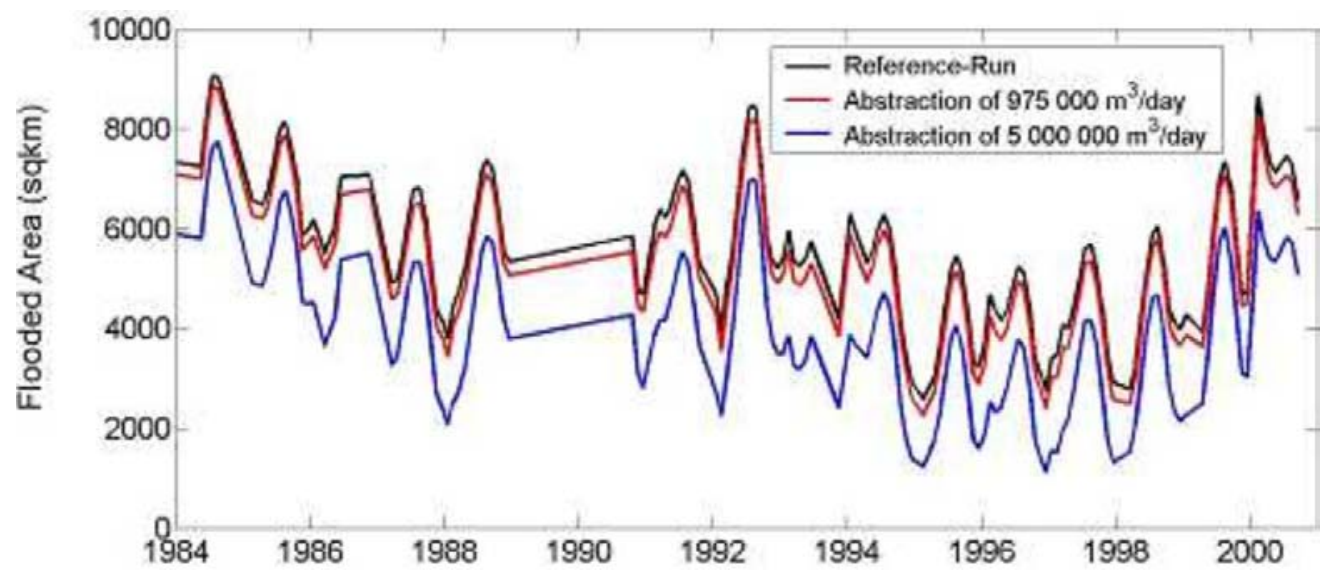

Figure 7: Temporal development of swamp area for two different abstraction scenarios $(0.975$ Mio. $\mathrm{m}^{3} / \mathrm{d}$ and $3 \mathrm{Mio} \mathrm{m}^{3} / \mathrm{d}$ ) in comparison with the modelled natural development of the last 20 years.

The model can provide a quantitative basis for the political debate between the three riparian nations. It is clear that the conservation of the delta must bring some revenue to the upstream in exchange for a guaranteed inflow. The key parameter for an administrable negotiated solution will be the minimum inflow at Mohembo and the seasonal variability of inflow. 


\section{Salination of soils and water resources in Yanqi Basin, Xinjiang, China}

The third example studies a region in China's arid west. The Yanqi basin is formed by the lowlands of the Kaidu River and lake Bostan (Figure 8). The area has been used intensively for agriculture over the past 50 years. The main products are grapes, cotton and red peppers. As precipitation is only $70 \mathrm{~mm} / \mathrm{a}$ and thus negligible compared to the potential evaporation of $1800 \mathrm{~mm} / \mathrm{a}$, no agriculture is possible without irrigation. The last 50 years have seen a tremendous growth of the population. This has led to a strong increase in agricultural production. The intensive irrigation with river water caused a water table rise, followed by serious soil salination. To maintain production, over-irrigation is required to push salt from the surface beneath the root zone. This practice increases the amount of water used per unit crop and contributes again to water table rise. A vicious circle is triggered, leading to higher and higher salinity in the water flowing off the irrigation area both in the subsurface and in the drains. One could argue that the applied irrigation techniques and efficiencies in the Yanqi Basin are sustainable, as a steady state has been reached (the amount of salt transported out of the Yanqi Basin is equal to the amount of salt imported by the Kaidu) and production stabilized on a level still profitable. This of course cannot be called sustainable because only the needs of the farmers in this particular irrigation system are satisfied. With the rising groundwater table and the increased non-productive evaporation of water the salinity in the lake has increased and the lake level has fallen.

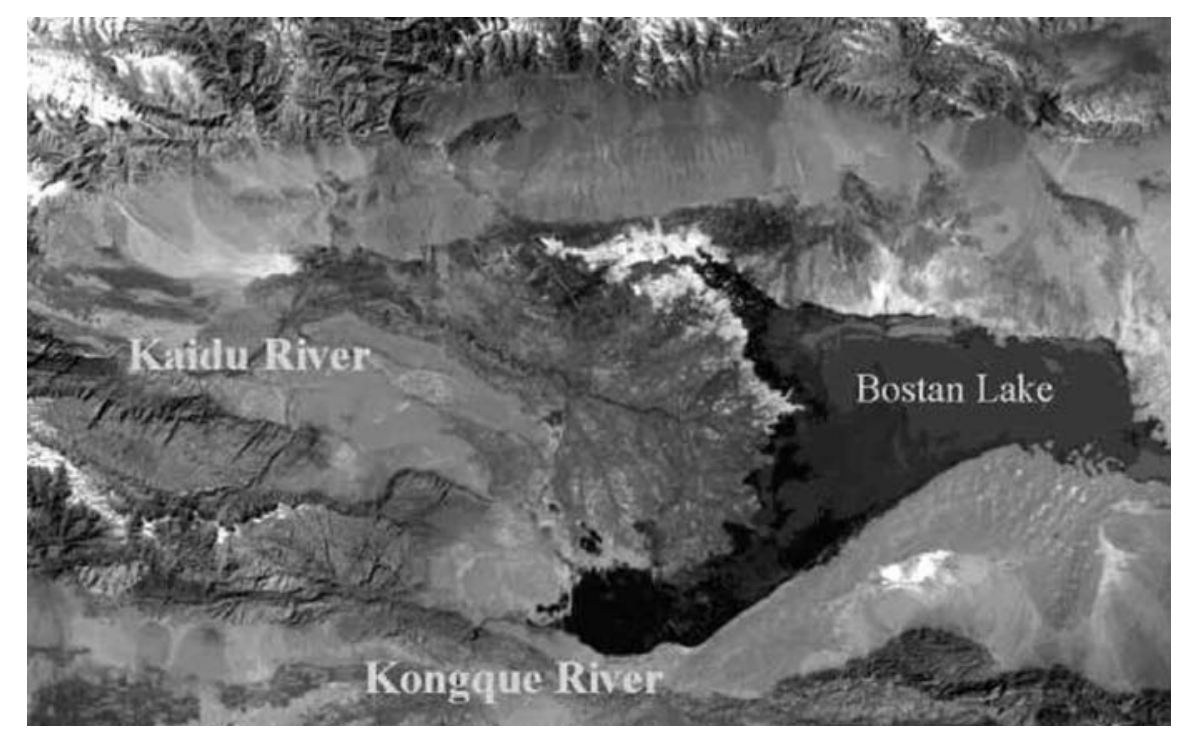

Figure 8: Satellite map of the Yanqi basin showing the irrigation areas along the Kaidu river, Lake Bostan and the Kongque river 
The amount of water available for the downstream of lake Bostan, carried by the Kongque River, has decreased thus limiting natural vegetation growth and agriculture in the so called Green Corridor. The Green Corridor is a landscape, which extends down to Lop Nor and is characterized by the riverine desert poplar forests. Today, no water reaches Lop Nor due to the high consumptive use in the upstream irrigation systems.

In order to improve the situation of the system as a whole, a number of measures in the upstream have been proposed. They include

- the reduction of the irrigation area,

- substitution of irrigation water from the river by groundwater thus guaranteeing that the groundwater table stays below critical levels,

- changes in the crop mix and irrigation techniques (e.g. drip irrigation for grapes),

- the transfer of water directly from Kaidu river to the Kongque river bypassing the lake,

- the lowering of the lake level in order to reduce non-productive evaporation of the lake and others.

In an integrated modelling approach all these options are investigated. Again, some relevant data can be obtained using remote sensing techniques. In this case we constructed a digital terrain model from stereo images of radar satellites [15]. The absolute elevations were obtained from single point DGPS measurements (Figure 9).

The ground surface elevation is of particular interest in salination problems as evaporation from groundwater is a function of the distance to groundwater table. Hence salinity observed at the ground level is a data type, which allows the regional verification of the groundwater model. The distribution of surface salinity was obtained from multispectral ASTER data and measurements in the field. Based on the spectral response of a completely salinized pixel, the closeness of any pixel to this reference is determined yielding an uncalibrated salinity map. To convert these values into salinity or its physical measure of electrical conductivity, a calibration with ground truth is required. The ground truth was obtained both by single core samples and less time-consuming geophysical measurements. A good correlation between ground truth and the uncalibrated salinity map was found (Figure 10). Of course, this correlation only holds for the non-irrigated areas. 
$-112-$

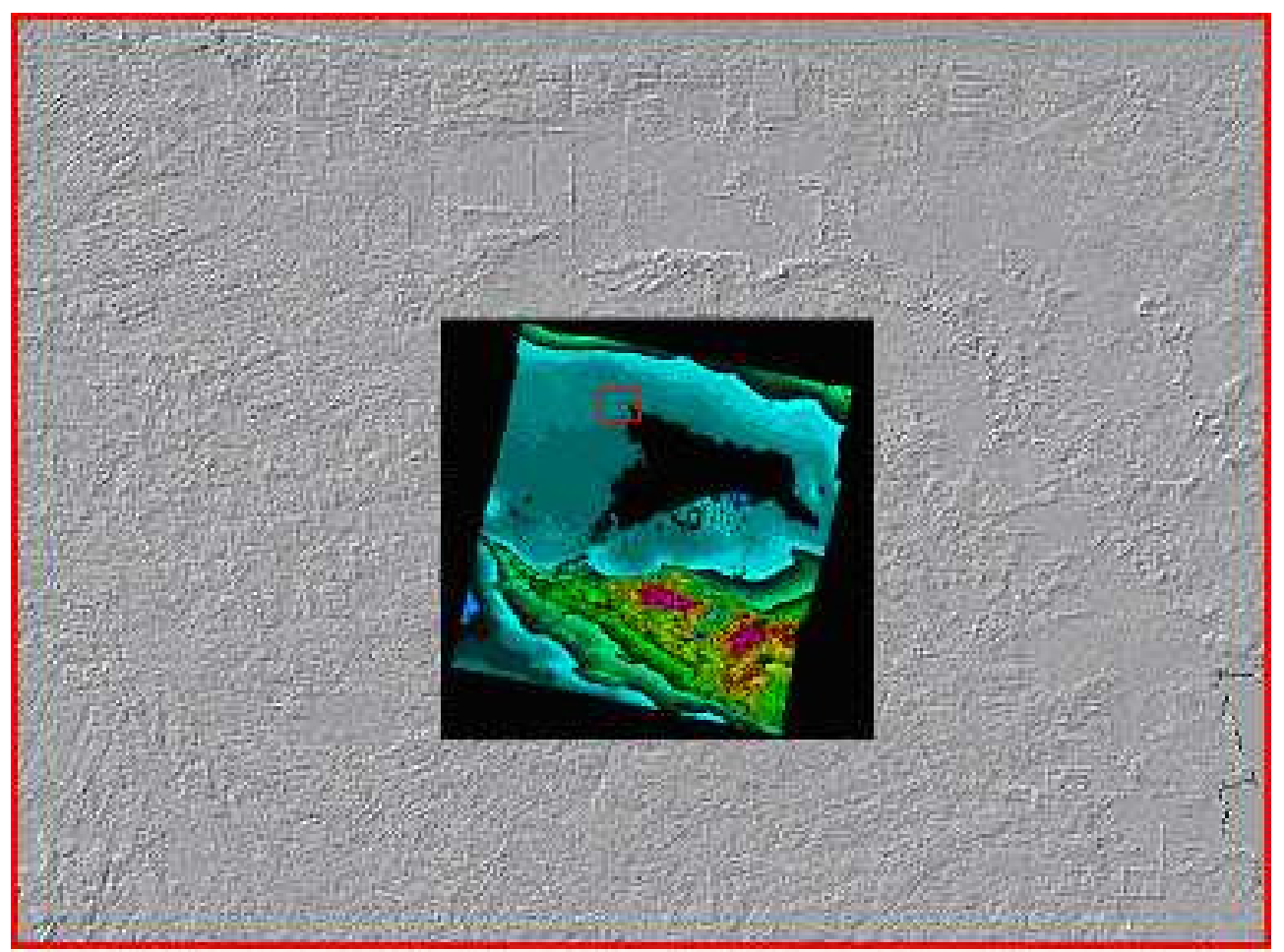

Figure 9: Digital terrain model of the Yanqi basin.

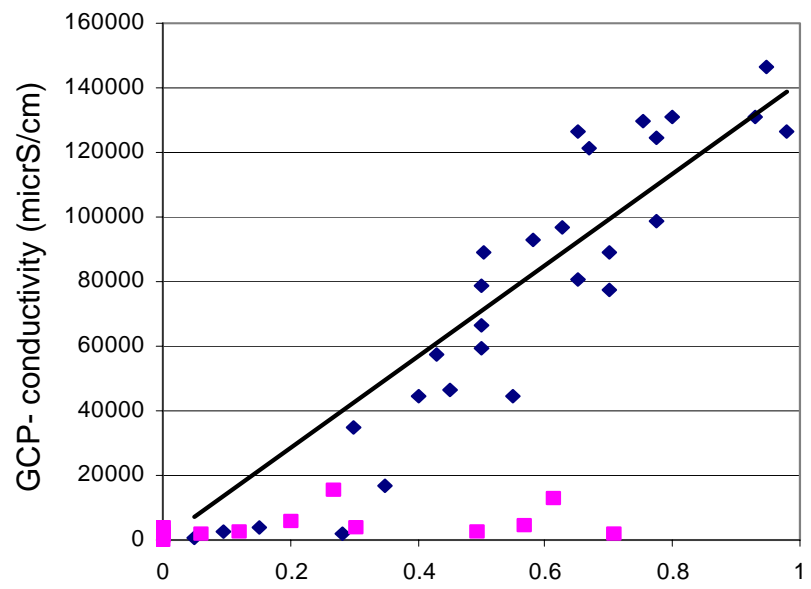

Spectral match between GCP and Referenz

Figure 10: Correlation between measurements at ground control points (GCP) of soil conductivity and spectral match to salt pixel (blue dots: non-irrigated areas, red dots irrigated fields). 
$-113-$

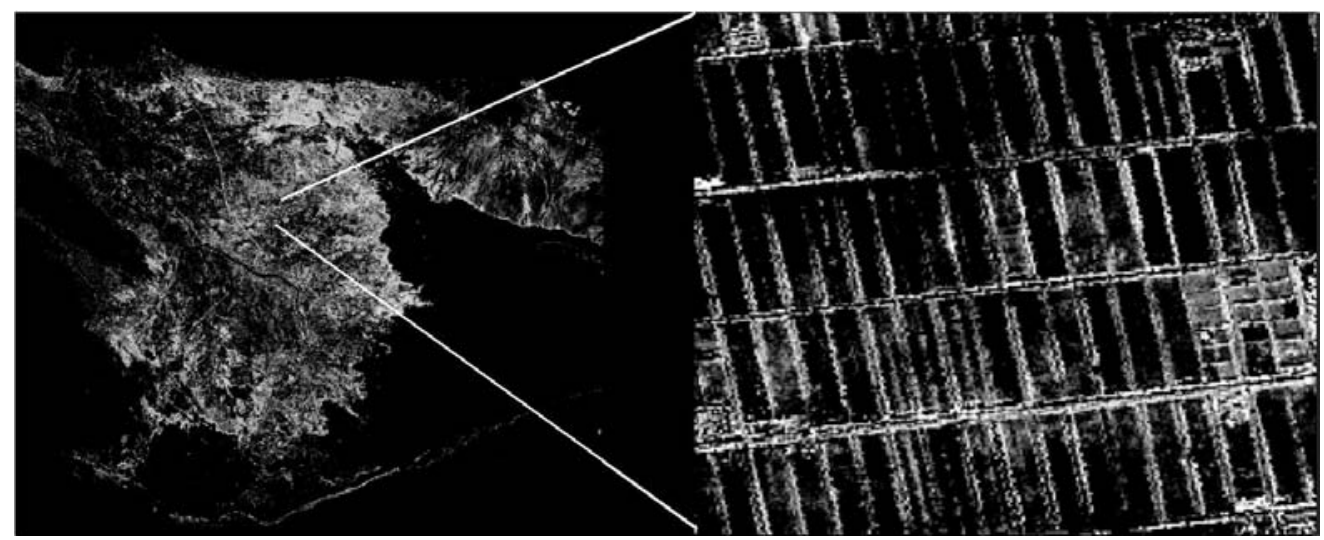

Figure 11: Salinity map obtained from a multispectral satellite image

The salinity map (Figure 11) clearly shows the salt accumulation in the paths between fields while in the irrigated fields themselves no increased salinity is visible due to over-irrigation.

While a coupled groundwater-surface water model is still under development, preliminary estimates are already available on the basis of a multi-box approach with the irrigation area, the aquifer and the lake being the respective boxes. Despite the fact that the box approach is a major simplification, it demonstrates that steady states for groundwater tables as well as salt concentration exist. The long term average water balance is shown in Figure 12 .

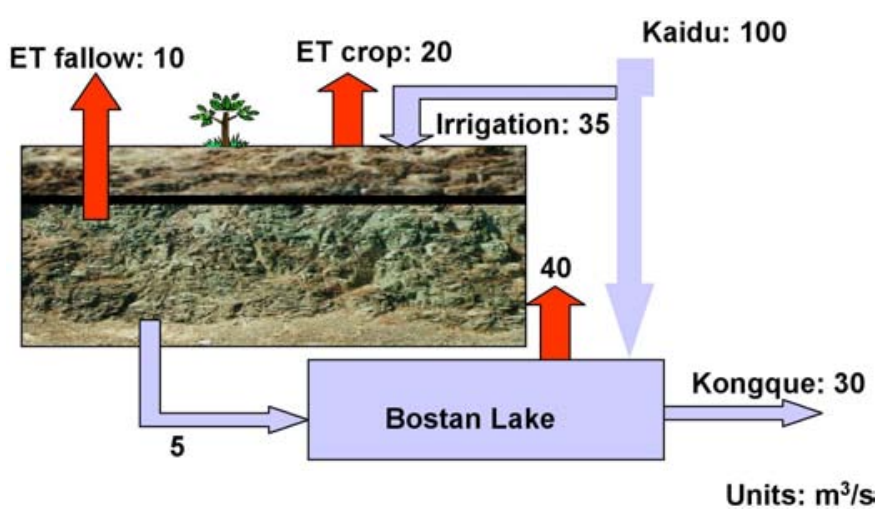

Figure 12: Average water balance of 2-box model.

Depending on how water in a steady state is exported from the system, reaching a steady state salt concentration can take a very long time compared to reaching a steady state in groundwater tables (Figure 13). The steady state salt concentration is 
directly determined by the ratio of the flux of water draining from the aquifer into the lake and the groundwater recharge. Furthermore, the box approach shows that the rate of accumulation of salt increases rapidly as soon as direct evaporation from the aquifer occurs.

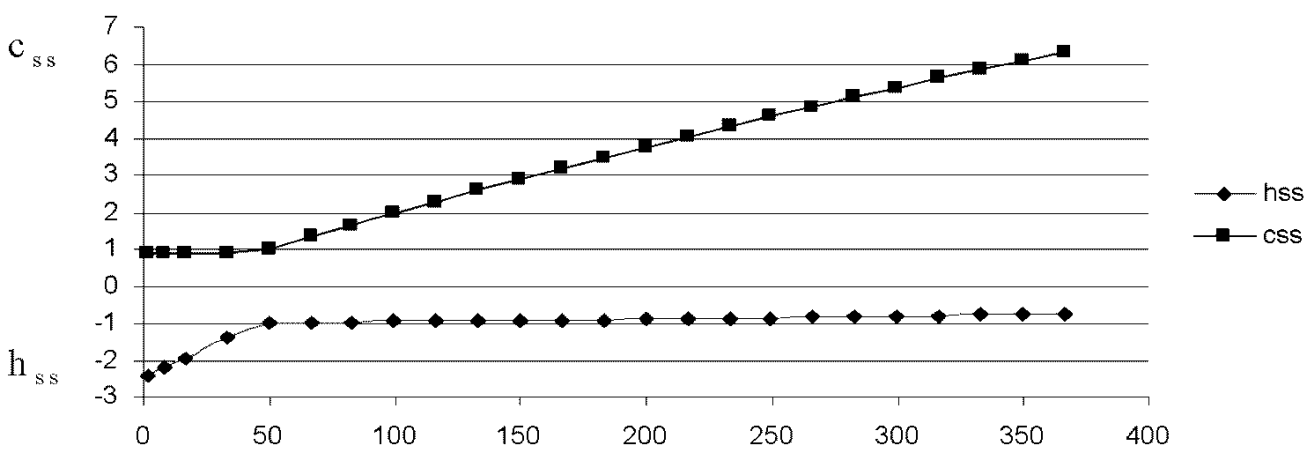

Figure 13: Steady state for groundwater tables (hss, $m$ below surface) and salinity (css, $g / l)$ in the Yanqi basin aquifer as functions of the amount of applied irrigation water (in $10^{7} \mathrm{~m}^{3} / \mathrm{a}$ ).

Pumping groundwater for irrigation purposes would not only reduce the need for over-irrigation, but also directly contribute to the water availability downstream. This solution is costlier as groundwater comes at about 10 times the price of surface water. However, if the water table can be kept low by pumping groundwater, the conservation of soil and the increased availability of surface water in the downstream might strike the balance with a higher price of water. Table 1 uses the 2-box model of the system to compare the present management to a new variant.

Table 1: Comparison of a new strategy with present practice (Basis: Present inflow of 3500 Mio. $\mathrm{m}^{3} / \mathrm{a}$ ) [16].

\begin{tabular}{ccc}
\hline & Present & $\begin{array}{c}\text { Variant } \\
\text { "Much groundwater, some water saving" }\end{array}$ \\
\hline $\begin{array}{c}\text { Groundwater use in irrigation } \\
\left(\text { Mio. } \mathrm{m}^{3} / \mathrm{a}\right)\end{array}$ & 80 & 380 \\
$\begin{array}{c}\text { Surface water use in irrigation } \\
\left(\text { Mio. } \mathrm{m}^{3} / \mathrm{a}\right)\end{array}$ & 1260 & 720 \\
$\begin{array}{c}\text { Average groundwater level } \\
\text { change (m) }\end{array}$ & 0 & -1.3 \\
$\begin{array}{c}\text { Lake water level (mamsl) } \\
\text { Lake salinity (TDS) (g/l) } \\
\text { Flow to "Green Corridor" } \\
\left.\text { (Mio. } \mathrm{m}^{3} / \mathrm{a}\right)\end{array}$ & 1046.6 & 1047.2 \\
& 1.40 & 1.03 \\
\hline
\end{tabular}


In this variant some water saving by new irrigation techniques and a considerably larger use of groundwater is implied. On all three counts - size of salination prone area, remaining flow for the green corridor and salinity of the lake - the new strategy is superior. An evaluation on the basis of cost and value of ecological gains is required. Also, the box model is only a first crude approximation, which has to be followed by a spatially resolving groundwater model, which will allow to allocate the measures to places, where they are most effective with regard to the goals to be achieved.

\section{Conclusions}

In arid countries the problems of sustainability in the water sector are prominent. On a worldwide basis the three subjects discussed in more detail are among the most widespread. They show several common features. Water management in the arid and semi-arid environment must include salt management. Introducing modern tools such as remote sensing, geophysics, environmental isotopes, and modelling into hydrological science helps - especially in regions with weak infrastructure - to quantify the implications of human interaction and give advice to decision makers on the sustainability of water management practices. Models summarize the state of affairs and are the only means to make predictions about the asymptotic implications of certain practices. They are bound to be crude and simulations will always be idealized. Still, they can serve as points of reference. A further common feature is that sustainable solutions require the system boundary to be taken sufficiently large, often transgressing political boundaries. While science can give some decision support, the decisions for or against sustainability are made in the political arena.

\section{References}

[1] Postel, S.L., Daily, G.C. and Ehrlich, P.R., 1996. Human appropriation of renewable fresh water. Science, 271(5250): 785-788.

[2] Alcamo, J., Doell, P., Henrichs, T., Kaspar, F., Lehner, B., Rosch, T. and Siebert, S., 2003. Development and testing of the WaterGAP 2 global model of water use and availability. Hydrological Sciences Journal-Journal Des Sciences Hydrologiques, 48(3): 317-337.

[3] ERESS 1972. Etude des Ressources en Eau du Sahara Septentrional. Rapport sur les Résultats du Projet, Conclusions et Recommandations, UNESCO, Paris.

[4] Mamou, A. 1990. Charactéristiques et evaluation des resources en eau du sud Tunisien. Dissertation, Université de Paris-Sud, Centre d'Orsay.

[5] Siegfried T., 2003. Management of internationally shared groundwater resources in semiarid and arid regions: the Northern African Aquifer System. In 
E. Servat et al. (eds), Hydrology of Mediterranean and Semiarid Regions, IAHS Publ. No. 278, 2003.

[6] Hutchins, D.G., Hutton, L.G., Hutton, S.M., Jones, C.R. and Loenhert, E.P., 1976. A summary of the geology, seismicity, geomorphology and hydrogeology of the Okavango Delta, Geological Survey Botswana, Gaborone.

[7] Thomas, D.S.G. and Shaw, P.A., 1991. The Kalahari Environment. Cambridge University Press, Cambridge.

[8] McCarthy, J., Gumbricht, T., McCarthy, T.S., Frost, P.E., Wessels, K. and Seidel, F., 2003. Flooding Patterns of the Okavango Wetland in Botswana between 1972 and 2000. Ambio, 32(7): 453-457.

[9] McCarthy, T.S., Ellery, W.N., Rogers, K.H., Cairncross, B. and Ellery, K., 1986. The roles of sedimentation and plant growth in changing flow patterns in the Okavango Delta. South African Journal of Science, 82: 579-584.

[10] Ellery, W.N., Ellery, K., Rogers, K.H., McCarthy, T.S. and Walker, B.H., 1993. Vegetation, hydrology and sedimentation processes as determinants of channel form and dynamics in north-eastern Okavango Delta, Botswana. African Journal of Ecology, 31: 10-25.

[11] Gumbricht, T., McCarthy, T.S. and Merry, C.L., 2001. The topography of the Okavango Delta, Botswana, and its tectonic and sedimentological implications. South African Journal of Geology, 104: 243-264.

[12] Gumbricht, T., McCarthy, T.S. and Bauer, P., 2003. Microtopography of the Okavango Delta using correlation between land cover and elevation. Earth Surface Processes and Landforms, in press.

[13] Bauer, P., 2004. Flooding and Salt Transport in the Okavango Delta, Botswana: Key Issues for Sustainable Wetland Management, Dissertation, ETH Zurich.

[14] Bauer, P., Gumbricht, T. and Kinzelbach, W., 2004. A large-scale coupled surface water / ground water model of the Okavango Delta, Botswana. Water Resources Research, submitted.

[15] Zebker, H.A. and Goldstein, R.M., 1986. Topographic Mapping from Interferometric Synthetic Aperture Radar Observations. Journal of Geophysical Research-Solid Earth and Planets, 91(B5): 4993-4999.

[16] Dong, X., Jiang, T. and Jiang, H., 2001. Study on the pattern of water resources utlilsation and environmental conservation of Yanqi Basin. In: G. Li (Editor), Development, Planning and Management of Surface and Groundwater Resources. IAHR congress proceedings. Tsinghua University Press, Beijing, China, pp. 333-340. 


\title{
TOWARDS A SUSTAINABLE USE OF NATURAL RESOURCES IN THE ARAL SEA BASIN
}

\author{
C. Martius, J. Lamers, M. Ibrakhimov and P. Vlek \\ Center for Development Research (ZEF Bonn) \\ D-53113 Bonn, Germany \\ c.martius@uni-bonn.de
}

\begin{abstract}
This paper discusses the environmental, social and economic aspects of the Aral Sea crisis, and describes a proposal designed to overcome the problem of unsustainable land and water use in the region. The Aral Sea has lost $>60 \%$ of its surface compared to 1960, due to increased water diversion in irrigation systems. The production of cotton in huge irrigation systems has brought about water misuse and land degradation, and due to the tough economic transformation process faced by the central Asian countries, the region is characterized by increasing poverty. Therefore, international development efforts today concentrate on improving ecological sustainability and economic efficiency of natural resource use in the region, as a contribution to combating poverty and desertification in the Basin, rather than on saving the Aral Sea as such. The Center for Development Research (ZEF) at the University of Bonn, together with its partners, has set up a research program aimed at providing options for a restructuring of land and water use that are based on sound, longterm, interdisciplinary integration of different disciplines of science, and that are aiming at strengthening local institutional and individual capacity building. The elements of this program and first results are presented.
\end{abstract}

\section{Introduction}

The Aral Sea Crisis, the most visible and best-known symbol of which is the shrinking of the Aral Sea surface - has become a symbol for large-scale man-made social and ecological disasters. Desertification is progressing in this area, with highly unfavorable environmental and socio-economic consequences. In 40 years, from 1960 to 2000, the Aral Sea, formerly the world's fourth largest inland water body with an estimated size of $68.000 \mathrm{~km}^{2}$ in 1960 [1] has lost $62 \%$ of its water surface area, and over $80 \%$ of the original water volume [2].

In 1992, the UN declared the Aral Sea region as a world "ecological disaster area". The "Aral Sea Syndrome" has been coined by the WBGU [3]; the Aral Sea being used here as a typical example for environmental damage as a result of poorly managed or unsuccessful large-scale development projects (in this case, the expansion of irrigated land at the expense of ecological sustainability during Soviet times). Glantz [4] has defined the Aral Sea problem as a typical example of a "creeping environmental problem" (CEP), i.e. an environmental change that evolves slowly and almost imperceptibly, making both its perception and the start of 
$-118-$

counterbalancing actions especially difficult ("...the demise of the Aral Sea has become acknowledged as one of the major examples of human-induced environmental degradation in the twentieth century").

\section{Environmental Consequences of the Aral Sea Crisis}

The shrinking of the Aral Sea has several consequences for the environment and for the local population (cf. [5] and references therein), such as:

- The dry Aral Sea bed in 2000 amounted to >4 million ha, and today represents an area of newly formed sandy-loamy sand and salt desert, the so-called Aralkum [2]. This area is thought to be a chief source for salt drifts and deposits in the region, because strong winds or storms (300 out of 365 days) carry sand and salt particles throughout the Aral Sea basin, sometimes as far as $>200 \mathrm{~km}$ [6]. The shrinking process has continued since then.

- Due to the shrinking of the Aral Sea the average temperature in July in Muynak increased from $25.7^{\circ} \mathrm{C}$ to $28.3^{\circ} \mathrm{C}$ between 1960 and 1985 , and the frost-free period shortened to 170 days in the delta area. Today, the first frost sets in 10-12 days earlier compared to the situation before 1960 [5].

- The formerly important fishery industry has disappeared, from a total of 43.000 metric tons of fish that were caught in the Aral Sea in 1960 down to no fish production at all since 1980 [7]. The view of fish trawlers lying in the sand has become a well-known visual metaphor of the Aral Sea catastrophe.

- The whole of Central Asia suffers from a severe loss of biodiversity. The quality of surface water bodies has changed, soils have become halomorphic and chemical pollution of water and soils in irrigated lands is very high (see below), which all affects the biodiversity of the organisms facing these conditions. Besides having been put under high ecological pressure due to receding river water availability, most of the so-called Tugai forests, the extensive river floodplain forests along the major rivers, have been cut down in order to make space for agricultural land [8]. The ecosystems of the deltas formed by the Amu Darya and Syr Darya Rivers have largely been destroyed. In the Aral Sea, the composition of the fish fauna has strongly changed because only a few fish species survived the highly increased salinity of the water [7]. 


\section{The Causes for the Aral Sea Crisis}

What were the causes for this development? Since the 1920ies, the desert areas in the Aral Sea Basin (ASB) were transformed into artificially irrigated agricultural land for the production of cotton, which was a major strategic crop for the Soviet Union. Over $60 \%$ of all cotton produced in the Soviet Union was produced in the ASB. In order to achieve this, the irrigation system was gradually but steadily increased in a huge engineering effort, from 2.0 million ha of irrigated farmland in the early twenties to 7.9 million ha in 1999 :

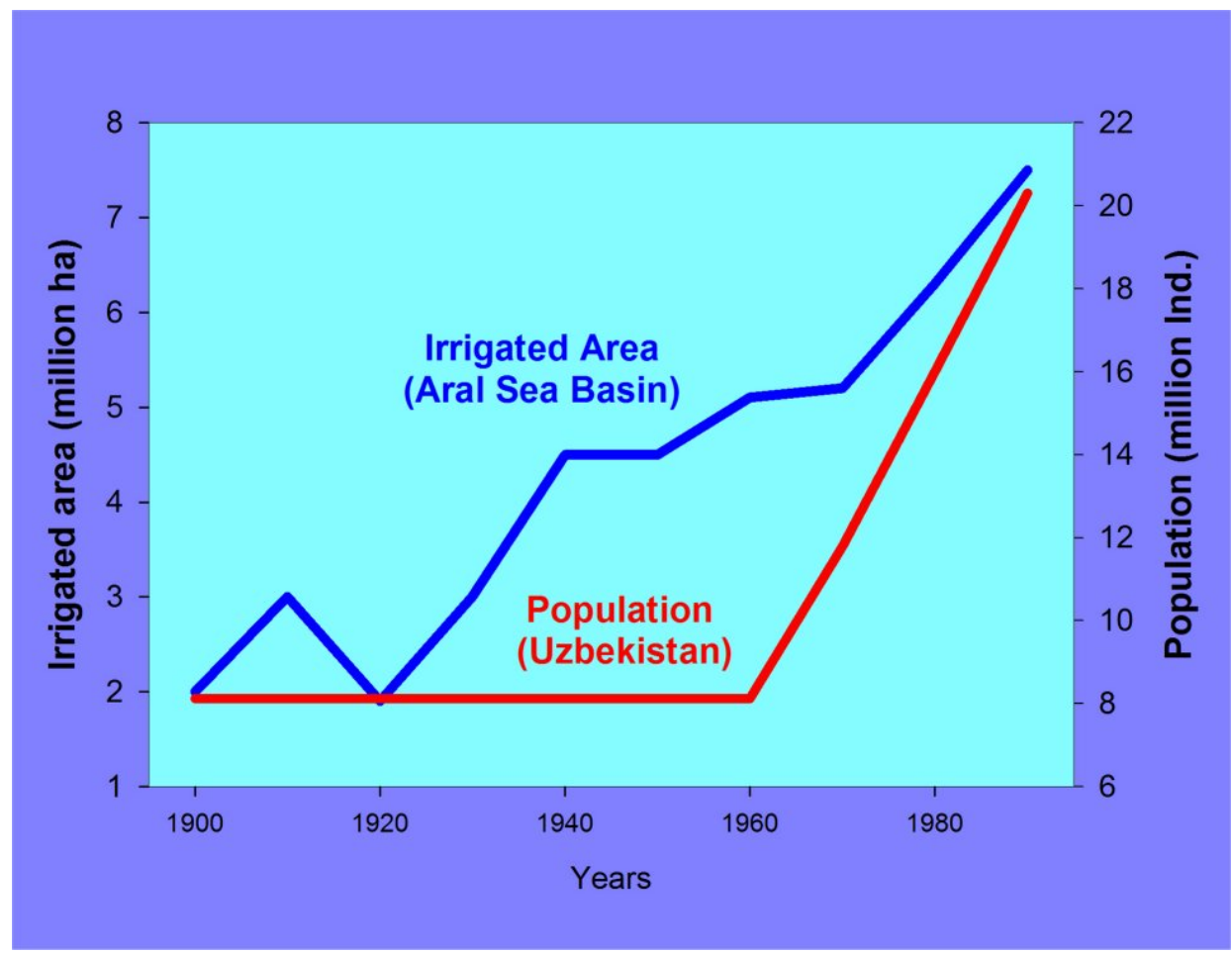

Figure 1: Development of the extension of the irrigated area in the Aral Sea Basin, and of the population in Uzbekistan. Adapted from [34]

Large quantities of river water have been withdrawn from the tributaries of the Aral Sea into the various irrigation systems along the rivers. The present system of main \& inter-farm irrigation canals in the ASB has a total length of $28.000 \mathrm{~km}$, and main \& inter-farm drainage canals amount to $30.000 \mathrm{~km}$; the total length of on-farm irrigation and drainage canals is 168.000 and $107.000 \mathrm{~km}$, respectively [9]. In 1999, these immense irrigation systems used $96.3 \mathrm{~km}^{3}$ of water $\mathrm{yr}^{-1}$, which corresponds to $83 \%$ of the average water resources available in all rivers in the ASB (cf. Table 1). This 
$-120-$

figure explains why in most years nowadays, and principally so in dry years, the water of the rivers rarely reaches the Aral Sea.

Table 1: Water resources in the Aral Sea Basin and their use, from [31].

\begin{tabular}{lllllll}
\hline Indicator & $\begin{array}{l}\text { Unit of } \\
\text { measurement }\end{array}$ & 1960 & 1970 & 1980 & 1990 & 1999 \\
\hline Population & Million people & 14.1 & 20 & 26.8 & 33.6 & 39.9 \\
Irrigated land area & 1000 ha & 4510 & 5150 & 6920 & 7600 & 7900 \\
$\begin{array}{l}\text { Summary water intake } \\
\text { For irrigation }\end{array}$ & $\mathrm{km}^{3}$ per year & 64.7 & 83.5 & 120.7 & 118.1 & 107.6 \\
$\begin{array}{l}\text { Specific intake per } \\
1 \text { ha of irrigation }\end{array}$ & $\mathrm{km}^{3}$ per year & 55.2 & 74 & 108.5 & 106 & 96.3 \\
$\begin{array}{l}\text { Specific intake per } \\
\text { capita }\end{array}$ & $\mathrm{m}^{3}$ per ha & 12240 & 14370 & 15680 & 13950 & 12190 \\
\hline
\end{tabular}

Water losses in the mostly unlined irrigation canals are estimated to be up to $40 \mathrm{~km}^{3}$ of water $\mathrm{yr}^{-1}$; an amount which, if it could be saved, would be enough to slowly refill the Aral Sea. However, the costs of lining and refurbishing the whole system prohibit accomplishing this task in face of the huge extension of the irrigation system. Also, any radical solution like simply stopping all water diversion to the irrigation systems in order to restore the Aral Sea would not be feasible. It would take several decades to fill up the Aral Sea again to its former levels, and, worse, such a decision would throw the 39.9 million inhabitants (1998) of the ASB into chaos, 62\% of which are rural population directly or indirectly depending on agriculture in the irrigated land.

\section{Land and water use for crop production}

In the ASB, $90 \%$ of the crops are produced under irrigation. Overall cotton yield in the agricultural production systems that is characterized by the long-term growth of cotton has decreased from 3.0 ton/ha in 1976 over 2.8 ton/ha in 1992 to 2.3 ton/ha in 1996 (Trevisani, unpublished). In order to maintain the agricultural production levels, the use of fertilizers, pesticides and other inputs has been increased.

Also, it is well known that the long-term irrigation with surface water in drylands almost invariably leads to soil salinization [10]. Large parts of the irrigated land in Uzbekistan are nowadays seriously compromised by salinity; in Khorezm, for example, the areas with moderately and strongly saline soils (soils with 0.06 to $>0.12 \mathrm{meq} \mathrm{L}^{-1}$ ) in the period 1990 and 2000 invariably amounted to about $50 \%$ of the total irrigated land [11]. In Khorezm, areas at risk of waterlogging and salinization 
represent about $65-70 \%$ of the irrigated areas and only huge amounts of water used for irrigation and leaching of the soils (washing out of salts during winter time) allow keeping the land productive. This is why the amount of water used for crops in central Asia is much higher than in other parts of the world; e.g. for cotton in Khorezm, for example, between 5.000 and $20.000 \mathrm{~m}^{3}$ of water are used per hectare $[12,35]$.

The environmental consequences of the salinization and extensive use of agricultural inputs are that drinking water is highly saline, and that soils and water are contaminated by salts, pesticides and nitrates, all factors that present serious problems for the health of the local population. In the region, salt-related diseases like kidney and heart diseases are common [5]; contamination of drinking water and breast milk with DDT is widespread and by far exceeds the critical threshold levels [13], respiratory diseases affect large parts of the population [14] and the psychosocial effects of the environmental situation are felt by respondents to a study of Médécins sans Frontières [15]. Pesticides such as DDT and Lindane also accumulate in fish and in drinking water reservoirs like the Tuyamuyun on the Amu Darya, although DDT is reported to not being used any more. The total use of fertilizers and pesticides has decreased from 1989 to 1993 but effects are still felt. Over $50 \%$ of the rural population in Khorezm obtains drinking water from surface water bodies, which contributes to the large amount of drinking-water related dieases. To improve the health situation in the Basin as a whole, water supply will be one of the major factors, because over $40 \%$ of the drinking water does not correspond to the sanitary and bacteriological standards [16].

At the same time, it is well-known that poverty in the central Asian states has increased since independence [17, 18]; e.g. in Uzbekistan GDP has halved in the last five years since 1999 (Table 2). 24\% of the Kazakh population in 2002 lived in absolute poverty with incomes below the subsistence minimum of 31 US Dollars per month [19].

Table 2: Economic indicators in Uzbekistan. Source: [32] and own calculations.

\begin{tabular}{ccccccc}
\hline & 1999 & 2000 & 2001 & 2002 & 2003 & 2004 \\
\hline Population (million people) & n.a. & n.a. & n.a. & n.a. & 25.8 & $26.3^{\star}$ ) \\
GDP (billion US\$) & 17.0 & 13.7 & 11.6 & 9.7 & 9.0 & 10.1 \\
GDP per capita (US\$) & 70 & 551 & 463 & 380 & 347 & $384^{\star \star}$ ) \\
\hline
\end{tabular}

*) value for the population in 2004 calculated from population in 2003, assuming an annual growth rate of 2.5 [33]

**) per-capita GDP of 2004 calculated from GDP/population

Therefore, leading development agencies in the world nowadays agree that restoring the Aral Sea to its former size is not a feasible development goal; instead, 
developing the region towards increased sustainability of natural resource use and a better livelihood of the local population are high on the agenda because they recognize the social dimension of the project and can be achieved [12].

\section{Economic Aspects of the Crisis}

Of all central Asian states, Uzbekistan has the largest population living in the ASB (14 million inhabitants). Therefore, the political analysis here is concentrated on this country. Uzbekistan is today the world's 5th largest cotton producer, and the world's 2nd largest cotton exporter after the USA; cotton accounts for $45 \%$ of Uzbekistan's export earnings (after gold, with 22\%) [20,21]. It is the declared policy of the government of Uzbekistan is to use export earnings from cotton production to build up the industry in the country [22]. The agricultural production of main crops like cotton, wheat and rice is therefore controlled by the "state order", meaning that there are production targets for these crops which are defined centrally and broken down by region, district, and individual farms [23]. Individual private farmers have to allocate a certain share of their total land to cotton and grain production. Until 2002, this amounted to $100 \%$ of the cotton harvest and $50 \%$ of the planned grain quantity. The production must be delivered to the government agencies at pre-set prices which for cotton are approx. $30 \%$ of the world market prices; the potential surplus can be sold on the free markets where prices normally are higher than those paid by government agencies.

This system gives the state strong control over the agricultural production; however it is often overlooked that in compensation, the farmers receive all inputs from the state. The government controls not only distribution and prices of major inputs (e.g. fertilizers and biocides), but also the processing of the production and the marketing and exports of agricultural commodities. Not least, the government also is responsible for maintaining the extensive irrigation system and providing water at no cost to the farmers. Thus, possible benefits but also potential shortcomings of any attempts at privatization in the agricultural system should be carefully balanced.

Macro-economic reforms have been slow in Uzbekistan. One reason for this has been the attempt to buffer the negative social effects of economic transition, in view of the experience in neighboring countries where too quick reforms often led to huge social problems (e.g. [19]). For example, inflation increased at relatively low annual rates of $<50 \%$ in Uzbekistan, and one objective of the gradual reform approach was to keep food prices at affordable levels [5]. The gradual, almost reluctant approach to change may be responsible for the relative stability in the country, but has delayed economic reforms in all sectors of economy and may be impossible to be maintained at the same pace for the near future. 


\section{Economic and Ecological Restructuring as a Pilot Project to Improve Resource Utilization in Khorezm (Uzbekistan)}

Ecology and Development in the Aral Sea Basin are therefore characterized not only by the well-known and much emphasized ecological problems due to unsustainable resource management, such as the large water losses in irrigation system, the salinized irrigation and drainage water that leads to salinized and degraded soils, the large (though receding) use of pesticides and herbicides, the ensuing air and water pollution (due to wind-borne dusts, pesticides and salts), the biodiversity loss, and the regional climate change towards a more continental climate. The situation is also characterized by the reduced livelihood affected by the economic transformation process, the widespread poverty, above all in rural areas (Table 3), the widespread health problems, the high child mortality and low life expectancy. Furthermore, one should keep in mind the strong path dependency given by the predominance of cotton in the Uzbek agricultural sector, the extensive irrigation system, and the Soviet legacy in institutions as well as the slow reforms towards market economy.

Table 3: Rural poverty in Uzbekistan, modified from [22].

\begin{tabular}{ccc}
\hline & $\begin{array}{c}\text { Average cost of consumption, } \\
\left.\text { per capita, Uzbek Soum }{ }^{\star}\right)\end{array}$ & $\begin{array}{c}\text { Percent of people living below of a half } \\
\text { of the mean level of consumption }\end{array}$ \\
\hline Urban & 10926 & $18.6 \%$ \\
Rural & 7539 & $39.6 \%$ \\
\hline
\end{tabular}

*) exchange rate: approximately 1000 Uzbek Soum = 1 US\$ (values of 2000)

No easy solutions can be given to the challenge of finding ecologically sustainable and economically effective options for land and water use in the region. Technical solutions to land and water use require some research to be done, but basically, many options are available and well known, such as better drainage and leveling of irrigated fields, the introduction of conservation agriculture, water-saving irrigation technologies and the like. However, the strong control the Uzbek state holds on the agricultural sector requires that institutional aspects must be addressed in the first place, and the economic feasibility of any measures under the peculiar local conditions must be carefully assessed before recommendations can be given.

ZEF has therefore designed, in consultation with its partners (UNESCO, DLR, University of Urgench and TIIAME in Uzbekistan and many others), an interdisciplinary, application-oriented research program with the aim to provide appropriate regional development concepts based on sustainable and efficient land and water use. The program started in 2001 and is based on an integration of natural resource management, economic studies and studies of institutions. The philosophy is that of a long-term, participatory commitment to deliver decentralized development 
options based on a system where markets function and sound ecological principles are adhered to. The program includes a strong human capacity building component, particularly the training of young Uzbek scientists from the Aral who will be the potential future decision-makers in the region.

Recognizing that most of the Aral Sea is lost, the ZEF program assumes that a sustainable restructuring of land and water use in the Aral will have to improve the livelihood of the local population through a careful transformation towards privatization of agriculture based on (ecologically, economically and socially) sustainable land-use options. A more efficient use of the existing resources is required. One approach is a reduction in the area of cropped land, which we expect to achieve through diversification of land use, utilization of the "service potential" of ecologically sound land-use systems, efficient use of production factors, liberalization of the input and output markets, increase in rural income and careful modification of existing legislation and decision-making systems to enable this process.

The inhabitants of Karakalpakstan and Khorezm, two districts on the lower reaches of the Amu Darya River, the largest of the Aral Sea's tributaries, suffer most from the accumulated effects of low water availability, soil degradation and salinization, and from the economic and administrative orientation of Uzbekistan towards soviet-style centralized structures. The region of Khorezm was chosen as a target region to this project due to several reasons. Khorezm is located downstream in the Amu Darya basin, but still has a downstream area (Karakalpakstan) itself, and is therefore more typical for irrigation systems in Uzbekistan. Karakalpakstan has arguably the most severe environmental problems, but is relatively untypical of Uzbekistan as a whole. Khorezm is a small district for Uzbek measures, with clear boundaries, thus relatively easy to study, and it is important in the Uzbek cotton trade because it only delivers $5 \%$ of the total Uzbek cotton production, but, due to its high quality, accounts for about $20 \%$ of the Uzbek cotton export revenues.

The ZEF project aims at increasing economic efficiency through improved economic farm management, a wiser utilization of inputs (fertilizer and rotation management, alternative crops), a diversification of sources of income (trees, aquaculture), and at increasing ecological sustainability through a reduction in water use, the halting or reversing of soil degradation, e.g. through the introduction of conservation agriculture (this is also a goal of a recently initiated FAO project). We expect to be able to set marginal land, actually used for agricultural production at high costs, free for ecological services, and to achieve a diversification of the landscape in order to draw ecological service functions into the system.

Under the conditions of the existing "path dependencies" (predominance of cotton as a major crop in the prevailing economic reasoning, the existence of vast irrigation systems, the population pressure, and the prevailing of the state order), the steps needed for developing options for restructuring land and water use in Uzbekistan are: 
1. The development of adopted sustainable resource management options (water, soils, and crops management; diversification);

2. the privatization of agriculture, of input- and output markets (a loosening of the state order, the introduction of basic principles of economic farm management (training is required here), the liberalization of the markets, and the scientific research of market options for new agricultural products, e.g. for fish, wood, and new crops);

3. the improvement of institutional performance in the sector of water distribution (efficient and reliable water distribution, unambiguous rights and obligations for users, e.g. concerning withdrawal of water and maintenance of the irrigation system);

4. Finally, instead of parting from the apparent "optimum technical solutions", those technologies must be identified that will be embraced by the farmers because they respect the farmer's priorities, needs and economic possibilities and adapt to their intellectual and ideological universe without giving up the need for ecological sustainability.

\subsection{A long-term project in four phases}

The project is planned for a total of four phases covering a 10- to 12-year program:

Table 4: The different planned phases in the ZEF development project for land and water use in Khorezm (Uzbekistan).

\begin{tabular}{|c|c|c|c|}
\hline Phase & Years & Main activities & Status \\
\hline 1 & $\begin{array}{l}2001- \\
2003\end{array}$ & $\begin{array}{l}\text { Inventory; establishment of central databases and } \\
\text { infrastructure }\end{array}$ & finished \\
\hline II & $\begin{array}{l}2004- \\
2006\end{array}$ & $\begin{array}{c}\text { Field trials for process understanding, development } \\
\text { of a Modeling and Decision Support Tool (Khorezm } \\
\text { Ecological-Economic Model, KEOM) for research } \\
\text { purposes }\end{array}$ & started \\
\hline III & $\begin{array}{l}2007- \\
2010\end{array}$ & $\begin{array}{l}\text { Testing of the concept for the restructuring of the } \\
\text { land use, and demonstration of "good practice" on } \\
\text { pilot farms, fields and plots }\end{array}$ & planned \\
\hline IV & $\begin{array}{l}2011- \\
2012\end{array}$ & $\begin{array}{l}\text { Adaptation of concept and implementation in the } \\
\text { region (Khorezm-wide) }\end{array}$ & planned \\
\hline
\end{tabular}

In Phase I (18 months) started in 2001 the project concentrated its efforts on assessing the state-of-the-art, based on secondary data acquisition, surveys of land use, ecological conditions and current economic, institutional and social/health 
conditions of the Khorezm region [5]. The project has by now been firmly established with excellent institutional arrangements, infrastructure and national and local support. Moreover, there is a clear tendency in the country to shift to privatization and liberalization of markets, so that the project is drawing increasing interest from various government levels.

In Phase II, the main aims of the project are (1) to gain the necessary understanding of natural, economic, and social processes that allow the proposition of a alternative restructuring concepts; (2) to develop an Ecological-Economic Optimization Model (KEOM) that will help assess the impact of various restructuring concepts on economic and ecological developments; and (3) to develop together with the local land users and with the help of KEOM, a pilot scheme for large-scale privatization of Shirkats (communal farms). Thus, the model developed in Phase II will provide the concepts to be tested on the pilot farms in Phase III, when also the DSS will be fully developed.

In Phase III, the scope of the project will be in applying the results of the research of the first 2 phases including the research on technologies and the options for institutional re-organization under real-life conditions, on-farm. The concept of pilot farms has been extensively discussed and much criticized in the development literature, but should be seen in the context of a strategy for stakeholder involvement that addresses two levels, (a) the private farmers who have to be convinced that new technologies aimed at ecological sustainability will also improve their livelihood; and (b) the decision-makers at the administrative level in government organizations both at the district as well as at the national level where agricultural policies are defined. Therefore, we see a need for establishing pilot areas, farms and fields on which demonstration trials of best practices in land and water management, crop production and agricultural management will be demonstrated.

The activities on these demonstration farms will be based on KEOM as the platform on which important economic and biophysical processes have been modeled while taken into consideration the social framework, and which will be used to simulate the effects of different scenarios (business-as-usual, minimum improvements, optimum improvements) on social, economic and ecological indicators. Based on this, the most promising restructuring options will be selected that will then be implemented in the demonstration scheme. Participatory approaches will be used to closely link the project activities to the target groups (both farmers and decision-makers among the local and national authorities) and to assure that the solutions are user-driven, and not donor- or project-driven.

The goals of Phase III will therefore be (1) to demonstrate good farm management practice concerning both resource management and farm management; (2) to raise perception and adoption of improved technologies by collaborating partners and farmers; and (3) to demonstrate sustainable, applicable water and land management options on a larger (geographical and administrative) scale. 
Phase IV will then be used to draw on the lessons from Phase III and on further simulations in the improved KEOM, to implement the emerging restructuring concept on a larger spatial scale, i.e. in Khorezm.

\subsection{Interdisciplinary Research to provide feasible development options}

The project in Phase II is divided into four thematic research areas that provide the baseline data input for the integrative, interdisciplinary model (KEOM) (cf. Figure 2). These areas are discussed in the following section.

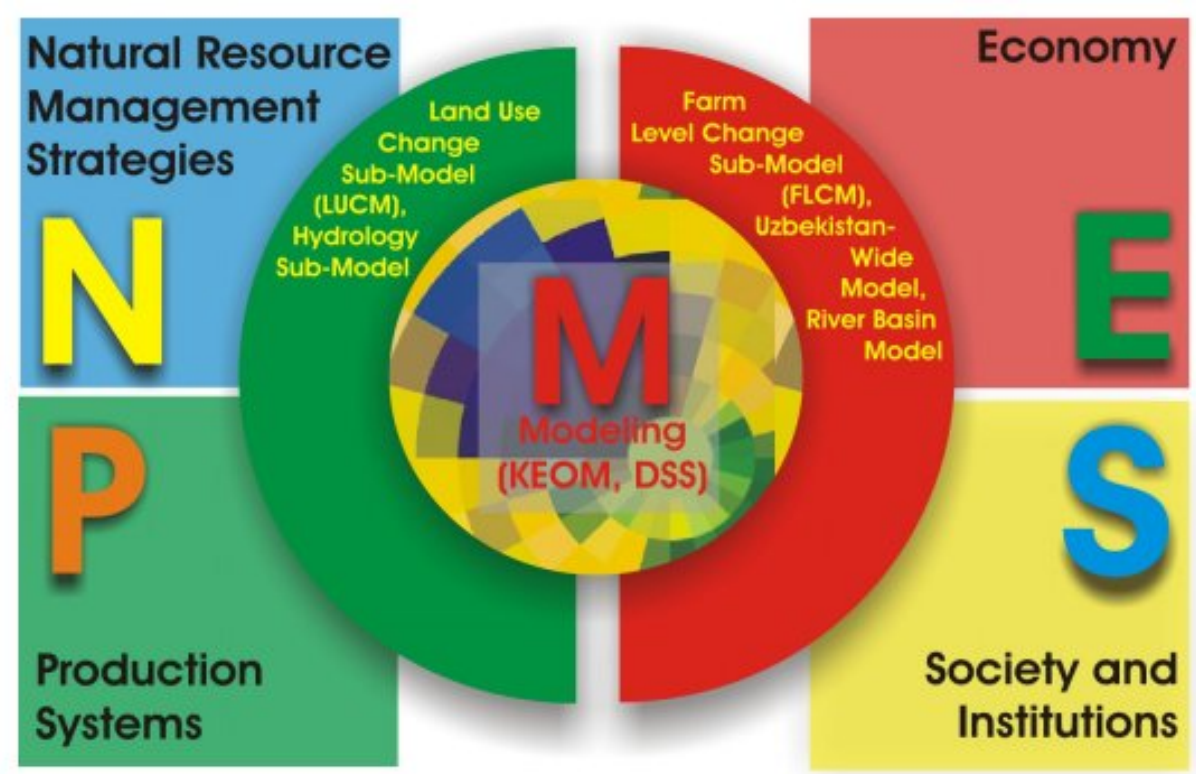

Figure 2: The four project research areas feed through sub-models into the Khorezm Ecological-Economic Optimization Model (KEOM).

The sub-models (representing the thematic components) developed during Phase I and II of the project will be integrated in the central model (KEOM). The model's main purposes are research, planning and teaching; however, it will also provide the basis for a concept to implement changes in land and water use, free of the Uzbek state order, in experimental pilot farms at a later stage in Phase III.

\subsection{Natural Resource Management Strategies to support Decision Makers}

In the field of natural resource management strategies (research area $N$ ) optimal land-use patterns (including the introduction of trees and ponds as alternative land uses with ecological functions) will be determined through field research and remote sensing, in order to prepare an efficient and sustainable management of the two 
most important resources, water and land. Furthermore indicators for a sustainable resource use, for example for soil quality (such as soil ecology and carbon storage) and water use (quantity) and water quality (such as water salinity and a positive balance of the total water budget) will be established to allow assessing the success of the restructuring measures. The results of this research area are primarily addressing the decision makers.

Resource utilization begins with the allocation of land to various land uses. One alternative for land use is the establishment of tree plantations. Trees can provide ecological services such as biodrainage, organic matter input, improvement of the microclimate through shadow, and they provide marketable products such as wood, fruit or fodder. Actually the suitability of 15 tree species from the region is being assessed, through the monitoring of growth characteristics, and biological as well as production parameters such as fodder value or the energy content as a basis for the use as fuelwood [24]. Furthermore, the mapping of existing tree stands from aerial photographs and of indicators showing sites suitable for trees will allow the later implementation of the tree plantation schemes on a larger scale.

Another alternative explored in this program is the installation of ponds for fish farming in the region. The concepts for this are basically available, but details as for example the availability of local plants (trees as well as annual plants such as Amaranth) for providing cheap fish feed are actually being studied.

The status quo of land use over the region is being established through remote sensing of the Leaf Area Index (LAl), through which we expect, in combination with biophysical parameters, to be able to provide optimum watering options [25].

Detailed hydrological and soil quality studies have been undertaken, e.g. a study of the groundwater depth and salinity dynamics in time and space over the last 10 years, which revealed that the areas east and south of Khorezm, i.e. those deeper in the topographical profile and in longer distance to the irrigation water inflow from the Amu Darya suffer from higher groundwater salinity risk. Also, it was found that some areas experience a higher and faster increase of groundwater salinity than others. These so-called "hotspots" reveal a high spatial heterogeneity of groundwater salinity dynamics and will provide the basis for site-specific approach for water resources management that is needed in the region [11].

The project has further established a research program on indicators that will allow assessing the effects of the measures to be introduced on a larger scale at a later stage in the program (Phase III). For example, the spatial distribution of healthrelated aspects of drinking water quality, such as the incidence of hepatitis $A$ and diarrheal diseases related to drinking water contamination have documented [26, 27] and will serve as a base-line from which to assess the impact of restructuring in the pilot scheme at a later date.

A soil-ecological monitoring program has been established in 2004 to evaluate the impact of the newly introduced land-use and cropping systems on soil "health", its 
ecological functionality. This is coupled to an intensive investigation of the dynamics of carbon and nitrogen budgets in these systems under different irrigation regimes starting in 2004 also.

\subsection{Production Systems Research as Support to Farmers}

Field research on production systems $(P)$ has been intensified in 2004, covering all major aspects needed to develop recommendations for farmers as the main land users. These include research on the potential for a diversification of crops through the introduction of alternative crops (e.g.; potatoes, sunflower, and sorghum) and the improvement of the existing cropping systems and rotations. Also, the optimization of fertilizer use and its efficiency is addressed through extensive on-farm field research in close collaboration with the farmers, and a study of irrigation efficiency on the field level is carried out in which for the first time detailed measurements of the farmer's irrigation practice are carried out.

As agriculture consumes about $80 \%$ of all water resources in Uzbekistan, and as the agricultural water-use efficiency in Khorezm is low, field research on how to establish alternative cropping and crop management systems that have been successful elsewhere has been initiated in close cooperation with the International Wheat and Rice Center (CIMMyT) and TIIAME, an agricultural university in Tashkent. These include the introduction of a permanent bed-and-furrow system, the development of adequate planters and seeders, and improved irrigation techniques in combination with optimized fertilizer management via a judicious combination of organic and mineral materials.

Furthermore, the introduction of alternative crops like potatoes, sorghum, or sunflowers, is being studied in on-farm pilot trials, some of them in cooperation with German Agro Action (Welthungerhilfe). The competitive advantages of crops with a high value density such as flowers or spices that can be advantageously grown, processed and marketed in Khorezm, will be assessed in another economic study.

\subsection{Economic Research to provide efficiency of farming operations}

The research on economic aspects (research area E) aims at establishing development pathways for transforming the local economy from a commandstructured to a market-oriented system, and the acquisition of primary research data on farm management, market conditions, profitability of diversified crop production systems, expenditures of regulating the economy as well as costs of intergenerational distribution.

In the context of the Uzbek economy it is necessary to assess up to which point privatization and land set-aside policies may diminish the employment opportunities in the farm sector, and how far market restructuring might be able to compensate for these losses [28]. An in-depth analysis of the institutions necessary to create functioning markets, of constraints prevailing in input markets as well as in those affecting output at various stages (processing, storage, and marketing) will be 
undertaken in order to assess the various options for privatization of these sectors as a viable alternative to the procurement system of the government. In addition, a socio-economic evaluation of possible winners and losers of agricultural reform is providing the necessary background information to minimize or avoid social disruptions. Judgment on the economic effects of re-allocating land and water use will be mainly based on analyses of individual farms started in 2002 and carried out with Linear Programming Models (LPM) that will represent the three major farm types at each district level. These investigations not only will provide insight into the status quo, but will also provide the levers for economic re-organization of the agricultural sector. The economic studies will be integrated on different levels; in an Uzbekistan-wide economy model, in an economic model of the Amu Darya river basin that allows a larger disaggregation, and the integration of the farm data gathered in intensive interviews of farmers into the so-called Farm Level Change Sub-Model (FLCM) to support the overall model, KEOM.

\subsection{Research on Institutional Performance}

The research on society and institutions (S) aims at (a) understanding the formal (legal) ways of resource distribution in the state institutions and the newly formed Water User Associations, (b) increasing our understanding of the informal ways of by-passing these institutions in decision-making, (c) assessing environmental legislation and the legal aspects of land tenancy and land use with the aim of identifying the possibilities for legal, institutional and administrative modifications needed for a land reform, market liberalization and an effective increase in land/resource use efficiency and sustainability

Any implementation of modifications of resource use will involve regulatory, organizational and social issues. Current studies look at the conflict potential that lays in the Uzbek reform process, and ways of how to mitigate it; at the functioning of the newly introduced water user associations that substitute the water distribution according to farms in favor of water allocation based on hydrological units; and try gauging the perceptions and expectations of farmers towards a project that supposedly will provide changes in their day-to-day life [29]. Privatizing farms and liberalizing markets calls for alternative institutional arrangements in water delivery as well as in monitoring markets. Research will be intensified on appropriately anchoring the new institutional settings in the formal and traditional societal structures in Khorezm.

\subsection{Integrative Modeling}

The modeling of economic and ecological processes is undertaken in order to understand the dynamics of these highly complex and intertwined processes. It is expected that through simulations with this model, it will be possible to develop scenarios for optimization of land and water use. We expect this model to be a spatially distributed computer model that allows differentiating land use in the sub- 
$-131-$

units ("pixels") of a grid laid over the region. The model (dubbed the EcologicalEconomic Optimization Model; KEOM) furthermore accounts for resource utilization, natural constraints, economical and human driving forces. The process of developing KEOM is deliberately not focusing on developing the software as such, but on using it as a strongly stakeholder-driven integration tool that should bring together the different disciplines as well as researchers and farmers. It is based on applying the Unified Modeling Language (UML; cf. [30]) as an integrative tool that guides a social process much more than a software developing process. KEOM should then allow assessing the impact of different possible scenarios (climatic changes, policy changes, introduction of different land management, etc.) on the long-term sustainability of ecological and economic conditions of Khorezm and Uzbekistan. KEOM will assemble the different parallel multi-disciplinary approaches into a truly integrated interdisciplinary research tool.

\section{Concluding Remarks}

This project intends to make a difference by supplying applicable, operational concepts based on four pillars that form its basic philosophy. These are (1) the establishment of a long-term scientific cooperation between German and Uzbek research institutions including other internationally important players such as UNESCO and CIMMyT; (2) the strong emphasis on human capacity building of young Uzbek students as integrants of an international work group; (3) the interdisciplinary integration of different science disciplines; and (4) the development of a science-based concept for land and water use. We thus expect this project to be of competitive advantage in the development scene in Central Asia where natural resource exploitation, strongly hierarchical institutions and the shortfalls of a transition economy mingle to form a complex situation that is translating into natural resource degradation and poverty. To overcome these requires uniting "the best of both worlds".

\section{Acknowledgements}

This paper was prepared based on contributions of many people at the Center for Development Research. It dwells on contributions by Ruzimbay Eshchanov, Peter Mollinga, Alim Pulatov, Gerd Rücker, Anja Schoeller-Schletter, and Peter Wehrheim as well as the work of numerous Ph.D. students of the project. This study was funded by the German Ministry for Education and Research (BMBF; project number 0339970A). 


\section{References}

[1] P.P. Micklin and W.D. Williams. 1996. The Aral Sea Basin. NATO ASI Series 2. Environment, Vol. 12. Springer Verlag, Berlin, Heidelberg.

[2] G. Strunz, G. Rücker and R. Colditz (2003): Mapping of desertified areas in the former Lake Aral region and evaluation of the suitability for tree-growth. Unpublished Report. DFD-DLR, Oberpfaffenhofen, 8 p.

[3] WBGU (1998): Worlds in transition. Ways towards sustainable management of freshwater resources. Berlin, Springer-Verlag, $419 \mathrm{p}$.

[4] M.H. Glantz (1998): Central Eurasian water crisis: Caspian, Aral, and Dead Seas. In: I. Kobori. and M.H. Glantz (eds.): United Nations University Press, New York, pp. 25-52.

[5] Vlek, P.L.G., Martius, C., Wehrheim, P., Schoeller-Schletter, A., Lamers, J. (2001): Economic Restructuring of Land and Water Use in the Region Khorezm (Uzbekistan) (Project Proposal for Phase I). ZEF Work Papers for Sustainable Development in Central Asia, 1, 79 p.. Available at http://www.khorezm.unibonn.de/ [last checked 6-6-2004]

[6] E. Giese (1998): Die ökologische Krise des Aralsees und der Aralsee Region:Ursachen, Auswirkungen, Lösungsansätze. In: Giese, E., Bahro, G. and D. Betke: Umweltzerstörungen in Trockengebieten Zentralasiens (West- und Ost-Turkestan). Franz Steiner Verlag, Stuttgart, Erdkundl. Wissen 125, 189 p.

[7] R. Létolle and M. Mainguet (1996): Der Aralsee - Eine ökologische Katastrophe. Springer Verlag, Berlin, Heidelberg, New York, $517 \mathrm{p}$.

[8] S.Y. Treshkin, S.K. Kamalov, A. Bachiev, N. Mamutov, A.I. Gladishev, and I. Aimbetov (1998): Present status of the Tugai forests in the Lower Amu-Dar'ya Basin and problems of their protection and restoration. In: UNESCO: Ecological research and monitoring of the Aral Sea Deltas. UNESCO Aral Sea Project. 1992-1996, Final Scientific Report, UNESCO, Paris.

[9] FAO AQUASTAT (2004): County Profile Uzbekistan. Available at http://www.fao.org/ag/agl/aglw/aquastat/countries/uzbekistan/index.stm [checked 6.6.2004]

[10] D. Hillel (2000): Salinity Management for Sustainable Irrigation. Integrating Science, Environment and Economics. The International Bank for Reconstruction and Development/The World Bank, $92 \mathrm{p}$.

[11] M. Ibrakhimov (2004): Spatial and temporal dynamics of groundwater table and salinity in Khorezm (Aral Sea Basin), Uzbekistan. Ph.D. thesis, Univ. Bonn. 
[12] UNESCO (2000): Water related vision for the Aral Sea Basin for the year 2025. UNESCO, Division of Water Sciences with the Co-Operation of the Scientific Advisory Board for the Aral Sea Basin.

[13] V. Chashchin, and A. Kuzmin. (2003). The Khorezm Region Water Quality and Health Study: Persistent Toxic Substances in Drinking Water and Human Blood. INTAS Project 00-1015 (1). Available at http://www.intas.be

[14] S.L. O'Hara, G. Wiggs, R. Hubbard, J. Wegredt, D. Falzon and J. van der Meer (2001): Dust exposure and health respiratory health amongst children in the Environmental disaster zone of Karakalpakstan, Central Asia: preliminary findings of the ASARD project. First International Conference on the Impact of Environmental Factors on Health 10 - 12 September 2001, Cardiff, Wales, UK, MSF Kiev, 10 pp. Available at http://www.msf.org [checked 6.6.2004]

[15] E. Crighton, J. van der Meer, V. Yagodin, and S. Elliott (2001): Impact of an Environmental Disaster on Psychosocial Health and Well Being in Karakalpakstan. MSF Aral Sea Ara Program, 1999. 32 p. Available at http://www.msf.org [checked 6.6.2004]

[16] U.A. Karimov, O.S. Machmudov, T.B. Eshanov, and G.A. Mambetkarimov (1999): Aktualnie voprosi ochrani sdorovja detei v ekologisheski neblagoptijatmom regione Usbekistana. Vestnik KKOAN No. 2 (160), pp. 15-17.

[17] A. Bauer, D.Green, and K. Kuehnast. 1997. Women and Gender Relations. The Kyrgyz Republic in Transition. Asian Development Bank (ADB), Manila.

[18] A. Bauer, N. Boschmann, D. Green, and K.A. Kuehnast. 1998. Generation at Risk. Children in the Central Asian Republics of Kazakstan and Kyrgyzstan. Asian Development Bank (ADB), Manila.

[19] UNDP Kazakhstan (2004): Poverty in Kazakhstan: Causes and Cures. UNDPKAZ 08. $122 \mathrm{p}$.

[20] USDA-ERS (United States Department of Agriculture - Economic research Service) (2004): Briefing Room: Cotton trade. Available at http://www.ers.usda.gov/Briefing/Cotton/trade.htm [checked 31.5.2004]

[21] Bharat Textile (2004): Global Textile Statistics - World Cotton production. Available at http://www.bharattextile.com/textstat6.php [checked 31.5.2004]

[22] T. Trevisani (2004): Uzbekistan's agricultural sector as a context for development. Unpublished Report, Urgench, Khorezm, 2004

[23] ZEF (2003): Economic and Ecological Restructuring of Land- and Water Use in the Region Khorezm (Uzbekistan). A Pilot Project in Development Research. Project Phase II: Field Research and Development of a Restructuring Concept (2004-2006). ZEF Bonn. 58 p. 
[24] A. Khamzina , J.P.A. Lamers , M. Worbes , E. Botman , and P.L.G. Vlek (2004 submitted): Assessing the potential of trees for afforestation of degraded landscapes in the Aral Sea Basin of Uzbekistan. Establishment, growth, nutritive and calorific values. Agroforestry Systems.

[25] G. Ruecker, and C. Conrad (2004): Exploring leaf area index development and land cover classification in the lower Amu Darya Basin in Uzbekistan based on multi-temporal and multi-spatial remote sensing data. ZEF Work Papers for Sustainable Development in Central Asia, 4. 24 p. Available at http://www.unibonn.de/khorezm [last checked 6.6.2004]

[26] S. Herbst, T. Kistemann, and D. Fayzieva (2003): Comparison of the incidence of diarrhoeal diseases in two regions of the Aral Sea area, Uzbekistan. Brebbia CA, Fayzieva D (eds.): Environmental Health Risk II, 153-161, WIT Press.

[27] S. Herbst, T. Kistemann, and D. Fayzieva (2004): Monitoring of microbial drinking water quality and diarhoeal disease in the Aral Sea region, 6th International Congress "Water: Ecology and Technology" ECWATECH-2004, Moscow, 01.-04.06.2004.

[28] B. Ruzmetov, Z. Rahimov, and I. Rudenko (2004): Analysis of farm enterprises and agricultural markets in the region Khorezm (Uzbekistan). ZEF Work Papers for Sustainable Development in Central Asia, 2. 39 p. Available at http://www.uni-bonn.de/khorezm [last checked 6.6.2004]

[29] C. Wall and J. Lamers (2004): Farmer Priority Setting: Issues and Research Needs for Khorezm, Uzbekistan. ZEF Work Papers for Sustainable Development in Central Asia, 5. 39 p. Available at http://www.uni-bonn.de/khorezm

[30] M. Fowler (2004): UML distilled. Third edition. Addison-Wesley, Boston, 175 p.

[31] Grid-Arendal (2001): State of Environment of the Aral Sea Basin. Regional report of the Central Asian States' 2000. Available at http://www.grida.no/aral/aralsea/english/water/water.htm [last checked 6.6.2004]

[32] Australian Government. Department of Foreign Affairs and trade (2004): Uzbekistan fact sheet. Available at http://www.dfat.gov.au/geo/fs/uzbe.pdf [checked 6.6.2004]

[33] UNICEF (2004): At a glance: Uzbekistan - Statistics. Available at http.//www.unicef.org/infobycountry/Uzbekistan_statistics.html [checked 31.5.2004]

[34] J. Shirokova (2000): Problemy uchudshenia kachestva pochv v Usbekistane. Unpublished work paper, Tashkent.

[35] M. Müller (2004): Where Has All The Water Gone? Estimation of a production function for the agricultural sector in the region Khorezm, Uzbekistan.

Unpublished Draft Paper, ZEF Bonn, 19 p. 


\title{
WATER AND IRRIGATION IN AUSTRALIA
}

\author{
Keith L. Bristow \\ CSIRO Land and Water and CRC for Irrigation Futures, \\ PMB Aitkenvale, Townsville QLD 4814, AUSTRALIA \\ Keith.Bristow@csiro.au
}

\begin{abstract}
Having access to adequate good quality water supplies is fundamental to Australia's long term prosperity. This is being addressed through implementation of an ambitious water reform agenda, requiring Governments and communities to rethink how water is valued, allocated and managed. The aim is to deliver improved social, economic and environmental outcomes while at the same time returning all currently over allocated water systems to environmentally sustainable levels of extraction. Irrigation, as the single biggest user of water, will remain under scrutiny as it searches for new ways of improving water use efficiency while minimising unwanted environmental impacts. It is essential that Australia has well managed water systems that support productive and profitable irrigation within a catchment context. This paper provides a brief overview of key issues facing water and irrigation in Australia. It highlights in particular challenges facing irrigation and water management in the lower Burdekin, one of Australia's premier irrigation districts.
\end{abstract}

\section{Introduction}

There is an increasing need to ensure Australia's water resources are maintained in a healthy state to deliver social, economic, and environmental benefits. While this will not be easy, it is recognised as being critical to the long term prosperity of the country. This need is attracting greater attention from Governments and various parts of the community.

Australia, the world's driest inhabited continent, is a large country (770 million ha compared with 920 million ha for the continental USA) with a small population (20 million people compared with 290 million people in the USA). More than $80 \%$ of Australians live in 5 cities (Perth, Adelaide, Melbourne, Sydney, Brisbane) around the southern and eastern coastline (Figure 1).

This distribution in population leads to particular challenges as most urban dwellers have a limited understanding of the role of water in our natural and agro-ecosystems, and of the impacts resulting from the demands a largely urban society places on water and other natural resources. In contrast, rural landholders usually have a better understanding of the role of water in ecosystem function and food production, but many lack the financial resources to maintain environmental values associated with water. The lack of understanding and lack of resources to implement environmentally sustainable practices both contribute to the enormous pressure being placed on Australia's water and other natural resources. 


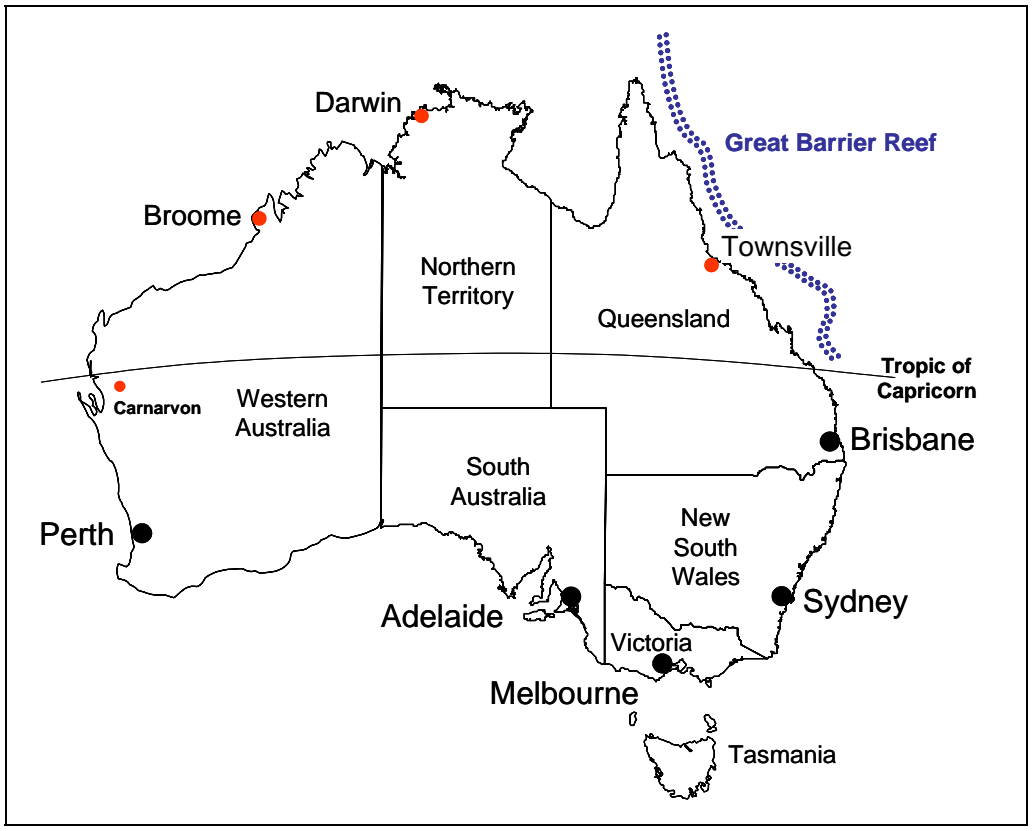

Figure 1: Map of Australia showing some key cities and the Great Barrier Reef

The Australian landscape is very old with generally low fertility soils. The landscape is also generally flat (mean altitude $200 \mathrm{~m}$ ) with low hydraulic gradients. This means that water and solutes (salts, nutrients, chemicals) tend to move slowly through the landscape. Salts, mainly of atmospheric origin, have therefore accumulated in soils over large parts of the continent over long periods of time.

The Australian climate is typically dry and highly variable. The aggregate rainfall is $455 \mathrm{~mm}$ per year, with $50 \%$ of Australia receiving $<300 \mathrm{~mm}$ rain per year, and only $20 \%$ receiving $>600 \mathrm{~mm}$ rain per year. Around $40 \%$ of the continent is too dry for any form of agriculture. There is significantly less (50 - $70 \mathrm{~mm}$ per year) and more variable runoff than any other inhabited continent. Given that some $70 \%$ of runoff takes place north of the tropic of Capricorn, and more than $80 \%$ of the population lives in 5 coastal cities south of the tropic of Capricorn, there is a huge mismatch between where the freshwater occurs (water supply) and were the people live (water demand).

There is also increasing competition between uses and users of water. There is a growing realisation that our surface water and groundwater is over allocated and in need of help if these systems are to continue to provide their goods and services well into the future. Redressing this will require a change in thinking for many. What has often been considered as wasted water passing by unused to the oceans, is usually part of the highly valuable 'environmental flow' required to maintain healthy catchments. 
When considering the value of water, one must also consider the quality, not just the quantity. Poor quality water (e.g. highly saline water) can limit the benefits of volume based environmental flows and lead to rapid degradation of natural resources (e.g. soils) which otherwise may only have been marginally affected by the same amount of good quality water. It is therefore important to understand and manage the interconnectedness of the water and solute (salt, nutrient, chemical) flow paths within catchments and to know what impurities are present and what role they have in exacerbating unwanted impacts.

Governments and communities are now realising how vital good quality water is to every aspect of the Australian economy. This has lead to a major water reform agenda and a growing number of community and Government programs aimed at improving water and other natural resource management issues within a catchment context.

This paper provides a brief overview of water and irrigation in Australia, an outline of the water reform agenda which is driving considerable change within the water sector, and a more detailed description of irrigation and water management in the lower Burdekin, one of Australia's premier irrigation districts.

\section{Water in Australia}

Recent statistics show that Australia used 20,000 GL of water in 1995/96 to support economic activities (Figure 2). That's equivalent to about 1 million litres per person.

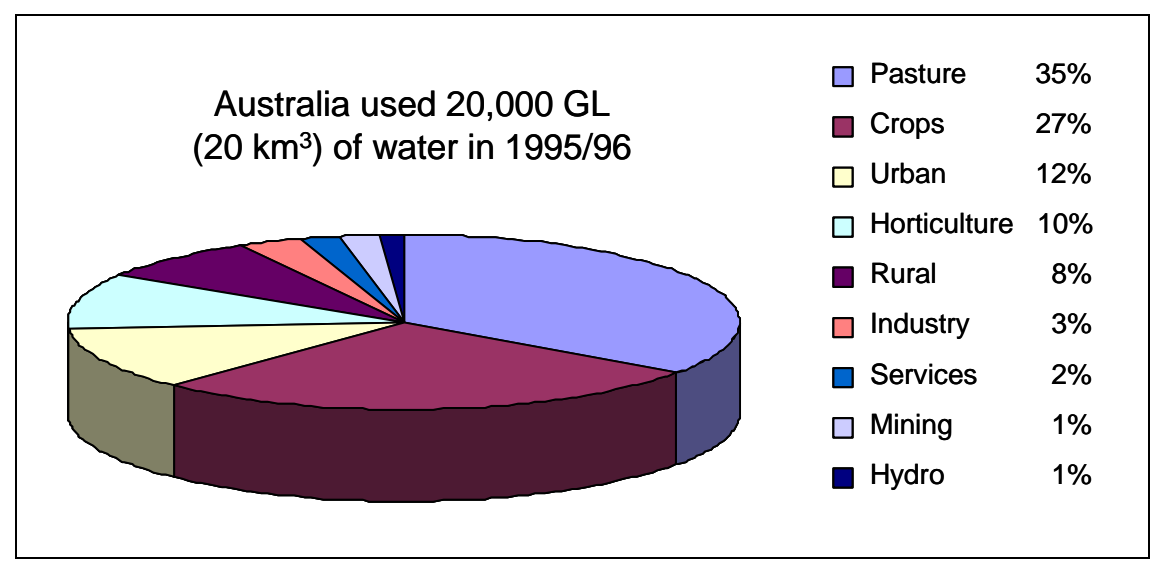

Figure 2: Water use in Australia [11].

The approach to water management has in most places changed over time, from capturing and storing more water (engineering and dams), to using it more efficiently (water use efficiency programs with emphasis on biophysical processes), to allocating it more equitably (a social process that addresses needs and makes explicit allocation for the environment). 
$-138-$

While improvements are evident, there is still room for more vigor in the debate about how water should be valued, allocated and managed, and how adjustments will be made to help ensure water is used most effectively. The aim should be to harness as much social, economic, and environmental value as possible from each litre of water that passes through a catchment while providing sufficient good quality water to support healthy river systems, estuaries and marine environments. Perhaps this will require a more businesslike approach, but it must involve urban and rural communities if Australia is to end up with robust, resilient and productive water systems.

\section{Irrigation in Australia}

Irrigated agriculture in Australia occupies only 2.2 million ha compared with 470 million ha for dryland agriculture. The fact that irrigated agriculture represents only $0.5 \%$ of Australia's agricultural land area but produces $49 \%$ of total profit highlights the importance of irrigation to Australia's economy. It also emphasises the importance of continually looking for new ways to improve the sustainability of irrigated production systems.

A large number of irrigation systems in Australia, like many around the world, are struggling to deliver on expectations because of increasing problems associated with rising water tables and salinization. There are fundamental differences between our natural systems and irrigation systems that are still not adequately understood and taken into account when designing and managing irrigation systems.

Most natural systems involve a range of species with different canopy heights and structures, different rooting depths and water requirements, and strategies to cope with climate variability (Figure 3 ). We can summarise natural systems as being characterised by:

- diversity (several different kinds),

- complexity (several components with various functions),

- variable water input (discrete and irregular rainfall events),

- continuity in nutrient cycling,

- little if any deep drainage, and a

- net downward movement of salt.

Introduction of irrigation (or just about any agricultural system) leads to fundamental changes in the natural system, and especially in its functioning. When converting to irrigation we introduce modified soil profiles, straight lines, single plant species with uniform canopy heights and rooting depths, and a regular supply of water (Figure 3 ). We can summarise most current irrigation systems as being characterised by:

- uniformity (oneness),

- simplicity (one component with one function), 
- regularity in water input (variable rainfall smoothed out by regular input through irrigation),

- discontinuity in nutrient dynamics (large inputs of fertiliser at planting and removal of massive amounts of product and dry matter at harvesting),

- excess deep drainage, and

- rising water tables and salinization.

It is obvious from the above that greater attention should be going into better understanding our natural systems so that irrigated (and other agricultural) systems can be designed to fit within the uniquely Australian environment. Designing agricultural systems to function more like natural systems even if they don't look like natural systems, should, in the longer term, lead to improved environmental performance.

To further improve irrigation water use we must improve our measurement, allocation, use conditions, and drainage, and be prepared to pay the full cost for managing all forms of drainage and effluents. We must also drastically improve our ability to irrigate precisely for crop need.

Meyer [7] stated that '... the single most outstanding issue is that irrigation must be accompanied by drainage. Without adequate provision for surface and subsurface drainage, without confronting the need to reuse, store or change the form of irrigation effluents, namely excess water, salt, nutrient and chemicals, irrigation will not be allowed or be economically viable in the long term ...' This statement still holds largely true. It highlights the fact that we have not learned the lessons from the past, and that we are still largely ineffective at managing drainage and salinity within an irrigation system context. We need to change this if we are to reverse ongoing degradation of many our systems around Australia and the world.

Irrigation in Australia is the single biggest user of water, accounting for some $70 \%$ of national water use. Of concern is that less than $30 \%$ of water stored in dams for irrigation is actually used by plants. More effort must be focused on improving water use efficiency (WUE). This will require identifying and reducing water losses at all points in the system, from water capture and storage, through the water transport and delivery system, to field application and plant water use. Development of improved sensors and monitoring systems is needed to assist in this area.

There is also a need to recognise that irrigation is a high energy input system and needs high level management input. This implies the need for a business approach to irrigation and suggests that water should, wherever possible, be used in high productivity - high return enterprises. Table 1 demonstrates typical quantities of water required to produce various products, highlighting how much water is needed to produce wool and diary products which rely heavily on irrigated pastures. 


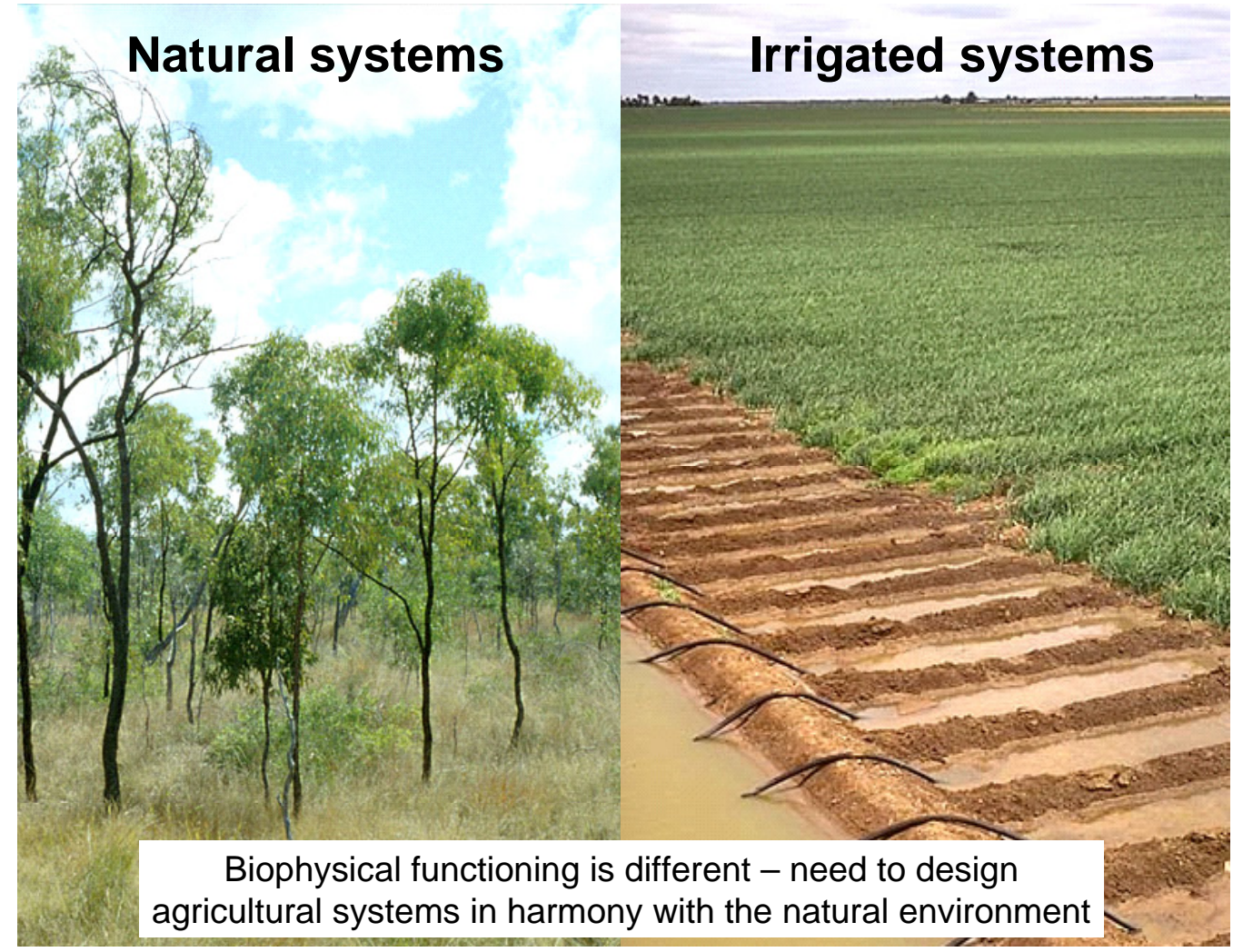

Figure 3: Example of a natural system (characterised for example by complexity and diversity) and an irrigated system (characterised for example by simplicity and uniformity) in which the biophysical functioning is different

Table 1: Water use per unit of production (d.m. = dry matter; Meyer, pers com. 2004)

\begin{tabular}{|l|l|l|l|}
\hline Crop & Yield (t/ha) & $\begin{array}{l}\text { Total } \\
\text { Evaporation } \\
(\mathrm{mm})\end{array}$ & kg water / kg yield \\
\hline Maize & grain 13.8 & 700 & 576 \\
\hline Rice (paddy) & grain 9.0 & 1200 & 1550 \\
\hline Cotton & lint 1.7 & 900 & 5300 \\
\hline Pasture (dairy) & d.m. 25 & 1500 & $600 /$ I milk \\
\hline Pature (wool) & d.m. 25 & 1500 & $171500 /$ kg wool \\
\hline
\end{tabular}

Table 2 demonstrates typical differences in the value added per mega litre of water applied ( $M L=1$ million litres). While it seems obvious from these data that it would be better for an individual to produce vegetables rather than say rice or sugar, one 
$-141-$

needs to be careful in generalising this as not everyone will be able to grow vegetables.

Table 2: Value added per ML of water applied (farmgate return - all costs; after [11])

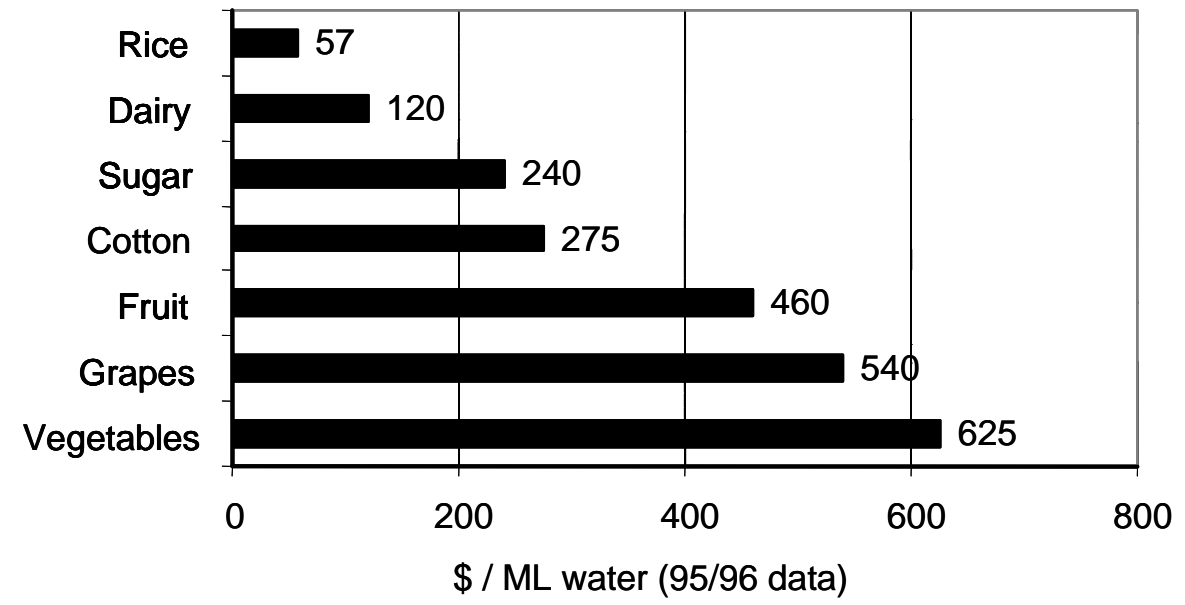

\section{Water reform - Coalition of Australian Governments (COAG) and the National Water Initiative (NWI)}

Water in Australia is vested in Governments who allow others to access and use water for a variety of purposes. By 1980 , almost all urban supply and most irrigation water was carried out under Government control, with water usually delivered well below cost. Increasing demands for water from all sectors of the economy (people, agriculture, industry, and environment) raised questions as to whether water was being put to best social, economic and environmental use. Organisational reform started in the late 1980's and culminated in 1994 with COAG (Council of Australian Governments; http://www.coag.gov.au/) agreeing on a National Agenda for Water Reform. This was a product of competition policy and ecologically sustainable principles. Key features of the 1994 COAG water reform agenda included:

- the water industry to be based on commercial principles, including privatisation or corporatisation of utilities

- separation of water wholesale and retail supply organisations

- performance monitoring at bulk and retail levels

- separation between supply responsibilities and regulatory functions

- prices based on consumption and to cover all costs of supply

- water rights to be separate property rights from the land

- markets for the free trading of water rights separately from land

- reduction of cross-subsidies in water provision

- specific water allocation to the environment

- integrated catchment management as the vehicle for resource management

- public involvement and consultation 
Australia has made considerable progress in some areas in moving towards more efficient and sustainable water management since 1994. Opportunities to complement and extend the reform agenda to more fully realise the benefits intended by the 1994 CAOG agreement has resulted in the National Water Initiative (NWI), an intergovernmental agreement between the Commonwealth Government of Australia and the Governments of New South Wales, Victoria, Queensland, South Australia, the Australian Capital Territory and the Northern Territory.

Full implementation of the NWI Agreement will result in a nationally-compatible, market, regulatory and planning based system of managing surface and groundwater resources for rural and urban use that optimises economic, social and environmental outcomes. It will achieve this through:

- clear and nationally-compatible characteristics for secure water access entitlements

- transparent, statutory-based water planning

- statutory provision for environmental and other public benefit outcomes, and improved environmental management practices

- completing the return of all currently over allocated or overused systems to environmentally-sustainable levels of extraction

- progressive removal of barriers to trade in water and meeting other requirements to facilitate the broadening and deepening of the water market, with an open trading market to be in place

- clarity around the assignment of risk arising from future changes in the availability of water for the consumptive pool

- water accounting which is able to meet the information needs of different water systems in respect to planning, monitoring, trading, environmental management and on-farm management

- policy settings which facilitate water use efficiency and innovation in urban and rural areas

- addressing future adjustment issues that may impact on water users and communities

- recognition of the connectivity between surface and groundwater resources and connected systems managed as a single resource

A National Water Commission (NWC) will be set up to assist in the implementation of the NWI through provision of appropriate advice to COAG. There is much debate taking place around the country as to how best to respond in meeting the NWI objectives, with particular attention being given to the water pricing reforms. The sorts of issues being addressed include the:

- capacity of the industry to meet scheme costs, particularly a rate of return on capital assets

- impact that water prices could have on the valued contribution rural industry makes to the local, regional and state economies 
$-143-$

- need for pricing to reflect the reliability of the supply of water

- transparency and efficiency of water supply costs

- need for Government to consider the implications of water prices for the implementation of other environmental reforms, particularly the implementtation of sustainable practices on farms

- need to ensure that irrigators do not bear the costs of the benefits to community from state wide water planning

- importance of ensuring transparency and efficiency of resource management at a catchment or regional level

- opportunity for schemes to move to local management if they wish

- etc

These are difficult issues for some to work through, especially when trying to accommodate specific needs of different regions while at the same time meeting the intent of the NWI.

There are also several other natural resource management programs with a significant water focus, all trying to ensure Australia's water resources are placed on a more sustainable footing. Plans of particular relevance include the:

1. National Action Plan for Salinity and Water Quality (NAP) - this involves a commitment of $\$ 1.4$ billion over seven years for applying regional solutions to salinity and water quality problems. The aim is for all levels of government, community groups, individual land managers and local businesses to work together in tackling salinity and improving water quality (http://www.napswq.gov.au/)

2. Natural Heritage Trust - this was set up by the Australian Government to provide funding to community groups and organisations to help restore and conserve Australia's environment and natural resources (http://www.nht.gov.au/)

3. Reef Protection Plan - the overall aim of this plan is to halt and reverse the decline in the quality of water entering the Reef within 10 years in order to achieve a sustainable future for the Reef and the industries in the Reef's catchments

(http://www.gbrmpa.gov.au/corp site/key issues/water quality/rwqpp.pdf)

The Reef Protection Plan is of particular importance in Queensland (Figure 1) where it is increasing pressure on all industries in catchments draining into the Great Barrier Reef Lagoon to review and improve their land and water management practices. Irrigation, which uses large of amounts of water, nutrients and other chemicals, is receiving particular scrutiny, especially in the Burdekin catchment which has been identified as one of the high risk catchments in all categories identified within the Reef Protection Plan. 


\section{The Lower Bourdekin}

The lower Burdekin is one of Queensland's premier irrigation areas with a reputation for producing some of the highest yields and highest quality sugarcane in Australia. It is situated in the dry tropics on the northeast coast of Queensland, Australia, approximately 90 kilometres southeast of Townsville (Figure 4). It has 80,000 ha of irrigated sugarcane and other crops and is dependent on access to large quantities of good quality water. Furrow irrigation is the dominant method of irrigation used on more than $95 \%$ of irrigated land.

While large parts of the lower Burdekin are underlain by extensive groundwater systems, security of surface water supplies was increased dramatically in 1987 on completion of the Burdekin Falls dam. It is the largest water storage in Queensland with a capacity of $1,860,000 \mathrm{ML}$. This water is used to supply surface irrigation water particularly to the Burdekin-Haughton Water Supply Scheme, and to recharge aquifers in the Burdekin delta, where groundwater is the main source of irrigation water.

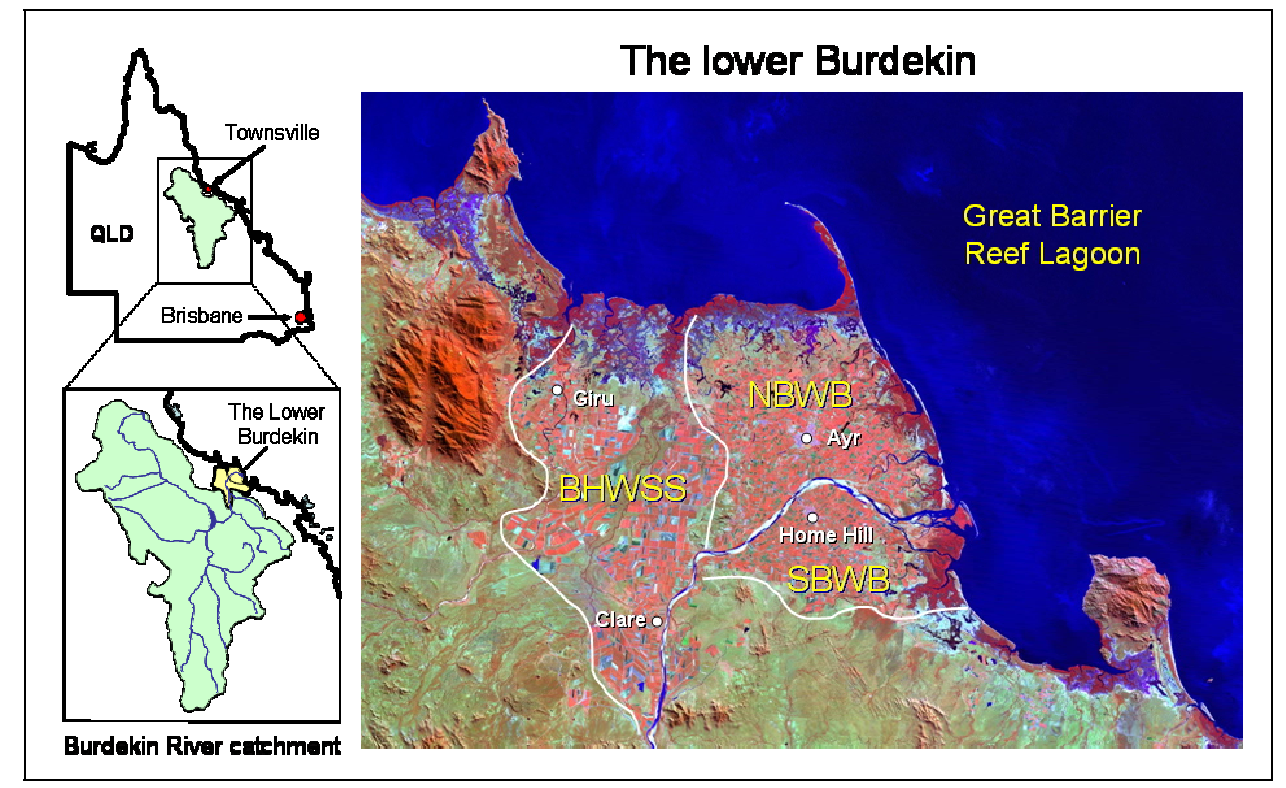

Figure 4: Locality map and satellite image showing the lower Burdekin and adjacent Great Barrier Reef Lagoon (BHWSS = Burdekin Haughton Water Supply Scheme; NBWB = North Burdekin Water Board; SBWB = South Burdekin Water Board).

Water management in the lower Burdekin is carried out by three different organisations (Figure 4). The Burdekin Haughton Water Supply Scheme (the BHWSS), which is managed by SunWater (a Government owned Corporation), lies mainly to the north and west of the Burdekin River and stretches from inland of Clare down through Giru towards the coast. Nearly all of the remaining irrigated area falls within the Burdekin delta system, which lies closer to the coast on both the north and 
south side of the Burdekin River. These areas are managed by the North Burdekin Water Board (NBWB) and South Burdekin Water Board (SBWB), respectively. These autonomous Boards are funded by the industry.

The lower Burdekin delta is unique in that

1. it overlies shallow major groundwater supplies and relies heavily on these supplies for irrigation water

2. it is situated in close proximity to environmentally sensitive wetlands, waterways, estuaries, and the Great Barrier Reef

3. water pricing and water management practices have evolved in response to local needs. These currently do not meet COAG water reform requirements.

Most irrigation water in the Delta is drawn from groundwater bores. While there is currently minimal direct metering of bores, the Water Boards maintain a close check on water level and quality trends. Details of the Burdekin delta system and operations of the two Water Boards are described in the next section. The connection between the Delta groundwater systems and the BHWSS aquifers is not yet fully understood.

As in most parts of the world, irrigation in the lower Burdekin has come under increasing scrutiny. Governments, environmentalists and other community groups have questioned the way water is allocated and managed, and in some cases increased pressure to make changes to current practices. Responding in a meaningful way to these pressures requires full understanding of water use in the lower Burdekin. This is being addressed through the Lower Burdekin Initiative (LBI) which has brought a range of organisations together in an industry/science partnership. The issues being addressed are multi-faceted and complex, and beyond the capability of one organisation, or discipline, or individual. Further detail regarding the LBI is given by [2], [4] and in the LBI section below.

\subsection{The Delta Water Boards}

A series of very dry years in north Queensland in the early 1960's and unprecedented pressures being placed on the Burdekin delta groundwater systems led to the formation of the NBWB and SBWB in 1965 and 1966, respectively. The Delta Water Boards have a charter that requires them to manage replenishment of groundwaters contained in an open aquifer system that is subject to a constant threat of seawater intrusion. Figure 4 shows there is a very long land-ocean frontage that needs protection.

The Water Boards currently use a number of strategies to manage groundwater replenishment, including the use of sand dams in the Burdekin River and a series of distribution channels and natural waterways together with large recharge pits. The sand dams are constructed and maintained in the Burdekin River and are used to help maintain practical operating levels at river pump stations by containing releases from upstream storages. Farm water practices such as 'recycling', and 'water 
spreading' or direct pumping from recharge channels to farms in some distal aquifer zones have also evolved to play an integral role in the management of the groundwater systems (Figure 5).

'Recycling' refers to the practice where irrigation water from private production bores that is not used by the plants (excess irrigation) returns through the soil back to the groundwater. It is felt that this helps with the recharge and maintenance of groundwater levels. 'Water spreading' refers to the practice where Board pumped river water that is too turbid to be used for artificial recharge via the recharge pits (because it clogs the pits making them ineffective) is made available across the scheme benefited area as surface water for farm irrigation. This helps spread the silt load across the farmland and, while keeping the silt out of the recharge pits, is thought to benefit the soils and assist the replenishment process.

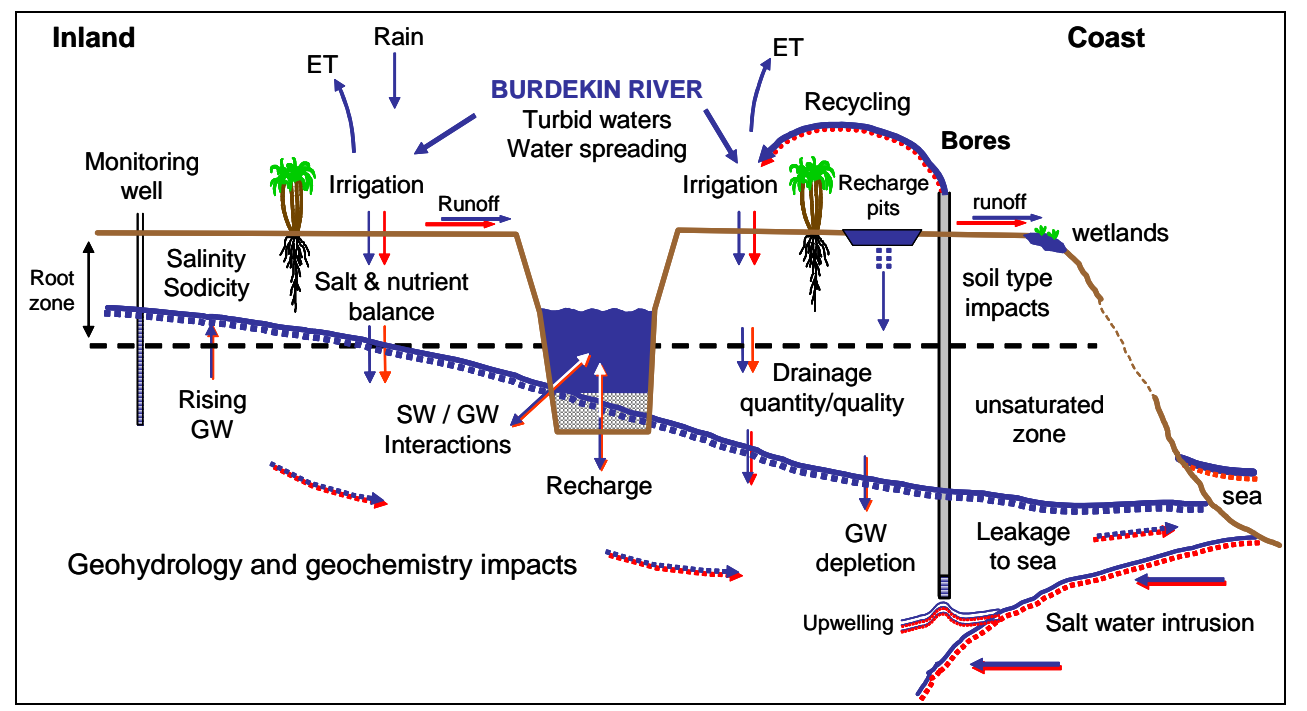

Figure 5: Lower Burdekin Framework showing interconnectedness of water (blue arrows) and solute (red arrows) balance terms and key issues to be addressed when assessing water resources and water management in the lower Burdekin (GW = groundwater; SW = surface water; $E T=$ evapotranspiration)

The SBWB operates three main river pump stations and three relift stations while the NBWB operates three main river pump stations and eight relift stations. The purpose of these pumping stations is to divert water from the Burdekin river into main supply channels to service additional works including secondary supply channels, natural waterways and lagoons, lagoons that serve as balancing storages, and recharge pits. In recent years, the NBWB has also started to shift its emphasis from pure recharge to groundwater management via conservation. The aim here is to encourage growers to take open water direct from the Board's distribution system so as to reduce the net demand on the aquifer. To help achieve this, the distribution 
system is currently being broadened. Although a perceived benefit of this approach is improved groundwater quality, there are currently insufficient data to demonstrate this. The Delta Water Boards are non-profit making organisations and have since inception had all operational, maintenance and infrastructure costs funded by the serviced industries. Additional details of the lower Burdekin and Water Boards are provided by [3] and [6].

\subsection{Linking groundwater quantity / quality with on-farm practice}

A major concern within the lower Burdekin in recent years has been the realisation that there is insufficient data and knowledge of the interaction between current scheme and farm activities and groundwater quality / quantity and other offsite impacts. It is therefore difficult to assess whether the practices and hence continued use, or increased use, of the groundwaters are indeed sustainable in the long-term. Of particular importance are questions relating to the impacts of current and improved irrigation efficiency on 'recycling' and 'water spreading' and the subsequent interactions with nutrient, salt and chemical loading of the groundwaters (Figure 5). From a long-term sustainability point of view, these could be the most critical issues affecting the whole system, together with the threat of salt water intrusion as discussed later.

When contemplating making changes to the way water is managed in the lower Burdekin it is essential that we take a systems approach to water resources and water management, and be fully aware of and understand the interconnectedness of the various water balance components (flows and storages). Considerable effort has, and is going into, developing this understanding. Figure 5 summarises many of the key factors and issues identified so far as being critically important. Depending on which area within the lower Burdekin, these issues include water quality, rising ground waters, salinity, nutrient leaching, groundwater pollution, falling water tables (groundwater depletion) and salt-water intrusion, amongst others.

Improving water use efficiency (WUE) and sustainability requires full understanding of what is meant by these terms:

- Do we mean improved WUE on a particular paddock, or for the scheme as a whole?

- $\quad$ Are they the same thing ?

- If something works in one region will it work in a nearby region with different soils and crops?

- If we talk about sustainability, what is the time period we are interested in ?

In addressing these issues we need to understand the likely impacts of maintaining the status quo, or of implementing changes at the farm and/or irrigation scheme level. When making changes we need to avoid shifting problems from one area to another, or generating different and maybe worse problems because we have not fully explored the impact and flow-on effects of changes we think need to be made. 
Development and application of appropriate modelling tools and scenario analyses will clearly be important in tackling these issues and are currently receiving considerable attention by various organisations involved in the LBI. This includes development and application of a range of modelling tools ([6], [3] and [10]), and where possible, coupling of biophysical and economic models (e.g. [9]). The aim is to design economically viable solutions based on practical management practices that are suited to the different areas, but that together lead to improved water management and use across the lower Burdekin.

Effective management of salinity is an ongoing challenge in the lower Burdekin. There are three different causes of salinity, each requiring different management techniques. Dryland salinity in the upper catchment affects the water supply from the Burdekin River and ultimately the quality of water available for irrigation. Irrigation is by default a 'concentrating' process and demands considerable effort in understanding and managing the water and salt balances of different soils within different parts of the irrigation scheme. The third form of salinity is salt-water intrusion. This is particularly important in the lower Burdekin because of its proximity to the ocean, the dependence on groundwater supplies for irrigation, and the very small change in elevation across the delta. This can make it difficult to maintain adequate groundwater levels to ensure the salt-water wedge is subjected to a sufficient pressure head to prevent it moving inland. Salt-water intrusion could be one of the major threats faced by the lower Burdekin. Studies aligned with effective management of the water table are in progress to understand how best to manage the salt water wedge [8].

As mentioned above, irrigation is a concentrating process. The leaching fraction (LF) concept has been developed to help address this by managing the salt balance within the root zone. However, if inappropriately applied, the LF could be one of the main reasons causing rising groundwaters in many irrigated areas, as the inclusion of LF's can lead to large quantities of water draining below the root zone. This water is usually not considered 'wasted water', and there is currently discussion as to whether this additional water applied for deliberate leaching of salts should be considered as "irrigation water beneficially applied" [1]. Based on this, LF's are thought to be of benefit at the farm enterprise level. What has not been adequately addressed when applying LF's is the effect the 'excess irrigation' may have on leaching of soil applied nutrients and chemicals, and the potential on- and off-site effects such as pollution of ground and surface waters. Also, the impacts on the broader groundwater systems and potential for causing rising water tables have not been adequately considered. These issues need further study.

Given the potential problems associated with LF's, perhaps the whole concept needs rethinking, at least in those situations with problematic soils and geohydrology. Would it not be better to match irrigation with plant needs and rely on rainfall and inevitable inefficiencies in irrigation management to ensure a net downward movement of salts out of the root zone ? If irrigation water quality is such that salt 
accumulation still occurs, then it suggests that irrigation will not be sustainable unless adequate subsurface drainage and appropriate management of the drainage waters are implemented. The choice therefore seems to be between careful scheduling with no specific LF, or application of a LF and implementation of proper management of the deep drainage. Either way, it is important that irrigation be properly scheduled. To achieve this the irrigation scheme water must be available to each irrigation field as and when it is needed.

The LF concept also provides an interesting contrast with current water and irrigation management practices that have evolved in the Burdekin delta. These practices include 'recycling' and 'water spreading', both of which can result in excess irrigation. This excess irrigation is viewed by some as part of the groundwater replenishment program and hence as positive. Others however view the excess irrigation as 'wasted water' because it is not used by the plants and can carry nutrients and chemicals to depth, and hence as negative. Perhaps this excess irrigation, which results in higher water contents in the unsaturated zone, helps maintain an effective connectivity between the soil surface and underlying aquifer. If this is the case then perhaps it underpins the overall recharge of the aquifers by facilitating distributed replenishment, which could be more effective in managing regional groundwater levels than the point replenishment from relatively few scattered recharge pits and canals. Ensuring effective recharge of the aquifers and maintaining appropriate groundwater levels is essential to prevent inland migration of the salt-water wedge. One wonders if this excess irrigation should also be viewed as "irrigation water beneficially applied", but in this case mainly for the benefit of the scheme (the groundwater reservoir) rather than the individual farm. Gaining a better understanding of these issues is part of the current LBI efforts.

While implementing various management strategies to deal with the water associated with excess irrigation may be feasible, what is probably more important to consider is the potential long-term impact excess irrigation may have on soil applied nutrients and chemicals. It also means that more effort needs to go into understanding and managing soil applied nutrients and chemicals, particularly within a systems framework that properly accounts for the impacts irrigation has on the storage and transport of nutrients and chemicals in different soils. Here again, it will be important to move beyond simple individual aspects (such as the behaviour of an individual chemical species under steady state and constant temperature conditions) and learn how to deal with the interactions and function of the system as a whole (multiple chemical species in a changing thermal and water environment).

This is clearly not a simple task, but all that has been covered above highlights the need for irrigation system managers to plan for and manage the water, nutrients and chemicals that are likely to move out of the root zone, either as surface runoff or deep drainage. It is clear that while we 'understand' particular features of irrigation, we still do not fully understand how to put it all together so that we can optimise 
irrigation performance in different areas. We must make progress with this to ensure we get the system as a whole to work in an economically viable and sustainable way.

Efforts are now also underway to analyse the lower Burdekin monitoring systems and data collection so that they can be changed and/or improved to support better decision making. Of critical importance are the bore data, which provide information about the health of the groundwater systems and the location of the salt-water wedge. They will also play an important role as the groundwater models move from the development to application phase. Examples of bore data from the BHWSS and Delta regions are provided in Figure 6 and Figure 7, respectively, and illustrate some interesting differences that need to be understood and acted on.

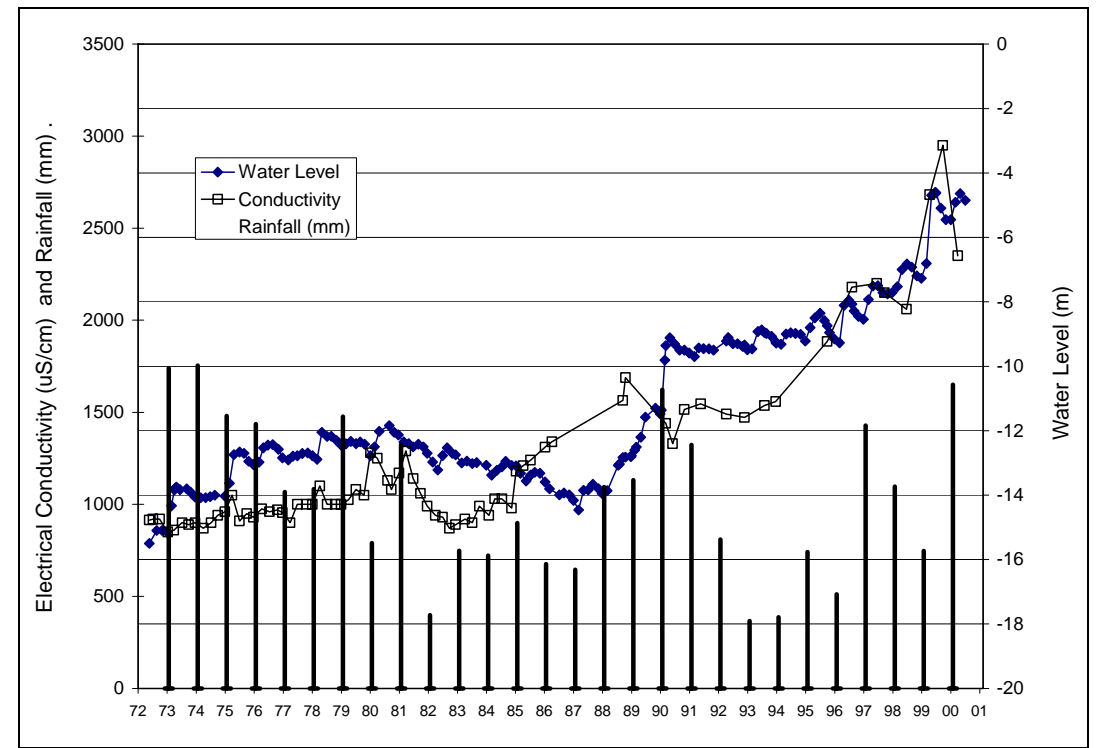

Figure 6: Water level and electrical conductivity of a representative bore in the BHWSS from 1973 to 2000. Annual rainfall is given by the vertical bars.

The BHWSS data in Figure 6 show water levels and conductivity from 1973 to late 2000 , the striking feature being the gradual increase in water level and conductivity with time. The water levels varied by less that $4 \mathrm{~m}$ between 1973 and about 1987, and appear to reflect the general trend in rainfall, which was relatively high through to 1981, and then relatively low through to 1987. After this point there is a rapid increase in water levels, a stabilisation through the very dry period from 1993 to 1996, and then a gradual increase again through to the present. The onset of the increasing trend also coincides with the availability of more surface water in the late 1980's following completion of the Burdekin dam. Salinity has also shown a significant increase with time, from less than $1000 \mu \mathrm{S} / \mathrm{cm}$ to around $2500 \mu \mathrm{S} / \mathrm{cm}$ in 2000. These trends must not be allowed to continue. Land and water managers will need to review and implement more appropriate management practices to reverse these trends. 
The Delta data in Figure 7, which covers a longer time period than in Figure 6, show water levels and conductivity from 1963 to late 2000. The striking feature about these data is the responsiveness of the groundwater levels to rainfall, the clear seasonal variation, and the rapid increase in salinity to very high levels above $6000 \mu \mathrm{S} / \mathrm{cm}$ in the late 1960's early 1970's. This is then followed by a gradual decrease to around $1500 \mu \mathrm{S} / \mathrm{cm}$ in 2000. The dry spell in the 1960's resulted in rapid declines in water levels to around $-12 \mathrm{~m}$, which have since improved, with strong seasonal variations and a gradual increase since 1994 to current levels, which are within a few meters of the surface. These data suggest that the replenishment programs instituted by the Water Boards have been effective in improving water levels and that they may also have played a role in improving the salinity status, at least in the vicinity of this bore.

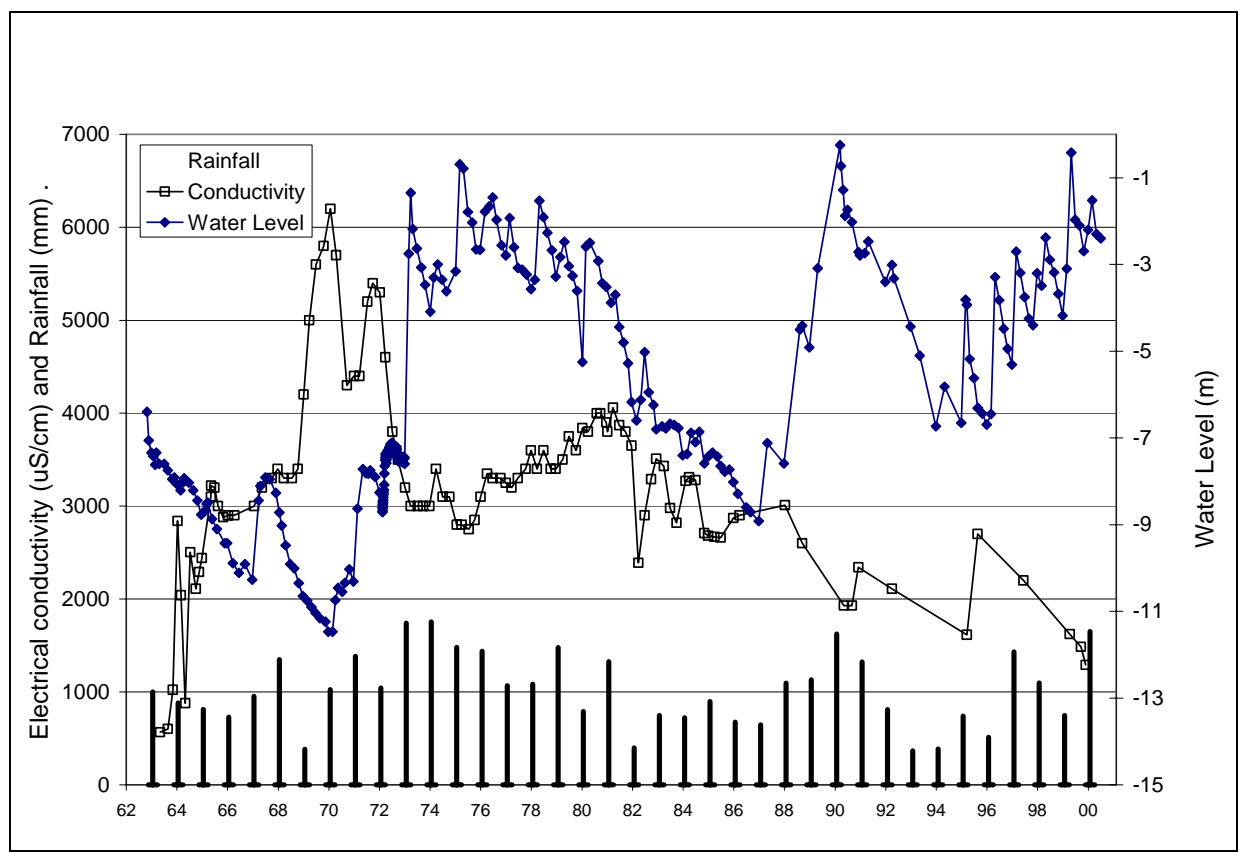

Figure 7: Water level and electrical conductivity of a representative bore in the Delta from 1963 to 2000. Annual rainfall is given by the vertical bars.

These bore data contain a wealth of information and if carefully analysed and properly understood, should be of help when tailoring specific solutions for specific regions. They also emphasise the need to monitor both water and salt levels as they can behave very differently in different parts of the system. We also need to monitor a range of other nutrients and chemicals in order to obtain a more complete understanding of the true health of the groundwater systems.

Government agencies (NR\&M) are drawing on the work described above in developing ground and surface water models that in time will be linked to provide an 
overall resource assessment and management tool. The aim in developing these tools is to ensure water dependent ecosystems are maintained in good order whilst providing certainty for water use entitlements, and where possible future allocations. NR\&M have also recently completed the Burdekin River Catchment Study that will provide input to the Water Resource Plan on potential development scenarios to be evaluated in the Plan. This planning will attempt to address and resolve competing interests between up valley users as well as users in the lower Burdekin, taking account of the social and environmental needs within the Burdekin catchment.

\subsection{Water quantity}

Improving understanding and effective management of the water balance at field, sub-region and irrigation system levels remains a challenge but is vital to ensuring long term sustainability of the lower Burdekin system. Obtaining accurate data to compile water balances is not easy because most of the bores in the delta region (around 2000 production bores) are not metered. Studies in recent years have provided some data that are helping build a better understanding of the field scale water balance (Figure 8). Some farmers still use large amounts of irrigation water, and deep drainage from the root zone can also be large, more than $5000 \mathrm{~mm}$ a year. It is the quality of the drainage water that is of particular concern and this is addressed in the next section. Of particular importance from a water quantity point of view is what is happening to the water table. Parts of the system are suffering from groundwater depletion through excessive pumping while other parts are experiencing rising water tables and salinization (Figure 5).

What has become clear from this work is the need to set and meet local and regional water table targets, in terms of quantity (water table depths) and quality. While these will need to be spatially specific, it is not yet clear whether a temporal component will be needed. Providing both farm and scheme managers with water table targets will help guide development of management strategies to achieve these targets. This would involve a focus on recharge strategies in parts of the system, and surface and deep drainage management strategies in other parts of the system.

Maintaining water table heights and required hydraulic heads near the land-ocean interface will be particularly important in terms of minimising threats of salt water intrusion. This may require rethinking the number and location of current production bores, and if need be their removal along the coastal fringe. If this were to happen, it would require a change in irrigation practice involving greater reliance on surface water supplies to these parts of the system. Given current understanding based on 2-D cross sectional modelling of saltwater intrusion [8], it is essential that the saltwater wedge not be allowed to migrate inland as it may be difficult or even impossible to push back once it has penetrated inland. A three dimensional density induced flow model is now needed to assess impacts of the large number of pumps $(\approx 2000)$ currently employed in the delta, which affects stability of the saltwater interface. 
$-153-$

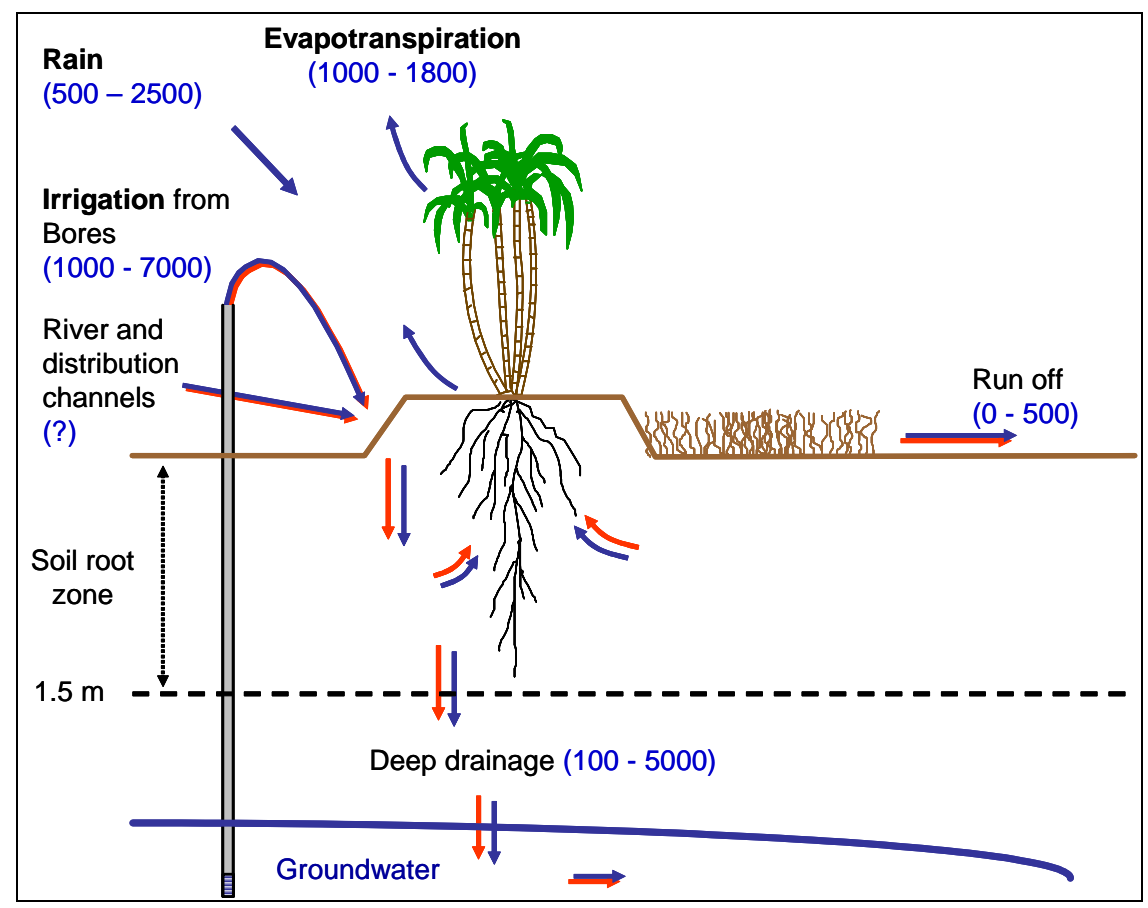

Figure 8: Schematic showing components of the annual water balance for sugarcane in the lower Burdekin (units are $\mathrm{mm}$ per year)

\subsection{Water quality - The fate of nitrogen $(\mathrm{N})$}

To address water quality it is important to understand the nitrogen $(\mathrm{N})$ balance and to be able to determine the fate of $\mathrm{N}$ applied as part of farming (Figure 9; Figure 5). There are several sources of $\mathrm{N}$, the main source being fertiliser $\mathrm{N}$, which is typically $160-220 \mathrm{~kg} \mathrm{~N} \mathrm{ha}^{-1} \mathrm{yr}^{-1}$ on sugarcane farms in the lower Burdekin. Small amounts of $\mathrm{N}$ are also added via rainfall, some could be applied via irrigation water drawn from the river, and large amounts of $\mathrm{N}$ are potentially available via irrigation water drawn from bores. Measurements show that nitrate-nitrogen concentrations of bore water used for irrigation can vary from very small amounts to more than $10 \mathrm{mg} \mathrm{L}^{-1}$ (Figure 10) [5]. Applying $20 \mathrm{ML} \mathrm{ha}^{-1} \mathrm{yr}^{-1}$ irrigation drawn from a bore with $10 \mathrm{mg}$ nitratenitrogen $\mathrm{L}^{-1}$ would add a further $200 \mathrm{~kg} \mathrm{~N} \mathrm{ha}^{-1} \mathrm{yr}^{-1}$ on top of whatever fertiliser $\mathrm{N}$ is applied. Although these are seemingly large quantities of $\mathrm{N}$, we see from Figure 9 that, depending on soil type, it could be relatively small compared with the total $\mathrm{N}$ that can be held by the soil and organic matter in and above the root zone. This can add to the difficulty in ascertaining what happens to the applied $\mathrm{N}$.

Ideally, the $\mathrm{N}$ we apply as fertiliser will be used by the crop and removed from the field when the crop is harvested. It is clear from Figure 9 however that we are only removing a fraction, between $30-70 \%$ of the fertiliser $\mathrm{N}$ applied. 


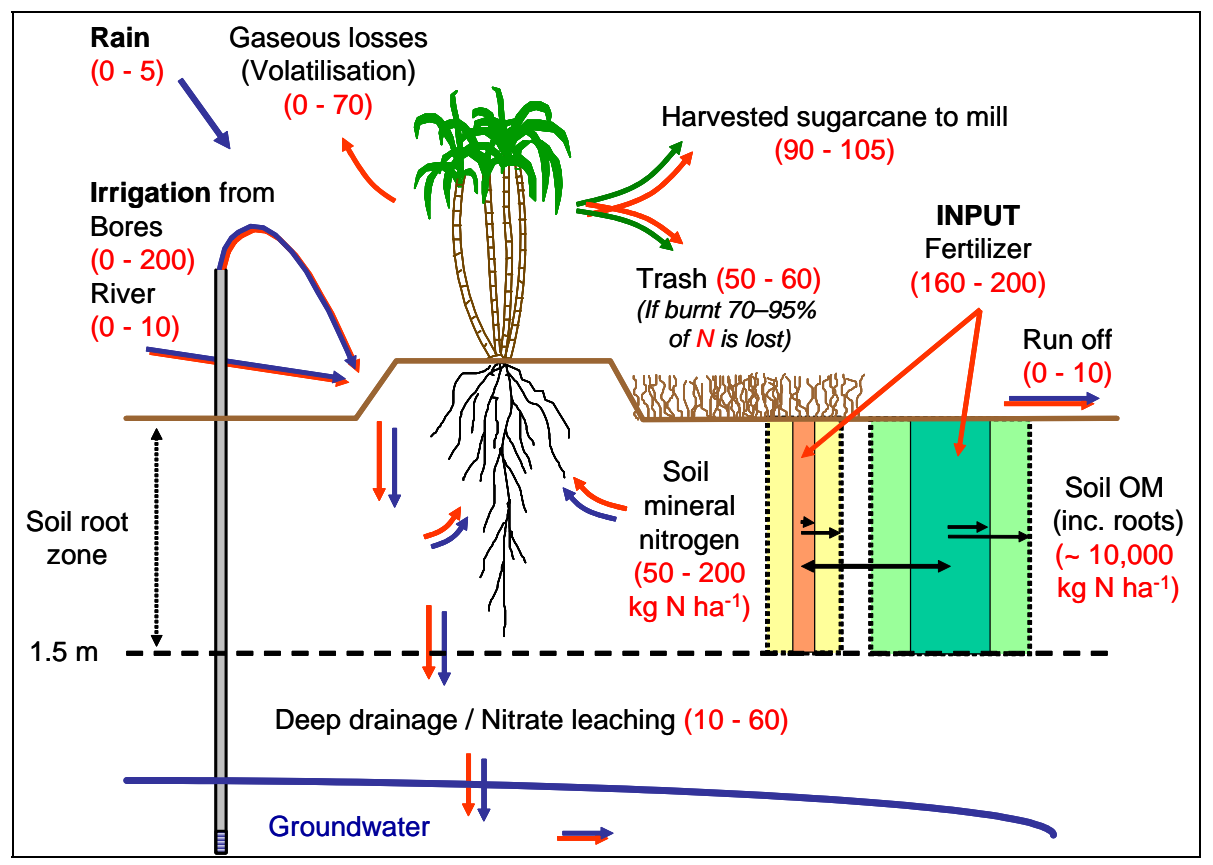

Figure 9: Schematic showing likely ranges in nitrogen balance components in $\mathrm{kg} \mathrm{N} \mathrm{ha}^{-1} \mathrm{yr}^{-1}$ for sugarcane. Fertiliser inputs range between 160 and $220 \mathrm{~kg} \mathrm{~N} \mathrm{ha}^{-1} \mathrm{yr}^{-1}$ for target crop yields of $100-150$ t ha $^{-1}$ (OM=organic matter)

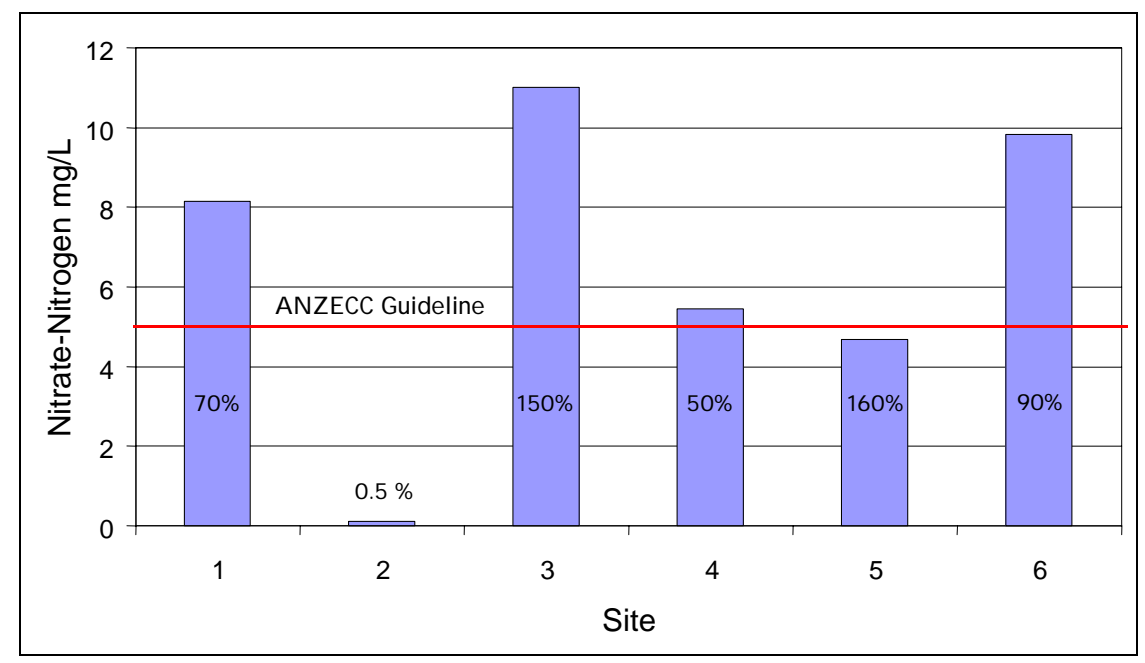

Figure 10: Nitrate-nitrogen levels of irrigation water drawn from bores at selected sites across the Burdekin delta. The numbers in each column indicate the amount of nitrogen added via irrigation during an irrigation season (2000/2001) as a percentage of the recommended nitrogen fertiliser rate of $200 \mathrm{~kg} \mathrm{~N} \mathrm{ha}^{-1}$. The $5 \mathrm{mg} \mathrm{L}^{-1}$ is the ANZECC long term environmental trigger value 
Given that there can be as much or more $N$ applied via irrigation as applied via fertiliser, there are potentially large amounts of $\mathrm{N}$ unaccounted for that will either build up in the system or leave the system through volatilisation, denitrification, surface runoff, or deep drainage. The $\mathrm{N}$ retained in the system will build up in the organic matter (above and below ground) and soil mineral $\mathrm{N}$ pools. Once the upper limit of these pools has been reached, large amounts of $\mathrm{N}$ could then relocate within or leave the system with potentially unwanted impacts on downstream rivers, groundwaters, wetlands, and near shore marine environments.

While there is concern about these issues, our ability to accurately quantify the fate of applied $\mathrm{N}$ is lacking. One reason is that it is difficult and expensive to measure the various components of the $\mathrm{N}$ balance, and there are no long term field sites where efforts have been or are being made to measure each of the $\mathrm{N}$ balance components independently. The data on various $\mathrm{N}$ balance components that are available tend to come from different field sites, with different soils, climates, and histories. This leaves uncertainty about the relationship between the various components and uncertainty about our ability to accurately close the $\mathrm{N}$ balance at particular sites.

Of particular interest is the amount and fate of $\mathrm{N}$ that leaves the root zone as deep drainage. We need to know if it is held in the unsaturated zone above the water table, and if so, for how long before it enters the groundwater systems. Determining the fate of $\mathrm{N}$ once it enters the groundwater systems is crucial, as we need to know whether it goes back into the river systems, wetlands, or out into the near shore marine environment. This is important in terms of setting and meeting within catchment and end of catchment water quality targets and protecting the Great Barrier Reef from excess nutrients.

'Fluctuating' water tables and their role in 'stripping' $\mathrm{N}$ and other solutes from the root zone is also not fully understood. This could be important in terms of the overall $\mathrm{N}$ balance given that water tables in the region can rise and fall by several meters in relatively short periods of time in response to wet season rainfall and drawdown through bore extraction for irrigation. We need to understand these processes to improve our modelling capability, and hence analysis of the longer term fate of applied N.

There are also concerns given current measurement techniques that we are underestimating the amount of $\mathrm{N}$ entering the groundwater systems. Many of the bores tend to be relatively deep, drawing groundwater from near the base of the aquifer. When making measurements of bore water quality it is fairly common for large quantities of bore water to be extracted until some measure such as EC stabilises, before samples are removed for $\mathrm{N}$ analysis. This could enhance mixing of the deeper groundwater resulting in a lower average concentration of a particular constituent. Sampling water from near the top of the aquifer is likely to provide a more accurate assessment of the $\mathrm{N}$ entering the groundwater system. If $\mathrm{N}$ is entering the groundwater system in this way, it could be beneficial to extract water for irrigation from the upper parts of the aquifer. This would enable better recycling of $\mathrm{N}$, 
$-156-$

and by accounting for $\mathrm{N}$ applied in this way, could lead to associated reductions in the amount of $\mathrm{N}$ applied as fertiliser and hence improvement in groundwater quality.

It is clear that there are many important issues regarding water and $\mathrm{N}$ balances that need to be addressed in the lower Burdekin. This will require both field measurement and modelling approaches in order to make progress. Klok et al. [5] through their measurement program and Stewart et al. [10] through their modelling efforts have already made some progress. More effort is needed, however, particularly in linking the land and water management practices with the groundwater systems, to accurately determine the actual fate of applied N. Perhaps of higher priority in fostering short and long term economic and environmental benefits is to cut back on $\mathrm{N}$ applications through a $\mathrm{N}$ replacement strategy as suggested by Thorburn et al. [12].

\subsection{The Lower Burdekin Initiative and Associated Programs}

The Lower Burdekin Initiative (LBI) was established in 1999/2000. It comprises a number of community, industry, regulatory, research, and environmental groups working together to address community concerns about the long-term sustainability of current management practices. It is also helping minimise duplication and fragmentation of the research effort aimed at addressing these issues. This is not a simple task and requires a gradual change in trust levels among the many groups, and in so doing building a better understanding of their different motives and drivers.

When considering the roles of the various industry, community, and science groups involved, there are three conditions that need to be met to realise the benefits of effective collaboration. These are:

1. the groups involved should appreciate the value in sharing resources and data, the skill base of other groups, and that the result of integration is greater than the sum of the individual parts,

2. the existence of a high level of trust that every group is both competent and focussed on the overall goal, and

3. the maximum amount of data and knowledge is made available to all bodies and debated in an open, honest and vigorous way.

The challenge to integration is that when transcending group boundaries, for example the industry-research boundary, both groups usually have limited understanding of each other's expertise and motivation and this can lead to incompatibility. For instance, industry usually wants rapid answers to its real or perceived problems to enable timely incorporation of improved processes and methods. The emphasis is on quick solutions that have a high likelihood of leading to improvements. On occasion, the timescales used may mean important consequences of these expected solutions have not been adequately considered. 
Conversely, the researcher's quest is usually to understand as much as possible about the problem or system being addressed. The motivation being that such understanding could lead to a package of highly robust solutions with clear connection not only to the initial question, but also to other associated questions. The main limitation of this approach is that the time required to gain this knowledge is often too slow to meet immediate industry requirements. It also assumes that complete understanding and hence prescriptive solutions are possible in natural systems with high degrees of complexity and uncertainty, something that is probably highly unlikely. The LBI process has had to grapple with this and challenge the research groups to deliver practical solutions (or improved management strategies) in a timely manner.

Funding (e.g. via the Natural Heritage Trust) is being increasingly directed through community groups such as the Burdekin Dry Tropics Board and Burdekin-Bowen Integrated Floodplain Management Advisory Committee (BBIFMAC). While these groups are well suited to identifying some areas that require attention, particularly regarding on-ground works, their understanding of research methods for addressing more complex long term problems can in some cases be limited. This impacts on true collaboration, since for the community to play an effective role in the research it needs reasonable knowledge of the methods employed.

Studies of these issues have suggested that all groups involved in collaborative efforts need extra skills, and that when developing the participatory framework such as that adopted in the LBI, energy needs to be invested in capacity building [13]. The diagram given in Figure 11 describes the process involved in addressing research needs in a collaborative manner, and shows the need for iteration in the needs analysis process following wider consultation with other groups. This will ultimately lead to a set of objectives and research methods that all groups both endorse and understand, with the ultimate goal of increased ownership of research outcomes and wider adoption. The process should encourage the incorporation of all data, assumptions, and uncertainty judgements into the needs analysis/research method decision. Continuous evaluation of the collaborative process is required to ensure the overall objective is still relevant and is being met. Several different strategies are being attempted within the LBI in an effort to achieve this.

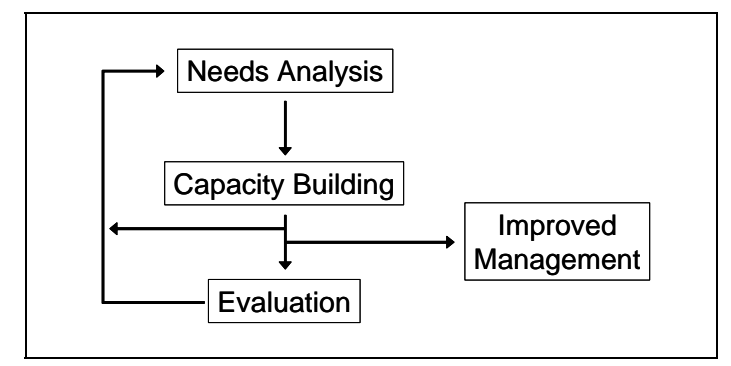

Figure 11: Essential steps in the collaborative process (adapted from [13]) 
The original vision of the LBI was to produce a robust modelling framework based on accurate information that can be used to highlight strengths and weaknesses of current and potential irrigation and water management practices, and to provide direction for future research. While the LBI has been largely successful in helping the lower Burdekin move along this path it needs to keep reviewing itself and evolving to ensure it adds value to the overall process. Part of this process involves linking with other local, national and international programs. The most recent success has been the inclusion of the Burdekin catchment as a Demonstration catchment within the UNESCO HELP program. The aim of the UNESCO HELP program is to encourage integrated catchment management through the creation of a framework for water law and policy experts, water resource managers and water scientists to work together on water-related problems; just what the LBI has been doing.

\section{Concluding comments}

Current indications are that demand for water will continue to increase and that water resources in parts of Australia will become more stressed before we are likely to see improvements.

Water reform will remain high on the agenda for the next few decades as efforts intensify to increase the productivity and efficiency of Australia's water use while addressing the health of river and groundwater systems. A key goal within this reform agenda is to return all water systems to environmentally sustainable levels of extraction.

Irrigation, as the largest single user of water, will remain under scrutiny to ensure efficiency improvements are ongoing. While there is an ongoing need to improve our understanding and management of components of an irrigation system, the more important need is to understand and make the whole irrigation system work. This will require better understanding of how natural systems function, together with improved design and/or modification of irrigation systems so that they function more like natural systems in tune with the uniquely Australian environment. It will also require people to work both individually and collectively to ensure effective and sustainable management of our water and irrigation systems.

It appears that significant benefits can accrue from setting and meeting local and regional water table targets in irrigation systems that rely on groundwater for their water supplies. The targets need to accommodate both quantity (water table depths) and quality objectives, and serve as a catalyst for ongoing refinement and improvement of practical management strategies to ensure the targets are met.

Sustainability of irrigated systems is still being hampered by poor solute management practices, especially in terms of salt and nitrogen management practices. The nitrogen replacement strategy is one approach worthy of further 
$-159-$

attention in an effort to minimise the ongoing application of excess nitrogen. Lack of adequate drainage and lack of approved disposal strategies for excess drainage water of various qualities are also hampering progress. The aim in addressing these issues needs to be practical and profitable management guidelines that can be readily implemented by land and water managers.

We can be certain that Australia's water future will be different to what it is today. It will need to include well managed water systems that support productive irrigation within a sustainable catchment context. To get there will require

- new thinking and more vigorous debate about how water should be valued, allocated and managed,

- more effective communication and greater understanding and trust between urban and rural communities, and

- society as a whole to take responsibility for designing and implementing more sustainable urban and rural water management practices.

Progress in these areas is critical to the long term success of all sectors of the Australian economy which is ultimately dependent on access to adequate supplies of good quality water.

\section{Acknowledgements}

I thank Professor Harry Vereecken and his staff of the Research Centre in Jülich for facilitating my participation in the Environment Colloquium and for their hospitality during my stay in Jülich. My thanks also to a wide range of colleagues and collaborators whose efforts have been central to much of the work discussed in this paper.

\section{References}

[1] Barrett Purcell and Associates Pty Ltd. (1999): Determining a framework, terms and definitions for water use efficiency in irrigation. Published by Land Water Resources Research and Development Corporation, 23 pages.

[2] Bristow, K.L., Charlesworth, P.B., Lowis, B., Laidlow, G., \& P. Gilbey (2001): The Lower Burdekin Initiative: An industry/science partnership to facilitate improved water management. In: Proceedings of the ANCID Conference, 29th July - 1 August, Bunbury, Western Australia, Australia.

[3] Bristow, K.L., Charlesworth, P.B., McMahon, G.A., Arunakumaren, J., Bajracharya, K., Ham, G., Sutherland P., Laidlow, G., Lowis, B., Nielson, G., Qureshi, E., Christianos, N., Enderlin, N. \& S. Eldridge (2000): Towards a more integrated approach to water management in the Burdekin delta irrigation area. In: Proceedings ANCID Conference, 10-13 September 2000, Toowoomba, Australia. 12 pp. 
$-160-$

[4] Charlesworth, P.B., Bristow, K.L., Stewart, L.M., Narayan, K. A. \& R. Greiner (2003): The Lower Burdekin Initiative - water management practices to support regionally sustainable communities. In: Proc. Aust. Soc. Sugar Cane Technol. Vol 25, 8 pp.

[5] Klok, J.A., Charlesworth, P.B., Ham, G.J. \& K.L. Bristow (2003): Management of furrow irrigation to improve water use efficiency and sustain the groundwater resource: Preliminary results from a case study in the Burdekin delta. In: Proc. Aust. Soc. Sugar Cane Technol., Vol. 25. 7 pp.

[6] McMahon, G.A, Arunakumaren, N.J \& K. Bajracharya (2000): Hydrogeological conceptualisation of the Burdekin river delta. In: Hydro 2000, Proceedings of the 3rd International Hydrology and Water Resources Symposium of the Institution of Engineers, Australia, 20-23 November 2000, Perth W.A., pp. 208213.

[7] Meyer, W.S. (1997): The irrigation experience in Australia - Lessons for the sugar industry. In 'Intensive Sugarcane Production' (Eds. BA Keating and JR Wilson JR) pp. 437-454 (CAB International, Wallingford).

[8] Narayan, K. A., Schleeberger, C., Charlesworth, P. B. \& K.L. Bristow (2003): Effects of groundwater pumping on saltwater intrusion in the lower Burdekin delta, north Queensland. In: Post, D.A. (Ed), MODSIM 2003 International Congress on Modelling and Simulation. Volume 1: 224-229. Modelling and Simulation Society of Australia and New Zealand, July 2003.

[9] Qureshi, M.E., Mallawaarachichi, T., Wegener, M.K., Bristow, K.L., P.B. Charlesworth \& S. Lisson (2001): Economic evaluation of alternative irrigation practices for sugarcane production in the Burdekin delta. Australian Agricultural and Resource Economics Society 45th Annual Conference, 23-25 January 2001, Adelaide, Australia.

[10] Stewart, L., Charlesworth, P.B. \& K.L. Bristow (2003): Estimating nitrate leaching under a sugarcane crop using APSIM-SWIM. In: Post, D.A. (Ed), MODSIM 2003 Intern. Congress on Modelling and Simulation. Vol. 1: 218-223. Modelling and Simulation Society of Australia and New Zealand, July 2003.

[11] Thomas, J.F. (1999) Water and the Australian Economy. Australian Academy of Technological Sciences and Engineering, Parkville, Australia.

[12] Thorburn, P.J., Park, S.E. \& I.M Biggs. 2003. Nitrogen fertiliser management in the Australian sugar industry: Strategic opportunities for improved efficiency. In: Proc. Aust. Soc. Sugar Cane Technol. Vol. 25. 12 pp.

[13] Walker, D.H., Cowell, S.G. \& A.K.L. Johnson (2001): Integrating research results into decision making about natural resource management at a catchment scale. Agricultural Systems 69: 85-98. 


\section{Hydropower and Sustainability}





\title{
HYDROPOWER AND SUSTAINABILITY
}

\author{
K. U. Birnbaum and J.-F. Hake \\ Research Centre Jülich \\ Systems Analysis and Technology Evaluation (STE) \\ $D-52425$ Jülich, Germany \\ k.birnbaum@fz-juelich.de
}

\begin{abstract}
Hydropower is a renewable energy source. Compared to solar radiation or wind, hydropower generates continuously and calculable electricity at a high yearly availability. The water flow does not depend on short-time fluctuations caused by calm or storm for wind or by clouds for photovoltaic generators. The efficiency is high and it is hoped as well as expected, that hydropower will play an increasingly role in the future energy carrier mix.

The main supply contribution of hydropower is rendered by large dams, of which 45.000 exists world-wide. In the past these dams were built often enough without taking into account their social or ecological impacts. Today the international community has a better understanding of the cause-effect-chains and there is a strong international opposition, which requires a greater consideration of environmental, social and economic aspects in the assessment of new hydro projects and in the management and operation of existing hydro facilities too.

The report analyses the relevance of water for the world population with a focus on sanitation, health, food production and electricity generation. Against the background of a rising electricity demand and the availability of electricity the potential of hydropower is analysed as well as the impacts on environment. The report closes with remarks on the sustainability of hydropower.
\end{abstract}

\section{Introduction}

First proofs of the purposeful use of hydropower come from the 2nd millennium before Christ, when water wheels were used for scooping in Mesopotamia. Greeks and Romans advanced the technique and employed it in order to grind grain. The first known technical description of a watermill was given by the roman architect and engineer Marcus Vitruvius Pollio, who wrote the theoretical manual "De Architectura" in the times of the emperor Augustus [1].

The technical evolution had continued so far in the following time, that the efficiency of the water wheels could be tripled opposite the earlier ones. However, it lasted up to the 8th century, to the cheap human worker (Slaves) were replaced by water wheels as prime mover on a large scale. About 500.000 water wheels are supposed to have been operated in the 18th century in Europe, in order to grind grain, to drive forging hammers or saws in order to call only some few targeted applications. 
In the 19th century the water wheels themselves were replaced by the advanced development, water turbine. They were characterised by a higher efficiency opposite to water wheels and were suitable for the operation of a very important and helpful technical innovation, the electrical generator. Because of missing long distance transmission technique it took a while until hydropower became widely used.

\section{Hydropower}

\subsection{Types of hydropower, facilities and turbines}

According to the mode of operation one distinguishes mainly three different kinds of hydropower stations, as shown with the pictures in Figure 1.
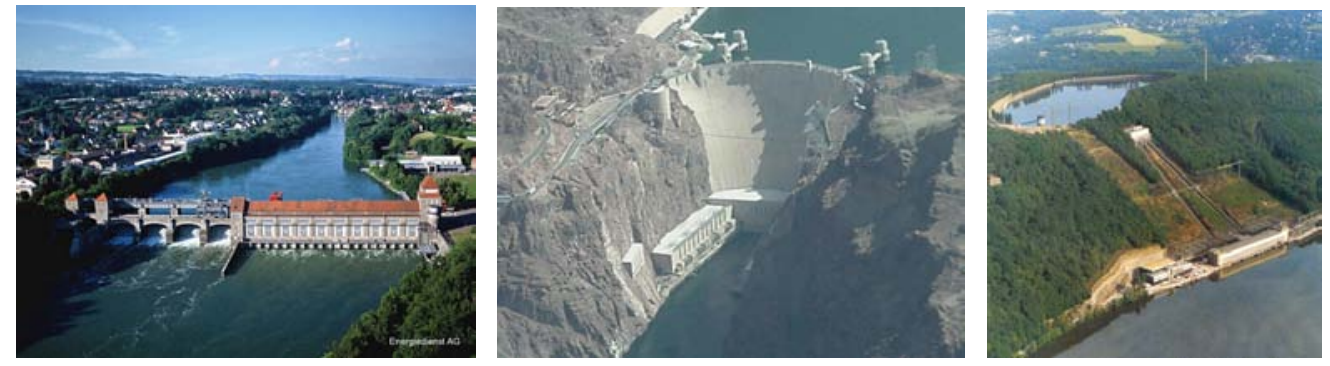

Figure1: Examples of hydropower types

Run-of-River power stations (diversion facility) use the available vigour of the river flow and generate constant base load electricity. The capacity of the power station depends form the volume of the water flow and its velocity, so to say it depends from the largeness of the creek, rivulet or river and its drop. When the river flow falls the generation decreases and it can happen while dry periods that the generation stops. The opposite can happen too, the generation must stop, as the installation is unexploited against flooding by long running heavy rainfall [2].

At Storage power stations rivers are impounded by a dam so that man made lakes/reservoirs arise. The large volume of the reservoir makes the power production relatively independent from variations in short-term inflow and enables to supply relatively quick changing load curve, to generate peak power or to control the frequency and others more. Depending from the volume of the reservoir, it is even possible to shift the electricity generation over from rainy seasons with high inflow rates to dry seasons.

A special type of hydropower utility is the pumped storage power station. The intension for its development was the wish to store electricity in form of water. At times with cheap excess electricity water is pumped from a river or a lake to an upper sited reservoir, from where the water is bled over penstocks onto turbines to generate electricity faster than other power plant types on demand. As the reservoir 
volume is limited, the power production can be hold only for a certain time, perhaps some hours or so.

In a today's hydro-electric power plant the turbine still represents one of the most important elements during the transformation of water-energy into electricity. The choice of a certain type of turbine is determined with regard to the local facts like the volume of running/falling water, which depends from the dimension of the river or the reservoir, and the height of standing water - labelled as "head". There are the two categories reaction and impulse turbine with three very common representatives:

The Pelton-turbine appertains to the group of the free jet turbines/wheels. It is an impulse turbine where the water flows onto the shovels with very high rate and hits in free jet on the running wheel (Figure 2). The potential vigour of the water is converted into kinetic energy already in the guiding-appliance.

The turbine has 20 to 40 running wheel shovels according to its size. These running wheel shovels consist in the middle from two closure halves with a partition. The water hits on the edge from one or several variable nozzles with high pressure between the closure halves. The water jet is distracted in the shovel hollows around almost $180^{\circ}$ and gives off his vigour to the turbine almost completely. Pelton-turbines are set in mainly in power facilities with very high drop heights between the reservoir and the power house and can be as large as 200 megawatts.

Francis-turbines belong to the reaction turbines and most widespread since they are universally usable. They are suitable for drop heights up to 500 meters. The water flows onto the with counter-rotation curved shovels of the running wheel through a guiding-apparatus with adjustable shovels, see Figure 3.

The water enters the turbine via a snail-shaped curved tube. In order to fit the turbine capacity to the requirements, the inflowing water can be adjusted by the adjustable shovels of the guiding-apparatus. The worked off water is discharged in an axial direction. The turbine axis can be stored differently. With power stations with larger service and greater drop heights it is installed as a rule uprightly. Francis-turbines achieve an efficiency of about $90 \%$ and a capacity of 800 megawatt.

A representative of the axial-flow reaction turbines is the Kaplan-turbine, shown with Figure 4. This type is qualified in particular for watercourses at which great water amounts are available at small slopes. Vertical built-in Kaplan-turbines are used in run-of-river power stations for drop heights to a maximum of $65 \mathrm{~m}$. The guiding-apparatus consists of blind-like lamellae and has the task of leading the inflowing water masses so that they hit on the shovels of the running wheel parallel to the turbine wave. Both the shovels of the guiding-apparatus and the shovels of the running wheel are adjustable. They are adapted to the variations of the water guided tour and the slope. 
$-166-$

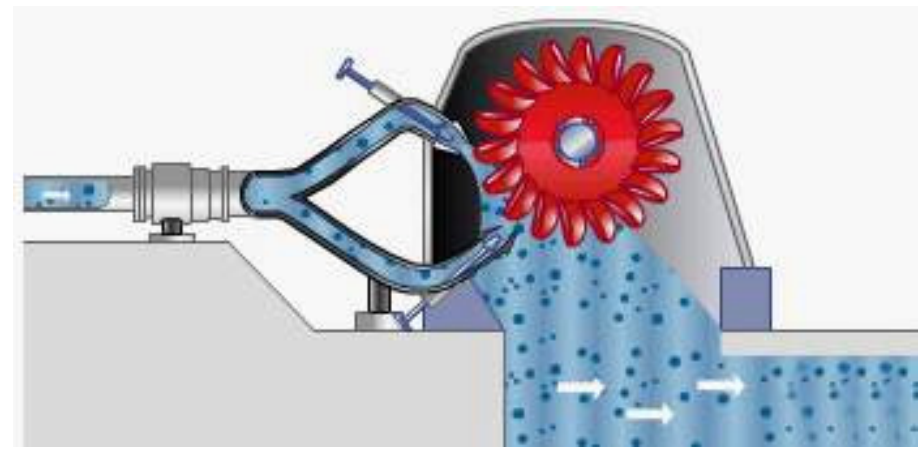

Figure 2: Pelton-turbine for hydropower.

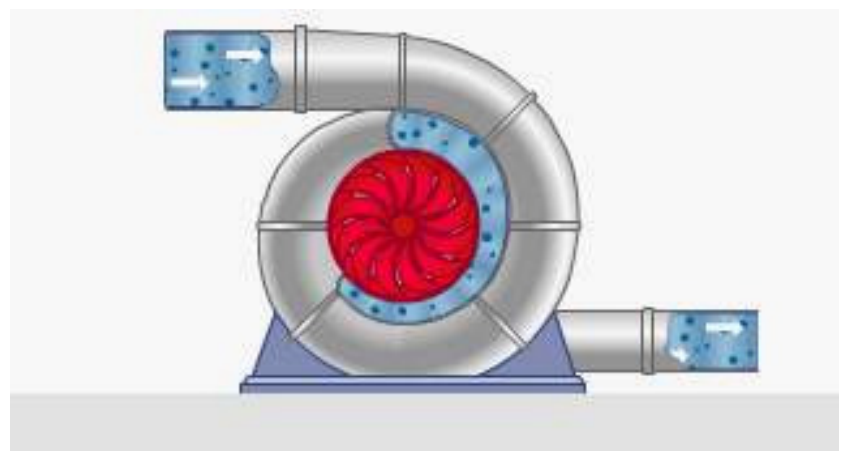

Figure 3: Francis turbine.

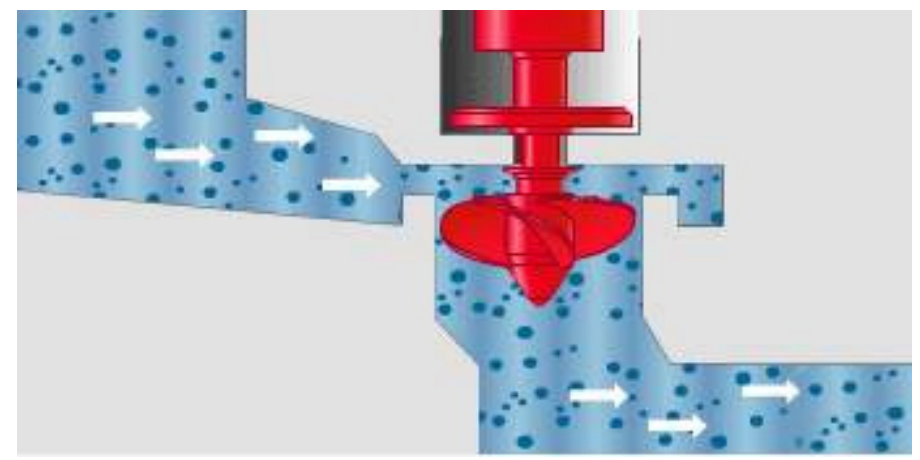

Figure 4: Kaplan-turbine (running water because low height and much water). 
According to the application area Kaplan-turbines are equipped with three to six running wheel shovels. Big ones are mainly vertical built-in so that the water flows from above to below. Kaplan-turbines run most extremely fast and have an efficiency up to $95 \%$ and can be as large as 400 megawatt.

\subsection{Classification to the size of hydropower plants}

Hydro power is available in a range of sizes from a few hundred watt to over some $\mathrm{GW}$. But there is not a real international consensus on the size-classification. The norms vary from country to country, even in the EU, where facilities of less than $10 \mathrm{MW}$ are regarded as "small" and those with $10 \mathrm{MW}$ and more as "large-scale hydropower" [3]. Respecting the different international conventions, it seems to be tolerable to classify four categories, as shown with Figure 5.

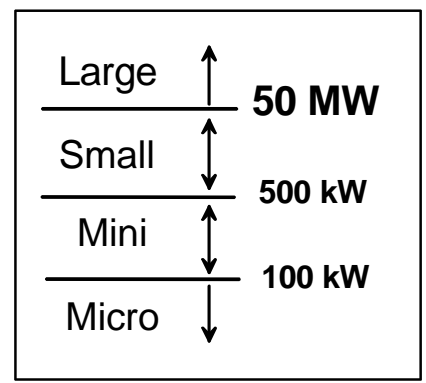

Figure 5: Classification of Hydropower Schemes

Naturally the Micros and Minis are run-of-river facilities, whereas the rivers are of small to middle European category, that means rivers like the Ruhr. Often they supply an industrial firm or they are operated by private owners and feed electricity into the grid. The category Small and Large, build as run-of river plants need a larger water flow. There is for example a $108 \mathrm{MW}$ facility at the upper Rhine. The limit for the run-of-river type seems to be in the range of 1 to $2 \mathrm{GW}$, but for such a capacity you need really large rivers, like the St. Lawrence in North America.

The most common types of hydropower and those which are mostly discussed today are large to ultra large storage schemes, with which large rivers are impounded and whole valleys as well as wide regions are inundated.

There are more than 45.000 large dams worldwide, and more than 300 of them defined as 'major dams' - giants - which meet one of a number of criteria on height (at least 150 metres), dam volume or reservoir volume.

The highest rate at which large dam-projects were planned and constructed was between the 1950s and the mid of the 1970s with around 1.000 schemes per year. But that rate has declined to around 260 projects per year since the early 1990s. A couple of reasons are responsible for that development, for example the depletion of 
the technical potential, economical reasons, in form of raising construction costs, and last but not least the opposition and resistance of the people which are living in the area of the storage lake.

\section{Electricity Demand and Hydropower Capacity}

In the past century the energy demand rose rapidly and although the curve at upward gradient loses, a stagnation or a decrease cannot be predicted yet, see Figure 6. As reasons can be seen at one hand the energy demand of the industrialised countries with a relatively high productivity and on the other hand the effort of the threshold and developing countries to improve the living standards by industrialisation which needs energy for building production facilities and infrastructures as well as transportation routes/lines and others more.

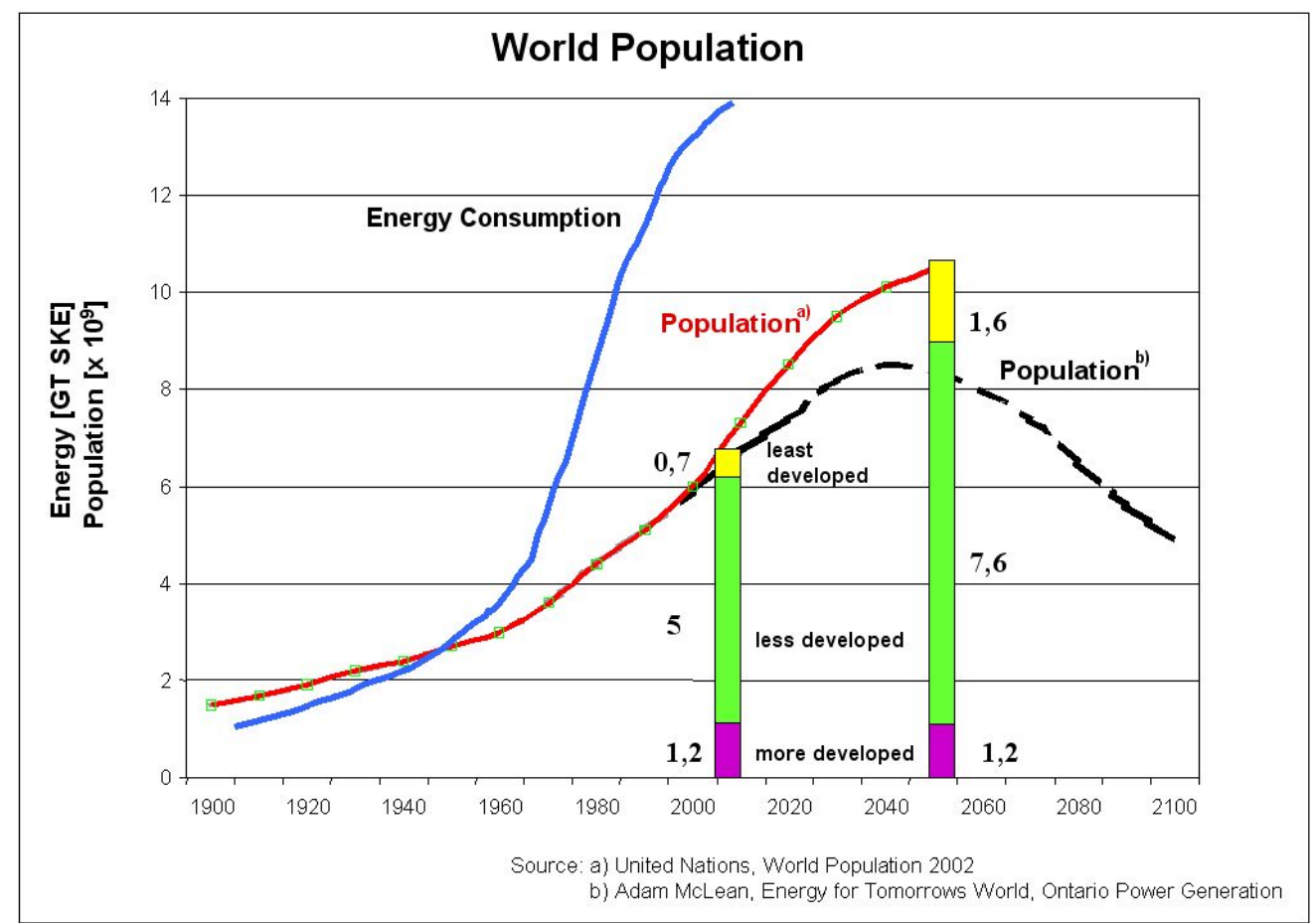

Figure 6: Energy consumption and population growth.

At the moment, coal and oil are the dominant primary energy carriers, followed by natural gas, see Figure 7. But it must be seen, that the resources of oil and of natural gas too are not unlimited. Therefore also other resources must be used to supply the growing demand in the future. For environmental reasons, stopping and reducing of the carbon-dioxide-emission, the availment and development of all technically feasible potential from clean renewable sources. 
$-169-$

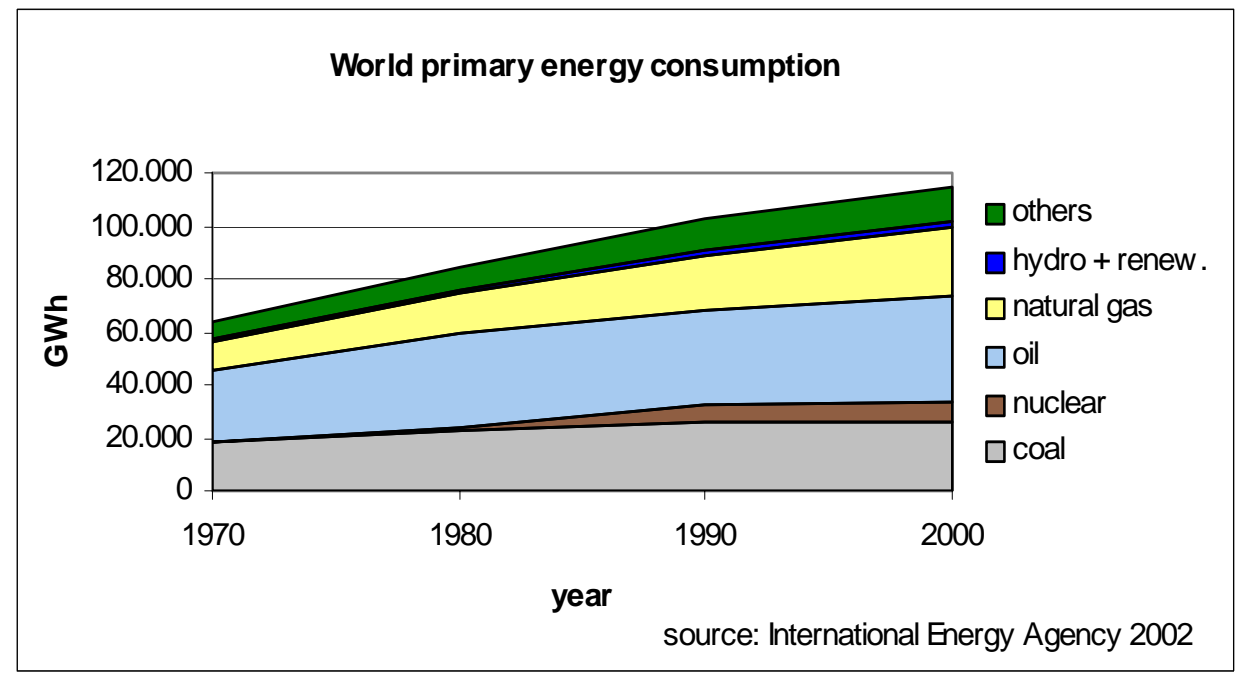

Figure 7: Development of the world primary energy demand.

A high efficient and in the use clean energy carrier is electricity, which has meanwhile a share of $18 \%$ at the final energy consumption worldwide. Figure 8 shows the results of a scenario of the World Energy Outlook 2002, which underlines the growing importance of electricity as final energy carrier in the future.

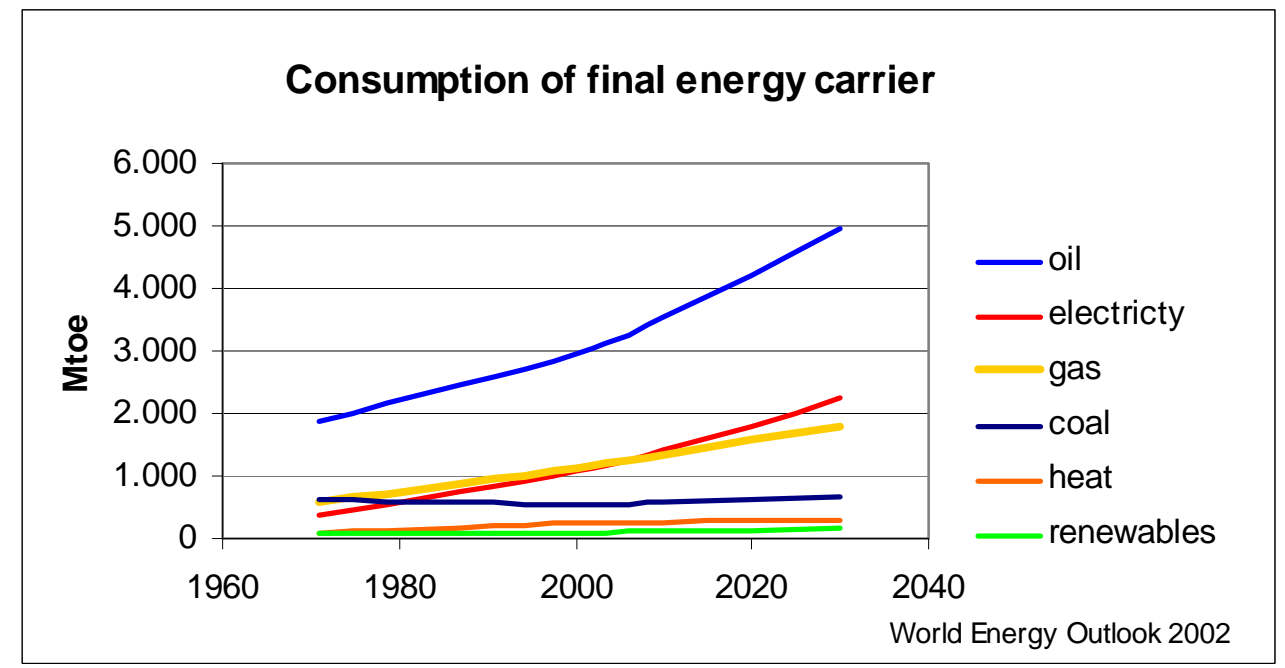

Figure 8: The importance of electricity as final energy carrier [4].

The still existing dominance of oil or oil products is mainly caused by the transportation sector. But for stationary applications, electricity has passed not only 
$-170-$

coal in the early 80th but also the natural gas around 2000 and it is assumed, that that development is irreversible.

The main fuel for electricity generation is coal, which has a share at the generation of nearly $40 \%$. Because of its chemical composition coal is a fuel with a high level of greenhouse gas and acidification potential. That potential or better the environmental impact of the flue gas components can be reduced and limited by technical features as flue gas desulphurisation, denitrification, dust removal and carbon dioxide sequestration. All these measures need a high investment and consume several percentage points of the efficiency of the generation process. The lack of capital and the high effort for retrofitting are responsible for the fact, that many coal power plants are not equipped with modern cleaning systems. Figure 9 demonstrates that the share of nuclear power generation decreases from $18 \%$ to $16 \%$ while natural gas did win some \%-points. The use of oil for electricity generation is reduced significantly, among others because of the restrictions on burning heavy oil and the raising oil prices. The share of hydropower and other renewables remained relatively constant at a value of $\sim 20 \%$ over the last 15 years, whereby it raised in absolute terms, from 2.300 TWh in 1990 up to $2.900 \mathrm{TWh}$ in 2002. (Without the growing wind capacity the share would have reached only $17 \%$. In 1990 the world wide wind capacity amounted to $2 \mathrm{GW}$ and in 2002 to $32 \mathrm{GW}$.)

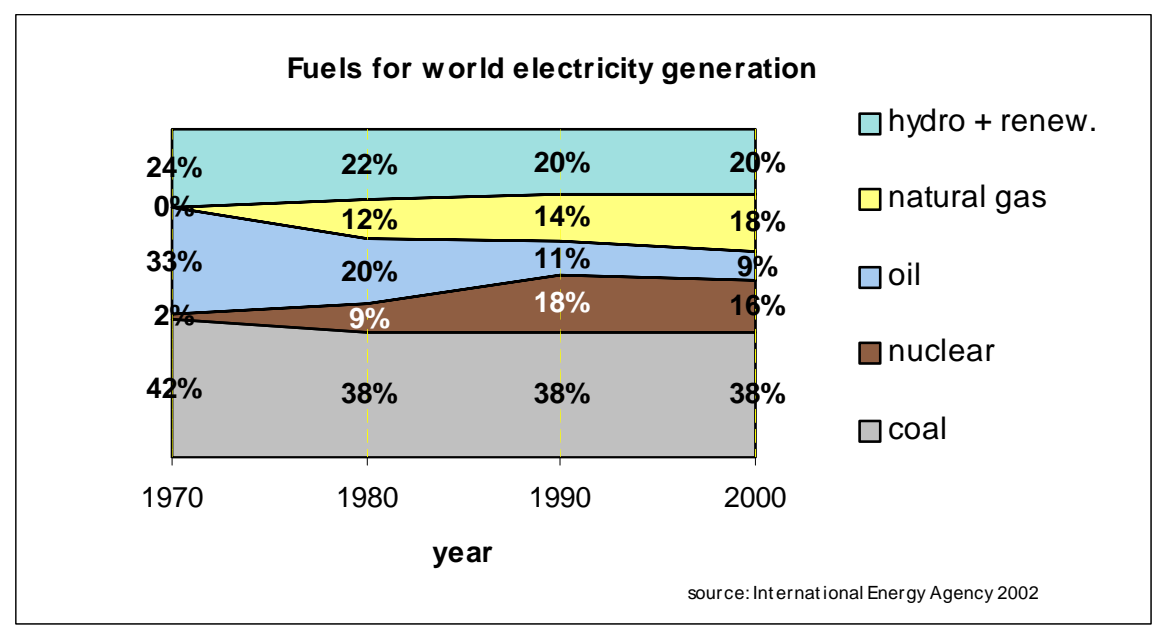

Figure 9: Fuels for world electricity generation [4].

The necessity for cleaner energy carrier, a sustainable energy use and the limited resources situation for oil and natural gas, see Figure 10, lead towards the expectation that in the near future renewables have to contribute at a clearly higher portion to the energy supply. 
$-171-$

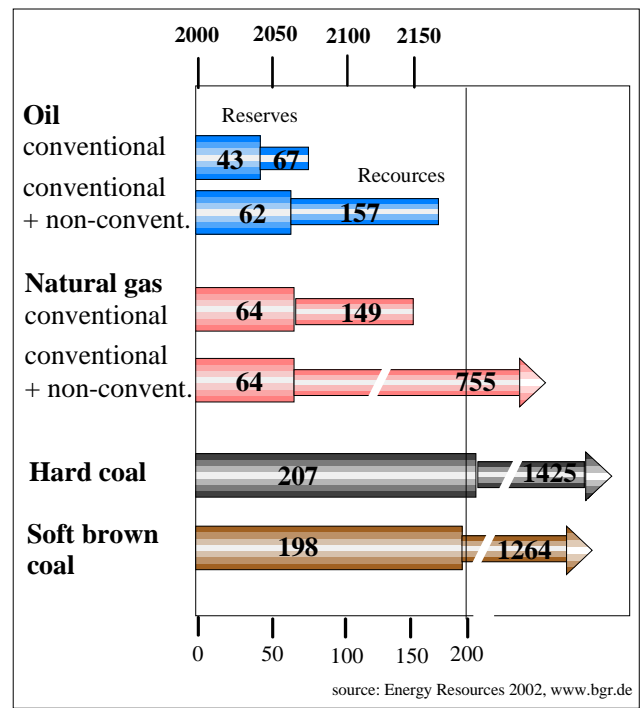

Figure 10: Reserves and resources of fossil energy carrier [5].

Hydropower seems to have the potential to fulfil the expectations which are set into it, with regard to the electricity generation, with regard to sustainability and with regard to improve the living conditions in developing countries, where a great hydropower potential still exists. The planned development (110 GW under construction and $67 \mathrm{GW}$ planned), together with the existing installed hydropower capacity $(692 \mathrm{GW})$, see Figure 11, can make a noticeable contribution to the avoidance of greenhouse gas emissions and the related climate change issues [6].

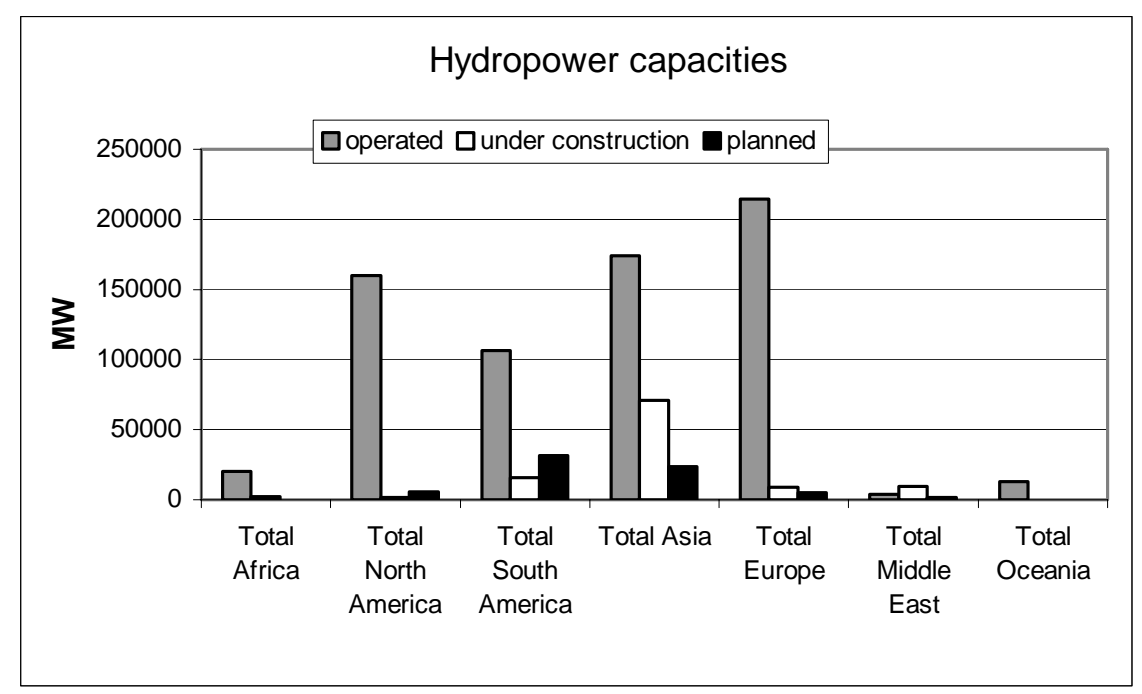

Figure 10: Hydropower capacities, in operation, under construction, planned [6]. 
Hydroelectricity, at present the most important option of the economically feasible renewable energy carrier, can be a major benefit of a broad water resources development project; however, seldom it is the only reason for planning and realisation. Power generating is normally integrated within multipurpose developments and meets other fundamental human needs (for example, irrigation for yield increase or domestic and industrial water supply or improvement of flood protection). The reservoir water may also be used for other functions such as fisheries, discharge regulation downstream for navigation improvements, and even for recreation centres. Hydropower plants can help to finance these multipurpose benefits, as well as some environmental improvements in the area, such as the creation of wildlife habitats.

\section{Potential of Hydropower}

Due to different definitions and a non-uniform data acquisition resulting from that one finds a range to the hydroelectric power potentials in the technical literature, so that the following data hold a certain measure of uncertainty. In spite of that they do offer however the possibility to outline the future meaning of hydropower roughly. The world's total technically feasible hydro potential as TWh/a is estimated at $\sim 14.000$ $\mathrm{TWh} / \mathrm{a}$, of which about $8.000 \mathrm{TWh} / \mathrm{a}$ is currently considered economically feasible for development. About 2.600 TWh was the generation in 1999 with a power plant capacity of around $700 \mathrm{GW}$. Further $\sim 110 \mathrm{GW}$ are under construction [7].

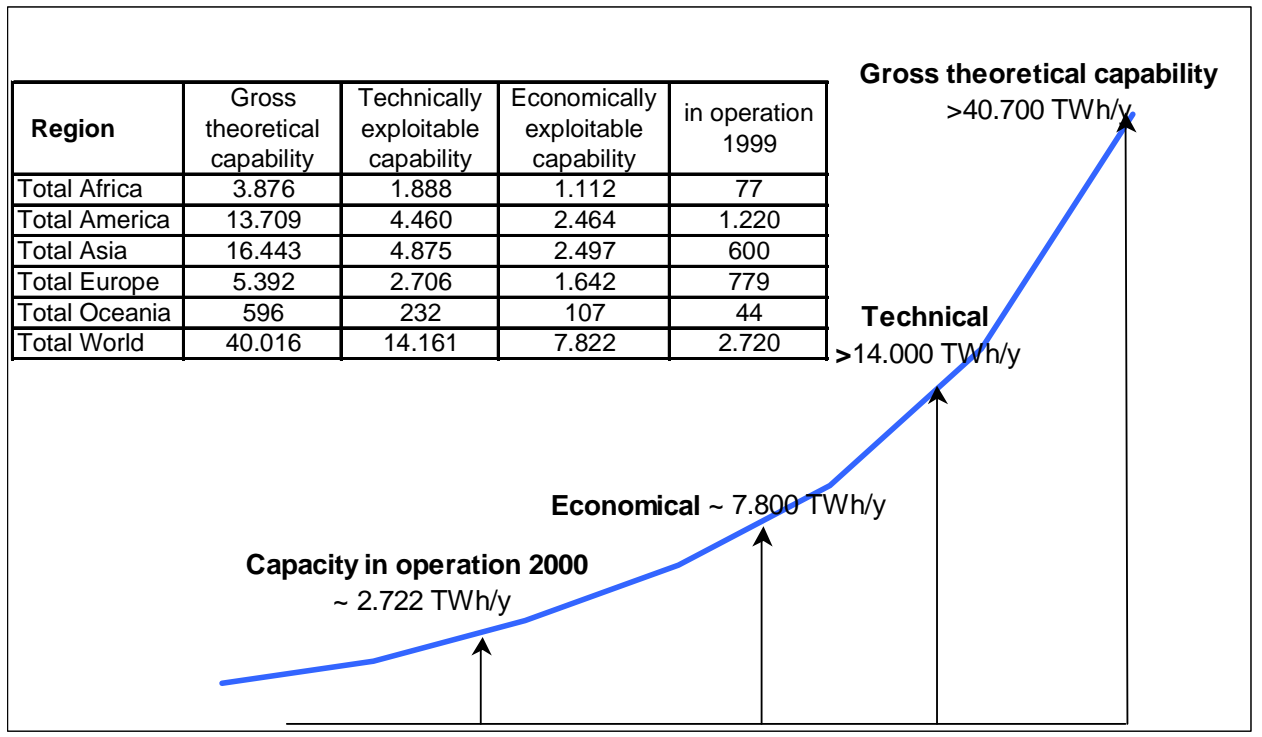

Figure 11: Hydropower and its capability [8]

The above standing Figure 11 gives an impression of the worlds hydropower potential and shows with the "Gross theoretical capability" a further classification category, see the definitions in Table 1. 
Table 1: Definitions of the hydropower potential classification [6].

\begin{tabular}{|l|l|}
\hline $\begin{array}{l}\text { Gross theoretical } \\
\text { capability }\end{array}$ & $\begin{array}{l}\text { The annual energy potentially available, if all natural flows in a } \\
\text { country were turbined down to sea level (or to the border of } \\
\text { the country) without any energy losses }\end{array}$ \\
\hline $\begin{array}{l}\text { Technically exploitable } \\
\text { capability }\end{array}$ & $\begin{array}{l}\text { That amount of the gross theoretical capability that can be } \\
\text { exploited within the limits of current technology }\end{array}$ \\
\hline $\begin{array}{l}\text { Economically ex- } \\
\text { ploitable capability }\end{array}$ & $\begin{array}{l}\text { That portion of the technical potential, which can be exploited } \\
\text { under present and expected local economic conditions or has } \\
\text { been developed, are costs competive with other energy } \\
\text { resources }\end{array}$ \\
\hline Capacity in operation & $\begin{array}{l}\text { The total of the rated capacities of the electric generating } \\
\text { units that are installed at all sites which are generating, or are } \\
\text { capable of generating, hydro electricity }\end{array}$ \\
\hline
\end{tabular}

Actually the gross theoretical capability is a redundant definition, since it considers so to say each flowing water drop, but it is a used definition. And even if also the other data are taken from the Survey of Energy Resources 2001, doubts are allowed, if for example the economical or even the technical capability can ever be reached. Hydropower is not only a point of availability of rivers or storage lakes, it is also a question of financing, as the investment is really high, the investment for a dam, for the facility, for the infrastructure and

also the investment for resettlement of the people, which are living along the rivers. But nevertheless, the table within Figure 5.1 shows, that the potential in the countries of Africa or Asia is still much higher than in Europe or America.

Figure 12 illustrates the rate of the development of the technical hydropower potential and by that possibilities for future expansions. While the development of the capabilities is progressed far in Europe and North-America with $75 \%$ respectively $69 \%$, there is still a high realisable potential in South-America, Asia and Africa.

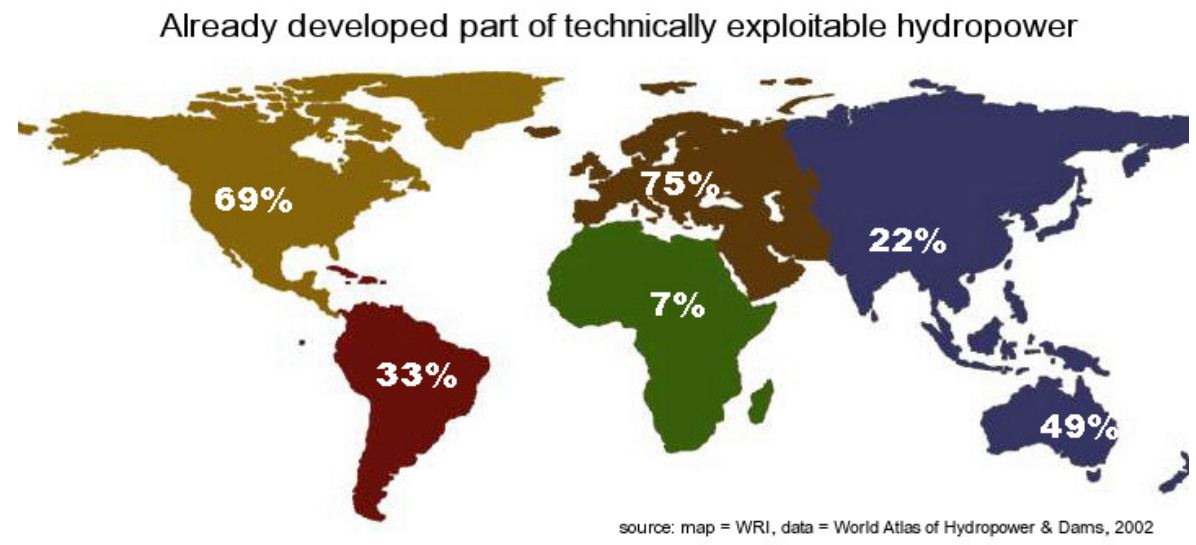


$-174-$

Figure 12: Percentage of technically feasible hydropower which has been developed.

For the countries of South-America the diagram shows that only $33 \%$ of the technically hydropower capability ( $>2792$ TWh/a) are already exploited. And it can be said, that hydro electricity has long tradition and an important function in these countries. That is underlined by its supply share in several countries, see Figures 13 and 14.

Take Brazil, the total electricity generation was in 2002 nearly 344 TWh (Germany $\sim 544$ TWh) and more than $80 \%$ were generated by hydropower [9]. Paraguay generates all of its $\sim 50 \mathrm{TWh}$ electricity from two large hydropower plants, Peru approximately $80 \%$ of its $\sim 20 \mathrm{TWh}$, Venezuela about three quarters of its nearly $90 \mathrm{TWh}$, and Chile about $60 \%$ of $\sim 40$ TWh. Another example for the hydropower importance are the more than 1.000 large dams in the region, Brazil has 594 of them, Argentina 101 and Chile 88. Together with Paraguay, Brazil maintains the world's largest operational hydroelectric complex, the Itaipú facility at the Paraná River, with a capacity of $12.600 \mathrm{MW}[10,11]$. Another huge scheme is the planned Belo Monte dam in the Amazon basin with a capacity of $11.182 \mathrm{MW}$ and an annual generation of 41,2 TWh if it is realised and ready to start its operation in 2008.

It is considered to be one of the world's most rational hydroelectric facilities. In order to generate the amount of electricity mentioned above an area of $400 \mathrm{~km}^{2}$ will be flooded, half of which is the bed of the Xingu River itself. That is equal to more than $28 \mathrm{MW} / \mathrm{km}^{2}$ flooded area for Belo Monte, against $9.3 \mathrm{MW} / \mathrm{km}^{2}$ in case of Itaipu for example [12]. Nevertheless the project is not indisputably, as the ecosystem of the Amazon basin is seen to be sensitive and important not only for the local region but for the whole world as the Amazon rainforest is the world's best supplier of oxygen.

In Figure 12 it was shown, that the hydropower capability in Asia is only developed at $22 \%$. That means, $78 \%$ are unused and that is much regarding the consequences of conventional generation. In the meantime some governments countries have realised the chances of hydropower so that developing Asia is a region with ambitious plans for the development of large-scale hydropower projects. China, India, Laos, Malaysia, Nepal and Vietnam have the most ambitious plans to expand their hydropower resources. Beside large-scale schemes all countries also develop small hydropower plants, generally as part of their renewables programmes.

The Survey of Energy Resources 2001 of the WEC estimates the economically exploitable capability at $2.497 \mathrm{TWh} / \mathrm{a}$ and the technically exploitable capability at 4.875 TWh/a. The report shows too, that China will have the highest potential with 1.260 TWh/a resp. 1.920 TWh/a for the technical potential. That estimations are far larger than for any other country in the world. The current hydropower output exceeds $200 \mathrm{TWh} / \mathrm{a}$, and means a contribution of about $17 \%$ to the republic's electricity generation, see Figure 15 . The total amount of hydro capacity under construction is about $35.000 \mathrm{MW}$, as large as the combined current construction programme of the next three largest hydro developers (Brazil, India and Iran). By far 
$-175-$

the largest hydro scheme under way is the Three Gorges Project (18.200 MW), scheduled for commissioning between 2003 and 2009.

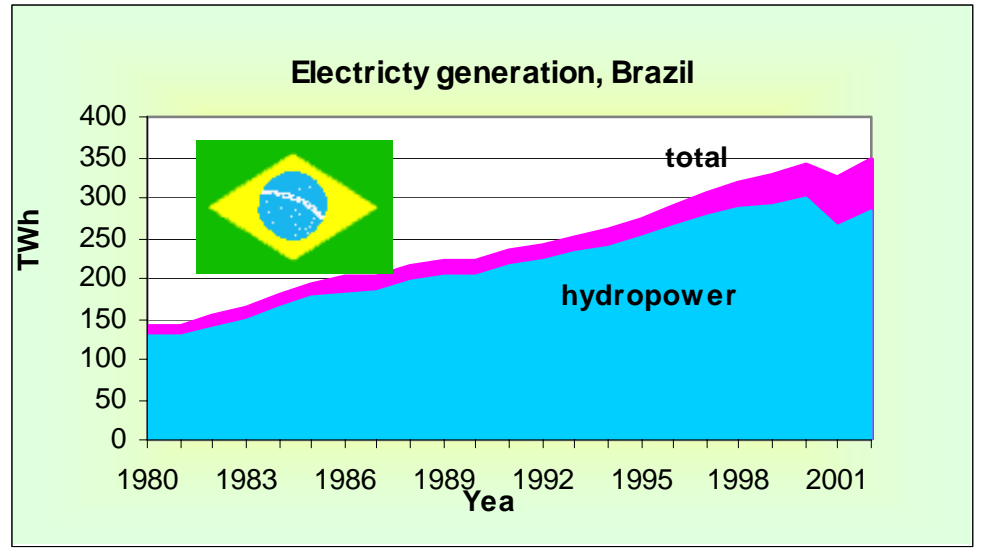

Figure 13: Electricity generation and hydropower in Brazil [9].
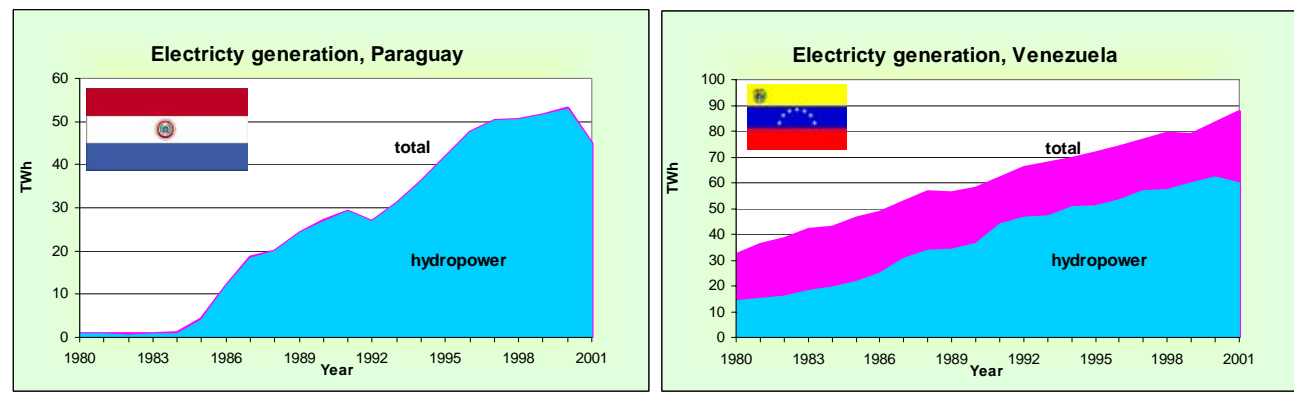

Figure 14: Hydropower for the electricity generation in other countries of South America [9].

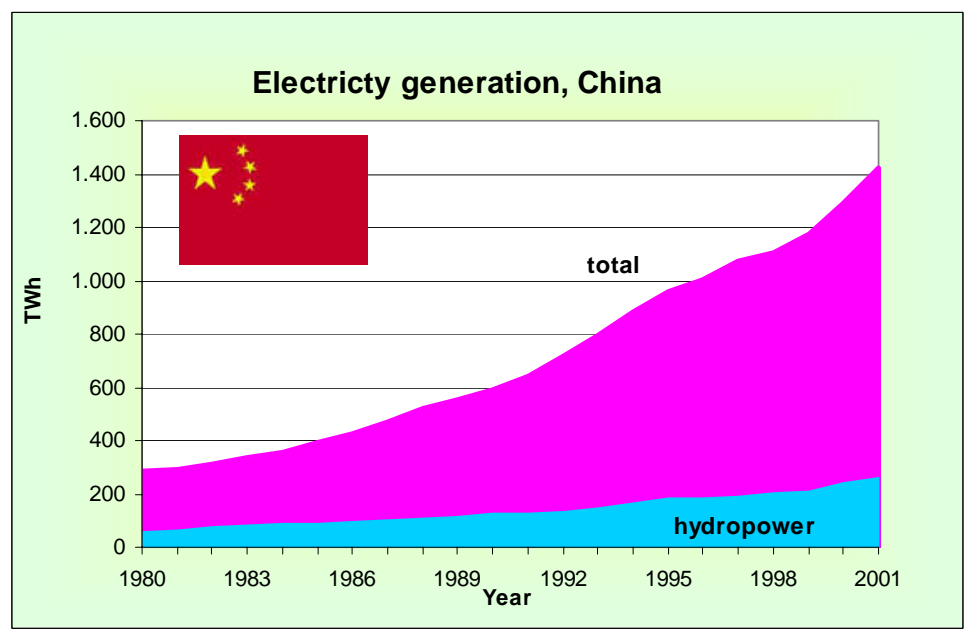

Figure 15: Hydropower at part of the Chinese power generation [9] 
Ertan (3.300 MW), Xiaolangdi (1.800 MW) and several other hydro schemes with individual capacities exceeding $1.000 \mathrm{MW}$ have been brought into operation recently or are approaching completion. More than $50 \mathrm{GW}$ of pure hydro-electric capacity is planned for construction, including five very large schemes: Xiluodu (14.400 MW) and Xiangjiaba (6.000 MW) in the Yangtze river basin, Nuozadu (5.000 MW) and Xiaowan (4.200 MW) in the Lancang basin and Longtan (4.200 MW) in the Hongshui basin.

India is already mentioned, its hydropower potential ranks fifth in the world. Its gross theoretical hydropower potential is put at $2.638 \mathrm{TWh} / \mathrm{a}$. According to the Central Electricity Authority (CEA), India has a net exploitable potential of $149 \mathrm{GW}$, and an economically viable hydropower potential of $440 \mathrm{TWh} / \mathrm{a}$ respectively $84 \mathrm{GW}$. The contribution of hydroelectric stagnated while the last 20 years also constantly expanding electricity generation, so that its share is declined clearly, Figure 16 . The installed hydropower capacity stood at $\sim 25 \mathrm{GW}$ in May 2001, and 15,4 GW is reported to be under construction. So far, only 17 percent of the net exploitable potential and 30 percent of the economically viable potential have been harnessed.

The ideal hydro thermal mix should be in the ratio of 40:60. Even if the share of hydro power is to be maintained at the existing level, the capacity addition during the 9th and 10th economy plan should have been enlarged to $23.000 \mathrm{MW}$. If the share would to be enhanced to 30 per cent, it would require a further addition of 10.000 MW of hydro capacity.

The constraints which have affected hydro development are technical (difficult investigation, inadequacies in tunnelling methods), financial (deficiencies in providing long term financing), tariff related issues and managerial weaknesses (poor contract management). The hydro projects are also affected by geological surprises (especially in the Himalayan region where underground tunnelling is required), inaccessibility of the area, problems due to delay in land acquisition, and resettlement of project affected families, law \& order problem in militant infested areas [13].

The gross theoretical hydro potential of Indonesia is estimated to $\sim 2.100 \mathrm{TWh} / \mathrm{a}$ and it is by that the third largest in Asia. Its technically exploitable capability is just over $400 \mathrm{TWh} / \mathrm{a}$, of which about $10 \%$ is considered to be economically exploitable. Hydro output in 1999 was about 13 TWh, indicating the possible scope for further development within the feasible potential. Hydro provides approximately $11 \%$ of Indonesia's electricity supplies [6].

Hydropower \& Dams World Atlas 2001 reports that about 565 MW of hydro-electric generating capacity is under construction and that another six hydro projects (all in the range of 330-400 MW) are planned for early implementation.

In Africa at the one hand, hydropower has not been widely established as the electrification level is low with an access to electricity for only $10 \%$ of the population, but on the other hand it is the main electricity source in several countries with a 
share of $70 \%$ to $100 \%$ like in Cameroon, Congo (DRC), Ghana and Tansania or a share of up to $50 \%$ like in Zimbabwe and Nigeria.

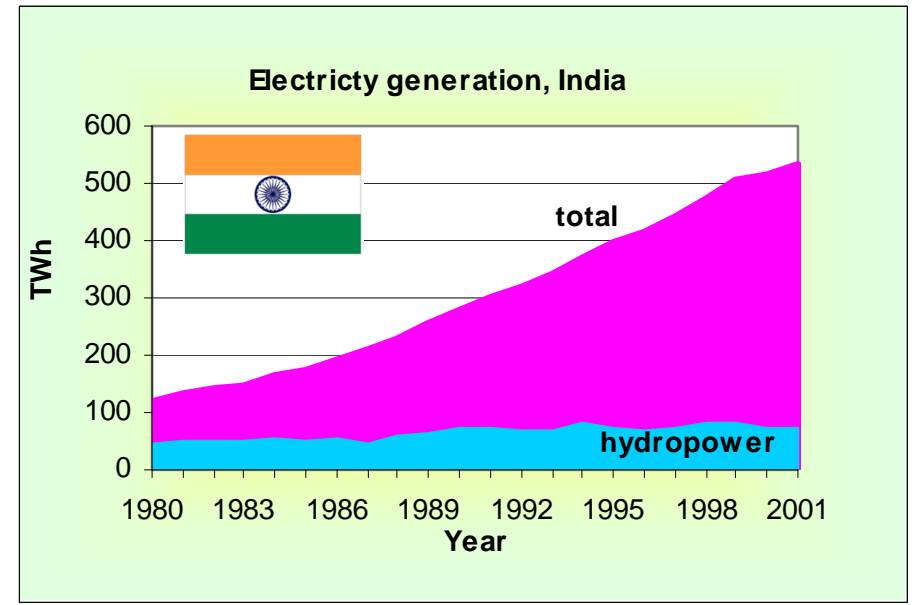

Figure 16: Hydropower as part of the Indian power generation [9].

The total installed hydro capacity in Africa is about $20 \mathrm{GW}$ with a total hydro production capability of $76 \mathrm{TWh} / \mathrm{a}$, see Figure 17 . That is less with regard to economically exploitable capability of $112 \mathrm{TWh} / \mathrm{a}$ or the technically exploitable capability of about $1.900 \mathrm{TWh} / \mathrm{a}$ or the gross theoretical hydropower potential is of about $4.000 \mathrm{TWh} / \mathrm{a}$.

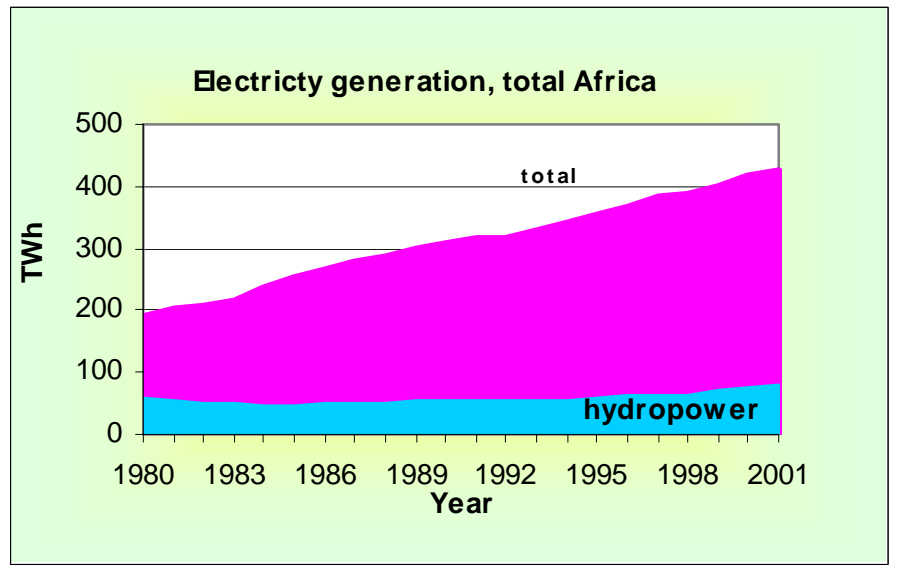

Figure 17: Electricity generation and hydropower in Africa [14].

It should be mentioned, that some of the African's hydropower schemes are among the largest in the world. For example the Aswan Dam on the Nil in Egypt with the largest catchment area of any dams world wide or the Kariba Dam which dams the 
$-178-$

Zambezi river between Zambia and Zimbabwe with the world's largest reservoir capacity or the Akosombo Dam at the river Volta in Ghana with a surface area of $8.730 \mathrm{~km}^{2}$ [15]. (That is around the half of the area of the state Schleswig-Holstein of the Federal Republic of Germany which has a surface area of $15.731 \mathrm{~km}^{2}$.)

As one reason for that not sufficient situation must be seen the political circumstances which constrain or even prevent the engagement of international consortia or organisations and which complicate transnational planning and solutions. Another reason is the missing electricity demand as the industrial and commercial developments are practically non-existent. Last but not least there must be mentioned the insufficient transmission grid, whose improvement needs a high investment too, which cannot or is not be procured by the most governments.

\section{Environmental Impacts of Hydropower, small - large}

Hydropower is in principle nothing else than the use of the power/energy of moving water, so to say the use of a natural process that has its source in the hydrologic cycle. The several steps of that cycle are evaporation of water from lakes and oceans, precipitation as rain or snow and the flow back to the oceans via creeks and rivers. The running or falling water turns the blades of turbines which are connected with an electricity generator. Nothing is burned, no chemical elements did react, no greenhouse gas emissions are set free during that generation. Hydropower has no air quality impact, so that it is designated as "green power".

But the ecological, social as well as economic consequences of several large dams, which were used for power generation, let rise doubts about the benefit and sustainability of this special form of the waterpower use. A controversial debate started and catches fire from the environmental and social impacts issues associated with large dam schemes and projects. It became unanimous sense that the coherences of water, large dams and development should be considered new to avoid mistakes, as happened in the past. This process is not yet finished, but there is consensus that new standards must be defined to appraise the necessity and compatibility of projects with far reaching consequences.

The impacts can be significant and unavoidable. The most important ones are generally related to the flooding of land in the impoundment zone upstream of the dam and the area can reach nearly vast dimensions. The changed relations can also touch the water flows and water levels downstream of the dam.

Directly affected by a large impoundment are those people who loose their houses, their working places and their local community with the traditional social structures. It is guessed, that worldwide between 40 and 80 million people were resettled in consequence of dam building [16]. And it is not proven, that the most of them could restore their livelihoods or their communities. 
$-179-$

Affected too are the wildlife and the fish population, the latter especially by the powerhouse turbines or the dam as an insurmountable barrier if there is no fish passage system which enables them to continue their migration or to reach their spawn grounds. (So far even small dams can have serious influence.)

The changing conditions can lead altogether to a loss of aquatic biodiversity, of upstream and downstream fisheries, of the services of downstream floodplains, of wetlands, to changes at estuarines and adjacent marine ecosystems. But it should not be concealed, that there are also a couple of examples for an enhancement of ecosystem values, mainly through the creation of new wetland habitat.

There are some first hints from recent studies, that reservoirs themselves emit greenhouse gases due to the rotting vegetation and carbon inflows. That can be observed indeed in all reservoirs, in natural ones as well as in man made ones, however, the scale of the emission is especially high in those reservoirs which are built in tropical forest areas. And preliminary data from a study on a hydropower dam in Brazil show a range which is comparable to that of equivalent thermal power plants [16]. It should be pointed out, that this effect varies as it depends from the local circumstances. It is known for example, that reservoirs in the northern hemisphere do not emit at a comparable range.

Another ecosystem impact may occur by the temperature differences which appear in the different layers of the reservoir. It has to do with the large surface and the solar radiation, which warms the upper layers, while the lower ones remain cold. If water is released from the top of the reservoir, it may increase the river water temperature down stream. Cooler downstream temperatures may result when water is released from the bottom of a reservoir where the temperature is much lower than at the surface. The habitat of the downstream river itself and the river basin is influenced by such effects, up to the survival-question for the population of fish and other species.

A severe problem can result from sediments which are carried by the rivers. As far as the flow velocity slows down and that is the case, when the river is impounded, the sediment will fall out and settle to the bottom. An impressive example gives the river Nile in Egypt, which carried an average of 124 million tons of sediment to the sea each year, and deposited another 9,5 million tons on the floodplain, where it was the fertiliser for agricultural activities; That was finished with the construction of the High Aswan Dam, which hold back $\sim 98 \%$ of the sediment, which is deposited at the bottom of reservoir. The deposited sediment not only spills the original and special habitat for fish spawning, it also may contain components or chemical as well as industrial residues from upstream sources, which lead to a contamination and deterioration of the water quality. Last the deposition may reduce the impoundment volume in a longer or shorter time, which depends from the normally carried sediment mass. On the other hand the deposited and so far lost sedimentation will effect deficits and river bed erosion in downstream rivers and estuaries [17]. 


\section{Economical Aspects of Hydropower}

Economic aspects of hydroelectric power plants are determined by a number of factors. The capital costs for construction and equipment/installation are presumptive the most important direct cost share but it is only one component under different. The operating and maintenance costs are a second position and a characteristic criteria for power plant calculations in general.

The resettlement costs, which were already mentioned, are not really typical for power generation but they are a serious aspect especially for large dam-schemes. The same applies to the investment for compensation measures like habitat restoration or fish passage facilities. Other power plant technologies normally have not such extensive impacts, except special fuel production methods like surface mining of lignite, oil share or tar sand. A forth directly matter of expense is the decommissioning, which will occur to each hydro scheme in the future.

Credit faces to the debits for economical consideration. And a credit is the generated power, which enables social and industrial development as well as an improvement of the living conditions and the reduction of the use of fossil fuels and by that a reduction of GHG-emissions. A credit is too the availability of water for sanitation or/and the possibility of irrigation with the prospect of rising harvests, a better food supply, a higher income.

Back to the construction cost as the first and important point of the direct costs. They depend partly on the unique physical characteristics of the site and the project configuration and thus only limited generalisation is possible about the investment costs. Even if there are normally no standardized solutions possible as no project equates another one, it can be said, that the plant size influences the costs, as higher the capacity as lower the specific costs (Euro/kWel installed). That coherence is published by VA Tech Hydro with the curve in Figure 18.

The extra stars in Figure 18 represent projects, whose costs lie far outside of the VA Tech curve. That underlines the difficulties in giving cost standards for hydropower constructions. The costs of the mechanical part of the facility is depending from the applicable machine and its size. And that choice is influenced by characteristics as hydraulic gradient and the available water quantity.

Concentrating on dam-schemes, it is to mention, that the geographical and geological conditions can become cost-dominant, as they do stipulate or enable certain dam solutions and by that the effort which must be done to construction. And as higher the effort as higher will be the costs, as the civil work has a cost share of $60 \%-70 \%[18]$. 
$-181-$

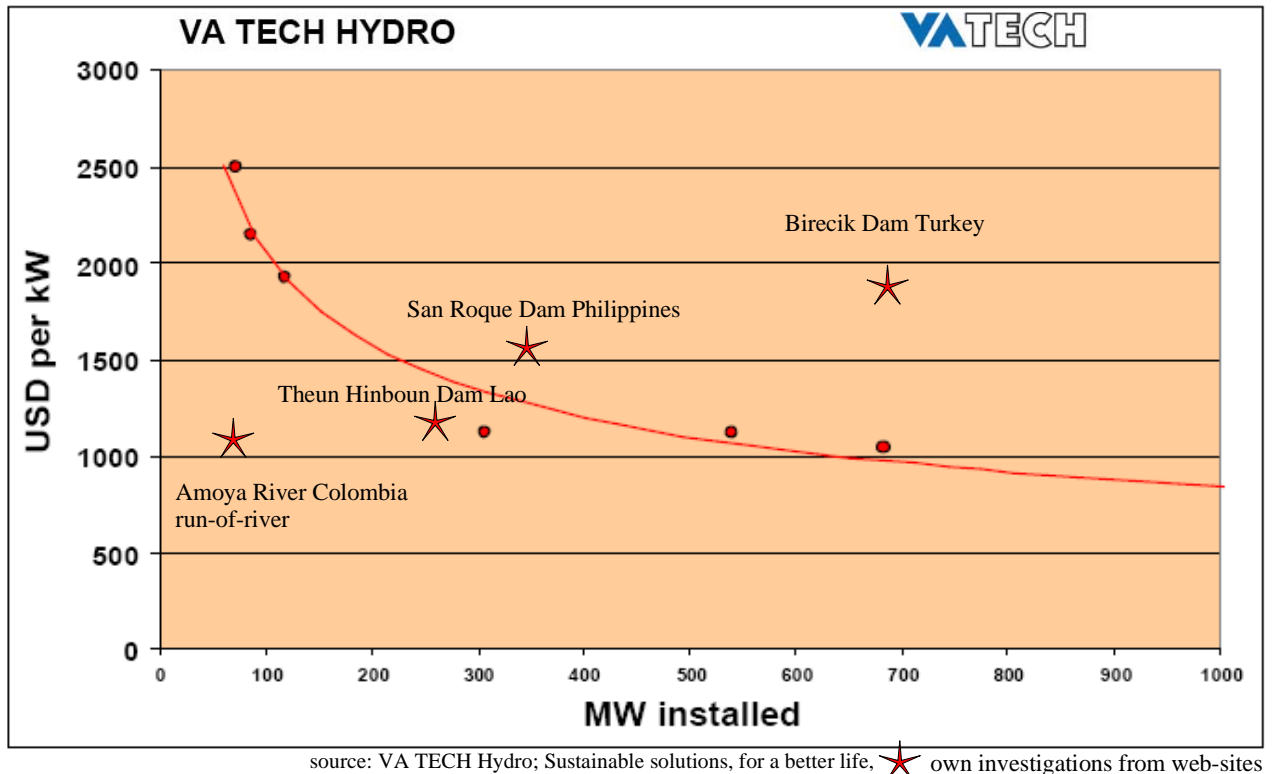

Figure 18: Specific investment for hydropower plants ( 90\% of total construction costs).

With the previous chapters the relevance of water as source for the advancement of the living condition, prosperity, health and industrialisation was pointed out especially for developing countries. It was also mentioned, that the potential of hydropower is tapped to a wide extent in the industrialised countries and relatively untapped in the regions of Asia and Africa, as once more approved by Figure 19. That are the regions with the most developing countries.

For economical considerations the generation costs have high priority as the hydropower plants are normally operated as base load power plants with high operating hours per year. Those with a reservoir can also deliver peak power. That means, that hydropower is also in this sentence multifunctional. An additional advantage are the life time, which is minimum 50 years, and the low maintenance costs. The technology is simple and has no high requirements at the staff.

The IHA-White Paper [19] cites the World Energy Assessment report from 2000 and gives as generating costs for large hydroelectricity $2-8 \$ / \mathrm{kWh}$ and for small facilities $4-10 \$ / \mathrm{kWh}$, see Table 2. 


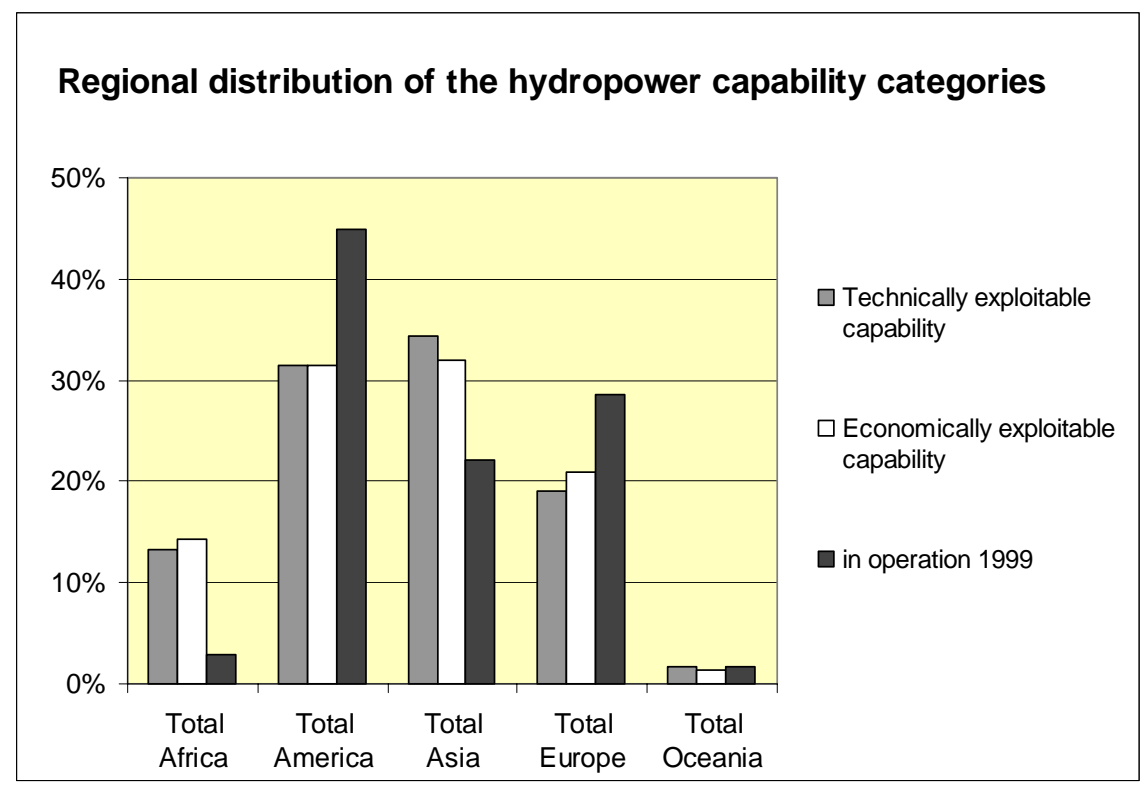

Figure 19: Regional assignment of the technically exploitable, the economically exploitable capability and of the operated hydropower plants.

Table 2: Energy technologies and generating costs (2002) [19].

\begin{tabular}{|c|c|}
\hline Technology & Costs in US\$ \\
\hline Biomass electricity & $5-15 \mathrm{~d} / \mathrm{kWh}$ \\
\hline Wind electricity & $5-13 \$ / \mathrm{kWh}$ \\
\hline Solar photovoltaic electricity & $25-125 \$ / \mathrm{kWh}$ \\
\hline Solar thermal electricity & $3-20 \$ / \mathrm{kWh}$ \\
\hline Hydroelectricity Large & $2-8 \$ / k W h$ \\
\hline Hydroelectricity Small & $4-10 \$ / \mathrm{kWh}$ \\
\hline Geothermal electricity & $2-10 \mathrm{\$} / \mathrm{kWh}$ \\
\hline \multicolumn{2}{|l|}{ Marine energy } \\
\hline Tidal & $8-15 \$ / k W h$ \\
\hline Wave & $8-20 \$ / k W h$ \\
\hline Current & $8-15 \$ / k W h$ \\
\hline Coal power plant with flue gas desulphurisation & $3,2-3,9 \$ / \mathrm{kWh}$ \\
\hline Coal integrated gasifier combined cycle & $3,6-4,2 \mathrm{c} / \mathrm{kWh}$ \\
\hline Natural gas combined cycle & $3,1-3,4 \mathrm{c} / \mathrm{kWh}$ \\
\hline Natural gas combined cycle cogeneration & $2 \$ / \mathrm{kWh}$ \\
\hline Spark-ignition engine-generators & $6,9 \mathrm{\phi} / \mathrm{kWh}$ \\
\hline Microturbine generators & $4,2 \$ / \mathrm{kWh}$ \\
\hline
\end{tabular}


In this calculation the hydroelectricity generation costs can be found at the lower end of the generation-cost scale and the expected time for the return of the investment in principle makes such projects interesting for investors. As a certain risk must be seen the cognition, that a lot of large dam projects do have serious cost overruns [30].

\section{Sustainability of Hydropower}

Hydropower is a major renewable energy resource that can play an increasingly important role in enabling communities around the world to meet sustainability objectives. As a high quality, reliable and flexible energy source, it has a pivotal role in integrated energy systems. The multiple-use benefits of hydropower, particularly in relation to the availability, reliability and quality of freshwater supplies, can also contribute to a fundamental sustainability goal - the alleviation of poverty. But more and more people are convinced, that the impacts of hydropower especially of large hydropower, which can be traced back to them will imperil its green reputation.

Therefore the International Hydro Association has worked out "Sustainability Guidelines" to promote greater consideration of environmental, social and economic sustainability in the assessment of new hydro projects and the management and operation of existing power schemes. The membership is convinced, that detrimental social and environmental impacts can be avoided if the guidelines will be regarded [20].

The guideline is divided into several chapter which are addressed to the national governments as well as to the decision makers. It is required to determinate the land use and environmental priorities, as well as goals for poverty alleviation and economic growth. As reaction to defaults from the past there are listed key criteria for evaluating various energy projects and different hydropower development options taking into consideration factors such as resource depletion, energy payback ratio, economic viability over the life of the facility, additional or multiple use benefits, poverty reduction through flow of benefits to local communities amongst others. It also outlines important considerations for environmental impact assessments, environmental management systems and dam safety.

The sections, Hydropower - Environmental Aspects of Sustainability, Social Aspects of Sustainability and Economic Aspects of Sustainability, provide guidelines for optimising sustainability outcomes for new and existing hydropower developments. In the case of optimising environmental outcomes for hydropower schemes, various issues outlined for management consideration include water quality, sediment transport and erosion, downstream hydrology and environmental flows, construction activities, rare and endangered species amongst others.

Despite these efforts there are many votes which demand to exclude large hydroelectric power plants from the title renewable and sustainable energy source as 
they fear, that the mentioned guidelines will not be regarded or that they would not be strong enough to provide the meantime known negative impacts.

These votes combine and accept only small hydropower with sustainability as that form of hydro-use has no or only a very limited impact on the close environment whereas the advantages can be used completely, as demonstrated with galaxy of small hydraulic installations even in Europe.

\section{Conclusion}

Hydropower uses the energy of the natural water cycle for electricity generation. Energy carrier as coal, oil, natural gas or other carbon containing fuels are not burned, so that neither relevant green house gases are set free nor complex pollutant separating measures must have to be seized, like flue gas desulphurisation, denitrification or carbon dioxide sequestration with a following waste management.

In the past the impacts especially the impacts of large dams, which were also built for electricity production, were not known and not taken into account, with the consequence of many disadvantages for people and the local to regional habitat.

Today the understanding of the coherences is much better and it is common sense not to repeat the mistakes made in the past. The consideration of sustainability criteria will make accessible furthermore hydropower schemes, which can fulfil multifunctional tasks, i.e. irrigation, sanitation, electricity generation and flood control. It can be assumed, that the sustainable guidelines will limit the hydropower potential, that means that the realisable potential will be lower than described in Chapter 5 .

Besides the large dams also small hydropower plants can have considerable impacts on the fish migration and/or river ecosystems. But normally that is not fact or only in a small range. In an over-regional or global view the contribution of small hydro is not so great, but for a close defined area, a single factory or a little settlement such a decentralised generation facility can be a good solution. A large number of them can play an important role in a sustainable energy mix, especially in developing countries where they can be a cost-effective way of providing electricity.

\section{References}

[1] Expressum $(2001,5)$; Die Mühle- eine geniale Erfindung; Universitätsbibliothek Freiburg i. Br.

[2] ISET Kassel, EuroWasser: Europe's hydropower potential today and in the future, chapter 8

[3] Status Report on variable Speed Operation in Small Hydro Power, "ENERGIE", EUROPEAN COMMISSION, Directorate-General for Energy and Transport, 2000

[4] International Energy Agency, World Energy Outlook 2002 
$-185-$

[5] Energy Resources 2002, www.bgr.de

[6] World Energy Council, Survey of Energy Resources 2001 - Hydropower

[7] World Commission on Dams, Reuters Media Symposium 14 July 1999

[8] Energy Statistics Yearbook 2000, United Nations

[9] EIA Energy Information Administration, Country Analysis Briefs, www.eia.doe.gov/emeu/cabs/contents.html

[10] International Association on Electricity Generation, Transmission and Distribution (Afro-Asian Region), http://www.aaro.info/hydrobrazil.htm

[11] Institute of International Education; http://www.iie.org/programs/energy/downloads/Proceedings/EnergySectorProfil es/Brazil.doc

[12] Complexo Hidreléctrico Belo Monte, http://www.belomonte.gov.br/menu.html

[13] National Hydroelectric Power Corporation Ltd., NATIONAL POLICY FOR HYDRO POWER DEVELOPMENT; http://www.nhpcindia.com

[14] 2001 World Atlas and Industry Guide - International Journal of Hydropower and Dams

[15] PROBLEMS AND PROSPECTS FOR HYDROPOWER DEVELOPMENT IN AFRICA. Prepared by E.A.K. Kalitsi, Kalitsi and Associates, Ghana, The Workshop for African Energy Experts on Operationalizing the NGPAD Energy Initiative, 2 - 4 June 2003, Novotel, Dakar, Senegal

[16] Dams and Development, A New Framework for Decision-Making, The Report of the World Commission on Dams, November 2000

[17] International Energy Agency, Implementing Agreement for Hydropower Technologies and Programmes, Annex III; Hydropower and the Environment: Present Context and Guidelines for Future Action, Subtask 5 Report VOLUME I: Summary and Recommendations; May 2000

[18] C. Head, Financing of Private Hydropower Projects, World Bank Discussion Paper 420, July 2000

[19] IHA White Paper "The Role of Hydropower in Sustainable Development", February 2003

[20] International Hydropower Association, Sustainability Guidelines, February 2004 



\title{
THE THREE-GORGES-PROJECT IN CHINA
}

\author{
G. Subklew \\ Institute for Chemistry and Dynamics of the Geosphere \\ Research Centre Jülich \\ D-52428 Jülich, Germany \\ g.subklew@fz-juelich.de
}

\begin{abstract}
The China Three Gorges Project (TGP) at the Yangtze River (Changjiang River) is one of the largest water conservation projects in the world being discussed for over half a century. The dam site is situated at Sandouping of Yichang City, Hubei Province, about $40 \mathrm{~km}$ upstream from the existing Gezhouba Project in Yichang. With the normal pool level (NPL) at $175 \mathrm{~m}$, the total storage capacity of the reservoir is 39.3 billion $\mathrm{m} 3$. The construction period of the whole project will be 17 years, from 1993 to 2009. It will bring many benefits to China including flood control, power generation, navigation improvement, etc. On the other hand, more than 1 million people have to be resettled and great influence on the environment has to be considered.
\end{abstract}

\section{Introduction}

From its origins in the glacial marshlands of the 6,100-meter high Tibetan plateau, the Yangtze River, or the Changjiang (Long River) winds its way nearly $6,300 \mathrm{~km}$ to deposit annual 960 billion $\mathrm{m}^{3}$ of water into the East China Sea. It is the third longest river in the world after the Amazon and the Nile, and the third largest in terms of annual runoff after the Amazon and the Congo Rivers. The Yangtze passes through an area inhabited by more than 400 million people, approximately one third of the country's population.

Known since ancient times as the "Golden Waterway," the Yangtze has served as a main transmission belt for products and people, with 3,600 rivers open for navigation in its mainstream and its branches for 70,000 kilometres. In the late 1980s, the volume of goods transported on the Yangtze represented 80 percent of all goods transported in China. The fertile Yangtze basin, including the great delta region formed by the sediment from the Yangtze River, produces 40 percent of China's grain, 33 percent of its cotton, 48 percent of its freshwater fish, and 40 percent of the total industrial output of the country.

Along the banks of the Yangtze are situated some of China's major industrial cities, Chongqing, Wuhan, Nanjing, and Shanghai. From Chongqing, the waters flow through the 200-kilometer long stretch of majestic gorges, beginning at Fengjie, east 
$-188-$

of Chongqing, and gathering strength from the hundreds of tributaries on its way through the narrow limestone canyons to the fertile Jingjiang plain below, and on to the broad Yangtze delta. The river has a drainage area of 1.8 million $\mathrm{km}^{2}$, accounting for 18.8 percent of China's territory.

The river has also been the cause of great destruction and loss of life that devastate the valley. From time immemorial, flooding has been a problem. During the spring and summer, flood waters rush down from the mountains in the west, through the gorges, overrunning the fields and plains and towns on the middle and lower reaches, and wreaking havoc in the lives of the millions of people inhabiting the region.

During the 2,200 years, from the beginning of the Han Dynasty to the end of the Qing Dynasty in 1911, there have been 214 floods, an average of one every 10 years. In this century, there have been five severe floods. Combined flooding on the Yangtze and the Han rivers in 1911, is said to have claimed hundreds of thousands of lives. The great flood in 1931, took the lives of 145,000 people, submerged more than 3 million hectares of farmland, and destroyed 108 million houses. In the flood of 1935, 142,000 people were killed.

The 1954 flood inundated 48 million hectares of farmland, affected 18 million people, and claimed 30,000 lives. An additional 18.88 million people suffered from flood damage, and the operation of the vital Beijing-Guangzhou railway was suspended for more than 100 days. Most recently, a major flood in 1996 was followed by an even greater one in 1998, which led to 3,656 fatalities, and affected the lives of 290 million people. In that flood, there were more than 5 million houses destroyed and 21.8 million hectares of farmland submerged. The total economic cost of the 1998 flood for China was $\$ 30$ billion. Ironically, the continual development of the Yangtze Basin is increasing the economic cost of such flooding.

The flooding problem has generally been dealt with by constructing levees in the Jingjiang plain area. Since the 1950s, more than $30,000 \mathrm{~km}$ of dikes and levees have been reinforced or raised. As sedimentation lifts the river bottom, however, the dikes are continually in danger of being overrun, for the water level during flood season rises 6 to 17 meters higher than that of the plain region along both banks.

In the middle reaches of the Yangtze, the Jingjiang Flood Diversion Project and the Dujiatai Flood Diversion Project were completed in the 1950s. But since that time, most of the flood diversion areas have been economically developed and are now densely populated, so that diverting a flood, even temporarily, would displace people, and result in heavy economic losses. It is estimated that if there were a 1954-level flood today, inundating the flood-diversion areas, it would affect 933,000 hectares of farmland, and millions of people would have to be relocated for several months. It is supposed $t$ after completion of the Three Gorges Dam, the need for flood diversion is will be greatly reduced. 
$-189-$

Dongting Lake, lying just to the south of the Yangtze as it makes its way up from the southwest towards Wuhan, and connecting to it by the Jingjiang River, has also been used as a reservoir to "capture" the rising waters of the Yangtze during flood season. Because of silting, however, the level of Dongting Lake has been rising, while the total area of the lake has shrunk from $6,000 \mathrm{~km}^{2}$ in 1825 , to $2,700 \mathrm{~km}^{2}$ in 1983 . This has greatly reduced the flood-diversion capability of the Jingjiang River. If it keeps diminishing at the present rate, Dongting Lake would vanish in the near future. There is much hope that the Three Gorges Dam will help retard the process of siltation.

\section{History}

The idea of building a dam in the gorges has a long history. In 1919, Sun Yat-sen, the founding father of modern China, saw the tremendous economic benefits of building a dam on the Yangtze as a part of his economic development plan for China. Dr Sun was particularly interested in using the vast hydropower resources of the river to produce the electricity needed to build factories for making artificial fertilizer, the only means he could envision for China to make the leap in agricultural productivity needed to feed its growing population. He also saw the area of the gorges as the most suitable spot for building a dam to generate that electricity.

In 1932, seven years after his death, the Construction Committee of the Kuomintang, a party founded by Dr Sun, which took power in 1927, organized a prospecting team to survey the hydroelectric power generation of the upper reaches of the Yangtze River. The team recommended dams at one of two possible sites, at Huanglingmiao and at Gezhouba. The project was to include a 12.8-meter-high water-head dam with an installed generating capacity of 300 megawatts (MW), and equipped with shiplocks.

In May 1944, the Nanjing Government Resources Commission invited experts from the American Cultivation Bureau to evaluate the chance to set up a dam at the Three Gorges. They suggested that the dam should be set at the place which was 200 metres wide at the upper stretch of the Nanjingguan Pass. The height of the dam should be 225 meters with an installed capacity of 10,560 MW. Because of the condition of society, politics, economy, science and technology, the plan was put aside.

Led by Changjiang Water Resources Commission (the Yangtze Valley Planning Office, CWRC) from the middle of the 1950s extensive efforts have been made for the Three Gorges Project. In March 1958, at a Central Committee meeting the decision was taken to begin preliminary design work on the Three Gorges project. In June of that year, the first Three Gorges Scientific Conference was convened to formulate the major research plans. The size of the project meant that some of its technical aspects would place it on the very frontiers of dam-building technology, and would establish world precedents. These aspects included deep-water weir construction; damming under high-flow conditions; super high voltage electrical 
$-190-$

transmission and transformation; large turbo-generator and ancillary equipment manufacturing; giant machinery for high-speed building and for elevating ships; automation in electrical systems and installations; new building materials; reservoir regulation; and prevention of reservoir sedimentation.

Two areas along the Gorges were chosen for a closer examination of the bedrock. One was the stretch of the river, from the entrance of the Xiling Gorge at Nanjingyuan Pass to Shipai. The bedrock there was limestone. The other area examined was in the Meirentuo section, along the upper portion of Xiling Gorge, from Meirentuo to Nantuo, a stretch of the river about $25 \mathrm{~km}$ long. The bedrock there is crystalline igneous rock. After comparisons were made, the Meirentuo area was chosen as more suitable.

At the end of 1969, provincial leaders in Hubei Province, where the dam was to be located, called for beginning construction on the Three Gorges Dam. The Chinese leadership struck a compromise, by deciding on first building the auxiliary dam further downstream at Gezhouba. The Gezhouba Dam, about 40 kilometres downstream from the proposed Three Gorges site, was originally conceived as an auxiliary to the major dam at Sandouping, and was to be constructed only after the main dam was built. The auxiliary dam was needed, because the construction of the major dam at Sandouping would have the immediate effect of lowering the water level through the portion of the canyon downstream from it, thus seriously impeding navigation there, especially during the dry season. The building of a second dam downstream would help maintain the water level in this difficult canyon area. Although there were still those in the Chinese leadership who opposed the construction of the Gezhouba (and even of the Three Gorges Dam itself), the Central Committee decided in December 1970, to build the Gezhouba Dam.

Located about 3 kilometres downstream from the Nanjingyuan Pass, at the entrance to the Three Gorges, the Gezhouba construction provided valuable experience in dam-building, preparing the major undertaking at Three Gorges. Gezhouba Dam began producing electricity in 1981, and was completed in 1988. It is 70 meters high and 2,606.5 meters long, and now produces an annual output of electricity of 15.7 billion $\mathrm{kWh}$.

\section{The Three-Gorges-Project}

The design for the main structures of the Three-Gorges-Project is classified into five stages, i.e., feasibility study, preliminary design, technical design for key individual items, bidding documents and detailed drawings. The feasibility study report was completed by CWRC at the end of 1989.

After an overall examination, in April 1992, 7th National People's Congress passed the Resolution on the construction of the Three Gorges Project at Zhongbao Islet near the village of Sandouping. This is the area which divides the Eastern and Western parts of the Xiling Gorge, the first of the Three Gorges (Figure 1). 
$-191-$
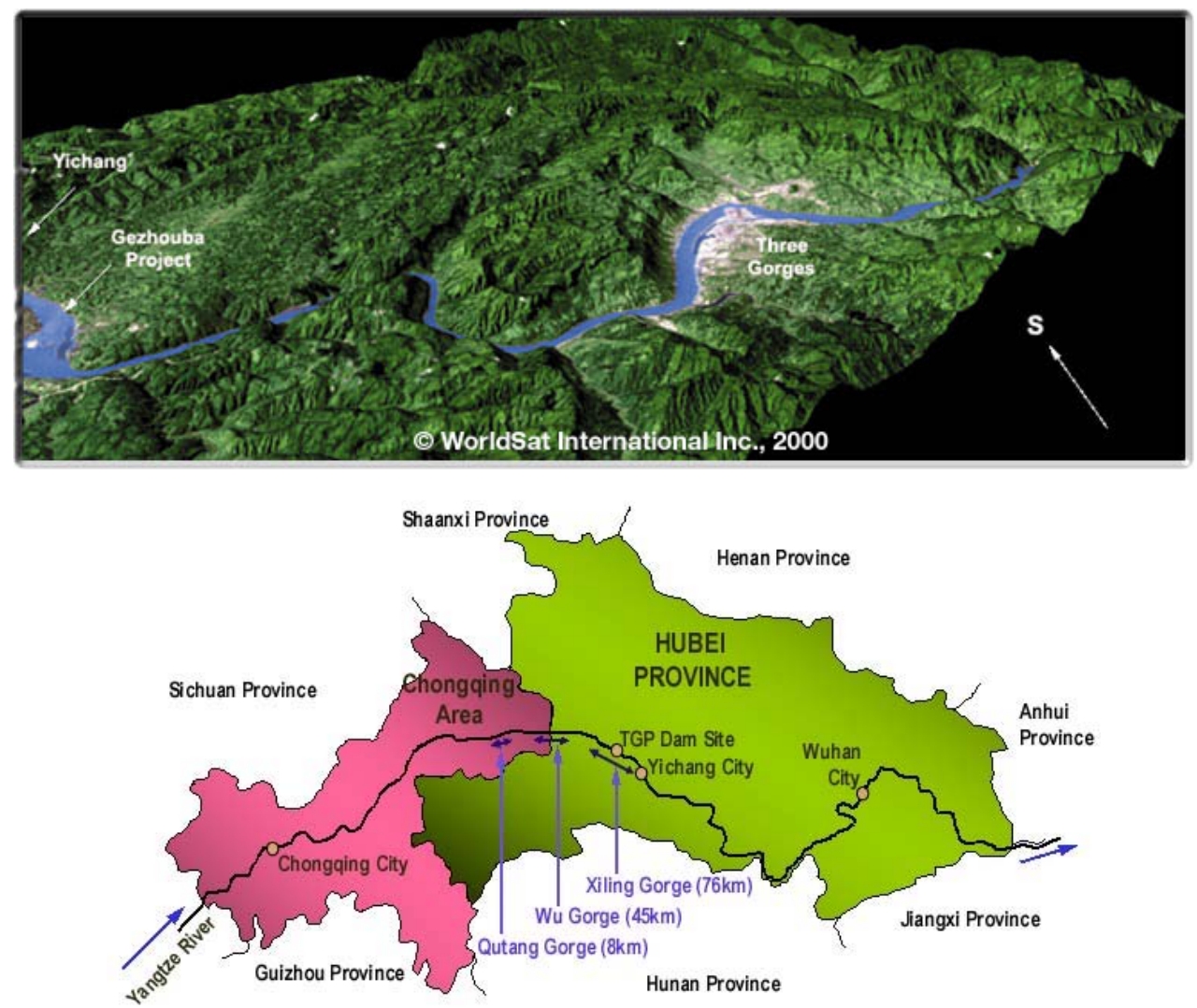

Figure 1: Site location of the Three-Gorges-Dam.

In December of the same year, the "Preliminary Design Report on the Three Gorges Project" was completed by CWRC. The technical design for the key specific items consists of eight parts:

- Dam

- Powerhouses

- Permanent ship locks

- Vertical ship lift

- Stage 2 upper stream cofferdam

- Mechanical and electrical equipment and facilities

- Dam safety monitoring

- Harbours and navigation channel regulation in the backwater zone (including effect of the scouring of the river bed downstream and the countermeasures)

Except for the last item, the technical design and the examination for seven items had been basically finished by the end of 1995 . 


\section{The Dam}

The construction of the dam (Figure 2 and 3), begun in September 1994, will take 17 years from its inception, proceeding in three stages. When the dam is completed, it will have a height, or crest, of 185 meters. In the early phase of operation, during the third phase of construction, the water level in the reservoir region is at 135 meters, and the final Normal Pool Level, or highest level, will be 175 meters.

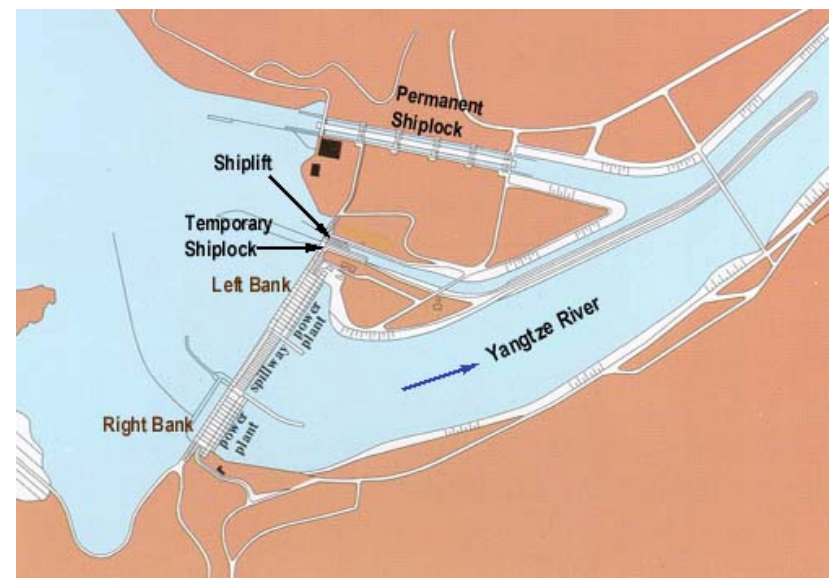

Figure 2: The technical design of the Three-Gorges-Dam.

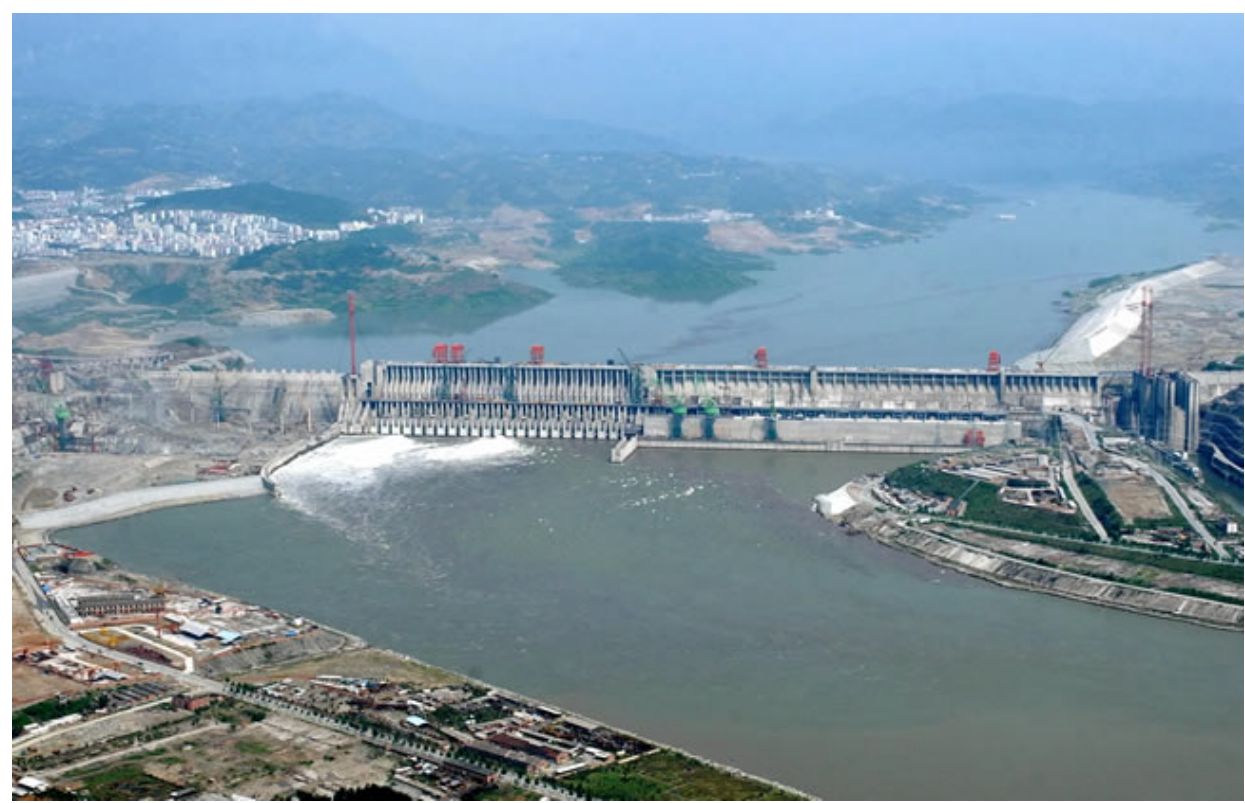

Figure 3: The Three-Gorges-Dam as seen in October 2003. 
Once the dam is completed, the raising and lowering of the water level in the reservoir behind the dam will provide the ability to control flooding. As the flood season approaches, from the end of May to the beginning of June, the water level in the reservoir region will be lowered to the flood control level of 145 meters, with the expectation that storage capacity will be needed during the flood season. After the passing of the potential flood peak, the water that has been stored, to a maximum of 175 meters, will be discharged, and the reservoir will again be lowered to 145 meters.

By October, the reservoir level will be gradually raised to 175 meters to allow the power station to meet the demand for electricity; regulating the water storage will be used to guarantee power output. Between January and May, the reservoir storage level will be lowered to increase the flow downstream during the dry winter season. At the beginning of the spring, the level will then be appropriately low, in preparation for the possible summer floods.

The first stage of construction, from 1992 to 1997, involved the building of two phase-one cofferdams to shut off the flow of the river from the construction site, and the re-routing of the river through an artificial diversion channel. Barges and other ships passed through the diversion channel, or if the river floods, through a temporary shiplock built for that purpose. Additional infrastructure, such as a new major highway road, the Three Gorges Project Expressway, was built to reach the otherwise inaccessible mountainous region, in order to transport the materials excavated from the construction site. Along the Expressway there are 34 bridges and 5 double-lane tunnels, including a 3,610-meter single-line tunnel, which is the longest in China. In addition, a major suspension bridge, the Xiling Yangtze Bridge, was built over the Yangtze River downstream from the dam site.

During the first stage, the site for the permanent shiplocks was excavated, and the foundation laid for the left-bank powerhouse. Construction also began on a vertical shiplift, a one-stage vertical hoisting system, accommodating those lighter, 3,000-ton passenger ships which may require a quicker route through the dam than the fivestep shiplock, which is designed to accommodate larger vessels.

During phase two, from 1997 to 2003, the construction of the left bank dam section was under way; the left-bank powerhouse was completed with the installation of some units, and construction of the spillway and continued construction of the permanent shiplock were taking place. The spillway dam, placed in the mid-section of the structure, is 483 meters long with 23 bottom outlets and 22 surface sluice gates. With a maximum discharge capacity of 102,500 cubic meters per second, the project is able to discharge the maximum level of water possible during floods.

In December 2002, before the flood season in the spring of 2003, the phase-three cofferdams in the diversion channel was finished. At this time, the permanent shiplock was ready for use, and the diversion channel was no longer being needed 
for navigation. According to the scheme for the second stage, approximately 10 billion US\$ had been invested.

By the end of phase three, the water level behind the dam will be raised to its final 175-meter level. The reservoir formed in the upper river will be with an average width of more than 1 kilometre, approximately twice the width of the present river. It will have a total storage capacity of 39.3 billion $\mathrm{m}^{3}$ including a flood regulation and storage capacity of 22.15 billion $\mathrm{m}^{3}$. This will effectively increase the flood control standard of the hard-hit Jingjiang section of the river, between the gorges and the city of Wuhan, from the present standard of sustained 10-year floods to the standard of 100-year floods. Even if there were a flood of the size that occurs only once every 1,000 years, the vast plains on both sides of the section of the river below the dam, with the appropriate flood diversion and retention capacity, would now significantly limit the damage.

\section{Hydroelectric Power}

The Yangtze contains the largest hydropower resources in China. Thus, the second major economic benefit from the dam will be the amount of hydroelectric power drawn from the river.

The Three Gorges Hydropower Station is comprised of two power plants, situated on each side of the central spillway, with a total of 26 generating units. Each unit has a capacity of $700 \mathrm{MW}$. The total capacity will be 18,200 million MW, with a planned annual power generation of 84.7 billion $\mathrm{kWh}$. It will be the single greatest power plant in the world, about 1.44 times bigger than the largest existing hydropower project built jointly by Brazil and Paraguay at Itaipu. The energy produced annually by the Three Gorges station would replace 40 to 50 million tons of coal, and relieve the corresponding stress on the nation's transport system.

The production of electricity from the Three Gorges Dam is particularly significant in light of China's recent drive to develop the western regions of the country. The city of Chongqing plays a very important role as one of the "gateways" to the Western regions. Much of the hydroelectric power from Three Gorges can help relieve some of the dependence on coal-burning plants, which has provided the bulk of China's energy production, but which leaves a perennial haze over Chongqing and other major Chinese cities. From the Three Gorges generators, there will be 15 transmission lines, with $500 \mathrm{kV}$ AC lines going west to Central China and Chongqing City, and 500 kV DC lines to East China.

\section{Navigation}

The reservoir will considerably improve navigation upstream on the river by raising the river's level between Chongqing, and the city of Yichang, which is just downstream from the dam. Even then, occasional avalanches take place, which pour 
massive rocks into the river, thus changing the contours of the river bottom, making the going treacherous even for old river hands. The raising of the water level in the massive reservoir region will slow the flow of the water and submerge the dangerous shoals. This will allow barges in the 10,000-ton class to sail upstream to the harbours of Chongqing. It is estimated that there will be a five-fold increase in the amount of shipping to Chongqing, and even ocean-going vessels will be able to reach it. This will increase the annual one-way passing capacity to Chongqing from the present 10 million tons, to 50 million tons.

In addition, with the regulation of the reservoir, the minimum flow downstream of Yichang in the winter dry season will be increased from the present $3,000 \mathrm{~m}^{3} / \mathrm{s}$ to more than $5,000 \mathrm{~m}^{3} / \mathrm{s}$, thus improving navigation also in the middle reaches of the Yangtze. Because it will be able, during low water conditions, to release water from the reservoir to the middle reaches of the Yangtze, the Three Gorges Project will also increase navigation along the mid-stream Jingjiang section of the river.

\section{Environment}

By the end of the 1960s, a paradigm shift was taking place in the industrialized nations, exemplified by the creation of the anti-growth Club of Rome in 1969. As the largest nation in the world, in terms of population, China came under attack for having "too many people", and whose continued growth would only further threaten the "environment". The Three Gorges Dam, as the largest economic development project in China, became a prime target for attack.

Nevertheless, the Three Gorges Dam is going to be built. The strange twist on all of this is that it is a hydroelectric dam. Many environmentalist obstructions did not stop the project; the dam had become too important. The Three Gorges Project had already become a critical element in the overall development of China, elaborated under Premier Zhou Enlai and developed by Deng Xiaoping, as the "four modernizations", in 1978, embracing industry and trade, education, military organization, and agriculture.

In 1999, the new dam also served as a major element in the new initiative by the Zhu Rongji government to "develop the Western regions".

\subsection{Real Environmental Concerns}

In addition to making the most important environmental improvement - changing the lives of the people - the Three Gorges Dam is part of an overall policy to improve the environment of the Yangtze Valley, including the control of the approximately 500 million tons per year of silt that course down the river. Mountainside farming will be replaced with terraced fields to preserve the top soil. Reforesting the mountains to reduce the water runoff and erosion has been under way, and will accelerate.

The possibility of the collection of silt in the huge reservoir to be created by the dam has been a main objection not only by the dam's opponents. Problems of silt build-up 
$-196-$

at dams around the world, have added to this concern. According to the Chinese, extensive and detailed studies on sedimentation in the reservoir region began in the early 1950s, and concern has increased, as the existing reservoirs and water diversion areas have been filling with silt. It is not clear if the operation of the Yangtze Gezhouba Dam has provided enough experience on how to solve such a problem.

Historical data suggest that the amount of silt content in the Yangtze River cannot be determined by examining only a few years' data, because the silt content can change dramatically, depending upon precipitation and its distribution in the region. The sediment load, for example, was 361 million tons in 1986, 320 million tons in 1992, and 210 million tons in 1994, with higher years in between. Based on more than 40 years of observations, sediment discharge averages about 526 million tons per year.

Unlike other dams, where the water storage for flood control is essentially static in non-flood years, and silt builds up year after year, the water in the Three Gorges Dam reservoir, which is not a lake but the widened river, will be raised and lowered throughout the year, to make room for flood waters in the spring, and to increase the flow downstream during the dry winter period.

During flood periods, between June and September, when 84 percent of the sediment comes down from the upper reaches of the river, the dam will release water downstream so that the reservoir can remain able to store flood waters at a height of 145 meters. Sediments will be flushed out through the sluice gates with the water when the flow of the Yangtze is high. The remaining sediment will be kept in dead storage.

At the end of the flood period, when there is less sediment content in the water, the reservoir will be impounded for power generation, and for aiding navigation, at the 175 meter level. Toward spring, the water level in the reservoir will be lowered again to the flood control level, at which time the sediments deposited in storage will be flushed out with the increased water flow.

The operational mode is to "store clear water but release muddy water." It is estimated that after about 100 years, when a balance is reached between deposition and flushing of sediment, 86 percent of the flood control capacity of the reservoir will be preserved.

\section{2 "Correcting" the Environment}

The Chinese approach is to "correct" the ecological problems in his country. The 1998 flood - which killed more than 3,000 people, required the evacuation of 13.8 million people, destroyed millions of houses, and ruined 4.78 million hectares of crops - was less severe, in terms of the amount of river flow, than previous floods. But the build up of silt, largely the result of the erosion of land along the banks, had raised the height of the river and the flood diversion regions, leading to widespread flooding. It is evident that the country has severe environmental problems. But in the 
south of China, the greatest threat to the environment is not "endangered species", but floods. And in the north, the greatest threat to the environment, and the economic growth of the people, is drought. The Three Gorges Dam project is the centrepiece of a vast plan designed to create a balance between areas of water abundance and water deficit, supposed to improve the environment for hundreds of millions of people. As already mentioned the most important environmental benefit of the Yangtze dam project is seen in the lives of the people.

\section{Resettlement}

A great deal has been made of the need to resettle as many as 1.2 million people from the lower slopes of the gorges, west of Sandouping, which will be inundated to create the great reservoir behind the dam. According to government figures, there are 846,200 people living there now who will have to be relocated. The figure of 1.2 million includes the natural population growth expected between the start of the project, and its completion in the year 2009.

The reservoir region behind the dam will inundate 17,160 hectares of farmland, and 3,867 hectares of riverside land will be flooded. It is estimated that 34.8 million square meters of rural and urban houses are below the inundation line. Also, land will be lost to the construction of roads, electricity transmission lines, communications lines, and other infrastructure.

According to one estimate, between 1949, when the People's Republic of China was founded, and the mid-1980s, more than 10 million residents have been affected by the building of reservoirs and other hydrological projects. The policy initially was to compensate them with a one-time payment to make up for the property they were to lose. But because there were not adequate opportunities for new work for those who were relocated, when that payment was exhausted, the relocated individuals had to turn to the government for help.

The one-time compensation policy has been replaced with the policy of "population relocation for development", the goal of which is to raise the standard of living of the relocated population, by providing employment and better living conditions after the move. In a development-oriented policy, the resettlement should be integrated with the development of the economy, the exploitation of resources, and construction in the reservoir region to increase productive capability, improve the living standards of the relocated individuals, and raise the environmental quality.

Today, one sixth of the total population in the region from which people will be moved, roughly 3 million people, is below the poverty line. Because about one quarter of the land that is cultivated along the gorges exceeds a 25-degree slope (cultivation on which has now been forbidden), the soil is heavily eroded.

Traversing the Yangtze River, it is plain what the government's plan for resettlement is. Above almost each settlement, or small town of old, and often dilapidated houses 
$-198-$

and small industries, entirely new cities are appearing, near the tops of the mountains. New roads, schools, health facilities, power lines, and housing are under construction. It is estimated that about 57 percent of the population in the inundation zone are urban dwellers, who could be resettled along with the relocation of the cities or towns.

Hillside slopes that are now farmed using the power of water buffalo and hand labour, and are fertilized with human and animal excrement, will be replaced with more modern farming methods and technology. But there will still be a gap between the amount of grain and basic foodstuffs that can be produced on the available land, and the number of farmers that will be displaced. The government planners expect now that 60 percent of the farmers will remain in farming, and the other 40 percent will be absorbed into secondary and tertiary industries. These industries will take advantage of the mineral resources, such as phosphorus, salt, and lime in the valley, which can serve as raw materials for chemicals, fertilizer, and building materials industries.

In May 1999, the Chinese government made another important change in its relocation policy for the dam. China has decided to relocate 125,000 rural people living in Chongqing City, who will be affected by the rise in the level of the Yangtze River there after the reservoir is inundated, to 11 regions in the eastern coastal provinces over the next years. A given portion of the income from the hydroelectric production at the dam will be returned to the relocates in other parts of the country, and the rest to the reservoir region for construction.

When the government announced this change in mid-1999, Prime Minister Zhu Rongji also voiced concern about the "misuse" of funds that have been given to local communities to build new housing and facilities for those who are relocated. Corruption by local officials has been given a public airing, with severe penalties imposed on those who are taking public money for personal gain.

\subsection{Putting People First}

Other "environmental" objections centre on the impact this great water project will have on "endangered species," and other non-human forms of life. The Chinese have taken a clear stand on the issue, by putting people first. Although there are more than 1,000 aquatic species in the river, including 370 species of fish, what is important is that freshwater fish production in the river accounts for more than half of the nation's total, and is an important source of protein.

Changes in the flow of the river, the deposition of sediment, and other factors will influence the balance of fish species in the Yangtze. It is expected that fish that move up to the higher reaches of the river to spawn and cannot navigate past the dam will decline, but that there will be an expansion of the habitats for the fish that favour living in still water, in the reservoir region. 
$-199-$

\subsection{Preserving a Cultural Heritage}

The Yangtze, together with the Yellow River, is one of the great sources of the origins of Chinese civilization. Some remains go back as far as 600,000 years ago, when so-called Laotian man inhabited the area. Remains from 100,000 years ago, when a group of hunters inhabited Hubei province, have also been found. Early forms of agriculture date back to 6,000 B.C. Many new sites and cultural discoveries have been made in the archaeological work where the great dam is being built. As much of the area will soon be under water, it is of prime concern to save as many as possible of the cultural artefacts before the area is inundated.

There are an estimated 108 sites of important cultural and historical value in the area of the Three Gorges Project. Some of these sites are located above the 175-meter water mark of the new reservoir, and will not be touched. The famous White Emperor City (Baidicheng) that is now on dry ground, 180 meters above the river, will remain, and become an island, surrounded by rivers on three sides. But many are not above the water mark.

Some of the relics, including entire buildings, like the Zhangfei Temple at Yunyang, will be removed from their present site, to a higher location or to a museum. Some of the tablets found carved on stones in the river will have to be reproduced or protected. The key question at this point, is the amount of money that will be available for such preservation work from now until the area is inundated. Since this is such an important treasure, not only for China, but for the world, one would hope there would be more resources put into the preservation project from the international community. In a very real sense, it is a race against time to save those artefacts that can be saved.

\section{References}

Written with contributions from the following sources, available at www:

- The Ministry of Water Resources of the People's Republic of China

- Schiller Institute, Washington D.C. (USA

- China Yangtze Three Gorges Project Development Corporation 

Schriften des Forschungszentrums Jülich Reihe Umwelt / Environment

1. Energiemodelle in der Bundesrepublik Deutschland. Stand der Entwicklung IKARUS-Workshop vom 24. bis 25. Januar 1996

herausgegeben von S. Molt, U. Fahl (1997), 292 Seiten ISBN: 3-89336-205-3

2. Ausbau erneuerbarer Energiequellen in der Stromwirtschaft Ein Beitrag zum Klimaschutz

Workshop am 19. Februar 1997, veranstaltet von der Forschungszentrum Jülich $\mathrm{GmbH}$ und der Deutschen Physikalischen Gesellschaft herausgegeben von J.-Fr. Hake, K. Schultze (1997), 138 Seiten ISBN: 3-89336-206-1

3. Modellinstrumente für $\mathrm{CO}_{2}$-Minderungsstrategien IKARUS-Workshop vom 14. bis 15. April 1997 herausgegeben von J.-Fr. Hake, P. Markewitz (1997), 284 Seiten ISBN: 3-89336-207-X

4. IKARUS-Datenbank - Ein Informationssystem zur technischen, wirtschaftlichen und umweltrelevanten Bewertung von Energietechniken IKARUS. Instrumente für Klimagas-Reduktionsstrategien Abschlußbericht Teilprojekt 2 "Datenbank“ H.-J. Laue, K.-H. Weber, J. W. Tepel (1997), 90 Seiten ISBN: 3-89336-214-2

5. Politikszenarien für den Klimaschutz Untersuchungen im Auftrag des Umweltbundesamtes Band 1. Szenarien und Maßnahmen zur Minderung von $\mathrm{CO}_{2}$-Emissionen in Deutschland bis zum Jahre 2005 herausgegeben von G. Stein, B. Strobel (1997), 410 Seiten ISBN: 3-89336-215-0

6. Politikszenarien für den Klimaschutz Untersuchungen im Auftrag des Umweltbundesamtes Band 2. Emissionsminderungsmaßnahmen für Treibhausgase, ausgenommen energiebedingtes $\mathrm{CO}_{2}$ herausgegeben von G. Stein, B. Strobel (1997), 110 Seiten ISBN: 3-89336-216-9 
Schriften des Forschungszentrums Jülich Reihe Umwelt / Environment

7. Modelle für die Analyse energiebedingter Klimagasreduktionsstrategien IKARUS. Instrumente für Klimagas-Reduktionsstrategien

Abschlußbericht Teilprojekt 1 "Modelle“

P. Markewitz, R. Heckler, Ch. Holzapfel, W. Kuckshinrichs, D. Martinsen,

M. Walbeck, J.-Fr. Hake (1998), VI, 276 Seiten

ISBN: 3-89336-220-7

8. Politikszenarien für den Klimaschutz

Untersuchungen im Auftrag des Umweltbundesamtes

Band 3. Methodik-Leitfaden für die Wirkungsabschätzung von Maßnahmen zur Emissionsminderung

herausgegeben von G. Stein, B. Strobel (1998), VIII, 95 Seiten

ISBN: 3-89336-222-3

9. Horizonte $\mathbf{2 0 0 0}$

6. Wolfgang-Ostwald-Kolloquium der Kolloid-Gesellschaft

3. Nachwuchstage der Kolloid- und Grenzflächenforschung

Kurzfassungen der Vorträge und Poster

zusammengestellt von F.-H. Haegel, H. Lewandowski, B. Krahl-Urban (1998),

150 Seiten

ISBN: 3-89336-223-1

10. Windenergieanlagen - Nutzung, Akzeptanz und Entsorgung

von M. Kleemann, F. van Erp, R. Kehrbaum (1998), 59 Seiten

ISBN: 3-89336-224-X

11. Policy Scenarios for Climate Protection

Study on Behalf of the Federal Environmental Agency

Volume 4. Methodological Guideline for Assessing the Impact of Measures

for Emission Mitigation

edited by G. Stein, B. Strobel (1998), 103 pages

ISBN: 3-89336-232-0

12. Der Landschaftswasserhaushalt im Flußeinzugsgebiet der Elbe

Verfahren, Datengrundlagen und Bilanzgrößen

Analyse von Wasserhaushalt, Verweilzeiten und Grundwassermilieu im

Flußeinzugsgebiet der Elbe (Deutscher Teil). Abschlußbericht Teil 1.

von R. Kunkel, F. Wendland (1998), 110 Seiten

ISBN: 3-89336-233-9 
Schriften des Forschungszentrums Jülich Reihe Umwelt / Environment

13. Das Nitratabbauvermögen im Grundwasser des Elbeeinzugsgebietes Analyse von Wasserhaushalt, Verweilzeiten und Grundwassermilieu im Flußeinzugsgebiet der Elbe (Deutscher Teil). Abschlußbericht Teil 2. von F. Wendland, R. Kunkel (1999), 166 Seiten ISBN: 3-89336-236-3

14. Treibhausgasminderung in Deutschland zwischen nationalen Zielen und internationalen Verpflichtungen

IKARUS-Workshop am 27.05.1998, Wissenschaftszentrum Bonn-Bad Godesberg. Proceedings herausgegeben von E. Läge, P. Schaumann, U. Fahl (1999), ii, VI, 146 Seiten ISBN: 3-89336-237-1

15. Satellitenbildauswertung mit künstlichen Neuronalen Netzen zur Umweltüberwachung

Vergleichende Bewertung konventioneller und Neuronaler Netzwerkalgorithmen und Entwicklung eines integrierten Verfahrens

von D. Klaus, M. J. Canty, A. Poth, M. Voß, I. Niemeyer und G. Stein (1999), VI, 160 Seiten

ISBN: 3-89336-242-8

16. Volatile Organic Compounds in the Troposphere Proceedings of the Workshop on Volatile Organic Compounds in the Troposphere held in Jülich (Germany) from 27 - 31 October 1997 edited by R. Koppmann, D. H. Ehhalt (1999), 208 pages ISBN: 3-89336-243-6

17. $\mathrm{CO}_{2}$-Reduktion und Beschäftigungseffekte im Wohnungssektor durch das $\mathrm{CO}_{2}$-Minderungsprogramm der $\mathrm{KfW}$

Eine modellgestützte Wirkungsanalyse von M. Kleemann, W. Kuckshinrichs, R. Heckler (1999), 29 Seiten ISBN: 3-89336-244-4

18. Symposium über die Nutzung der erneuerbaren Energiequellen Sonne und Wind auf Fischereischiffen und in Aquakulturbetrieben

Symposium und Podiumsdiskussion, Izmir, Türkiye, 28.-30.05.1998.

Konferenzbericht

herausgegeben von A. Özdamar, H.-G. Groehn, K. Ülgen (1999), IX, 245 Seiten ISBN: 3-89336-247-9 
Schriften des Forschungszentrums Jülich Reihe Umwelt / Environment

19. Das Weg-, Zeitverhalten des grundwasserbürtigen Abflusses im Elbeeinzugsgebiet

Analyse von Wasserhaushalt, Verweilzeiten und Grundwassermilieu im Flußeinzugsgebiet der Elbe (Deutscher Teil). Abschlußbericht Teil 3. von R. Kunkel, F. Wendland (1999), 122 Seiten ISBN: 3-89336-249-5

20. Politikszenarien für den Klimaschutz

Untersuchungen im Auftrag des Umweltbundesamtes

Band 5. Szenarien und Maßnahmen zur Minderung von $\mathrm{CO}_{2}$-Emissionen in Deutschland bis 2020

herausgegeben von G. Stein, B. Strobel (1999), XII, 201 Seiten ISBN: 3-89336-251-7

21. Klimaschutz durch energetische Sanierung von Gebäuden. Band 1 von J.-F. Hake, M. Kleemann, G. Kolb (1999), 216 Seiten ISBN: 3-89336-252-2

22. Electroanalysis

Abstracts of the $8^{\text {th }}$ International Conference held from 11 to 15 June 2000 at the University of Bonn, Germany

edited by H. Emons, P. Ostapczuk (2000), ca. 300 pages

ISBN: 3-89336-261-4

23. Die Entwicklung des Wärmemarktes für den Gebäudesektor bis 2050 von M. Kleemann, R. Heckler, G. Kolb, M. Hille (2000), II, 94 Seiten ISBN: 3-89336-262-2

24. Grundlegende Entwicklungstendenzen im weltweiten Stoffstrom des Primäraluminiums

von H.-G. Schwarz (2000), XIV, 127 Seiten

ISBN: 3-89336-264-9

25. Klimawirkungsforschung auf dem Prüfstand

Beiträge zur Formulierung eines Förderprogramms des BMBF

Tagungsband des Workshop „Klimaforschung“, Jülich, vom 02. bis 03.12.1999

von J.-Fr. Hake, W. Fischer (2000), 150 Seiten

ISBN: 3-89336-270-3 
Schriften des Forschungszentrums Jülich Reihe Umwelt / Environment

26. Energiezukunft 2030

Schlüsseltechnologien und Techniklinien

Beiträge zum IKARUS-Workshop 2000 am 2./3. Mai 2000

herausgegeben von U. Wagner, G. Stein (2000), 201 Seiten

ISBN: 3-89336-271-1

27. Der globale Wasserkreislauf und seine Beeinflussung durch den Menschen Möglichkeiten zur Fernerkundungs-Detektion und -Verifikation

von D. Klaus und G. Stein (2000), 183 Seiten

ISBN: 3-89336-274-6

28. Satelliten und nukleare Kontrolle

Änderungsdetektion und objektorientierte, wissensbasierte Klassifikation von Multispektralaufnahmen zur Unterstützung der nuklearen Verifikation von I. Niemeyer (2001), XIV, 206 Seiten

ISBN: 3-89336-281-9

29. Das hydrologische Modellsystem J2000

Beschreibung und Anwendung in großen Flußgebieten

von P. Krause (2001), XIV, 247 Seiten

ISBN: 3-89336-283-5

30. Aufwands- und ergebnisrelevante Probleme der Sachbilanzierung von G. Fleischer, J.-Fr. Hake (2002), IV, 64 Blatt ISBN: 3-89336-293-2

31. Nachhaltiges Management metallischer Stoffströme Indikatoren und deren Anwendung Workshop, 27.-28.06.2001 im Congresscentrum Rolduc, Kerkrade (NL) herausgegeben von W. Kuckshinrichs, K.-L. Hüttner (2001), 216 Seiten ISBN: 3-89336-296-7

32. Ansätze zur Kopplung von Energie- und Wirtschaftsmodellen zur Bewertung zukünftiger Strategien

IKARUS-Workshop am 28. Februar 2002, BMWi, Bonn. Proceedings herausgegeben von S. Briem, U. Fahl (2003), IV, 184 Seiten ISBN: 3-89336-321-1 
Schriften des Forschungszentrums Jülich Reihe Umwelt / Environment

33. TRACE. Tree Rings in Archaeology, Climatology and Ecology Volume 1: Proceedings of the Dendrosymposium 2002,

April $11^{\text {th }}-13^{\text {th }} 2002$, Bonn/Jülich, Germany

edited by G. Schleser, M. Winiger, A. Bräuning et al., (2003), 135 pages, many

partly coloured illustrations

ISBN: 3-89336-323-8

34. Klimaschutz und Beschäftigung durch das $\mathrm{KfW}$-Programm zur $\mathrm{CO}_{2-}$ Minderung und das $\mathrm{KfW}-\mathrm{CO}_{2}$-Gebäudesanierungsprogramm von M. Kleemann, R. Heckler, A. Kraft u. a., (2003), 53 Seiten ISBN: 3-89336-326-2

35. Klimaschutz und Klimapolitik: Herausforderungen und Chancen Beiträge aus der Forschung herausgegeben von J.-Fr. Hake, K. L. Hüttner (2003), III, 231 Seiten ISBN: 3-89336-327-0

36. Umweltschutz und Arbeitsplätze, angestoßen durch die Tätigkeiten des Schornsteinfegerhandwerks

Auswertung von Schornsteinfeger-Daten

von M. Kleemann, R. Heckler, B. Krüger (2003), VII, 66 Seiten

ISBN: 3-89336-328-9

37. Die Grundwasserneubildung in Nordrhein-Westfalen

von H. Bogena, R. Kunkel, T. Schöbel, H. P. Schrey, F. Wendland (2003), 148

Seiten

ISBN: 3-89336-329-7

38. Dendro-Isotope und Jahrringbreiten als Klimaproxis der letzten 1200 Jahre im Karakorumgebirge/Pakistan

von K. S. Treydte (2003), XII, 167 Seiten

ISBN: 3-89336-330-0

39. Das IKARUS-Projekt: Energietechnische Perspektiven für Deutschland herausgegeben von P. Markewitz, G. Stein (2003), IV, 274 Seiten ISBN: 3-89336-333-5

40. Umweltverhalten von MTBE nach Grundwasserkontamination von V. Linnemann (2003), XIV, 179 Seiten

ISBN: 3-89336-339-4 
Schriften des Forschungszentrums Jülich Reihe Umwelt / Environment

41. Climate Change Mitigation and Adaptation: Identifying Options for Developing Countries

Proceedings of the Summer School on Climate Change, 7-17 September 2003,

Bad Münstereifel, Germany

edited by K. L. Hüttner, J.-Fr. Hake, W. Fischer (2003), XVI, 341 pages

ISBN: 3-89336-341-6

42. Mobilfunk und Gesundheit: Risikobewertung im wissenschaftlichen Dialog von P. M. Wiedemann, H. Schütz, A. T. Thalmann (2003), 111 Seiten ISBN: 3-89336-343-2

43. Chemical Ozone Loss in the Arctic Polar Stratosphere: An Analysis of Twelve Years of Satellite Observations by S. Tilmes (2004), V, 162 pages ISBN: 3-89336-347-5

44. TRACE. Tree Rings in Archaeology, Climatology and Ecology Volume 2: Proceedings of the Dendrosymposium 2003, May $1^{\text {st }}-3^{\text {rd }} 2003$, Utrecht, The Netherlands edited by E. Jansma, A. Bräuning, H. Gärtner, G. Schleser (2004), 174 pages ISBN: 3-89336-349-1

45. Vergleichende Risikobewertung: Konzepte, Probleme und Anwendungsmöglichkeiten

von H. Schütz, P. M. Wiedemann, W. Hennings et al. (2004), 231 Seiten ISBN: 3-89336-350-5

46. Grundlagen für eine nachhaltige Bewirtschaftung von Grundwasserressourcen in der Metropolregion Hamburg von B. Tetzlaff, R. Kunkel, R. Taugs, F. Wendland (2004), 87 Seiten ISBN: 3-89336-352-1

47. Die natürliche, ubiquitär überprägte Grundwasserbeschaffenheit in Deutschland

von R. Kunkel, H.-J. Voigt, F. Wendland, S. Hannappel (2004), 207 Seiten ISBN: 3-89336-353-X

48. Water and Sustainable Development edited by H. Bogena, J.-Fr. Hake, H. Vereecken (2004), 199 pages ISBN: 3-89336-357-2 
Freshwater is called the raw material of the 21st century. In many regions, a sufficient future water supply of the population is not ensured due to the overuse of freshwater resources. Above all the developing countries and emerging nations are affected. Water pollution represents a further problem, which not only affects the developing countries, but also the industrialised countries. In view of the importance of freshwater and the problems of overusing it, a sustainable management of water as a natural resource must therefore be ensured.

The volume "Water and Sustainable Development" intends to integrate some important issues dealing with the above mentioned topics. It brings together the knowledge of some well-known experts being engaged with the challenge of working towards a sustainable usage of freshwater.

\section{Agrosphere Institute at the Research Centre Jülich}

Groundwater is a major source of our drinking water supply. Site specific and adapted agriculture combined with fundamental and applied research in the domain of soil and groundwater will help to improve the sustainable use of scarce natural resources. At the Agrosphere Institute (ICG-IV), the fate of natural and anthropogenic substances in soils and near-surface groundwater systems is investigated. Experiments are conducted on multiple scale (laboratory, lysimeter facility with a licence for radiolabelled substances, two field sites and also on a regional scale) and in an interdisciplinary manner. Mathematical models are developed and used to predict the fate of natural and anthropogenic substances in soil aquifer systems. The institute has a GLP-accredited isotope laboratory. The research at the Agrosphere Institute aims at contributing to a sustainable use of agroecosystems and our resources soil and water.

\section{Systems Analysis and Technology Evaluation at the Research Centre Jülich}

Many of the issues at the centre of public attention can only be dealt with by an interdisciplinary systems analysis. Scientific, economic and ecological subsystems which interact with each other often have to be investigated simultaneously. The Programme Group Systems Analysis and Technology Evaluation (STE) takes up this approach and concentrates its work on issues concerning the long-term orientation of the energy economy, on selected economically or ecologically relevant material flows in the technosphere and geosphere as well as on electronic information processing and communications and the changes in society brought about by these technologies. In these fields, STE analyses the consequences of technical developments and provides scientific aids to decision-making for politics and industry. This work is based on the further methodological development of systems analysis tools and their application as well as cooperation between scientists from different disciplines.

Forschungszentrum Jülich in der Helmholtz-Gemeinschaft
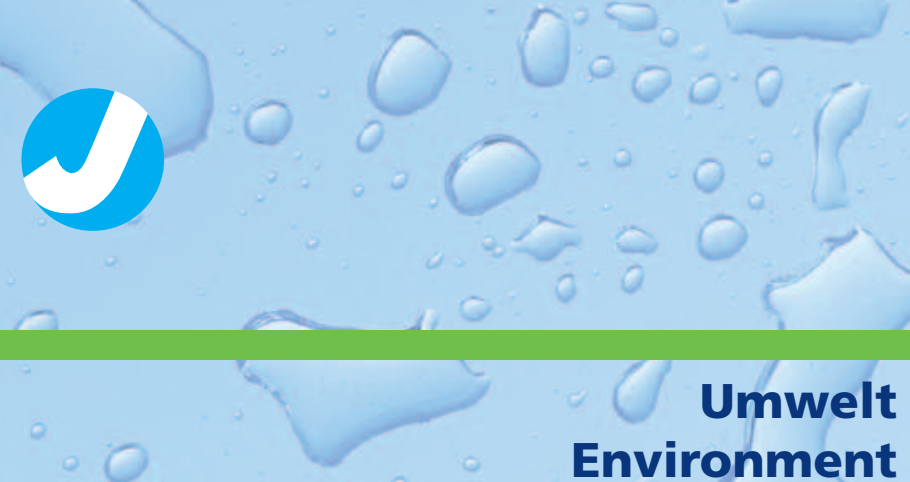

\section{Band/Volume 48

